\title{
PERFORMANCE-BASED SEISMIC DESIGN OF BUILDING STRUCTURES
}

\section{Mohammad Ghorbanie-Asl}

A thesis submitted to the Faculty of Graduate Studies and Research in partial fulfillment of the requirements for the degree of

Doctor of Philosophy

in Civil Engineering

Ottawa-Carleton Institute for Civil Engineering

Carleton University

Ottawa, Canada

April 2007

C Mohammad Ghorbanie-Asl 2007 


$\begin{array}{ll}\begin{array}{l}\text { Library and } \\ \text { Archives Canada }\end{array} & \begin{array}{l}\text { Bibliothèque et } \\ \text { Archives Canada }\end{array} \\ \begin{array}{l}\text { Published Heritage } \\ \text { Branch }\end{array} & \begin{array}{l}\text { Direction du } \\ \text { Patrimoine de l'édition }\end{array} \\ \begin{array}{l}\text { 395 Wellington Street } \\ \text { Ottawa ON K1A ON4 }\end{array} & \begin{array}{l}\text { 395, rue Wellington } \\ \text { Ottawa ON K1A ON4 } \\ \text { Canada }\end{array}\end{array}$

Your file Votre référence ISBN: 978-0-494-27095-0 Our file Notre référence ISBN: 978-0-494-27095-0

NOTICE:

The author has granted a nonexclusive license allowing Library and Archives Canada to reproduce, publish, archive, preserve, conserve, communicate to the public by telecommunication or on the Internet, loan, distribute and sell theses worldwide, for commercial or noncommercial purposes, in microform, paper, electronic and/or any other formats.

The author retains copyright ownership and moral rights in this thesis. Neither the thesis nor substantial extracts from it may be printed or otherwise reproduced without the author's permission.
AVIS:

L'auteur a accordé une licence non exclusive permettant à la Bibliothèque et Archives Canada de reproduire, publier, archiver, sauvegarder, conserver, transmettre au public par télécommunication ou par l'Internet, prêter, distribuer et vendre des thèses partout dans le monde, à des fins commerciales ou autres, sur support microforme, papier, électronique et/ou autres formats.

L'auteur conserve la propriété du droit d'auteur et des droits moraux qui protège cette thèse. $\mathrm{Ni}$ la thèse ni des extraits substantiels de celle-ci ne doivent être imprimés ou autrement reproduits sans son autorisation.
In compliance with the Canadian

Privacy Act some supporting forms may have been removed from this thesis.

While these forms may be included in the document page count, their removal does not represent any loss of content from the thesis.
Conformément à la loi canadienne sur la protection de la vie privée, quelques formulaires secondaires ont été enlevés de cette thèse.

Bien que ces formulaires aient inclus dans la pagination, il n'y aura aucun contenu manquant.

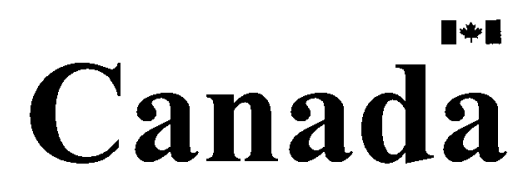




\begin{abstract}
A new method for the displacement-based design (DBD) of a variety of structures to resist the earthquake forces experienced by them is developed. The proposed method requires the determination of yield and ultimate displacements of the structure. For preliminary design these parameters are determined from approximate empirical relationships. The required strength of the structure is then determined from the inelastic demand spectrum corresponding to the ductility capacity and the estimated yield strength. The method can be used for a multi degree of freedom system by transforming it into an equivalent single degree of freedom system.
\end{abstract}

For final design, a modal analysis is carried out on a model of the structure that is based on its preliminary design. A pushover analysis of the structure for forces that are distributed according to the first mode now provides better estimates of the yield and ultimate displacements. These refined estimates are then used to obtain a more precise value of the required strength. Iterations may have to be carried out to obtain convergence between the assumed and calculated values of the design displacements. Finally, to account for the effect of higher modes in shear wall structures and high-rise moment resisting frames, the standard modal pushover analysis (MPA) method available in the published literature is used. 
Nonlinear time history analyses of the structures designed according to the proposed DBD method are carried out for sets of ground motions that are compatible with the design response spectra. Procedures for the selection and scaling of the spectrum compatible ground motions are studied. A set of such ground motions that is compatible with the UHS of Montreal corresponding to a probability of exceedance of $2 \%$ in 50 years is developed as a part of the present research. This set and a similar set for Vancouver, developed in another research study, are used in time history analyses, first to develop relationships between inter-story drift and roof drift, and second to validate the proposed DBD method. 


\section{Acknowledgment}

This project would not have been possible without the support of many people. It is a pleasure to convey my gratitude to them all in my humble acknowledgment.

In the first place I would like to record my gratitude to Professor Jag Mohan Humar for his supervision, advice, and guidance from the very early stage of this research as well as giving me extraordinary experiences throughout the work. He inspired and enriched my growth as a student and a researcher.

I am very grateful to Dr. John Adams and Stephen Halchuk from Geological Survey of Canada and Tuna Onur for their advice and willingness to share their bright thoughts with me.

I gratefully acknowledge the family of the late Professor John Adjeleian and the family of Professor Jag Mohan Humar for awarding me two prestigious scholarships and providing me with the financial means to complete this research.

Finally, I would like to express my special gratitude and appreciation to my wife Nasim and my mom and dad for their unconditional love, support, dedication and prayers.

iv 


\section{Table of Contents}

Section

Abstract

Acknowledgment

iv

Table of Contents

$\mathbf{v}$

List of Tables

xi

List of Figures

xiv

Symbols

xxiv

Acronyms

xxviii

\section{Chapter 1 Introduction}

1.1 General 1

$\begin{array}{ll}\text { 1.2 Performance Based Design } & 2\end{array}$

1.3 Displacement Based Design Guidelines $\quad 4$

1.3.1 ATC-40 and FEMA 274

$\begin{array}{ll}\text { 1.3.2 FEMA } 356 & 7\end{array}$

1.3.3 FEMA 440

1.3.4 SEAOC blue book $\quad 11$

1.4 Review of Literature related to Pushover Analysis 13

1.5 Studies Relating Elastic and Inelastic Displacements 17

1.6 Review of Literature related to Displacement Based Design Methods 19 


\section{Chapter 2 Displacement-Based Design}

2.1 Introduction

2.2 Ductility Capacity

2.3 Yield Displacement

2.4 Ultimate displacement

2.5 Target roof displacement based on ductility capacity

2.5.1 Concrete shear walls

2.5.2 Reinforced Concrete Frames

2.5.3 Steel Moment-resisting Frames

2.5.4 Concentrically Braced Frames

2.6 Relationship between roof drift and the maximum inter-story drift

2.7 Equivalent SDOF model

2.8 Inelastic demand spectra

2.9 Pushover analysis and Capacity diagram

2.10 Effect of Higher Modes and Multi-Mode Pushover Analysis (MMPA)

2.11 Steps of Displacement-based design 


\section{Chapter 3 Application of Displacement-based Seismic Design}

3.1 Introduction

3.2 DBD of 12-story Reinforced Concrete Moment Resisting Frame

3.2.1 Layout of the building

3.2.2 Equivalent static procedure of NBCC 2005

3.2.3 Displacement Estimates

3.2.4 Equivalent SDOF system

3.2.5 Capacity and Demand Diagrams

3.2.6 Design of Frames

3.2.7 Pushover Analysis

3.2.8 Subsequent Design Iterations

3.2.9 Multi-Mode Pushover Analysis

3.2.10 Operational level performance

3.3 DBD of other RC frame buildings

3.4 DBD of 12-story Steel Moment Resisting Frame

3.4.1 Layout of the building

3.4.2 Equivalent static procedure of NBCC 2005

3.4.3 Displacement Estimates

3.4.4 Equivalent SDOF system

3.4.5 Capacity and Demand Diagrams

3.4.6 Design of Frames

3.4.7 Pushover Analysis 


\section{Chapter 4 Selection and Scaling of Ground Motions for Canada}

4.1 Introduction

4.2 Review of Literature Related to Selection and Scaling of Ground Motions

4.2.1 Ground Motion Scaling Methods

4.2.2 Selection of Ground Motions for US

4.3 Deaggregation results for Eastern Canada 
4.7 Filtering of the records

4.8 Baseline Correction of the records

4.9 Ground motions of Western Canada

\section{Chapter 5 Validation of the Displacement-based Design Method}

5.1 Introduction

5.2 Time history analysis of the 12 story RC frame building

5.3 Validation of the proposed DBD method

5.4 Dynamic analyses of 6,15 and 20 story RC frames designed for Vancouver

5.5 Dynamic analyses of 6, 12, 15 and 20 story $\mathrm{RC}$ frames designed for Montreal

5.6 Dynamic analyses of $6,12,15$ and 20 story steel moment-resisting frames

5.7 Dynamic analyses of $6,12,15$ and 20 story steel moment-resisting frames designed

for Montreal

5.8 Dynamic analyses of 12 story concentrically-braced frame building designed for

Vancouver

5.9 Ratio of the roof drift to maximum inter-story drift

5.10 Conclusions 


\section{Chapter 6 Summary and Conclusions}

$\begin{array}{ll}6.1 \text { Summary } & 242\end{array}$

$\begin{array}{ll}6.2 \text { Conclusions } & 245\end{array}$

$\begin{array}{ll}\text { 6.3 Recommended future research } & 249\end{array}$

Appendix A. Displacement based design of a concrete frame building 250

$\begin{array}{ll}\text { References } & 273\end{array}$ 


\section{List of Tables}

Table

Page

(2.1) Yield and ultimate curvatures in rectangular beams

(2.2) Acceptance criteria for structural steel components (from FEMA 356)

(3.1) Results of the static analysis for design of 12-story RC frame in Vancouver

(3.2) Inter-story drifts

(3.3) Story Shears

(3.4a) Moments and plastic hinge rotations - middle span beam, positive moment

(3.4b) Moments and plastic hinge rotations - middle span beam, negative moment

(3.5) Shear forces - middle span beam, j-end

(3.6) Moments and plastic hinge rotations - the interior column

(3.7) Dimensions and properties of the RC frames located in Vancouver and designed with the proposed DBD method

(3.8) Dimensions and properties of the RC frames located in Montreal and designed with the proposed DBD method

(3.9) Dimensions and properties of the steel frames located in Vancouver and designed with the proposed DBD method

(3.10) Dimensions and properties of the Steel frames located in Montreal and designed with the proposed DBD method 
(3.12) Story shears, 12-story SMRF building in Vancouver

(3.13) Moments and ductilities of the middle span beams, 1st mode response of 12-story

SMRF building in Vancouver

(3.14) Moments and plastic hinge rotations - the interior column of 12-story SMRF

building in Vancouver (Moments in $\mathrm{kN}-\mathrm{m}$ and rotations in radians)

(3.15) Inter-story drifts, 12-story CBF building in Vancouver

(3.16) Tensile force in bracings, 12-story CBF building in Vancouver

(4.1) Probabilistic seismic hazard estimates for Montreal, 2\% in 50 years, (Open file

4459- Geological Survey of Canada 2003)

(4.2) Mean and mode magnitude and distance values for Montreal, 2\%/50 years (Halchuk and Adams, 2004)

(4.3) Probabilistic seismic hazard estimates for Vancouver, $2 \%$ in 50 years (Open file 4459- Geological Survey of Canada 2003)

(4.4) Mean and mode magnitude and distance values for Vancouver, 2\%/50 years

(Halchuk and Adams, 2004)

(4.5a) Available ground motions of Eastern Canada / North Eastern US

(4.5b) Available ground motions of other Stable Continental Regions

(4.6) Events of Stable Continental Regions (Johnston 1990)

(4.7) Final selection of ground motions, Eastern region of Canada

(4.8) Final selection of ground motions for Western region of Canada

(5.1) Inter-story drifts produced in the 12-story frame by 20 ground motions for Western Canada 
(5.2) Story shear forces in the 12-story RC frame under 20 ground motions of Western Canada

(5.3) Negative moments produced at the ends of middle-span beams of 12-story RC frame by 20 ground motions for Western Canada

(5.4) Positive moments at the ends of the middle-span beams in the 12-story RC frame under 20 ground motions for Western Canada

(5.5) Shear forces of the middle-span beams in the 12-story RC frame under 20 ground motions for Western Canada

(5.6) Moments at the bottom of the interior columns in the 12-story RC frame under

20 ground motions for Western Canada

(5.7) Median and dispersion values of the $\beta$ factor calculated from NL-TH analyses 205

(A.1) Inter-story drifts

(A.2) Story shears 263

(A.3) Moments and plastic hinge rotations, middle span beam, negative moment 264

(A.4) Moments and plastic hinge rotations - the interior column

xiii 


\section{List of Figures}

Figure Page

(1.1) Standard Performance Objectives (SEAOC Blue Book)

(1.2) (a) Demand and Capacity curves; (b) Idealized SDOF system with bilinear $\begin{array}{ll}\text { force-deformation relation } & 38\end{array}$

(1.3) Idealized force-displacement curves (FEMA 356) 39

(1.4) Direct Displacement Method (SEAOC Blue Book) 40

(2.1) Beam-Column assembly in steel moment resisting frames $\quad 72$

$\begin{array}{ll}\text { (2.2) Concentrically braced frame (CBF) } & 73\end{array}$

(2.3) Ultimate and yield drift ratios for a shear wall 73

(3.1) (a) Plan and Elevation of the frame structure (b) Definition of $i$ and $j$ ends of the $\begin{array}{ll}\text { beams } & 132\end{array}$

(3.2) Stress-Strain relationships for (a) Concrete and (b) Reinforcing Steel 133

(3.3) Displacement Based Design of 12-Story RC Frame In Vancouver-first try 134

(3.4) Pushover Curve-Initial design 134

(3.5) Displacement Based Design of 12-Story RC Frame In Vancouver-second try 135

(3.6) Columns and beams of the final design 136

(3.7) Pushover Curve-Second design $\quad 137$

$\begin{array}{ll}\text { (3.8) Inter-story drifts } & 137\end{array}$

(3.9) Displacement Based Design of 12-Story RC Frame in Vancouver-third try 138 xiv 
(3.10) Moment-Curvature relationship for first floor interior beam, positive moment 138

(3.11) Moment-Curvature relationship for first floor interior beam, negative moment 139 (3.12) Moment-Curvature relationship for first floor interior column, under gravity axial

force

(3.13) Uniform Hazard Spectra for Vancouver

(3.14) Displacement Based Design of 12-Story Steel Frame In Vancouver-first try

(3.15) Pushover Curve - first design

(3.16) Inter-story drifts

(3.17) Displacement Based Design of 12-Story Steel Frame in Vancouver-second try 142 (3.18) (a) Plan and Elevation of the concentrically braced frame (CBF) structure (b) Hysterisis behavior of the brace elements

(3.19) Displacement Based Design of 12-Story CBF in Vancouver-first try

(3.21) Displacement Based Design of 12-Story CBF in Vancouver-second try

(3.22) Pushover Curve-second design

(3.24) Displacement Based Design of 12-Story CBF in Vancouver-third try

(4.1) Deaggregation of seismic hazard for Montreal defined in terms of $S_{a}(0.2)$

for a probability of exceedance $2 \% / 50$ years (Halchuk and Adams, 2004)

(4.2) Deaggregation of seismic hazard for Montreal defined in terms of $S_{a}(0.5)$

for a probability of exceedance $2 \% / 50$ years (Halchuk and Adams, 2004)

(4.3) Deaggregation of seismic hazard for Montreal defined in terms of $S_{a}(1.0)$ 
(4.4) Deaggregation of seismic hazard for Montreal defined in terms of $S_{a}(2.0)$

for a probability of exceedance $2 \% / 50$ years (Halchuk and Adams, 2004)

(4.5) Deaggregation of seismic hazard for Vancouver defined in terms of $S_{a}(0.2)$ for a probability of exceedance $2 \% / 50$ years (Halchuk and Adams, 2004)

(4.6) Deaggregation of seismic hazard for Vancouver defined in terms of $S_{a}(0.5)$ for a probability of exceedance $2 \% / 50$ years (Halchuk and Adams, 2004)

(4.7) Deaggregation of seismic hazard for Vancouver defined in terms of $S_{a}(1.0)$ for a probability of exceedance $2 \% / 50$ years (Halchuk and Adams, 2004)

(4.8) Deaggregation of seismic hazard for Vancouver defined in terms of $S_{a}(2.0)$ for a probability of exceedance $2 \% / 50$ years (Halchuk and Adams, 2004)

(4.9) Robust Uniform Hazard Spectra for Vancouver (Open file 4459- Geological Survey of Canada 2003)

(4.10) The Stable Continental Region Data Set and Regression

Curve (Johnston, 1990)

(4.11) Acceleration spectra for all un-scaled SCR Ground motions compared to Montreal Design Spectrum

(4.12) Acceleration Spectra for Eastern Canada Ground motions (Scaled by the "Least Sum of Squared Error" Method)

(4.13) Acceleration Spectra for Western Canada Ground motions (Scaled by the "Least Sum of Squared Error" Method) 
(5.1) Roof displacements in the 12-story RC frame under 20 selected ground motions for western Canada

(5.2) Comparison of the modal and first mode responses with the results of Nonlinear Time History analyses for 12 story RC frame in Vancouver; (a) Inter-story drifts, (b) Story shears

(5.3) Comparison of the modal and first mode responses with the results of Nonlinear Time History analyses for 12 story RC frame in Vancouver; (a) Positive moment at the ends of middle span beams (b) Negative moment at the ends of middle span beams 208 (5.4) Comparison of the modal and first mode responses with the results of Nonlinear Time History analyses for 12 story RC frame in Vancouver; (a) Shear force in middle span beams, (b) Moment in the interior columns at the base of each story

(5.5) Comparison of the modal and first mode responses with the results of Nonlinear Time History analyses for 6 story RC frame in Vancouver; (a) Inter-story drifts, (b) Story shears

(5.6) Comparison of the modal and first mode responses with the results of Nonlinear Time History analyses for 6 story RC frame in Vancouver; (a) Negative moment at the ends of middle span beams (b) Moment in the interior columns at the base of each story

(5.7) Comparison of the modal and first mode responses with the results of Nonlinear Time History analyses for 15 story RC frame in Vancouver; Inter-story drifts, (b) Story shears

xvii 
(5.8) Comparison of the modal and first mode responses with the results of Nonlinear Time History analyses for 15 story RC frame in Vancouver; (a) Negative moment at the ends middle span beams (b) Moment in the interior columns at the base of each story

(5.9) Comparison of the modal and first mode responses with the results of Nonlinear Time History analyses for 20 story RC frame in Vancouver; (a) Inter-story drifts, (b) Story shears

(5.10) Comparison of the modal and first mode responses with the results of Nonlinear Time History analyses for 20 story RC frame in Vancouver; (a) Negative moment at the ends of middle span beams (b) Moment in the interior columns at the base of each story

(5.11) Comparison of the modal and first mode responses with the results of Nonlinear Time History analyses for 6 story RC frame in Montreal; (a) Inter-story drifts (b) Story shears

(5.12) Comparison of the modal and first mode responses with the results of Nonlinear Time History analyses for 6 story RC frame in Montreal (a) Negative moment at the ends of middle span beams (b) Moment in the interior columns at the base of each story (5.13) Comparison of the modal and first mode responses with the results of Nonlinear Time History analyses for 12-story RC frame in Montreal (a) Inter-story drifts (b) Story shears 
(5.14) Comparison of the modal and first mode responses with the results of Nonlinear Time History analyses for 12 story RC frame in Montreal (a) Negative moment at the ends of middle span beams (b) Moment in the interior columns at the base each story

(5.15) Comparison of the modal and first mode response with the results of Nonlinear Time History analyses for 15-story RC frame in Montreal (a) Inter-story drifts (b) Story shears

(5.16) Comparison of the modal and first mode responses with the results of Nonlinear Time History analyses for 15-story RC frame in Montreal (a) Negative moment at the ends of middle span beams (b) Moment in the interior columns at the base of each story

(5.17) Comparison of the modal and first mode responses with the results of Nonlinear Time History analyses for 20-story RC frame in Montreal (a) Inter-story drifts (b) Story shears

(5.18) Comparison of the modal and first mode responses with the results of Nonlinear Time History analyses for 20-story RC frame in Montreal Negative moment at the ends of middle span beams (b) Moment in the interior columns at the base of each story 223 (5.19) Comparison of the modal and first mode responses with the results of Nonlinear Time History analyses for 6-story steel moment-resisting frame in Vancouver (a ) Interstory drifts (b) Story shears

(5.20) Comparison of the modal and first mode responses with the results of Nonlinear Time History analyses for 6-story steel moment-resisting frame in Vancouver xix 
(a) Negative moment at the ends of middle span beams (b) Moment in the interior columns at the base of each story

(5.21) Comparison of the modal and first mode responses with the results of Nonlinear Time History analyses for 12-story steel moment-resisting frame in Vancouver (a) Interstory drifts (b) Story shears

(5.22) Comparison of the modal and first mode responses with the results of Nonlinear Time History analyses for 12-story steel moment-resisting frame in Vancouver (a) Negative moment at the ends of middle span beams (b) Moment in the interior columns at the base of each story

(5.23) Comparison of the modal and first mode responses with the results of Nonlinear Time History analyses for 15-story steel moment-resisting frame in Vancouver (a) Interstory drifts (b) Story shears 228

(5.24) Comparison of the modal and first mode responses with the results of Nonlinear Time History analyses for 15-story steel moment-resisting frame in Vancouver (a) Negative moment at the ends of middle span beams (b) Moment in the interior columns at the base of each story

(5.25) Comparison of the modal and first mode responses with the results of Nonlinear Time History analyses for 20-story steel moment-resisting frame in Vancouver (a) Interstory drifts (b) Story shears

(5.26) Comparison of the modal and first mode responses with the results of Nonlinear Time History analyses for 20-story steel moment-resisting frame in Vancouver 
(a) Negative moment at the ends of middle span beams (b) Moment in the interior columns at the base of each story

(5.27) Comparison of the modal and first mode responses with the results of Nonlinear Time History analyses for 6-story steel moment-resisting frame in Montreal (a) Interstory drifts (b) Story shears

(5.28) Comparison of the modal and first mode responses with the results of Nonlinear Time History analyses for 6-story steel moment-resisting frame in Montreal (a) Negative moment at the ends of middle span beams (b) Moment in the interior columns at the base of each story

(5.29) Comparison of the modal and first mode responses with the results of Nonlinear Time History analyses for 12-story steel moment-resisting frame in Montreal (a) Interstory drifts (b) Story shears

(5.30) Comparison of the modal and first mode responses with the results of Nonlinear Time History analyses for 12-story steel moment-resisting frame in Montreal (a) Negative moment at the ends of middle span beams (b) Moment in the interior columns at the base of each story

(5.31) Comparison of the modal and first mode responses with the results of Nonlinear Time History analyses for 15-story steel moment-resisting frame in Montreal (a) Interstory drifts (b) Story shears

(5.32) Comparison of the modal and first mode responses with the results of Nonlinear Time History analyses for 15-story steel moment-resisting frame in Montreal 
(a) Negative moment at the ends of middle span beams (b) Moment in the interior columns at the base of each story

(5.33) Comparison of the modal and first mode responses with the results of Nonlinear Time History analyses for 20-story steel moment-resisting frame in Montreal (a) Inter-story drifts (b) Story shears

(5.34)Comparison of the modal and first mode responses with the results of Nonlinear Time History analyses for 20-story steel moment-resisting frame in Montreal (a) Negative moment at the ends of middle span beams (b) Moment in the interior columns at the base of each story

(5.35) Comparison of the modal and first mode responses with the results of Nonlinear Time History analyses for 12-story concentric braced frame in Vancouver (a) Inter-story drifts (b) Tensile forces in braces

(5.36) Comparison of the modal and first mode responses with the results of Nonlinear Time History analyses for 12 story RC frame in Montreal, Alternative scaling factor for ground motions (a) Inter-story drifts (b) Story shears

(A.1) Plan and elevation of the 6-story building 265

(A.2) Demand and capacity curve for preliminary design 265 (A.3) Beam and Column forces under gravity loads for load combination of $1.25 \mathrm{D}+1.5 \mathrm{~L}$ (moments in $\mathrm{kNm}$ and forces in $\mathrm{kN}$, values are symmetrical) 266

(A.4) Beam moments for load combination of D+0.5L+E 266

(A.5) Column forces for load combination of D+0.5L+E 267

(A.6) Preliminary beam sizes

xxii 
(A.7) Moment-curvature relation for negative moment on the beam, floors 1 to $3 \quad 268$

(A.8) Moment-curvature relation for positive moment on the beam, floors 1 to $3 \quad 268$

(A.9) Moment-curvature relation for negative moment on the beam, floors 4 to $6 \quad 269$

(A.10) Moment-curvature relation for positive moment on the beam, floors 4 to $6 \quad 269$

(A.11) Moment curvature relationship for $600 \times 600$ column in stories 1 to $3 \quad 270$

(A.12) Moment curvature relation for the $500 \times 500$ column in stories 4 to $6 \quad 270$

(A.13) Base shear versus roof displacement relations obtained from a push over analysis

(A.14) Inter-story drifts versus roof displacement

(A.15) Demand and capacity curve for DBD design

xxiii 


\section{Symbols}

1

A

$A_{r}$

$\mathrm{A}_{\mathrm{s}}$

$\mathrm{A}_{\mathrm{y}}$

$a(t)$

$\delta \mathrm{a}(\mathrm{t})$

b

$\mathrm{c}_{\mathrm{u}}$

$\mathrm{C}_{\mathrm{o}}$

$\mathrm{C}_{1}$

$\mathrm{C}_{2}$

$\mathrm{C}_{3}$

D

$\dot{\mathrm{D}}$
Unit vector

Spectral Acceleration

Aspect ratio of wall

Area of reinforcing steel

Yield acceleration

Reference time history

Adjustment time history

Beam width

Depth of neutral axis at limit strain of concrete

Modification factor to relate spectral displacement of an equivalent SDOF system to the roof displacement of the building MDOF system

Modification factor to relate expected maximum inelastic displacement to the displacements calculated for linear elastic response

Modification factor to represent the effect of pinched hysteretic shape, stiffness degradation and strength deterioration on maximum displacement response

Modification factor to represent increased displacement due to dynamic P- $\Delta$ effects

Displacement of system

Velocity of system

xxiv 


\begin{tabular}{|c|c|}
\hline D̈ & Aceleration of system \\
\hline d & Beam effective depth \\
\hline f & Force distribution vector \\
\hline$f_{c}^{\prime}$ & Concrete compression strength \\
\hline $\mathrm{F}_{\mathrm{s} 1}$ & Load-deformation relationship of system \\
\hline$f_{y}$ & Yield strength of reinforcing steel \\
\hline g & Acceleration of gravity \\
\hline $\mathrm{H}, \mathrm{h}_{\mathrm{R}}$ & Height of structure \\
\hline$h_{b}$ & Beam depth \\
\hline $\mathrm{k}_{1}$ & Factor to relate the height at the roof to the effective height \\
\hline $\mathrm{k}_{2}$ & $\begin{array}{l}\text { Factor to relate the expected displaced shape function to a linear displaced } \\
\text { shape function }\end{array}$ \\
\hline $\mathrm{K}_{\mathrm{i}}$ & Elastic lateral stiffness \\
\hline $\mathrm{K}_{\mathrm{e}}, \mathrm{K}_{\mathrm{eff}}$ & Effective lateral stiffness \\
\hline $\mathbf{M}$ & Lumped mass matrix \\
\hline $\mathrm{L}, \mathrm{L}_{1}$ & Dynamic characteristic of system (equation 1.1) \\
\hline$l_{b}$ & Bay span \\
\hline $1_{w}$ & Length of wall in cross section \\
\hline $\mathrm{L}_{\mathrm{p}}$ & Length of plastic hinge \\
\hline $\mathbf{M}^{*}, \mathbf{M}_{1}^{*}$ & Effective modal mass of fundamental mode \\
\hline $\mathrm{M}_{\mathrm{eff}}$ & Effective mass \\
\hline $\mathrm{R}_{\mathrm{d}}$ & Force modification factor \\
\hline
\end{tabular}

XXV 


\begin{tabular}{|c|c|}
\hline $\mathrm{R}_{\mathbf{y}}$ & Yield reduction factor \\
\hline $\mathrm{R}_{\mathrm{o}}$ & System over-strength factor \\
\hline$S_{a}$ & $\begin{array}{l}\text { Response spectrum acceleration at the effective fundamental period and } \\
\text { damping ratio of the building }\end{array}$ \\
\hline$t_{i}$ & Time at step i \\
\hline$T_{n}$ & Natural vibration period \\
\hline $\mathrm{T}_{\mathrm{eq}}$ & Equivalent vibration period \\
\hline$T_{0}, T_{i}$ & Elastic period of structure \\
\hline $\mathrm{T}_{\mathrm{g}}$ & Characteristic period of site \\
\hline $\mathrm{T}_{\mathrm{e}}, \mathrm{T}_{\text {eff }}$ & Effective fundamental period \\
\hline $\mathrm{u}_{\mathrm{N}}, \mathrm{u}_{\mathrm{R}}$ & Roof displacement \\
\hline $\mathrm{V}_{\mathrm{b}}, \mathrm{V}_{\text {base }}$ & Base shear \\
\hline $\mathrm{V}_{\mathrm{y}}$ & Yield strength of system \\
\hline $\mathrm{W}$ & Weight of structure \\
\hline $\mathrm{z}$ & Distance from plastic hinge to the point of contraflexure \\
\hline$\alpha_{\text {st }}, \beta$ & Factor relating maximum inter-story drift to roof displacement \\
\hline$\delta_{\text {I }}$ & Inter-story drift limit \\
\hline$\delta_{\mathrm{t}}, \Delta_{\mathrm{t}}$ & Target displacement of system \\
\hline$\delta_{\mathrm{u}}$ & Target displacement of equivalent SDOF system \\
\hline$\delta_{\mathrm{y}}$ & Yield displacement of equivalent SDOF system \\
\hline$\Delta_{\mathrm{u}}$ & Ultimate roof displacement \\
\hline$\Delta_{\mathrm{u}}^{*}$ & $\begin{array}{l}\text { Inelastic spectral displacement of equivalent SDOF system } \\
\qquad x x v i\end{array}$ \\
\hline
\end{tabular}




\begin{tabular}{|c|c|}
\hline$\Delta_{\mathrm{y}}$ & Yield displacement \\
\hline$\varepsilon_{y}$ & Yield strain of reinforcing steel \\
\hline$\varepsilon_{\mathrm{u}}$ & Concrete compression strain limit \\
\hline$\varphi, \varphi_{1}$ & Fundamental mode shape \\
\hline$\varphi_{\mathrm{rl}}$ & Fundamental mode shape value at roof \\
\hline$\varphi^{T}$ & Transpose of fundamental mode shape \\
\hline$\phi_{\mathrm{s}}$ & Serviceability curvature \\
\hline$\phi_{u}$ & Serviceability curvature \\
\hline$\phi_{\mathrm{y}}$ & Effective yield curvature \\
\hline$\phi_{u}$ & Ultimate curvature \\
\hline$\Gamma, \Gamma_{1}$ & Dynamic characteristic of system (equation 1.2) \\
\hline$\mu$ & System ductility factor \\
\hline$\mu_{\Delta}$ & Displacement ductility factor \\
\hline$\theta_{\mathrm{y}}$ & Story yield drift \\
\hline$\theta_{\mathrm{u}}$ & Ultimate story drift \\
\hline$\theta_{\mathrm{p}}$ & Plastic story drift \\
\hline$\theta_{\mathrm{i}, \max }$ & Maximum inter-story drift \\
\hline$\omega_{\mathrm{I}}$ & Frequency of system \\
\hline$\Omega$ & System over-strength factor \\
\hline$\xi_{\mathrm{eq}}$ & Equivalent viscous damping ratio \\
\hline$\xi_{1}$ & Viscous damping ratio of system \\
\hline
\end{tabular}




\section{Acronyms}

ADRS Acceleration Displacement Response Spectrum

ATC Applied Technology Council

BSO Basic Safety Objectives

CMRF Concrete Moment Resisting Frame

CSM Capacity Spectrum Method

CSW Concrete Shear Wall

DBD Displacement Based Design

DCSM Drift Capacity Spectrum Method

EC Euro Code

EO Enhanced Objectives

FEMA Federal Emergency Management Agency

GAT Gatineau earthquake source zone

GSP Georgia Straight / Puget Sound earthquake source zones

H Model A model that in general uses relatively small source zones drawn around historical seismicity clusters

IRM Iapetan Rift Margin earthquake source zone

LDP Linear Dynamic Procedure

MDOF Multi Degree of Freedom

MPA Modal Pushover Analysis

NBCC National Building Code of Canada

NEHRP National Earthquake Hazard Reduction Program

xxviii 


\begin{tabular}{|c|c|}
\hline NSP & Nonlinear Static Procedure \\
\hline $\mathbf{N P}$ & Nonstructural Performance \\
\hline PBD & Performance Based Design \\
\hline PBSD & Performance Based Seismic Design \\
\hline PBSE & Performance Based Seismic Engineering \\
\hline PGA & Peak Ground Acceleration \\
\hline PGV & Peak Ground Velocity \\
\hline PUG & Puget Sound earthquake source zone \\
\hline R Model & A model that establishes large regional zones \\
\hline $\mathbf{R C}$ & Reinforced Concrete \\
\hline RHA & Response History Analysis \\
\hline SAC & $\begin{array}{l}\text { SAC steel project, seismic design criteria for steel moment frame } \\
\text { construction sponsored by SEAOC, ATC and CUREe }\end{array}$ \\
\hline SEAOC & Structural Engineers Association of California \\
\hline SCR & Stable Continental Region \\
\hline SDOF & Single Degree of Freedom \\
\hline SMRF & Steel Moment Resisting Frame \\
\hline $\mathbf{S P}$ & Structural Performance \\
\hline UBC & Uniform Building Code \\
\hline UHS & Uniform Hazard Spectrum \\
\hline ULS & Ultimate Limit State \\
\hline USGS & United States Geological Survey \\
\hline
\end{tabular}

xxix 


\section{Chapter 1}

\section{Introduction}

\subsection{General}

In the traditional method of designing a building structure for earthquake forces (forcebased design), an equivalent seismic base shear is calculated based on the estimated fundamental period of the structure and an elastic response spectrum that is representative of the seismicity of the site. The design base shear value depends on the height (period), type, location and importance of the structure as well as on the nature of foundation soil. The shear is adjusted to take into account the ductility capacity of the structure and its expected over-strength. It is then distributed along the height using an empirical relationship to determine the story level forces. An elastic analysis is carried out next to find the element forces and the elements are designed for such forces. Finally, the inelastic inter-story drifts produced by the design forces are obtained from the calculated elastic drifts and are checked against prescribed displacement limits. If necessary, the structure is stiffened to ensure that displacements do not exceed the specified limits. This method is widely used by seismic design codes all over the world, including the National Building Code of Canada (Canadian Commission 2005).

It is now recognized that the performance of a structure during an earthquake is a function of the ductility demand placed on it, and/or on the displacements and inter-story 
drifts induced in it. The force based design method, which controls the strengths, and only indirectly the displacements, is not capable of producing a uniform level of performance, and concerns have been expressed regarding the reliability and economy of the current design method. Displacement-based design (DBD) methods are better able to ensure a uniform level of performance and have therefore attracted considerable attention during recent years. They are being considered as the recommended methods of seismic design in the future design codes.

In this study a new displacement-based design method will be presented that could be used in the design of any structural system. The method can also be used to evaluate the performance of a given structure. It may be noted that by using a displacement-based design at various hazard levels, the desired performance at each hazard level can be achieved. For this reason, displacement based design could be considered as the main component of performance based design.

\subsection{Performance Based Design}

The primary goal of major building codes is to protect life safety by designing buildings that have sufficient integrity and strength to resist collapse in severe earthquakes. The secondary objective of these codes is to control property damage and maintain function in more moderate but frequent events. Tentative guidelines for Performance-Based Seismic Engineering (PBSE) are presented in Appendix I of SEAOC Blue Book (1999). 
In a performance-based seismic design, a procedure is developed to ensure that, at specific levels of ground motion and with definable levels of reliability, the designed structure would not be damaged beyond certain states. The Blue Book defines, in qualitative terms, five structural performance (SP) levels and five nonstructural performance (NP) levels. A performance level describes a damage condition that is considered satisfactory for a given building under a certain ground motion. At performance level SP1 damage is generally expected to be negligible while at SP5 partial collapse is imminent or has occurred. In non-structural elements, damage is classified from no damage at NP1 to collapse at NP5.

Four levels of earthquake hazard are defined for the performance objectives. EQ-I represents a frequent event and is defined as the earthquake that has an $87 \%$ probability of being exceeded in a 50 year period (annual probability of exceedance of $4 \%$ or mean recurrence interval of approximately 25 years). EQ-II has a mean recurrence interval of 72 years, EQ-III has a recurrence interval between 250 and 800 years, and EQ-IV has a recurrence interval between 800 and 2500 years.

Three standard performance objectives are defined as shown in Figure (1.1). Basic Safety Objective (BSO) is recommended for PBSE of standard occupancy structures and requires level 1 performance in EQ-I, level 2 performance in EQ-II, level 3 performance in EQ-III and level 4 performance in EQ-IV. Enhanced Objective 1 (EO1) is a higher objective than BSO and requires level 1 performance in EQ-II, level 2 performance in 
EQ-III and level 3 performance in EQ-IV. EO2 is considered for safety critical facilities and includes level 1 performance in the EQ-I, EQ-II and EQ-III and level 2 performance for EQ-IV.

As seen from Figure (1.1) a performance objective is a combination of a hazard level and the expected performance under that hazard. The hazard level is determined by a probabilistic hazard analysis (PSHA) and expressed in terms of the annual frequency of exceedance or return period. The SEAOC Blue Book and SEAOC Vision 2000 report (1995) define the performance levels in both qualitative and quantitative terms. The quantitative levels are defined through limiting values of measurable response parameters, such as story drifts and ductility demands. The DBD method presented here uses hazard estimates represented by Uniform Hazard Spectra given by codes, for example NBCC 2005, and quantitative displacement, drift and ductility measures to satisfy the desired performance objectives.

\subsection{Displacement Based Design Guidelines}

Displacement-based design methods have now been provided in certain design guidelines. ATC-40 (Applied Technology Council 1996) and FEMA 274 (Federal Emergency Management Agency 1997) presented a non-linear static procedure (NSP) that was based on the equivalent linearization method and equivalent damping concept. The NSP procedure was further developed by FEMA 356 (2000); the refined procedure used empirical coefficients for calculation of the inelastic demand displacement of the 
structures. Recently, FEMA 440 (2005) has further refined the FEMA 274 (ATC 40) and FEMA 356 procedures and implemented additional details. A comprehensive performance based design method was introduced by SEAOC blue book (1999); that method is also based on the equivalent damping concept. These procedures will be discussed briefly in the following sections.

\subsubsection{ATC-40 and FEMA 274}

The following steps are involved in calculating the expected inelastic deformation of the structures:

1. Select a lateral load pattern and develop the pushover curve, that is, a relationship between base shear, $\mathrm{V}_{\mathrm{b}}$ and roof (Nth floor) displacement, $\mathrm{u}_{\mathrm{N}}$.

2. Use the following dynamic characteristics to convert the pushover curve to a capacity diagram:

$$
\begin{aligned}
& \mathrm{L}=\varphi^{\mathrm{T}} \mathrm{M1} \\
& \Gamma=\frac{\varphi^{\mathrm{T}} \mathrm{M} 1}{\varphi^{\mathrm{T}} \mathrm{M} \varphi} \\
& \mathrm{M}^{*}=\mathrm{L} \Gamma=\frac{\left(\varphi^{\mathrm{T}} \mathrm{M} 1\right)^{2}}{\varphi^{\mathrm{T}} \mathrm{M} \varphi}
\end{aligned}
$$

where $\mathbf{M}$ is the lumped mass matrix, $\boldsymbol{\varphi}$ is the fundamental mode shape or its representation, $M^{*}$ is the effective modal mass for the fundamental mode and $\mathbf{1}$ is the unit vector. 
3. Convert the elastic design spectrum corresponding to the damping $\zeta$ to Acceleration-Displacement (A-D) format.

4. Plot the design spectrum in A-D format, also referred to as the demand spectrum, and the capacity diagram together and determine the displacement demand given by the intersection of the demand curve and the capacity curve; see Figure (1.2a). Obtain the vibration period $\mathrm{T}_{\mathrm{eq}}$ and damping $\zeta_{\mathrm{eq}}$ of the equivalent linear system, defined by the displacement demand just determined. For the bilinear system shown in Figure (1.2b) the natural vibration period of the equivalent linear system with stiffness equal to the secant stiffness $\mathrm{K}_{\mathrm{sec}}$ is:

$$
T_{e q}=T_{n} \sqrt{\frac{\mu}{1+\alpha \mu-\alpha}}
$$

where $T_{n}$ is the natural vibration period of the system, $\alpha$ is the ratio of the stiffness of the yielding branch to the elastic branch and $\mu$ is the ductility factor $\mu=u_{m} / u_{y}$. To define equivalent viscous damping, the energy dissipated in a vibration cycle of the inelastic system is set equal to that of the equivalent linear system. The total viscous damping of the equivalent system is obtained by adding the aforementioned equivalent viscous damping to the viscous damping of the bilinear system vibrating within its linearly elastic range.

5. Obtain a new elastic spectrum or demand curve corresponding to the updated damping value $\zeta_{\mathrm{eq}}$ and find a new demand point.

6. Repeat steps 4 and 5 until the process converges. 
7. On convergence, convert the demand displacement into roof displacement and calculate the structural components deformation and compare them to the limiting values for the respective performance objectives.

Approximations are involved in the various steps of this simplified analysis of an inelastic multi degree of freedom (MODF) system. In steps 1 and 2, a fixed lateral force distribution is assumed that is based only on the fundamental vibration mode of the elastic system. In step 4 through 6 , inelastic demand is calculated using a method that has no theoretical base and could lead to significant errors.

\subsubsection{FEMA 356}

The Non-linear Static Procedure (NSP) was developed further in FEMA 356. According to that document NSP could be used for structures in which higher mode effects are negligible. In order to verify this, two response spectrum analyses, one using sufficient modes to capture $90 \%$ participation mass and the other one using only the first mode should be performed. Higher mode effects could be neglected if the shear in any story resulting from the multi mode analysis does not exceed $130 \%$ of the corresponding story shear using only the first mode.

If higher mode effects are significant, the NSP is permitted provided that a Linear Dynamic Procedure (LDP) analysis is performed at the same time. The NSP is a more reliable method compared to the linear procedures. However, it is not exact and effects of 
stiffness or strength degradation and higher modes on dynamic response of structure could not be evaluated. In structures with higher mode effect, the LDP should be used with NSP to ensure the adequacy of the designed structure.

In NSP a monotonically increasing lateral load is applied to the structure until the target displacement is reached. The non-linear characteristics of the structural elements are incorporated in the analysis. Lateral loads are applied to the mathematical model in proportion to the distribution of inertia forces at each level. At least two vertical distributions of lateral load from five different proposed patterns should be used.

The target displacement represents the maximum expected displacement during the design earthquake. The internal forces produced in the structure when it reaches the target displacement will be reasonable approximations of those expected during the design earthquake.

The target displacement, $\delta_{\mathrm{t}}$, at the roof level is calculated using Equation (1.5):

$\delta_{t}=C_{0} C_{1} C_{2} C_{3} \mathrm{~S}_{a} \frac{T_{e}^{2}}{4 \pi^{2}} \mathrm{~g}$

where coefficient $\mathrm{C}_{0}$ relates spectral displacement of an equivalent SDOF system to the roof displacement of the MDOF system. If only the first mode shape $\left(\varphi_{1}\right)$ and elastic behavior are considered, it is equal to the first mode participation factor at the roof level. Coefficient $\mathrm{C}_{1}$ relates expected maximum inelastic displacement to the elastic displacements of the structure, coefficient $\mathrm{C}_{2}$ accounts for the effect of pinched hysteretic 
shape, stiffness degradation and strength deterioration on maximum displacement response, and coefficient $C_{3}$ represents increased displacement due to dynamic P- $\Delta$ effects. $S_{a}$ is response spectrum acceleration at the effective fundamental period and damping ratio of the building, $g$ is acceleration of gravity and $T_{e}$ is the effective fundamental period that is calculated as follows:

$T_{e}=T_{i} \sqrt{\frac{K_{i}}{K_{e}}}$

where $T_{i}$ is elastic (initial) fundamental period, $K_{i}$ is elastic lateral stiffness of the building and $\mathrm{K}_{\mathrm{e}}$ is effective lateral stiffness of the building as shown in Figure (1.3).

The design is considered satisfactory if demand deformation of structural components of the lateral load resisting system calculated at the target displacement, do not exceed their capacity. Also, the base shear at the target displacement should not be less than $80 \%$ of the effective yield strength of structure $V_{y}$.

\subsubsection{FEMA 440}

In the most recent publication of Federal Emergency Management Agency, "FEMA 440 Improvement of Non-linear Static Seismic Analysis Procedures", the current FEMA 356 and ATC-40 procedures are evaluated. Based on such evaluation certain modifications to the coefficients in non-linear static procedure of FEMA 356 are proposed. Improved relationships for coefficients $\mathrm{C}_{1}$ and $\mathrm{C}_{2}$ and replacing coefficient $\mathrm{C}_{3}$ with a limitation on minimum strength are suggested in the new guideline. 
In order to improve practical application of the equivalent linearization procedure (ATC-40), FEMA 440 suggests improved estimates of equivalent period and damping. An adjustment is also included to generate a modified acceleration-displacement response spectrum.

Other major improvements are as follows:

1. Use of the first mode load vector is recommended. Advantages are that it is consistent with derivation of equivalent SDOF system and lower error is produced. Use of multiple load vectors in FEMA 356 does not provide reliable results. Generally, for estimate of response quantities that are not significantly affected by higher modes a single first mode vector would be sufficient.

2. The spectrum is modified for kinematic soil-structure interaction effect. The spectral ordinate of the foundation input motion at each period is taken as the product of the free-field spectrum and a reduction factor that is calculated based on foundation size, structural period and soil type.

3. In order to take into account the effect of foundation damping, the response spectrum is calculated for a modified damping factor that incorporates both structural and foundation damping.

Several issues that are not fully studied in this publication are: non-linear modeling for cyclic and in-cycle degradation of strength and stiffness, soil and foundation interaction and non-linear multi-degree-of-freedom simplified modeling. 


\subsubsection{SEAOC blue book}

The Direct Displacement-Based Design (DBD) presented in the Blue Book includes the following steps (refer to Figure (1.4)):

1. Estimate the target displacements.

For each performance level, the target displacement can be estimated by the following Equation:

$$
\Delta_{T}=\delta_{1} \mathrm{~h}_{R} k_{1} k_{2}
$$

where, $\Delta_{T}$ is target displacement for the global system at the effective height of the equivalent SDOF systems, $\delta_{1}$ is inter-story drift ratio limit, $\mathrm{h}_{\mathrm{R}}$ is height at roof level, coefficient $\mathrm{k}_{1}$ relates the height at the roof to the effective height, and factor $\mathrm{k}_{2}$ relates the expected displaced shape function to a linear displaced shape function.

2. Determine effective period.

The effective period $\left(\mathrm{T}_{\text {eff }}\right)$ at each limit state or the target displacement $\Delta_{\mathrm{T}}$ is determined using the design response spectrum with a system damping value that includes both hysteretic damping and the 5\% viscous damping (Figure 1.4c). A relationship between system ductility and equivalent hysteretic damping could be found by using the equal dissipating energy concept. Next, using the ductility capacity that is defined for various structural systems, the equivalent damping ratio is calculated.

3. Determine effective stiffness. 
The effective stiffness ( $\left.\mathrm{K}_{\text {eff }}\right)$ and required initial stiffness $\left(\mathrm{K}_{\mathrm{i}}\right)$ are determined from Equations (1.8) and (1.9):

$$
\begin{aligned}
& K_{e f f}=4 \pi^{2} M_{e f f} / T_{e f f}^{2} \\
& K_{i}=\mu K_{e f f}
\end{aligned}
$$

where $\mathrm{M}_{\text {eff }}$ is the effective mass and $\mu$ is the system ductility capacity for the selected performance level.

4. Determine required strength and required yield strength.

The required strength is determined based on the effective stiffness and the target displacement:

$$
\begin{aligned}
& V_{\text {base }}=\mathrm{K}_{e f f} \Delta_{T} \\
& V_{y}=V_{\text {base }} / \Omega
\end{aligned}
$$

$\mathrm{V}_{\mathrm{y}}$ is the required yield strength and $\Omega$ is the system over-strength factor.

5. Perform preliminary design and determine the size of lateral load resisting elements.

6. Verify design using pushover analysis procedure.

7. Modify design if required.

8. Prepare final design and detailing.

The approximations that are implicit in the equivalent damping methods of FEMA and SEAOC guidelines may lead to unreliable analysis results for the inelastic MDOF systems. In these methods, effect of higher modes is neglected since a lateral force 
distribution that is based only on the fundamental mode is used. The dynamic analysis of the inelastic SDF system is avoided by using an iterative method that analyzes series of equivalent linear SDF systems, in which an extra viscous damping is considered to account for energy dissipated in yielding. Theoretically this cannot be justified because while the hysteretic energy is related to displacement, viscous energy is proportional to velocity.

\subsection{Review of Literature related to Pushover Analysis}

Pushover analysis is a major part of displacement-based design and performance evaluation. Basically, it is performed with monotonically increasing lateral load, usually distributed according to the first mode shape.

Krawinkler and Seneviratna (1998) evaluated the capabilities and shortcomings of the pushover analysis as a seismic performance evaluation tool. It was shown that a pushover analysis is able to provide valuable information about the performance of the structure during a severe earthquake. It was shown also that very good estimates of the local and global inelastic deformations demands could be obtained using this analysis method for the structures that vibrate in their first mode. In addition, design weaknesses, story mechanisms, excessive deformation demands, strength irregularities, and overload on brittle elements such as columns and connections that could remain hidden in an elastic analysis are detected in a carefully performed pushover analysis. However, since pushover analysis is based on a static loading, dynamic characteristics of the structure 
could not be evaluated. Also, in structures with significant higher mode effects and structures whose performance is very sensitive to the applied lateral load pattern, pushover analysis could produce significant inaccuracy.

The effect of higher modes sometimes is significant, as observed by Chopra and Chintanapakdee (2001) in the case of near-fault ground motions. For symmetric structures, Chopra and Goel (2001) have presented an improved pushover analysis procedure called modal pushover analysis (MPA). In this procedure the seismic demand is determined by a series of pushover analyses using the lateral force distribution for each of a few lower modes. The total seismic demand on inelastic systems is obtained by combination of these modal demands. It was shown that MPA procedure is accurate enough for building evaluation and design, however local response quantities such as hinge plastic rotations could not be accurately estimated.

Chintanapakdee and Chopra (2003) carried out studies to evaluate the validity and accuracy of modal pushover analysis. Idealized frames of six different heights and five strength levels were selected and each frame was analyzed for 20 ground motions. Results obtained by three different procedures were compared to the exact value from Response History Analysis (RHA). It was shown that if a sufficient number (2 or 3) of modes were included, the inter-story drifts variation in height determined by MPA could be generally similar to the exact results from RHA. For longer period frames the bias in 
the MPA method was higher and larger SDF system ductility factors compared to exact values were obtained.

Several non-linear static analysis procedures were evaluated by Chopra (2004). The lateral load distribution patterns for pushover analysis proposed by FEMA 356 were applied to SAC buildings (Goel and Chopra (2004)) and story drifts were compared to exact values. All of the values obtained by the FEMA 356 analyses underestimated the upper story drifts. The modified version of pushover analysis proposed by Chopra, considering the gravity loads, produced results closer to the exact RHA in general. Also, the comparison of the first mode and exact response of SAC (SAC steel project, seismic design criteria for steel moment frame construction) buildings under 20 ground motions showed that the bias in estimating the roof displacement of inelastic systems using the first mode was high.

Modal Pushover Analysis Method was applied to vertically irregular buildings by Chintanapakdee and Chopra (2004) and results were compared to those obtained from non-linear time history analysis. Stiffness, strength and combined stiffness-strength irregularities in different locations were considered. It was shown that bias in the MPA procedure did not increase for the buildings in which irregularity existed in middle or upper stories. The estimates of seismic demands in frames with softer, stiffer, weaker or stronger lower half, were less accurate than in the reference regular frames. 
Goel and Chopra (2005) presented a simplified but a more comprehensive method to calculate member forces. The extended MPA procedure could be used to estimate hinge bending moments, beam shear forces, column axial and shear forces and column bending moments taking into account the member capacities. The accuracy of the extended MPA procedure in estimating the member forces was evaluated for previously mentioned SAC buildings. This method provided good estimates of member forces except in the case of building with extreme inelastic deformation and degradation in lateral capacity.

Goel and Chopra (2006) presented a modified modal pushover analysis procedure in which the response contributions of higher modes were calculated assuming that the building remained linearly elastic. Avoiding the pushover analysis for higher modes substantially reduced the computational effort. Besides, reversal of the pushover curve that could occur in higher modes was avoided.

Pushover analysis was applied to asymmetric buildings by Kilar and Fajfar (1997). To simplify the analysis, they developed a few macro-elements to be used in pseudo-3D mathematical model of the structure. Bi- or multi-linear relations for base shear - top displacement of macro-elements representing the behaviour of structural components, including columns, walls and coupled walls, were derived. Once the model of structure was prepared, analysis of a sequence of linear systems using the event-to-event strategy was carried out. Several symmetric and asymmetric 7 and 21 story buildings were 
modeled and analyzed using this method. Good compatibility with test as well as with exact analysis results was observed.

Chopra and Goel (2004 and 2006) evaluated MPA for buildings that were not symmetric in plan. They showed that in cases of torsionally-stiff and torsionally-flexible systems, MPA results were as accurate as they were for the symmetric plan building. However, due to stronger coupling of elastic modes and also approximations associated with the modal combination rules, the accuracy of the results reduced in the case of torsionallysimilarly-stiff systems.

\subsection{Studies Relating Elastic and Inelastic Displacements}

In the regular steel moment resisting frame (SMRF) structures, the roof displacement and inter-story drift could be estimated from the demand response spectrum. This is due to the relatively predictable behaviour of SMRF of structures. Gupta and Krawinkler (2000) presented a process in which maximum story drift demands were estimated through a series of modification factors applied to the first mode spectral displacement. Nine SMRF structures from SAC steel program with heights of 3,9 and 20 stories and located in three regions of different seismicity zones were considered. The response of structures was evaluated for sets of ground motions representative of three hazard levels corresponding to $2 \%, 10 \%$ and $50 \%$ probabilities of being exceeded in 50 years. Results of the non-linear time history analyses of the structures were used to derive the proposed modification factors. These factors account for the effect of multiple degrees-of-freedom, 
inelasticity, P-delta and element deformation. It was found that the roof displacement demand in an inelastic structure could be estimated with good confidence, provided that the effect of P-delta was not significant so that drifts associated with a negative post-yield stiffness would be avoided.

Displacement-based methods of analysis are implemented in FEMA 273 (1998) for the seismic evaluation and design of buildings. One of the non-linear static procedures in FEMA 273 assumes that inelastic displacements can be estimated using the results of linear analysis. This process was investigated by non-linear response history analysis of SDOF systems by Whittaker et al (1998). Twenty earthquake ground motions scaled to match NEHRP (National earthquake hazard reduction program) spectrum for a soft rock to stiff soil site in a region of high earthquake hazard were used. Relations between inelastic and elastic displacements for SDOF systems with different values of strength ratio, post-yield stiffness and elastic period were presented. It was shown that for $T_{0}<T_{g}$ ( $T_{0}$ is the elastic period of structure and $T_{g}$ is characteristic site period) and for all values of strength ratio, mean inelastic displacements were considerably larger than the mean elastic displacements. This was accounted for in FEMA 273 by introducing a coefficient $C_{1}$. However, the presented data showed that the upper limiting value assigned to $C_{1}$ $(=1.5)$ may be non-conservative for small values of strength ratio. 


\subsection{Review of Literature related to Displacement Based Design Methods}

Fajfar and Gaspersic (1996) proposed a method for DBD, which they called the N2 method. In this method, using a simplified pushover curve and elastic demand spectrum, the demand roof displacement is determined and then damage index is calculated for the structure. The spectral acceleration is estimated using effective period of the structure obtained from idealized pushover curve. Inelastic displacement is calculated by the Newmark-Hall empirical relationship between $\mu-\mathrm{R}-\mathrm{T}$. The N2 method was applied to two 7 story RC frames and one frame-wall structure. Comparison with the exact analysis showed that this method provided good estimates of the global demand for the structures that vibrated primarily in the fundamental mode, but if higher modes effects were significant, some demand quantities could be underestimated.

Fajfar (1999) presented a modified method that used a graphical procedure to evaluate the performance of a designed structure. The proposed procedure, in the reverse order of steps, could be used for displacement based design. To build the inelastic demand spectra required in DBD, Vidic-Fajfar empirical formulae of $\mu-R-T$ were used. It was shown that the demand displacement of the equivalent single degree of freedom (SDOF) system could be obtained from intersection point of the idealized capacity diagram and inelastic demand spectrum in ADRS (Acceleration-Displacement) format.

Use of "equal displacement rule" in median and long period structures was considered by Fajfar (2000). According to this rule the elastic and inelastic displacements are equal 
when the fundamental displacement of the structure is larger than a certain value. Fajfar showed that regardless of the magnitude and model of damping, hysteretic behaviour, post-yielding stiffness, magnitude of earthquake, level of ground acceleration and distance to epicentre, this rule was valid for sites that had firm soil and for structures with stable hysteretic loops. However, in case of near-fault ground motions, soft soil sites, hysteretic loops with significant pinching or significant stiffness or strength deteriorations use of this rule was not recommended.

Chopra and Goel (1999) presented two procedures for DBD, which were both modified versions of the ATC-40 and FEMA-274 procedures. Instead of dealing with an elastic system having an equivalent damping value, they used the $\mathrm{R}-\mu-\mathrm{T}$ relationships to construct the inelastic demand spectra. Relationships proposed by Newmark - Hall, Krawinkler - Nassar and Vidic - Fajfar were used to develop inelastic spectra from elastic demand spectrum. Next, a trial and error graphical method using both capacity diagram and non-linear demand spectrum was used to determine the demand ductility and the inelastic displacement of the system. The estimate of deformation for the elastic system obtained by ATC-40 was compared with the deformation determined from the inelastic design spectrum using three different $\mathrm{R}-\mu-\mathrm{T}$ equations. All three relationships produced similar results. Chopra and Goel (2000) observed that relative to the reference values obtained from $\mathrm{R}-\mu-\mathrm{T}$ equations and also an exact analysis, the ATC-40 procedure significantly underestimated the deformation for a wide range of $T_{n}$ and $\mu$ values. 
Chopra and Goel (2001) compared two displacement based design methods. In the first method considered in their study, elastic design spectra and equivalent viscous damping were used to evaluate the demand strength or design base shear. The equivalent damping ratio for an elastic system was calculated assuming that the amount of energy dissipated in vibration cycles of the inelastic system was equal to the dissipated energy in the equivalent linear system. The second procedure was based on an inelastic design spectrum. The Newmark - Hall empirical equations were used to produce the inelastic design spectra. Comparison of the performance of the designed structures with these two methods showed that in structures designed using the inelastic spectra, plastic rotation remained in acceptable range, whereas in structures designed by the procedure based on equivalent damping, plastic rotation demand could exceed the acceptable limits. Also, the latter method could leave an unrealistic impression that the allowable plastic rotation constraints had been satisfied.

Chopra (2004) also presented new R- $\mu-T$ relationships to produce inelastic spectra from elastic demand spectrum. He observed that unlike the ATC method, which underestimated the deformation of the inelastic systems over a wide range of periods by as much as $40-50 \%$, the method based on the use of inelastic spectra determined from the new $\mathrm{R}-\mu-\mathrm{T}$ relationships provided a reasonably conservative estimate of median results for a variety of ground motions. However, in cases where P- $\Delta$ effect was included, more caution was necessary. 
The use of single-degree-of-freedom (SDOF) systems to estimate the target displacement to be used in a pushover analysis of buildings was studied by Chopra et al (2003). Two sets of $2 \mathrm{D}$ structures of 3 to 18 stories and also symmetric SAC buildings with 3,9 and 20 stories and 20 large-magnitude, and short-distance earthquake records were used in the analyses. Analyses were carried out considering the effect of P- $\Delta$. The authors showed that estimate of the median roof displacement for inelastic buildings using the first "mode" SDOF system produced biased results but magnitude and nature of inaccuracies depended on how far the structure was pushed into the inelastic range. For large ductility the SDOF system overestimated the median roof displacement with an increased bias for systems that had longer period. The situation was reversed for small ductilities.

The concept of strength dependent stiffness, which plays an important role in DBD, was presented by Paulay (1998). Moment-curvature analysis of reinforced concrete walls, considering the main parameters that govern the response, such as material properties, reinforcement content and axial compression load intensity, showed that in typical rectangular walls the reference yield curvature $\phi_{\mathrm{y}}$, did not change significantly with these parameters. It was affected only by the yield strain of the reinforcing steel and the wall length. The yield displacement would thus depend only on the wall dimensions and the steel yield strain and be independent of the element strength. In a design process, based on an idealized bilinear lateral force-displacement relationship, the lateral stiffness of an element could be related to its strength. Thus, contrary to the traditional assumption that 
the stiffness is related to the cross sectional dimension of the element, the stiffness is related to the strength and an increase in the amount of reinforcement in RC structural walls, would lead to an increase in both the nominal strength and the stiffness.

The concept referred to in the preceding paragraph was extended to other reinforced concrete (RC) elements by Paulay (2001(b)) and a new design procedure was presented. In this method, instead of stiffness, strength is assigned to the structural components, within rational limits. It was shown that the conventional existing design procedures that were based on the traditional definition of stiffness, produced displacement ductility demand values on structural components that were different than the demand actually imposed on the elements. Conventional method of assigning stiffness based on crosssectional dimensions was compared with the new method that uses strength dependent stiffness for shear wall structures. It was shown that the freedom in choosing element strength also made it possible to choose the location of the centre of strength and stiffness for a 3D system. Thus, undesired effects of torsional phenomena could be eliminated or reduced.

In a new DBD method presented by Paulay (2001(a)), displacement and ductility limits were established. It was shown that the allowable drift, aspect ratio of the wall and the steel yield strain limited the maximum usable ductility for $\mathrm{RC}$ wall. Relationship between the curvature ductility and displacement ductility and a value of $5 \%$ for the maximum steel strain were used as the other criteria to define the maximum displacement ductility. 
The limits on ductility and displacement could both be determined before the design started. For a wall system, overall displacement ductility demand was related to displacement ductility capacity of critical components.

Paulay (2000(a)) showed that apart from drift limits proposed by performance objectives, the displacement capacity of critical elements (elements with the smallest yield displacements) controlled the maximum acceptable displacement capacity of the system. A frame-wall dual system was considered in the displacement-based design method and strength of each frame and wall assigned considering the overall dimensions of components. Maximum ductility capacity of the system was obtained using the serviceability limits. Knowing the yield displacement and strength of each component, the strength-dependent stiffness could be calculated and used for analysis.

Another displacement-based design method that focussed on RC structures and dual systems, was presented by Paulay (2002(b)). Cantilever walls, conventionally and diagonally reinforced coupling beams, coupled structural walls and frame wall systems were designed by this method. The seismic displacement demands were not considered in this method but seismic response of elements could be evaluated using their strengthdependent stiffness. Moment patterns based on the typical lateral static design forces were used in this study. The effect of different load pattern was not considered and displacements were not estimated. 
Priestley and Kowalsky (1998) also studied the variation of yield curvature with wall properties and loading. It was shown that not only the yield curvature of walls but also the serviceability level and ultimate curvatures were insensitive to changes in axial load ratio, longitudinal reinforcement ratio and the distribution of reinforcement. They showed that the drift limits of code governed the design of walls even when the aspect ratio was very low. Thus the required displacement ductility capacity of walls may be less than recommended by codes. Displacement ductility $\mu_{\Delta}$ of walls at serviceability and ultimate limit states were considered. These limit states correspond to the serviceability curvature $\phi_{\mathrm{s}}$ (no spalling in concrete and no residual crack in sections) and the ultimate curvature $\phi_{\mathrm{u}}$ (the state of element before damage starts).

A direct displacement-based design method for SDOF systems using the equivalent damping concept was presented by Priestley and Calvi (1997). Structural yield displacement was estimated as a ratio of the effective height. The acceptable plastic rotation of the critical hinge, which is a function of the design limit states (serviceability or damage control) and the geometry of structure, was used to calculate the design displacement. The same procedure could be applied to a MDOF system assuming an approximate shape function.

A design method similar to that of Priestley and Calvi was developed for frame and wall structures with provisions for precast elements by Priestley (2002). Since the dissipated 
energy for unbonded precast / pre-stressed structure is less than that for conventional structures, a smaller equivalent damping was used in this method.

Analysis of typical beam design for seismic resistant frames indicated that a dimensionless yield curvature could be determined that was insensitive to the longitudinal reinforcement ratio or direction of loading (Priestley 1998). It was shown that the beam stiffness was proportional to its strength so the assumption of beam stiffness being equal to a portion of the gross stiffness was not valid for design. A simple equation predicting the yield drift ratio of frames depending on the beam aspect ratio and reinforcement yield strain was proposed. A wide range of beam column joint test data were used to calibrate this equation that showed good agreement in the average values obtained with a low coefficient of variation. Further analysis showed that the structural stiffness of frames was likely to be much lower than typically assumed by designers. As a result, most frame structures exceeded code drift limits before achieving a displacement ductility of $\mu=4$.

Medhekar and Kennedy (2000) presented an iterative displacement-based design method based on the equivalent damping concept. In this method an initial ductility factor was assumed for SDOF system and a base shear was calculated and used for design. Iteration was performed until the effective period or stiffness calculated for structure converged. Assuming a suitable shape function the same procedure could be applied to the MDOF structures. For asymmetric 3-dimensional structures, torsional effect could be considered 
assuming that the torque was resisted by the elastic elements that were perpendicular to earthquake direction.

Munshi and Ghosh (2000) introduced a displacement-based approach for the seismic design of coupled reinforced shear walls in buildings. Two lateral load resisting systems, one utilizing weakly coupled walls and the other using adequately coupled walls, were designed by this method for regions of high seismicity. It was shown that excessive ductility demand was developed in weakly coupled walls but adequately coupled walls produced displacement and ductility consistent with the design. Thus selecting an optimum value for the beam-to-wall strength ratio could produce minimum ductility demand in walls. Non-linear time history analysis was used to obtain the maximum demand displacement of coupled walls and yield displacement was calculated from the pushover analysis of the coupled walls.

Akkar and Gulkan (2000) compared two performance based deign methods, representing different ground motion demands for various earthquakes. The first method was Capacity Spectrum Method (CSM) that predicted the performance of structures considering the global demand from ground motions. The second method, Drift Capacity Spectrum Method (DCSM) predicted the structural performance considering the local deformation demand of earthquakes. Two frame type buildings were analysed under six different ground motions to evaluate these methods. The results indicated that both methods considerably underestimated the performance of model structures. The relative errors 
with respect to the non-linear time history analysis showed that CSM gave an error of $7.5-50 \%$ on the unsafe side, while DCSM errors reached $82 \%$ on the unsafe side. The unrealistic representation of excitation demand and equivalent damping rules in the nonlinear range were the source of errors.

A two-level displacement-based design procedure was developed by Rubinstein et al (2001). To obtain the displacement demands, elastic spectra for occasional earthquakes and inelastic spectra for rare earthquakes were used. Minimum global stiffness and strength considered for structural components were based on specific maximum allowable drift limits and on the condition that the structure responded within the elastic range for occasional earthquakes. Calculation of the damage indices and the performance evaluation of structure were performed by an inelastic pushover analysis in which the structure was pushed to the required displacement. This approach was applied to the design of a five-story reinforced concrete coupled wall structure. Nonlinear dynamic analysis confirmed the validity of pushover analysis.

Kowalsky (2001) examined the seismic provisions of the Uniform Building Code (UBC) for structural wall buildings. It was shown that although strain limits were present in the UBC 1997, the drift ratio limits generally governed design. The apparent inconsistency between assumed force reduction factors and actual ductility demand at the design limit state controlled by drift was also explored. Several buildings of 2 to 16 stories with varying wall lengths were designed using UBC 1997 and a displacement-based method 
(Priestly 2000) and non-linear time history analyses were carried out on the designed structure to evaluate the design. Considerable difference between the equivalent lateral force method (UBC) and the time history analysis results was observed.

A procedure for displacement-based design of reinforced concrete buildings was developed by Panagiotakos and Fardis (2001). The main elements of this method were: a preliminary design of member reinforcement based on the Ultimate Limit State (ULS) for the factored gravity load, capacity design of all elements in shear, detailing based on the non-earthquake-resistant provisions and then final detailing of members followed by possible revision of member properties to pass the deformation demands required by life safety design earthquake. The procedure was applied to a 2D 4-story test structure that included a coupled wall and a two-bay frame. Another structure was designed and detailed according to Euro Code 8. Major differences resulted in the reinforcement of two structures with significant saving on DBD side. Dynamic tests on frames constructed based on EC8 design and DBD were conducted. Non-linear dynamic analyses were performed on these frames and no major difference was noticed in the predicted and observed seismic performance.

Bertero (2002) presented the steps of a conceptual performance based design procedure. For multi-level design criteria including near collapse, life safety, operational and fully operational levels, based on the probability of occurrence, different load factors for earthquake load were obtained. Also, based on the shear beam model and distributed 
mass assumption, relationship for story drift index in both elastic and inelastic regions were derived that could be used for the construction of elastic and inelastic spectra. Local damage index, which included damage due to drift and also cumulative hysteretic energy, was presented. It was shown that the equivalent damping method produced unacceptable results. This was because the energy dissipated through ductile behaviour in the inelastic range was not considered in that method.

Tjhin et al (2004) presented an analytical study on yield curvature for estimating the effective yield displacements required in the design of structural wall buildings. Improved estimates of effective yield curvature were obtained for rectangular and bar bell cross sections based on the moment-curvature analyses. Variables considered included boundary and web reinforcement ratios, concrete compressive and reinforcing steel tensile strengths, and axial load ratio. Formulas for estimating effective yield curvature and displacements were also presented.

An analytical procedure for relating story drift and local deformations in steel moment resisting frames was presented by Gupta and Krawinkler (2002). In their method, story yield drift was estimated based on the weakest element in the connection, that is, beam or panel zone. Also, story plastic drift demand was related to the panel zone and beam plastic deformations demand by a function based on story geometry and member properties. Having obtained the story yield drift, the total story drift demand was related to the plastic story drift. 
Aschheim (2002) presented a new seismic design method based on the yield point spectra. He suggested that the yield displacement was a more stable parameter for seismic design rather than the period of structure. It was shown that the yield displacement of structures with dominant flexural response was a function of structural geometry and material property, in general, and was nearly independent of the strength of the system. In Aschheim's proposed method approximate yield displacement was calculated for the structure. From yield point spectra and using the allowable ductility and estimated yield displacement the required base shear coefficient for the building was obtained, which could be used in the design.

\subsection{Scope of the Proposed Study}

The present research includes two different aspects of earthquake engineering. First a new Displacement-Based Design method is introduced which can be used for various structural systems. In the second part, challenges regarding the selection, scaling and correction of the spectrum compatible ground motions are discussed and a procedure for the selection of records is presented. This method is applied to the selection of 20 records for eastern region of Canada.

In order to validate the presented design method and also to develop a relationship between the maximum inter-story and roof drifts, steel and reinforced concrete structures of 6 to 20 story designed with the presented DBD method are subjected to non-linear time history response analysis for the selected ground motions. Another set of 20 ground 
motions, selected for western Canada by a similar research (Pina 2006), are used for the analysis of the same type of structures designed for Vancouver.

\subsubsection{Development of a DBD Method}

In this thesis a simple, reliable and fast-converging DBD method will be introduced that can be used in the design of any structural systems. Its simplicity is comparable to that of the conventional force-based design methods and many of the design-related parameters and structural effects mentioned in the codes (e.g. over-strength, importance and foundation factors, P-Delta effect, etc.) are used in the same way. In the proposed method, the acceptable ultimate story drift or displacement is determined on the basis of:

(1) Limits specified in the code to meet the selected performance objectives

(2) Stability under P-Delta effects

(3) Ductility capacity

For preliminary design the yield displacement of the structural system is calculated from simple relations based on the general dimensions of the structure and material characteristics. The required strength of the structure is then determined from the inelastic demand spectrum corresponding to the ductility capacity, which is the ratio of the acceptable ultimate drift and yield displacement. In subsequent iteration of design a pushover analysis is carried out to obtain more refined estimates of the yield displacement and ultimate displacement. The method does not require computation of the period of the structure, so the unrealistic assumptions associated with the period 
calculation are avoided. The method can be used for a multi degree of freedom system by transforming it into an equivalent single degree of freedom system. Either graphical or numerical procedure can be followed. The method can be used in reverse order to evaluate the performance of a given structure.

In certain structures higher modes have considerable effect on the structural response. In order to account for this effect Modal Pushover Analysis method is incorporated in the proposed design method.

\subsubsection{Generation of Spectrum Compatible Ground Motions for Eastern Canada}

In order to study the non-linear response of structures, use of multiple realistic ground motion time histories having frequency content and phasing that are appropriate for the magnitude, distance, site conditions and wave propagation characteristics of the region is necessary. In this study, based on probabilistic estimates of seismic hazard appropriate to eastern Canada's geographic regions, a set of ground motions is developed. Recorded ground motions that are appropriate for Montreal, a large city at high earthquake risk, are considered. The selected ground motions are scaled to match the UHS for Montreal. In selecting the ground motions, priority is given to the ground motions from the same geographical region and hazard source. Use of synthetic time histories is avoided. 
In order to maintain the individual characteristics of the selected ground motions, the scaling of time histories is generally done using a single scaling factor (without changing the response spectrum shape).

\subsection{Objectives of The Study}

The following are the objectives of this study:

(1) Review the displacement-based design guidelines.

(2) Review the existing DBD methods.

(3) Develop a new DBD method that is simple and suitable for practical design of regular structures. This includes the following actions,

a. Evaluation of approximate yield displacement of structural systems.

b. Evaluation of the ultimate displacement of structural systems.

c. Use of modal analysis and pushover analysis of a preliminary design of the structure to obtain better estimates of the yield and ultimate displacements.

d. Use of Modal Pushover Analysis in the design process to account for higher modes effect.

e. Application of the proposed method to various structural systems

(4) Generate suite of ground motions for Montreal.

(5) Determine relationship between the roof drift and maximum inter-story drift. 
(6) Carry out analytical studies to validate the developed method. A series of nonlinear time history analyses is carried out for the ground motions developed in this study for Montreal and similar ground motions for Vancouver adopted from a similar study by another researcher.

\subsection{Layout of the Report}

This report is organized as follows:

Chapter 1 provides an overview of the current seismic design codes and the current developments in displacement-based design and modal pushover analysis.

Chapter 2 presents the theoretical background to the displacement-based design method and provides approximate relations for determining yield and ultimate displacements. The local ductility of elements is related to the roof displacement to evaluate the ultimate displacement of structure. Relationships between roof drift and maximum inter-story drift, use of equivalent SDOF system in design, and the development of inelastic demand spectra are discussed. Finally, steps of the proposed design method are presented.

Chapter 3 provides design examples. Using the proposed DBD procedure and the MPA method, four buildings having various structural systems are designed. 
Chapter 4 reviews the selection and scaling of design spectrum-compatible ground motions. Also selection, scaling and correction of ground motions that are compatible with the NBCC (National Building Code of Canada) uniform hazard spectra and with the deaggregation results of eastern Canada are discussed.

Chapter 5 presents the results of time history analyses of 2 sets of structure using selected ground motions. Steel moment resisting frames and reinforced concrete frames with 6,9, 12,15 and 20 stories are used in this study to validate the presented design procedure. Also, using these results, relationships between maximum inter-story drift and roof drift are suggested. 


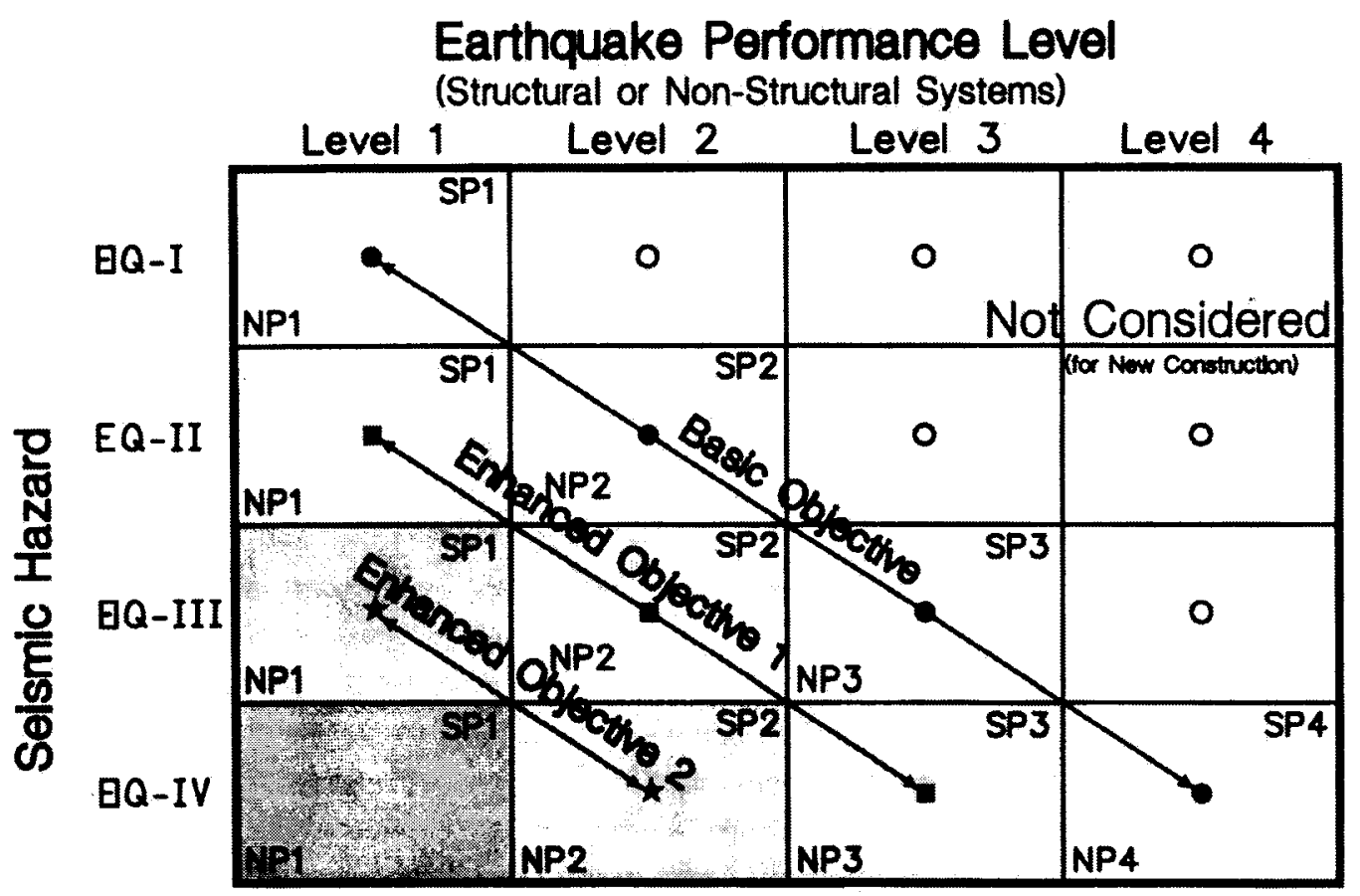

Figure (1.1): Standard Performance Objectives (SEAOC Blue Book) 
(a)

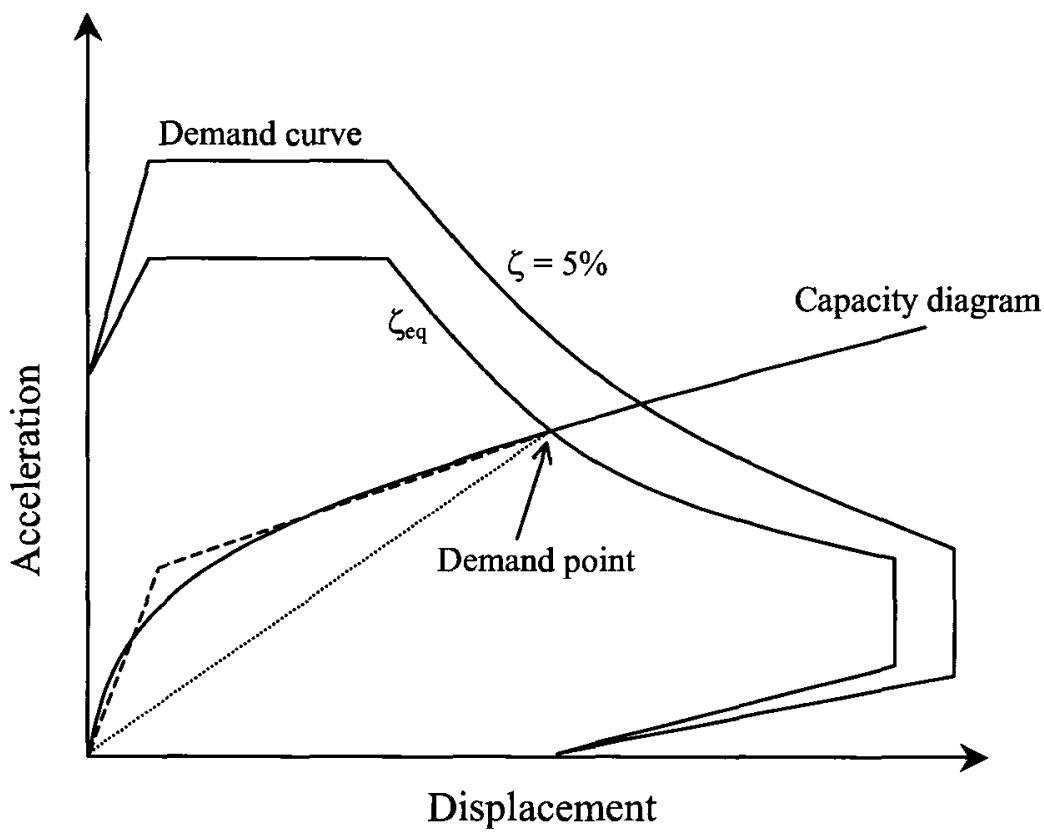

(b)

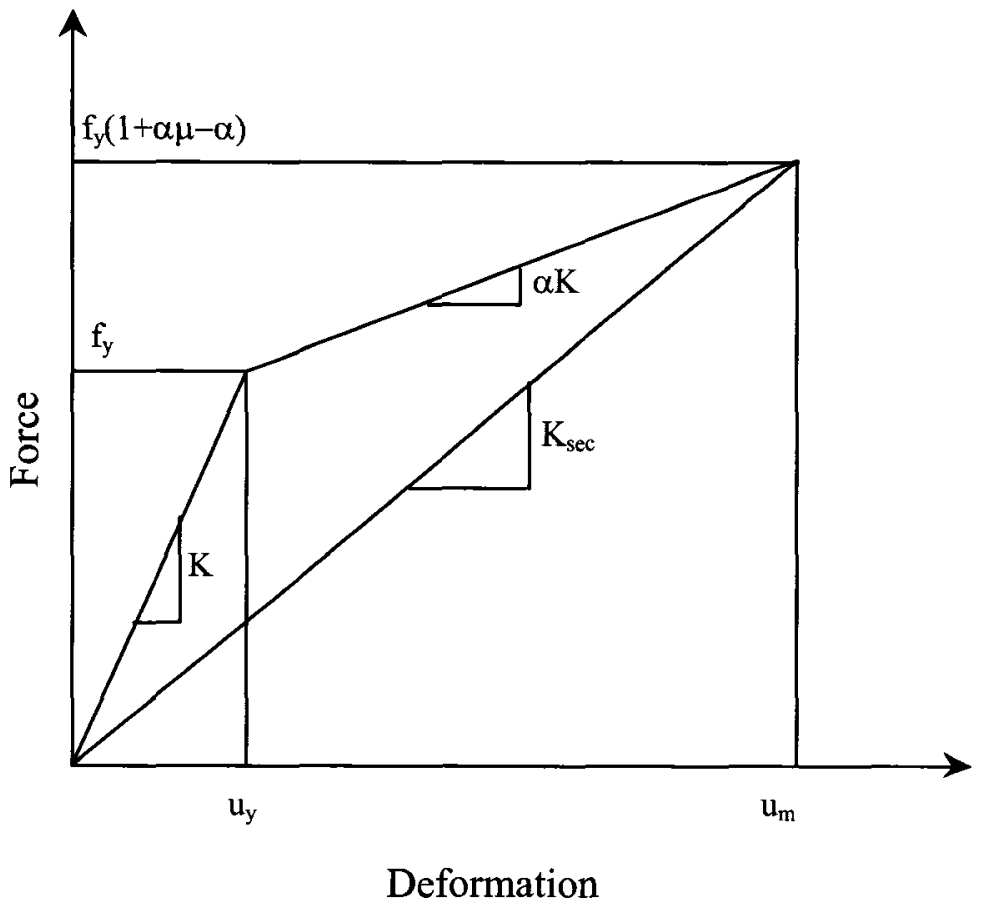

Figure (1.2): (a) Demand and Capacity curves; (b) Idealized SDOF system with bilinear force-deformation relation 


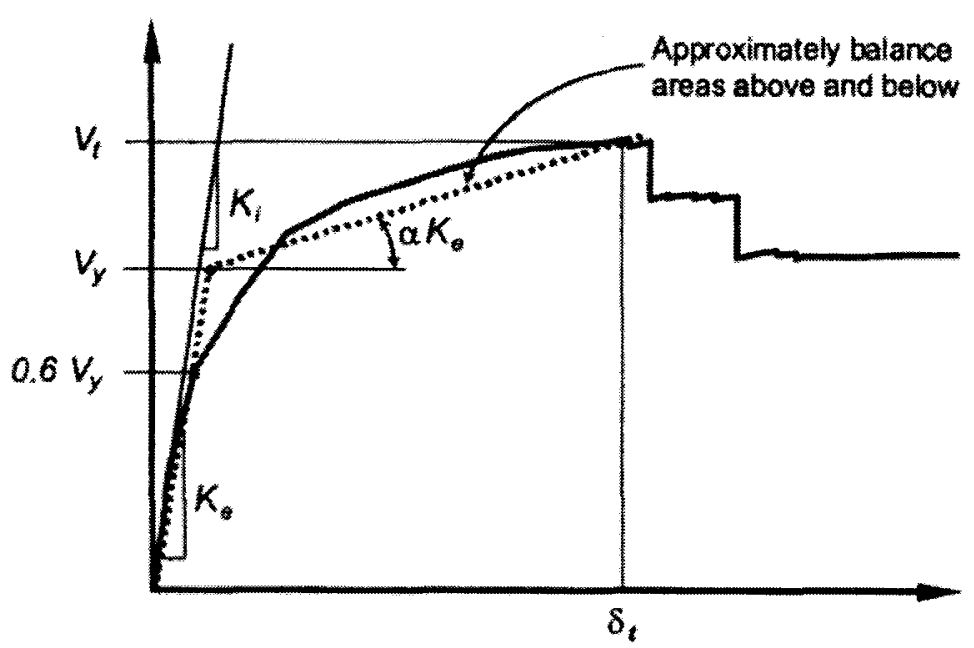

(a) Positive post-yield slope

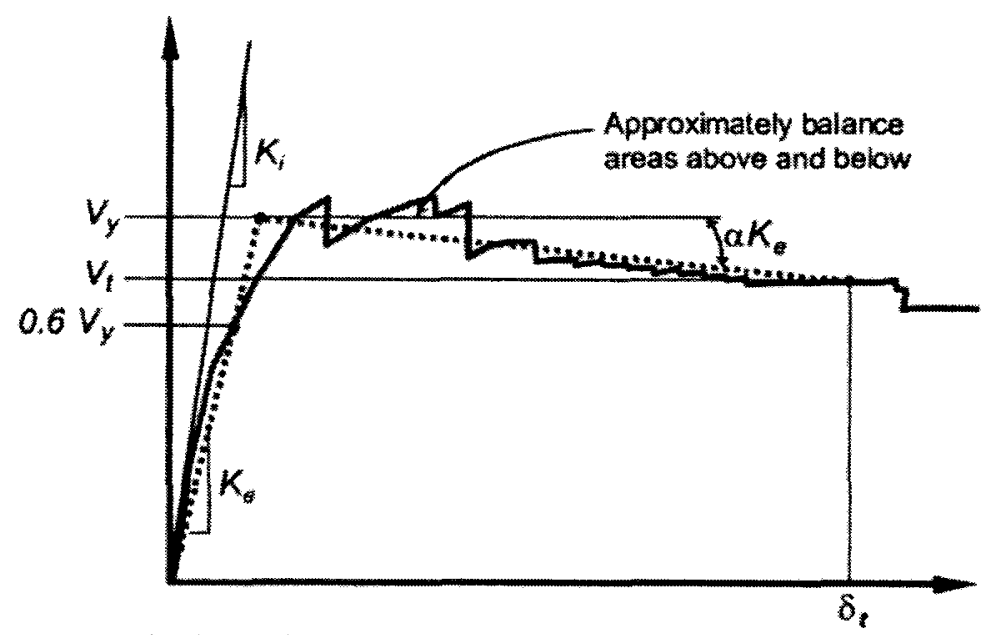

(b) Negative post-yield slope

Figure (1.3): Idealized force-displacement curves (FEMA 356) 


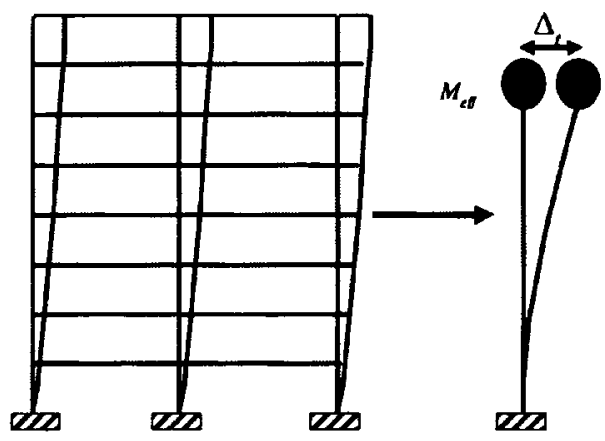

(a) MDOF to SDOF

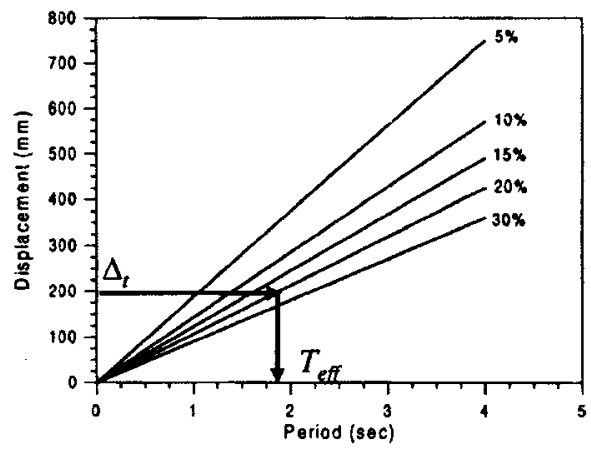

(c) Obtaining effective period

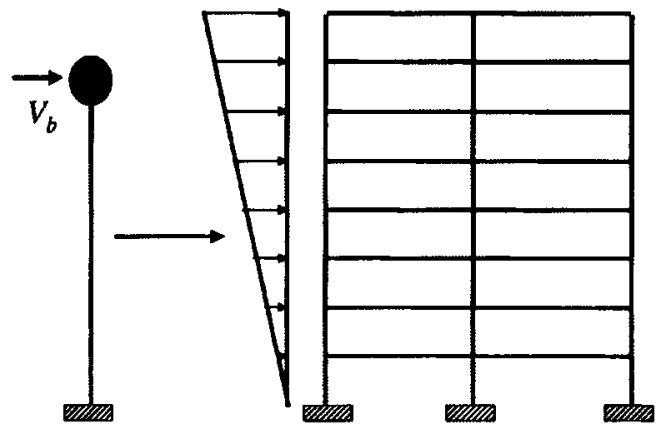

(e) SDOF to MDOF

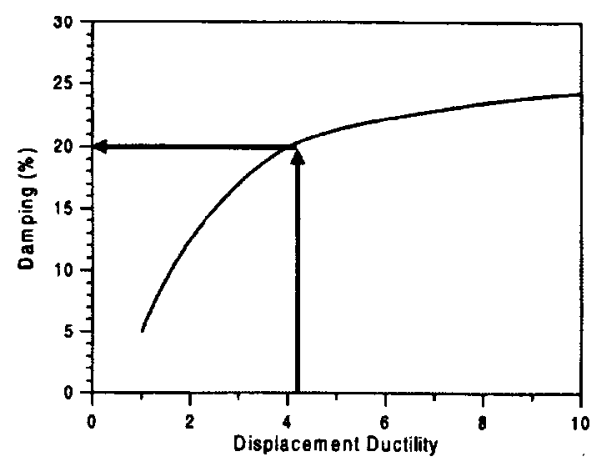

(b) Hysteretic damping

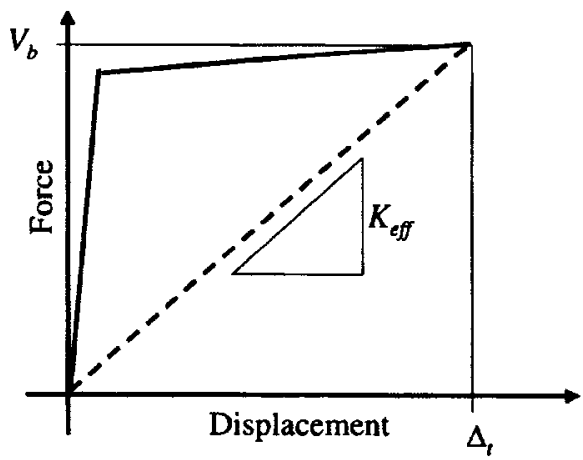

(d) Obtaining design force, $V_{b}$

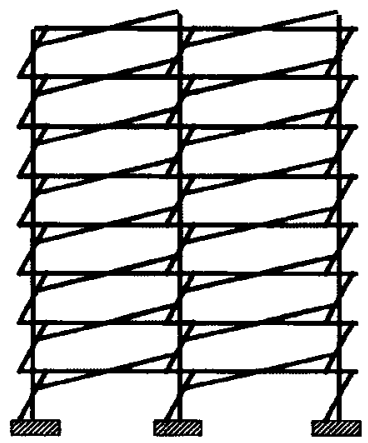

(f) Design moments and reinforcement details

Figure (1.4): Direct Displacement Method (SEAOC Blue Book) 


\section{Chapter 2}

\section{Displacement-Based Design}

\subsection{Introduction}

The main objective of the present seismic codes on the design of earthquake resistant structures has been to ensure life safety during a rare earthquake. Experience during some recent earthquakes has shown that although new design methods have considerably reduced the loss of life, economic losses due to property damage and interruption in the activities of businesses, companies and schools could be very large. Thus, it is necessary to consider another performance objective to limit the downtime and economical loss during a more frequent earthquake. The new design procedure in which one or more performance objectives are met is referred to as performance based seismic design (PBSD) method.

A framework for PBSD is presented in SEAOC blue book (1999) in which a range of performance levels from fully operational to near collapse is specified. As shown in Figure (1.1), at specified hazard levels, the structure should meet the respective performance levels. A probabilistic hazard analysis (PSHA) is used to determine the hazard, which is specified as annual probability of exceedance or the return period. Measurable response parameters such as inter-story drifts, floor velocities and accelerations, element deformation and ductility demand and damage indices are used to 
establish the quantitative performance levels. Damage to structural and nonstructural elements, supported elements and equipments and also instability due to P- $\Delta$ effect could be limited or avoided by defining a limit for the above response parameters. Since interstory drifts are commonly used to measure performance, PBSD is often referred to as displacement-based design (DBD). In fact DBD can be considered as an essential component of PBSD.

As discussed in Section 1.1, the traditional method of designing a building structure for earthquake forces is the force-based design method. It is recognized that the objectives of PBSD could not be satisfied by the traditional force based design method. The damage is strain or deformation related in structural components and drift related in non-structural components. Thus providing a certain amount of "strength", as in a force based design method, could not control the damage. Other shortcomings also exist in force based design method. First, the empirical relationships that are used to calculate the fundamental period of structure usually give a smaller value compared to the period that is obtained analytically, resulting in a much higher design base shear. Second, the force reduction factors that account for the effects of inelasticity or ductility and reserve strength are based largely on experience and judgment. Since such factors are based on limited experimental or analytical data, they often vary widely across different codes or even in the different versions of the same code. In fact, as will be shown in this study, the assumed ductility capacities are rarely utilized under demand earthquake. Third, element stiffnesses used in the elastic analysis to determine drifts and displacements are based on 
the geometry of the member cross sections. However, as shown by Priestley and Kowalsky (1998), stiffness is directly proportional to the strength of member. Finally, the risk of failure for the structures that are designed using this method is not uniform, because it only guarantees that the demand displacements will not exceed the limiting values, not reach them.

In this chapter a new displacement-based design method is presented that could be used in the design of any structural system. Two performance levels will be considered in the present study: near collapse level, and operational level. In the primary performance objective (PO), namely near collapse, the seismic hazard can be represented by site dependent uniform hazard spectra corresponding to a $2 \%$ probability of being exceeded in 50 years (a return period of 2500 years) specified in the 2005 National Building Code of Canada (NBCC) (Canadian Commission 2005). However, any other set of elastic or inelastic spectra could be used. The secondary PO is to ensure that the structure remains operational during a more frequent earthquake. In this study design spectrum corresponding to a $50 \%$ chance of being exceeded in 50 years, (a return period of 72 years) is used to define the seismic hazard for this PO. The UHS for such hazard level is not provided in NBCC 2005, but has been obtained for the present study from the Geological Survey of Canada (2006).

Commentary J in the User's Guide to NBCC 2005 defines the 2\% in 50-year earthquake as the design ground motion (DGM). According to the Commentary the primary 
objective of seismic design is to minimize loss of life. This objective is achieved by ensuring that while the building may suffer extensive structural and non-structural damage during the DGM, it will not collapse. The corresponding performance level is referred to as "extensive damage performance level", in which the structure retains some margin of resistance against collapse, even though it may have been heavily damaged and lost a substantial amount of its initial strength and stiffness.

FEMA 356 presents several different performance levels including the life safety and collapse prevention performance levels. Buildings designed to satisfy basic safety objective must achieve life safety performance level under an earthquake having $10 \%$ probability of being exceeded in 50 years and collapse prevention performance level in a $2 \%$ in 50 -year earthquake. The collapse prevention performance level is defined as the post-earthquake damage state in which the damage to structure is such that it continues to support gravity loads but has no margin against collapse. As stated above NBCC 2005 requirements are related only to the near collapse or "extensive damage" performance level; it is perhaps believed that the structure designed to the NBCC requirement will automatically achieve the life safety performance level under a more frequent earthquake ( $10 \%$ in 50 -year earthquake). In the present work drift limits prescribed in the NBCC 2005 for the near collapse are considered in the design. However, it is also ensured that the local ductility capacities specified in FEMA 356 corresponding to the life safety, which are smaller than those for the collapse prevention performance level, are not 
exceeded. In spite of the use of such conservative limits on ductility capacities, it is seen that in most cases they do not govern the design.

The DBSD method can be applied to a multi-degree-of-freedom system, whose displacements follow a single dominant shape, by transforming the system into an equivalent single-degree-of-freedom system. Either graphical or numerical procedure can be followed. The method can also be used to evaluate the performance of a given structure.

The effect of higher modes may be quite significant in the response of certain structures, especially high-rise building systems. In such cases, a design method, which is based on the first mode behaviour of a structure, may not be capable of providing reliable results. In order to account for the higher modes effect, Modal Pushover Analysis (MPA) method presented by Chopra et al (2002) is implemented in the proposed DBD method.

\subsection{Ductility Capacity}

In the proposed method approximate values of the target roof displacement $\Delta_{u}$ and roof yield displacement $\Delta_{\mathrm{y}}$ are determined first according to the procedures outlined in the following sub-sections. The required ductility capacity of the structure is then given by $\mu=\frac{\Delta_{u}}{\Delta_{y}}$ 
However, if a lower value is recommended in the code it should be the one to be used in the design.

\subsection{Yield Displacement}

Empirical relations that could be used to calculate the yield displacement $\Delta_{y}$ or yield drift ratio $\theta_{y}$ of the structure are available in the literature. For reinforced concrete frames Priestley (1998) recommends the following expression for story yield drift $\theta_{\mathrm{y}}$ :

$\theta_{y}=0.5 \varepsilon_{y} \frac{l_{b}}{h_{b}}$

where $l_{b}$ is the bay span, $h_{b}$ is the depth of concrete beams, and $\varepsilon_{y}$ is the yield strain of reinforcing steel. Equation (2.2) is based on the assumption that yield takes place first in the beams, while the columns are still below yield, and takes into account beam and column flexure, joint deformation, and member shear deformation. Assuming that all stories simultaneously attain yield displacement:

$$
\Delta_{y}=H \theta_{y}
$$

where $\mathrm{H}$ is the total height of the structure. Since it is unlikely that all stories will yield simultaneously, the actual roof displacement at yield is in general significantly lower.

For reinforced concrete shear walls an expression for $\Delta_{y}$ can be determined by assuming a distribution of curvature along the height. Thus, assuming that the curvature varies linearly from the base of the wall to zero at the roof level, it can be shown that: 
$\Delta_{y}=\frac{\phi_{y} H^{2}}{3}$

where $\mathrm{H}$ is the height of wall and $\phi_{y}$ is the effective yield curvature, which can be obtained from an empirical relationship available in the literature, for example, that given by Priestley [1998],

$\phi_{y} \approx \frac{2.0 \varepsilon_{y}}{l_{w}}$

in which $l_{w}$ is the length of the wall in cross section. The Uniform Building Code (UBC) gives another simple relationship,

$\phi_{y}=\frac{0.003}{l_{w}}$

For steel frames, Gupta and Krawinkler (2002) have derived expressions for story yield and plastic drifts by analyzing a beam column subassembly shown in Figure (2.1). Assuming that yielding takes place only in the beams, and neglecting the panel zone deformations, the story yield drift is given by,

$\theta_{y}=\left(\theta_{y b}+\theta_{y c}\right)=\left(\frac{M_{p b} l}{6 E I_{b}}+\frac{M_{p b} h}{6 E I_{c}}\right)$

where $h$ is the story height, $l$ is the beam length, $M_{p b}$ is the plastic moment of beam, $E$ is Young's modulus, $I$ is the cross-sectional moment of inertia, subscript $b$ denotes a beam, and subscript $c$ denotes a column. The plastic moment of the beam is obtained from, $M_{p b}=Z_{b} F_{y} \approx 1.14 S_{b} F_{y}$ 
where $S_{b}$ is the section modulus and $F_{y}$ is the yield strength of steel. Substituting $I_{b}=S_{b} d_{b} / 2$ and Equation (2.8) in first component of Equation (2.7),

$$
\theta_{y b}=\frac{1.14 F_{y} l}{3 E d_{b}}=0.38 \frac{F_{y} l}{E d_{b}}
$$

The relative contribution of column to story drift will vary over a range of values depending on the values of $I_{b} / l$ and $I_{c} / h$. If, as a rough estimate, it is assumed that the contribution of column is $40 \%$ that of the beam, which gives

$$
\theta_{y}=0.532 \frac{F_{y} l}{E d_{b}}
$$

In concentrically braced frames (CBF) such as the one shown in Figure (2.2), the yield drift of each story is reached when the braces yield. Assuming that the deformation of columns is negligible, the story yield deformation $\Delta_{\mathrm{yi}}$ will be a function of the geometry and material properties of the brace only

$$
\Delta_{y}=\frac{\Delta_{y, b r}}{\cos \theta}=\frac{F_{y} l_{b r}}{E \cos \theta}
$$

where $\Delta_{\mathrm{y}, \mathrm{br}}$ is the yield elongation of the brace, $l_{b r}$ is the brace length and $\theta$ is the angle of inclination of the brace with the horizontal.

For an $\mathrm{n}$-story building

$$
\Delta_{y}=\sum_{i=1}^{n} \frac{F_{y} l_{b r, i}}{E \cos \theta_{i}}
$$


Column deformations result in an increased lateral displacement. The lateral displacement at roof level of the n-story building $\Delta_{\mathrm{c}}$, due to the elastic axial deformations of all columns below it is (Medhekar et al 2000),

$\Delta_{c}=\sum_{i=1}^{n} \frac{C_{i} h_{i}^{2}}{A_{i} E D_{s}}+\sum_{i=1}^{n-1} \frac{T_{i} h_{i}^{2}}{A_{i} E D_{s}}$

where $D_{s}$ is the width of the concentrically braced frames, $h_{i}$ is the height, $A_{i}$ is the area of cross section of the column and $C_{i}$ and $T_{i}$ are the compressive and tensile axial forces in the columns of the ' $i$ ' th story. The axial stresses $C_{i} / A_{i}$ and $T_{i} / A_{i}$ may be assumed to be equal to $0.7 F_{y}$ to obtain an initial estimate of the roof displacement. The yield displacement of CBF system considering the columns deformations will be,

$\Delta_{y}=\sum_{i=1}^{n} \frac{F_{y} l_{b r, i}}{E \operatorname{Cos} \theta_{i}}+\left(\frac{1.4 F_{y}}{E D_{s}} \sum_{i=1}^{n-1} h_{i}^{2}+\frac{0.7 F_{y} h_{n}^{2}}{E D_{s}}\right)$

It may be noted that at the first stage of design, only an approximate value is needed for the yield displacement.

\subsection{Ultimate displacement}

At the near collapse level, the target roof displacement should not exceed any of the following limits:

1. The roof displacement corresponding to the inter-story drift limit, specified in the guidelines and codes. Such a limit is usually based on judgment and experience, and is intended to guard against inelastic deformations in structural components beyond 
their ductility capacity, non-structural damage that may jeopardize life safety and instability due to P- $\Delta$ effect (SEAOC 1999, Canadian Commission 2005). For normal buildings, the NBCC 2005 sets that limit as 0.025 when the design earthquake corresponds to one having a $2 \%$ chance of being exceeded in 50 years, or a return period of 2500 years.

2. P- $\Delta$ instability limit determined from a push over analysis of the structure. A lateral force distribution representative of the first mode is applied and the effect of P- $\Delta$ is considered. Ideally, the target displacement should not lie in the branch of the pushover curve that has a negative slope.

3. The roof displacement at which the ductility demand in any element of the structure exceeds its ductility capacity. The capacity could be expressed in various forms, including a limit on the material strain, curvature ductility, rotation ductility, or displacement ductility.

It should be noted that only the first of the three limits would normally be available at the start of the design process. However, once a preliminary design has been established the process of design can be repeated with a more refined estimate of the roof displacement.

\subsection{Target roof displacement based on ductility capacity}

As stated earlier, a consideration in choosing a value for the target roof displacement is to ensure that the ductility capacity of the elements of the structure is not exceeded. This will depend on the structural material and system. 


\subsubsection{Concrete shear walls}

In a shear wall structure, the plastic hinge is expected to form at the base of the shear wall. The inter-story drift takes its maximum value at the top and consists of two parts; yield drift $\theta_{\mathrm{y}}$ and plastic drift $\theta_{\mathrm{p}}$ (Kowalsky, 2001),

$$
\theta_{u}=\theta_{y}+\theta_{p}=\frac{\phi_{y} H}{2}+\left(\phi_{u}-\phi_{y}\right) L_{p}
$$

where $L_{p}$ is the length of plastic hinge and $\phi_{u}$ is the ultimate curvature. The ultimate roof displacement is given by:

$\Delta_{u}=\frac{\phi_{y} H^{2}}{3}+\left(\phi_{u}-\phi_{y}\right) L_{p}\left(H-0.5 L_{p}\right)$

If the inter-story drift limit $\theta_{\mathrm{u}}=0.025$ is the governing criterion for target roof displacement, $\Delta_{u}$ obtained from Equations (2.15) and (2.16) becomes,

$\Delta_{u}=\frac{\phi_{y} H^{2}}{3}+\left(H-0.5 L_{p}\right)\left(0.025-\frac{\phi_{y} H}{2}\right)$

setting $\phi_{y}=0.003 / l_{w}$ and $L_{p}=l_{w} / 2$, the target roof drift based on the maximum inter-story drift limit criterion is obtained as follows:

$$
\frac{\Delta_{u}}{H}=0.001 A_{r}+\left(0.025-0.0015 A_{r}\right)\left(1-\frac{0.25}{A_{r}}\right)
$$

where $A_{r}=H / l_{w}$ is the aspect ratio of wall. 
On the other hand, the acceptable roof displacement may be dictated by the limit on curvature imposed by the ductility capacity. For well-confined concrete UBC 1997 permits concrete compression strain up to $\varepsilon_{\mathfrak{u}}=0.015$. However providing sufficient confinement in shear walls is difficult and sometimes impractical. Adebar et al (2005) have shown that use of ultimate strain of up to 0.004 is appropriate for unconfined concrete. Moment curvature analyses using strain compatibility indicate that the depth of neutral axis $c_{u}$, varies between $0.1 l_{w}$ and $0.3 l_{w}$ for a range of steel ratio, the ultimate tensile strain in steel and the axial load ratio. Substituting $\phi_{u}=\varepsilon_{u} / c_{u}, \varepsilon_{u}=0.004$, $\phi_{y}=0.003 / l_{w}$ and $L_{p}=l_{w} / 2$ in Equation (2.15), we get:

$\theta_{u}=0.0185+0.0015 A_{r} \quad$ for $\quad c_{u}=0.1 l_{w}$

$\theta_{u}=0.0052+0.0015 A_{r} \quad$ for $\quad c_{u}=0.3 l_{w}$

The drift ratios given by Equations (2.18), (2.19a) and (2.19b) have been plotted in Figure (2.3) as functions of $A_{r}$. Also shown is the drift limit of 0.025 and the yield drift.

It is evident that for low-rise structures having a small $A_{r}$ and large neutral axis depth the concrete strain or local ductility limit is critical, but for taller structures and small neutral axis depth the maximum inter-story drift criterion governs the maximum roof displacement. In the latter case local ductility or full plastic rotation capacity is not utilized. 
When $\varepsilon_{\mathrm{u}}$ is assumed to be 0.015 , as for confined concrete, the expressions for $\theta_{\mathrm{u}}$ will become:

$$
\begin{array}{lll}
\theta_{u}=0.0735+0.0015 A_{r} & \text { for } & c_{u}=0.1 l_{w} \\
\theta_{u}=0.0235+0.0015 A_{r} & \text { for } & c_{u}=0.3 l_{w}
\end{array}
$$

In this case the drift limit of 0.025 will invariably govern.

\subsubsection{Reinforced Concrete Frames}

The inter-story yield drift $\theta_{y}$ can be obtained from Equation (2.2). That equation is based on the assumption that yield takes place first in the beams, while the columns are still below yield. Equation (2.2) takes into account beam and column flexure, joint deformation, and member shear deformation. As suggested by Priestley (1998) the yield curvature can be obtained from:

$\phi_{y}=\frac{1.7 \varepsilon_{y}}{h_{b}}$

and the total inter-story drift from:

$\theta=\theta_{y}+\left(\phi_{u}-\phi_{y}\right) L_{p}$

where $\theta_{\mathrm{y}}$ is given by Equation (2.2) and $\phi_{\mathrm{y}}$ by Equation (2.21). The length of plastic hinges could be obtained from an appropriate empirical equation, for example, that recommended by Mattock (1967),

$L_{p}=0.5 d+0.05 z$ 
where $d$ is the effective depth of the beam and $z=0.5 l_{b}$ is the distance from the hinge to the point of contraflexure.

In order to get an estimate of the limit on inter-story drift that will keep the plastic hinge rotation in the beams within acceptable magnitude, a series of doubly reinforced rectangular reinforced concrete beams are analyzed. The bay span is taken as $6 \mathrm{~m}$, beam width $b=400 \mathrm{~mm}$, and the beam depth $h_{b}=600 \mathrm{~mm}$. Clear cover is assumed to be $40 \mathrm{~mm}$ and the bar diameter as $24 \mathrm{~mm}$. The clear spacing between layers of reinforcement is taken as $24 \mathrm{~mm}$. The concrete compressive strength is assumed to be $f^{\prime} c^{\prime}=30 \mathrm{MPa}$, and the yield strength of reinforcing steel $f_{y}=400 \mathrm{MPa}$. Curvature at ultimate, corresponding to acceptable concrete strains of 0.003 and 0.004 is derived using a MATLAB program developed for the purpose. The stress-strain relations for concrete and steel used in the program are described by Yavari (2001) and are shown in Figure (3.2). Results are presented in Table (2.1) for several different reinforcing steel percentages.

Using the minimum value of $\phi_{u}$ corresponding to the maximum concrete strain of 0.004 , the permissible inter-story drift is obtained as follows: 


$$
\begin{aligned}
& \phi_{y}=\frac{1.7 \times 400 \times 1000}{600 \times 200000}=0.005667 \mathrm{~m}^{-1} \\
& \theta_{y}=0.5 \times \frac{400 \times 6000}{200000 \times 600}=0.01 \\
& L_{p}=0.5 \times 548+0.05 \times 3000=424 \mathrm{~mm} \\
& \theta=0.01+(0.03902-0.00567) \times 0.424=0.024
\end{aligned}
$$

Results of this analysis show that for a wide range of beam reinforcement ratio, the drift limit of 0.025 specified in the codes, would also guard against the ductility capacity being exceeded, even when the concrete is unconfined.

The foregoing discussion indicates that for concrete structures, in many cases the limit of 0.025 on the inter-story drift will also ensure that the ductility capacity is not exceeded. However, in order to determine the target roof displacement we still need a relationship between the permissible inter-story drift and the roof displacement.

\subsubsection{Steel Moment-resisting Frames}

The total story drift has two components

$$
\theta_{\text {total }}=\theta_{y, s t}+\theta_{p, s t}
$$


Assuming reasonable values for span length and beam depth, say $l=10 \mathrm{~m}$ and $d_{b}=610 \mathrm{~mm}$, and $F_{y}=300 \mathrm{Mpa}$ a rough estimate of the story yield displacement is calculated from Equation (2.10)

$\theta_{y, s t}=0.532 \times \frac{300 \times 10000}{200000 \times 610}=0.0131$

Setting the total story drift to 0.025 limit, the plastic story drift will be

$\theta_{p, s t}=0.025-0.0131=0.0119$

and the story ductility works out to

$\mu_{s t}=\frac{0.025}{0.0131}=1.9$

The local ductility for the plastic hinges in beams is calculated as follows. The yield rotation of beam is obtained from Equation (2.9)

$\theta_{y, b}=\frac{0.38 F_{y} l}{E d_{b}}=\frac{0.38 \times 300 \times 10000}{200000 \times 610}=0.00934$

Assuming that columns remain elastic and neglecting the panel zone deformations, the beam plastic rotation is directly related to story plastic drift,

$\theta_{p, b}=\theta_{p, s t}=0.0119$

and the ductility works out to

$\mu_{b}=\frac{0.0119+0.00934}{0.00934}=2.27$ 
Moment resisting frames of steel will be able to provide a ductility capacity to match both local and story ductility values even with a minimum of detailing requirements. Thus, in most cases, the recommended limit of 0.025 will automatically satisfy the ductility requirement and the higher ductility capacities specified in the code will rarely be mobilized. Ductility capacity of the components of steel structures (FEMA 356) are shown in Table (2.2).

\subsubsection{Concentrically Braced Frames}

In the concentrically braced frames, columns are designed to remain elastic. Thus, the story ductility capacity is directly related to the bracing ductility capacity. Steel elements under tension show a very ductile behaviour and a ductility capacity of above 10 is expected for braces. As a numerical example a braced frame of span $9 \mathrm{~m}$ and height $4.2 \mathrm{~m}$ is considered. Using Equation (2.11) and neglecting the columns deformations, the story yield displacement is calculated as follows:

$$
\begin{aligned}
& \Delta_{y}=\frac{F_{y} l_{b r}}{E \cos \theta}=\frac{300 \times 9932}{200000 \times 0.9062}=16.44 \mathrm{~mm} \\
& \theta_{y}=\frac{16.44}{4200}=0.0039
\end{aligned}
$$

The ductility demand corresponding to a story drift of 0.025 is given by

$$
\mu_{\text {demand }}=\frac{0.025}{0.0039}=6.3
$$


The acceptable deformation ductilities given in FEMA 356 code are shown in Table (2.2). For concentric braces in tension and in life safety (LS) criterion ductility capacities of 8 for primary and 12 for secondary elements are permitted.

The discussions in Sections 2.5.1 to 2.5.4 show that in a majority of cases, calculation of the target roof displacement based on the inter-story drift limitation of $2.5 \%$, guarantees that the ductility capacity of structure, either at local or story level, will not be exceeded. After the first displacement based design cycle, pushover curve of the designed structure would be available and the target roof displacement based on the aforementioned three criteria, P- $\Delta$ stability, code specified inter-story drift limit and ductility capacity could be extracted from the analysis results.

\subsection{Relationship between roof drift and the maximum inter-story drift}

As per discussions in the previous section, a performance-based design usually relies on the specifications of performance limits in terms of inter-story drift. On the other hand, the DBD procedure presented here requires the specification of the limiting value of roof displacement. We therefore need to find a relationship between inter-story drift and roof displacement.

Considerable difficulty exists in finding a relationship between the roof displacement or roof drift and the maximum inter-story drift. Gupta and Krawinkler $(1999,2000)$ have examined the roof drift produced in a given structure by a design earthquake. They found 
the relationship between the roof drift and the maximum inter-story drift, both obtained from non-linear time history analyses of various moment resisting frame structures for a range of ground motions. Since this relationship strongly depends on the characteristics of both the ground motion and structure, the results derived by Gupta and Krawinkler are valid only for the range of ground motions and structures studied. Their study shows that for low-rise regular steel moment resisting frames the ratio between the maximum interstory drift and roof drift $\alpha_{\mathrm{ST}}$ is about 1.2; for mid-rise structures it increases to about 2.0; for taller structures it increases further to about 2.5 to 3.0. Further work is required in this area.

In the displacement-based design method proposed here, the inelastic spectral displacement $\Delta_{\mathrm{u}}^{*}$ of the equivalent SDOF system is used. Therefore a relationship between the maximum inter-story drift and $\Delta_{u}^{*}$ is needed. This is given by

$$
\Delta_{u}^{*}=\frac{\Delta_{u}}{\Gamma}=\frac{\beta H \theta_{i, \max }}{\Gamma}
$$

If the factor $\beta$ is known, then for a given value of maximum inter-story drift $\theta_{i, \max }$, for example $0.025, \Delta_{\mathrm{u}}^{*}$ can be determined.

One objective of the present research is to determine the value of $\beta$ for different structural types, including steel moment resisting frames (SMRF) and concrete moment resisting frames (CMRF), and a range of ground motions representative of the seismic hazard in 
the eastern and western regions of Canada. The value of $\theta_{\mathrm{i}, \max }$ can be determined from a nonlinear time history analysis, while $\Delta_{u}^{*}$, the inelastic displacement of the equivalent SDOF system, can be obtained by solving the following equation of motion of an equivalent SDOF system (Chopra and Goel, 2002):

$\ddot{D}_{1}+2 \xi_{1} \omega_{1} \dot{D}_{1}+\frac{F_{s 1}}{L_{1}}=-\ddot{u}_{g}(t)$

in which $\mathbf{u}_{1}=D_{1} \phi_{1}, \mathbf{u}_{1}$ is vector of displaced shape, $\phi_{1}$ is the first mode shape, $\omega_{1}$ is the first mode frequency, $\zeta_{1}$ is the damping in the first mode, $L_{1}=\phi_{1}{ }^{\mathrm{T}} \mathbf{M 1}, \mathbf{M}$ is the mass matrix, 1 is the unit vector and $F_{\mathrm{s} 1}$ is a non-linear function of $D_{1}$. The relationship between $F_{\mathrm{s} 1}$ and $D_{1}$ is obtained from a pushover curve relating base shear $V_{\mathrm{b}}$ to roof displacement $u_{r}$ determined for a force distribution obtained from the first mode of the building according to the relationship:

$$
\mathbf{f}=\mathbf{M} \phi_{1}
$$

The pushover curve is converted to a relationship between $F_{\mathrm{s} 1}$ and $D_{1}$ noting that,

$$
\begin{aligned}
& \frac{F_{s 1}}{L_{1}}=\frac{V_{b}}{M_{1}^{*}} \\
& D_{1}=\frac{u_{r}}{\Gamma_{1} \phi_{r 1}}=\frac{u_{r}}{\Gamma_{1}}
\end{aligned}
$$

where $M_{1}{ }^{*}$ is the effective mass in the first mode. The last relationship holds because the mode shape has been normalized such that $\phi_{r 1}=1$. 
Once suitable values for factor $\beta$ have been determined, the target roof displacement corresponding to the inter-story drift limit (for example 0.025) can be obtained.

\subsection{Equivalent SDOF model}

The MDOF system should be represented by an equivalent SDOF system (Chopra and Goel 2002). This requires the selection of a displaced shape for the structure. Any logical shape including an inverted triangular shape, or a shape similar to the first mode shape could be selected. Assuming that the selected shape is represented by the vector $\phi$, the following parameters are calculated from Equations (1.1) to (1.3) repeated here.

$$
\begin{aligned}
& L=\boldsymbol{\phi}^{T} \mathbf{M 1} \\
& \Gamma=\frac{\phi^{T} \mathbf{M} 1}{\boldsymbol{\phi}^{T} \mathbf{M} \phi} \\
& M^{*}=L \Gamma=\frac{\left(\phi^{T} \mathbf{M 1}\right)^{2}}{\phi^{T} \mathbf{M} \phi}
\end{aligned}
$$

The term $\Gamma$ is referred to as the modal participation factor and $\mathrm{M}^{*}$ is the effective modal mass. The yield and target displacements for the equivalent SDOF system are given by:

$$
\begin{gathered}
\delta_{u}=\Delta_{u} / \Gamma \\
\delta_{y}=\Delta_{y} / \Gamma
\end{gathered}
$$




\subsection{Inelastic demand spectra}

In this study the seismic hazard corresponding to near collapse level is represented by the uniform hazard spectrum for a $2 \%$ probability of being exceeded in 50 years (a return period of 2500 years) as specified by NBCC 2005. The spectral acceleration values are given for period range of 0.3 to 2.0 seconds. For a period of $4.0 \mathrm{~s}$ it is suggested that the spectral value be taken as equal to half of that at $2.0 \mathrm{~s}$ period. Since spectral values for periods greater than $4.0 \mathrm{~s}$ are not defined, in this study the following expression will be used to obtain the spectral values for periods greater than $2.0 \mathrm{~s}$ :

$$
S_{a}(T)=\frac{2 S_{a}(2)}{T}
$$

The demand elastic response of a SDOF system is represented by the UHS. For structures with inelastic deformations, constant ductility curves are used to calculate the demand spectral acceleration or displacement. The peak displacement D of the inelastic system is determined as follows:

$$
D=\frac{\mu}{R_{y}}\left(\frac{T_{n}}{2 \pi}\right)^{2} A
$$

where $A$ is the elastic spectral acceleration and $\mathrm{R}_{\mathrm{y}}$ is yield reduction factor, which is itself dependent on $T_{n}$, the natural vibration period, and $\mu$ is the ductility factor. The $\mathrm{R}_{\mathrm{y}}-\mu-\mathrm{T}_{\mathrm{n}}$ relations proposed by Krawinkler and Nassar (1992) are used to construct the inelastic spectra,

$$
c=\frac{T_{n}^{a}}{1+T_{n}^{a}}+\frac{b}{T_{n}}
$$


$R_{y}=[c(\mu-1)+1]^{1 / c}$

where $a$ and $b$ are parameters that depend on the nature of force-displacement relationship. For elastic-perfectly plastic systems $a=1$, and $b=0.42$. The UHS is plotted in acceleration-displacement (A-D) format in which periods are represented with radial lines. Using this format both the demand and capacity curve are plotted on the same diagram. As discussed in Section (1.6), additional $R_{y}-\mu-T_{n}$ relationships have been proposed by other researchers. However regardless of the relationship used, for large periods $\mathrm{R}$ and $\mu$ values are almost equal.

\subsection{Pushover analysis and Capacity diagram}

For the final design and performance evaluation a push over analysis must be carried out to get the capacity diagram. The pushover curve is generated by carrying out a non-linear static analysis of the structure for the lateral forces distributed over the building height according to equation (2.27).

The resulting roof displacement versus base shear diagram (pushover curve) is idealized as a bi-linear curve using any recommended procedure, such as that in FEMA 356 (2000). The capacity diagram which represents the performance of the equivalent SDOF system is obtained by dividing the base shear and the roof displacement values in the idealized pushover curve by $M^{*} g$ and $\Gamma$, respectively. 


\subsection{Effect of Higher Modes and Multi-Mode Pushover Analysis (MMPA)}

Design of structures using the procedures that are based on only the first mode behavior could be un-conservative. In the displacement based design method presented here, higher modes effect is accounted for by using the MPA procedure proposed by Chopra et al (2002).

After the first phase of the design process, which is based on the first mode response, has converged and a designed structure is available, the second phase that includes the MPA starts. At this stage sufficient modes to capture $90 \%$ mass participation are considered. Use of a higher number of modes would of course provide a better estimate of the response. It should be mentioned that elastic mode shapes do not correctly represent the characteristics of the inelastic structure. However, use of nonlinear mode shapes that vary depending on the inelastic state of the structure is not practical. On the other hand, as observed by Chopra and Goel (2002), elastic mode shapes provide satisfactory results. For all higher modes the demand roof displacement is calculated using the modal period and demand displacement spectrum. Then, using the proper lateral force distribution, the structure is pushed up to the calculated target roof displacement in each mode. Equation (2.27) is modified by substituting the higher mode shape for $\phi_{1}$, and used to develop the lateral force pattern. The response parameters for each mode are obtained from the pushover analysis database of the respective mode at target displacement. Any suitable modal combination method (e.g. SRSS: Square Root of Sum of Squares) could be used to combine the modal response parameters. It is understood that use of 
superposition for nonlinear structures is not valid; however, Chopra and Goel (2002) have shown that errors due to this approximation are within acceptable range. Initial design is considered satisfactory if,

- Demand ductility (local or global) in all parts of structure is still less than the corresponding ductility capacity

- The inter-story drift at all levels is below the $2.5 \%$ limit

- Story shears after modal combination do not exceed story shear capacity If any of these conditions is not met, design should be revised and the design procedure repeated.

Definitions of the local ductility demand and capacity are different for different structural systems. In a concrete shear wall building, for the plastic hinge at the base of the wall, the demand curvature is calculated based on the plastic hinge rotation and compared to the curvature capacity that is calculated for permissible ultimate concrete strain, for example 0.004, by using the strain compatibility method. In concrete moment resisting frames, this procedure is repeated for all the plastic hinges at the base of columns and end of the beams. In steel moment resisting frames and concentric braced frames, the plastic rotations and plastic deformations are directly compared to the allowable values as given in the design codes. Acceptance criteria specified by FEMA 356 (2000) for some structural components are given in Table (2.2). 
Higher mode pushover analysis could be challenging as was observed during the application of the MMPA procedure in this study. At higher levels of lateral load, sometimes the direction of the roof displacement reverses and the pushover curve becomes confusing when compared to the first mode pushover curve. This is due to the occurrence of mechanism in upper levels of structure. However, in regular buildings, usually the higher mode demand is in the elastic state of structure. Thus, there will be no need to push the structure into inelastic region and displacements and member forces could be calculated using even an elastic pushover analysis of the structure. Alternatively, the lateral displacement may be measured at an intermediate level rather than on the roof.

\subsection{Steps of Displacement-based design}

The steps involved in the displacement-based design of a structure can be summarized as follows:

1. Calculate the yield displacement of structure $\Delta_{\mathrm{y}}$. For preliminary design, the approximate relations presented in the Section 2.3 of this chapter could be used.

2. Calculate the ultimate roof displacement $\Delta_{u}$ considering the ductility capacity, stability of the structure and limits prescribed in the codes. For preliminary design the stability limit is unknown but an approximate value of the limit obtained from the other two criteria could be used. In a shear wall structure story drift is largest in the top story and is to be limited to either 0.025 or that given by Equation (2.15) when the ductility capacity governs. The corresponding value of $\Delta_{u}$ is obtained from Equations 
(2.16) or (2.17). In other structural systems roof drift could be estimated as a portion of the maximum story drift.

3. Calculate the ductility capacity of structure $\mu$ according to Equation (2.1). If the ductility capacity recommended by NBCC 2005 is lower, it should be used.

4. Calculate the ultimate displacement $\delta_{u}$ of the SDOF system using Equation (2.33).

5. Construct the inelastic spectrum for ductility of $\mu$ in the A-D (accelerationdisplacement) format from the UHS corresponding to $2 \%$ probability of being exceeded in 50 years, using the $R_{y}-\mu-T_{n}$ relationships presented in Equations (2.37) and (2.38).

6. Find the acceleration $A_{y}$ on the inelastic spectrum corresponding to $\delta_{u}$. The design base shear for the structure is given by,

$$
V=A_{y} M^{*}
$$

7. Design the structure for the base shear calculated in step 6. Carry out a modal analysis to determine the mode shapes and modal periods. Using a first mode distribution given by Equation (2.27) perform a non-linear pushover analysis. Calculate refined values for yield and ultimate roof displacements from the resulting pushover curve and considering the code-prescribed story drift limit, the local ductility capacity criterion, as well as P-Delta instability. Calculate the global ductility demand using the inelastic design spectra.

8. The ideal design is achieved when the ductility capacity is slightly higher than the ductility demand (to preserve some capacity for higher mode demand). Increase or 
decrease the strength (design base shear) and repeat steps 3 to 7 until the desired performance is achieved (or design base shear converges).

9. Design process is concluded in step 8 provided that higher mode effect is negligible for this structure. If the effective mass of the first mode is less than $90 \%$ of the total mass, structural design should be verified for higher modes using MMPA as follows:

(a). Use sufficient modes to capture $90 \%$ mass participation. For each mode, calculate the demand roof displacement, perform the pushover analysis up to the demand roof displacement and extract the required displacements, drifts, rotations and member forces for this level.

(b).Combine the demand modal quantities of previous step using SRSS method and compare it to corresponding capacity or allowable value. Design is considered satisfactory for the effect of higher modes if all demands parameters are less than the allowed or capacity limits. Otherwise design should be revised and the design process repeated.

10. To satisfy the operational level performance of structure, find the demand acceleration from the UHS corresponding to $50 \%$ probability of being exceeded in 50 years using the fundamental period of the structure, and determine the demand base shear using Equation (2.39). The demand spectrum at this hazard level is obtained by scaling the UHS for $2 \%$ in 50 years by a proper factor. Using the results of push over analysis, find the inter-story drifts. For the structure to remain operational, inter-story drifts should not exceed $0.5 \%$ (SEAOC 1999). 
In step 9 of the procedure, the following verification is necessary.

a. Shear: Demand shear force should not exceed the shear capacity of the element. If the shear forces in shear walls, beams and columns of moment frames or story shears exceed the corresponding capacity, design should be revised.

b. Flexure: If the SRSS moments at the base of shear walls or beams and columns of frames are less than the plastic moment capacities, design is considered satisfactory and no further check is necessary. Otherwise, plastic hinge rotations obtained from the analysis should be compared to the maximum allowable plastic rotation as defined in codes (in steel structures) or as calculated from ultimate concrete strain (in RC structures).

c. Displacements and Drifts: Demand displacements and drifts in the first mode are considerably larger than those in the higher modes and usually SRSS combination of the displacements and drifts is not necessary.

Comprehensive application of the proposed DBD method will be presented for several structural systems in the next chapter. 
Table (2.1): Yield and ultimate curvatures in rectangular beams

\begin{tabular}{|c|c|c|c|c|}
\hline \multirow{2}{*}{ Reinforcement } & \multirow{2}{*}{$\begin{array}{c}\text { Yield } \\
\text { curvature } \phi_{\mathrm{y}} \\
\mathrm{x} 1000 \mathrm{~m}^{-1}\end{array}$} & \multirow{2}{*}{$\mathrm{K}=\mathrm{h}_{\mathrm{b}} \phi_{\mathrm{y}} / \varepsilon_{\mathrm{y}}$} & \multicolumn{2}{|c|}{$\begin{array}{l}\text { Ultimate curvature } \phi_{\mathrm{u}} \\
\qquad \times 100 \mathrm{~m}^{-1}\end{array}$} \\
\hline & & & $\varepsilon_{\mathrm{c}}=0.003$ & $\varepsilon_{\mathrm{c}}=0.004$ \\
\hline $\begin{array}{c}0.68 \% \text { top and bottom } \\
A_{s}=1500 \mathrm{~mm}^{2}\end{array}$ & 5.04 & 1.52 & 5.20 & 7.03 \\
\hline $\begin{array}{l}0.91 \% \text { top and bottom } \\
\mathrm{A}_{\mathrm{s}}=2000 \mathrm{~mm}^{2}\end{array}$ & 5.22 & 1.57 & 4.69 & 6.46 \\
\hline $\begin{array}{c}1.6 \% \text { top and bottom } \\
\mathrm{A}_{\mathrm{s}}=3500 \mathrm{~mm}^{2}\end{array}$ & 5.74 & 1.72 & 3.87 & 5.59 \\
\hline $\begin{array}{c}2.19 \% \text { top and bottom } \\
\mathrm{A}_{\mathrm{s}}=4800 \mathrm{~mm}^{2}\end{array}$ & 6.00 & 1.80 & 3.50 & 5.22 \\
\hline $\begin{array}{c}2.74 \% \text { top and bottom, } \\
\text { two layers each } \\
A_{s}=6000 \mathrm{~mm}^{2}\end{array}$ & 5.98 & 1.79 & 3.20 & 4.49 \\
\hline $\begin{array}{c}\text { Top As }=3500 \mathrm{~mm}^{2} \\
\text { Bottom As }=1750 \mathrm{~mm}^{2}\end{array}$ & 6.07 & 1.82 & 3.04 & 4.55 \\
\hline $\begin{array}{c}\text { Top As }=4800 \mathrm{~mm}^{2} \\
\text { Bottom As }=2400 \mathrm{~mm}^{2}\end{array}$ & 6.53 & 1.96 & 2.49 & 3.90 \\
\hline $\begin{array}{c}\text { Top As }=6000 \mathrm{~mm}^{2}, \text { two } \\
\text { layers } \\
\text { Bottom As }=3000 \mathrm{~mm}^{2}, \\
\text { one laver }\end{array}$ & 6.09 & 1.83 & 3.34 & 3.98 \\
\hline
\end{tabular}


Table (2.2): Acceptance criteria for structural steel components (from FEMA 356)

\begin{tabular}{|c|c|c|c|c|c|}
\hline \multirow{3}{*}{$\begin{array}{c}\text { Component / } \\
\text { Action }\end{array}$} & \multicolumn{5}{|c|}{ Displacement or rotational ductility capacity } \\
\hline & \multirow{2}{*}{$\begin{array}{l}\text { Immediate } \\
\text { Occupancy }\end{array}$} & \multicolumn{2}{|c|}{ Primary } & \multicolumn{2}{|c|}{ Secondary } \\
\hline & & Life Safety & $\begin{array}{c}\text { Collapse } \\
\text { Prevention } \\
\end{array}$ & Life Safety & $\begin{array}{c}\text { Collapse } \\
\text { Prevention } \\
\end{array}$ \\
\hline \multicolumn{6}{|c|}{ Rotational ductility capacity of beams } \\
\hline $\begin{aligned} \frac{b_{f}}{2 t_{f}} & \leq \frac{52}{\sqrt{F_{y e}}} \text { and } \\
\frac{h}{t_{w}} & \leq \frac{418}{\sqrt{F_{y e}}}\end{aligned}$ & 2 & 7 & 9 & 10 & 12 \\
\hline $\begin{aligned} \frac{b_{f}}{2 t_{f}} & \geq \frac{65}{\sqrt{F_{y e}}} \text { or } \\
\frac{h}{t_{w}} & \geq \frac{640}{\sqrt{F_{y e}}}\end{aligned}$ & 1.25 & 3 & 4 & 4 & 5 \\
\hline \multicolumn{6}{|c|}{ Rotational ductility capacity of columns, $\mathrm{P} / \mathrm{P}_{\mathrm{CL}}<0.2$} \\
\hline $\begin{aligned} \frac{b_{f}}{2 t_{f}} & \leq \frac{52}{\sqrt{F_{y e}}} \text { and } \\
\frac{h}{t_{w}} & \leq \frac{300}{\sqrt{F_{y e}}}\end{aligned}$ & 2 & 7 & 9 & 10 & 12 \\
\hline $\begin{aligned} \frac{b_{f}}{2 t_{f}} & \geq \frac{65}{\sqrt{F_{y e}}} \text { or } \\
\frac{h}{t_{w}} & \geq \frac{460}{\sqrt{F_{y e}}}\end{aligned}$ & 1.25 & 3 & 4 & 4 & 5 \\
\hline \multicolumn{6}{|c|}{ Rotational ductility capacity of columns, $0.2<\mathrm{P} / \mathrm{P}_{\mathrm{CL}}<0.5$} \\
\hline $\begin{aligned} \frac{b_{f}}{2 t_{f}} & \leq \frac{52}{\sqrt{F_{y e}}} \text { and } \\
\frac{h}{t_{w}} & \leq \frac{260}{\sqrt{F_{y e}}}\end{aligned}$ & 1.25 & $8\left(1-1.7 \mathrm{P} / \mathrm{P}_{\mathrm{CL}}\right)+1$ & $11\left(1-1.7 \mathrm{P} / \mathrm{P}_{\mathrm{CL}}\right)+1$ & $14\left(1-1.7 \mathrm{P} / \mathrm{P}_{\mathrm{CL}}\right)+1$ & $17\left(1-1.7 \mathrm{P} / \mathrm{P}_{\mathrm{Cl}}\right)+1$ \\
\hline $\begin{aligned} \frac{b_{f}}{2 t_{f}} & \geq \frac{65}{\sqrt{F_{y e}}} \text { or } \\
\frac{h}{t_{w}} & \geq \frac{400}{\sqrt{F_{y e}}}\end{aligned}$ & 1.25 & 1.5 & 1.8 & 2.2 & 2.2 \\
\hline $\begin{array}{c}\text { Displacement } \\
\text { Ductility capacity } \\
\text { of CBF Braces in } \\
\text { Tension }\end{array}$ & 1.25 & 8 & 10 & 12 & 14 \\
\hline
\end{tabular}

- $F_{y e}$ is the yield stress of steel in ksi, $b_{f}$ and $t_{f}$ are flange width and thickness, $h$ and $t_{w}$ are web height and thickness, $P$ is the column axial load and $P_{C L}$ is the lower-bond strength of column. Linear interpolation between the specified values is used. 


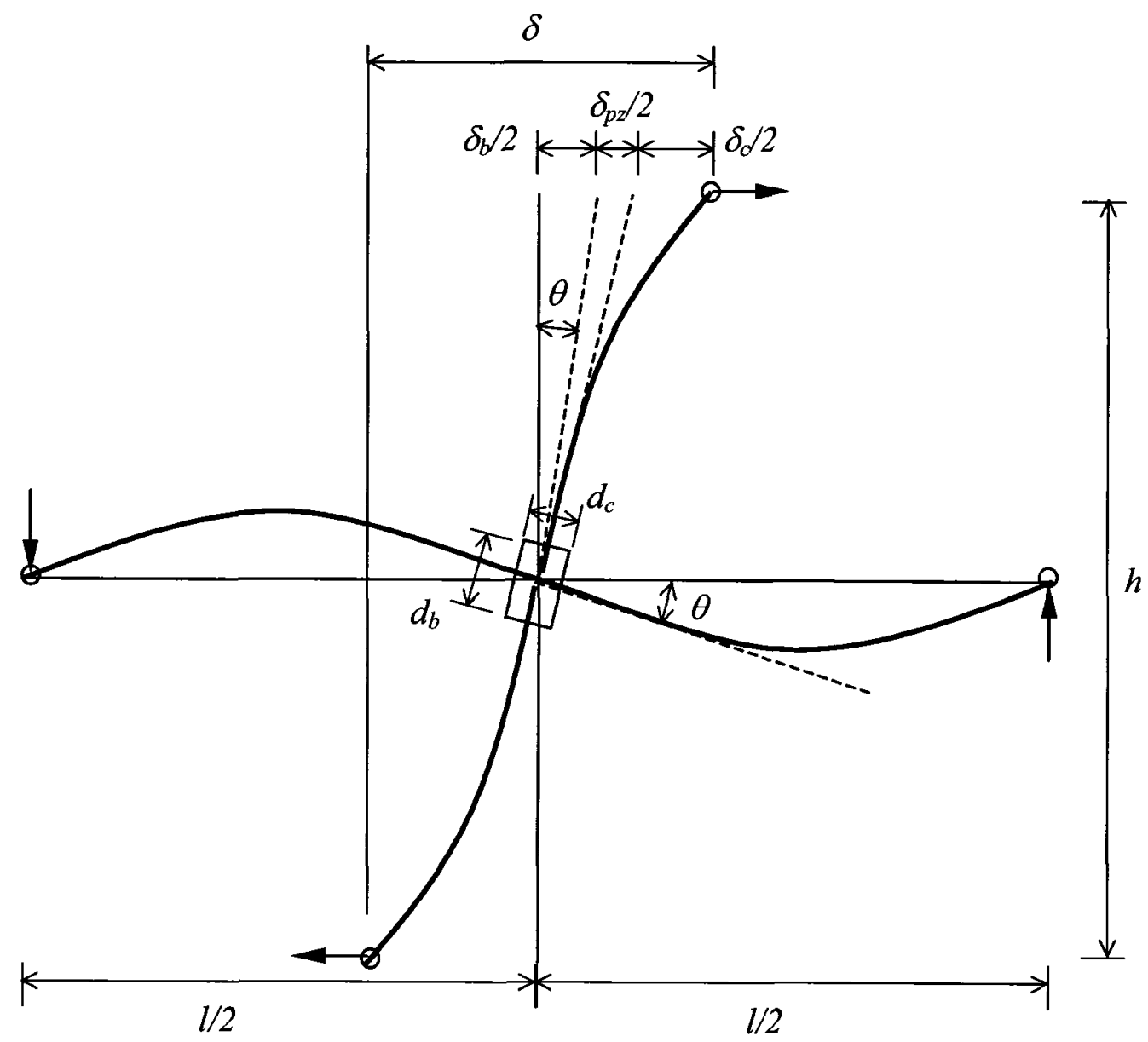

Figure (2.1): Beam-Column assembly in steel moment resisting frames 


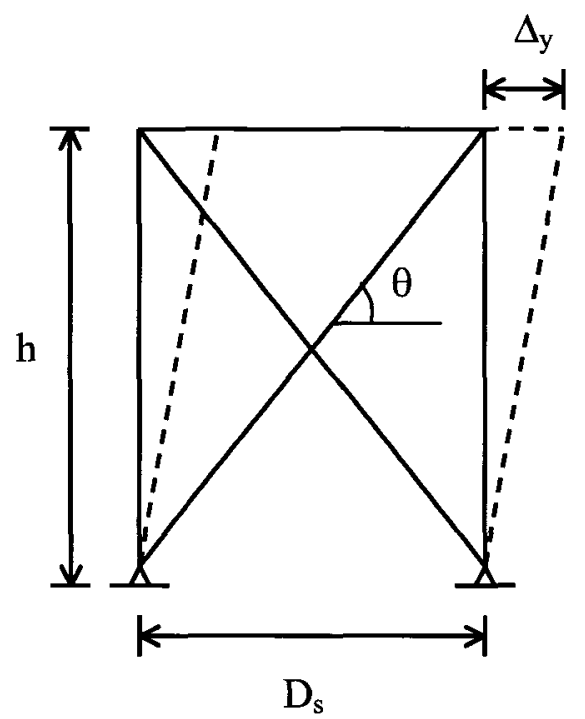

Figure (2.2): Concentrically braced frame (CBF)

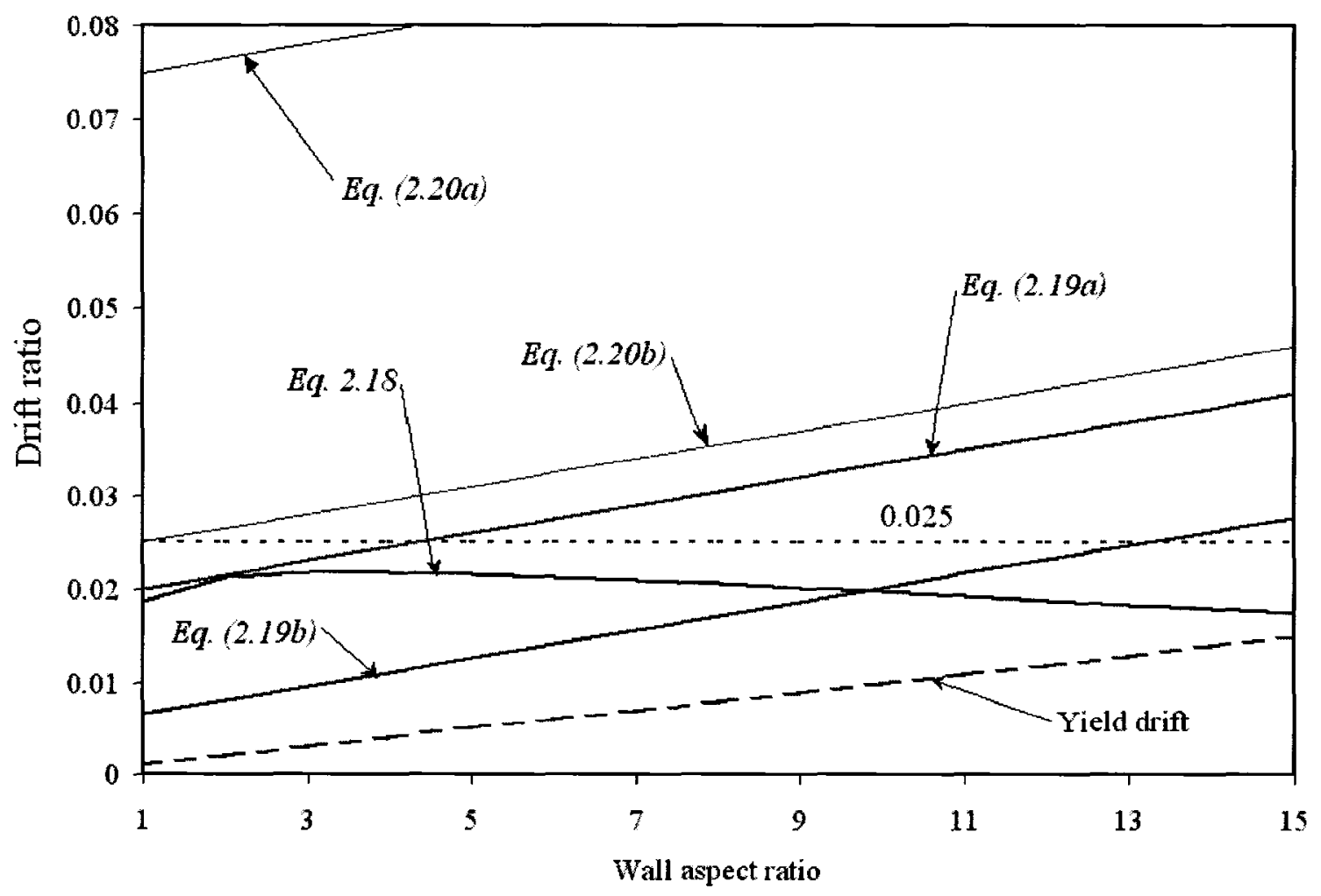

Figure (2.3): Ultimate and yield drift ratios for a shear wall 


\section{Chapter 3}

\section{Application of Displacement-based Seismic Design}

\subsection{Introduction}

To illustrate the application of the DBD procedure outlined in the previous chapter, the designs of three 12 story buildings including a reinforced concrete moment resisting frame (CMRF) building, a steel moment resisting frame (SMRF) building, and a concentrically braced frame (CBF) building, all located in the city of Vancouver, BC, Canada, are presented. Also presented is a summary of the designs of 6,15 and 20 story buildings and another set of 6 to 20 story buildings located in the city of Montreal. All buildings have a symmetric plan; thus torsional vibrations are ignored and only two-dimensional analyses are carried out. All buildings are assumed to be located on a site of class ' $C$ ', as defined in NBCC 2005. Pushover analyses of the structures are carried out using Drain-2DX program (Prakash et al. 1993).

\subsection{DBD of 12-story Reinforced Concrete Moment Resisting Frame}

\subsubsection{Layout of the building}

Plan and elevation of the structure are shown Figure (3.1a). The building has 6 bays, each $8 \mathrm{~m}$ wide, in the East-West (E-W) direction and 3 bays, each $8 \mathrm{~m}$ wide, in the NorthSouth (N-S) direction. The first-story height is $4.85 \mathrm{~m}$ and the height of each of the 
remaining stories is $3.65 \mathrm{~m}$, giving a total height of $45 \mathrm{~m}$. The lateral resistance in N-S direction is provided by three frames located on the $2^{\text {nd }}, 4^{\text {th }}$ and $6^{\text {th }}$ framing lines. The other frames take only gravity loads. Only the frames running in the N-S direction are designed. The floors consist of reinforced concrete flat slabs, $200 \mathrm{~mm}$ in thickness, supported by regularly spaced columns and beams as shown in Figure (3.1a).

The dead loads consist of the following: weight of floor slab $4.8 \mathrm{kN} / \mathrm{m}^{2}$; partitions $0.5 \mathrm{kN} / \mathrm{m}^{2}$; electrical, mechanical, ceiling $0.5 \mathrm{kN} / \mathrm{m}^{2}$; and roof insulation and water proofing $0.5 \mathrm{kN} / \mathrm{m}^{2}$ giving a total of $5.8 \mathrm{kN} / \mathrm{m}^{2}$ for both the floor and roof levels. The live load is comprised of snow on roof at $2.2 \mathrm{kN} / \mathrm{m}^{2}$, and floor load at $2.4 \mathrm{kN} / \mathrm{m}^{2}$. The following material properties are assumed: steel yield strength $f_{y}=400 \mathrm{MPa}$; concrete strength $f_{c}{ }^{\prime}=30 \mathrm{MPa}$; performance factor for steel $\phi_{s}=0.85$; and performance factor for concrete $\phi_{c}=0.60$. The stress-strain relations for concrete and reinforcing steel are shown in Figures (3.2a) and (3.2b).

The building is designed for earthquake forces in N-S direction neglecting the accidental torsion effect. For calculating the dead loads the following dimensions are assumed for the beams and columns: all beams are $400 \mathrm{~mm}$ by $600 \mathrm{~mm}$ deep; columns are $800 \mathrm{~mm}$ by $800 \mathrm{~mm}$ in stories 1 to 6 and $600 \mathrm{~mm}$ by $600 \mathrm{~mm}$ in stories 7 to 12 . The contribution of simple (gravity) frames to lateral resistance is ignored. The total dead load of the building including the estimated weight of frames works out to $98,372 \mathrm{kN}$, so that the inertia mass is 10,028 tonnes. For each lateral load resisting frame (LLRF), the floor mass is equal to 
$294.7 \mathrm{t}$ at the first floor, 287.2 $\mathrm{t}$ at levels 2 to $5,277.2 \mathrm{t}$ at floor 6, 268.7 $\mathrm{t}$ at levels 7 to 11 and $278.1 \mathrm{t}$ at the roof level, giving a total of $3342.6 \mathrm{t}$.

The live load that is applied directly on the beams is reduced using a reduction factor of 0.526. This factor is calculated based on the tributary area of each frame for gravity loads as follows,

Live load reduction factor: $\quad 0.3+\sqrt{\frac{9.8}{192}}=0.526$

Reduced live load $=2.4 \times 0.526=1.262 \mathrm{kN} / \mathrm{m}^{2}$

P- $\Delta$ effect developed by gravity loads on all frames is resisted by three LLRFs. For the earthquake load combination of $\mathrm{D}+0.5 \mathrm{~L}$, floor loads to be considered in the P- $\Delta$ analysis are calculated using the reduced live load. Conservatively it is assumed that the live load is reduced corresponding to the floor tributary area of $384 \mathrm{~m}^{2}$ (two bays),

Reduction Factor: $\quad 0.3+\sqrt{\frac{9.8}{384}}=0.460$

Reduced live load $=2.4 \times 0.46=1.104 \mathrm{kN} / \mathrm{m}^{2}$

Using the reduced load, the total gravity load of $\mathrm{D}+0.5 \mathrm{~L}$ is calculated at each level. A portion of this load is applied to LLRF as distributed gravity load on beams. The excess value at each level is applied through an imaginary column. 


\subsubsection{Equivalent static procedure of NBCC 2005}

The design base shear according to NBCC 2005 is calculated for comparison with the result of displacement-based design (DBD) as follows:

Effective mass tributary to each frame, $M=3,343$ tonnes

$\mathrm{R}_{\mathrm{d}}=4.0, \mathrm{R}_{\mathrm{o}}=1.7$

$\mathrm{T}=0.075(\mathrm{H})^{3 / 4} \times 1.5=1.95 \mathrm{~s}$

Note that when the period obtained analytically is larger than the empirical period, which is true in the present case, NBCC permits the use of a period equal to 1.5 times the empirical period but not larger than the analytical period. From UHS of Vancouver; the elastic spectral acceleration is

$\mathrm{S}_{\mathrm{a}}(1.95)=0.188 \mathrm{~g}$ and the base shear in each frame is given by

$$
V=\frac{S_{a} M_{1}}{R_{d} R_{o}}=\frac{0.188 \times 9.81 \times 3343}{4.0 \times 1.7}=907 \mathrm{kN}
$$

\subsubsection{Displacement Estimates}

The DBD is performed for two performance levels. Design for near collapse level is considered first. According to Gupta and Krawinkler (2000) the ratio of maximum story drift to roof drift for mid-rise steel structures varies between 1.2 and 2.0. As shown in Equation (2.25) the ratio of the roof drift to the maximum inter-story drift is defined as $\beta$ factor. As a rough guide we assume that $\beta$ is equal to 0.5 for our concrete moment resisting frame. Assuming a beam depth of $600 \mathrm{~mm}$, yield displacement at roof level is estimated using equations (2.2) and (2.3); 
$\Delta_{y}=0.5 \varepsilon_{y} \frac{l_{b}}{h_{b}} H \beta=\frac{0.5 \times 0.002 \times \frac{8000}{600} \times 4500}{2}=30.0 \mathrm{~cm}$

In order to meet the code requirements the maximum inter-story drift is taken as $2.5 \%$. The ultimate displacement at roof is thus given by

$$
\Delta_{u}^{R o o f}=\Delta_{u} \beta=\frac{0.025 \times 4500}{2}=56.2 \mathrm{~cm}
$$

and the global displacement ductility requirement works out to

$$
\mu=\frac{\Delta_{u}}{\Delta_{y}}=1.87
$$

\subsubsection{Equivalent SDOF system}

Assuming a linear displaced shape, the properties of the equivalent SDOF system are calculated using Equations (2.31) through (2.34);

$$
\begin{aligned}
& \phi^{\mathrm{T}}=\{0.108,0.189,0.270,0.351,0.432,0.513,0.594,0.676,0.757,0.838,0.919,1.000\} \\
& \Gamma=1.447 \\
& \mathrm{M}^{*}=2642 \text { tonnes } \\
& \delta_{\mathrm{y}}=30.0 / 1.447=20.7 \mathrm{~cm} \\
& \delta_{\mathrm{u}}=56.2 / 1.447=38.8 \mathrm{~cm}
\end{aligned}
$$




\subsubsection{Capacity and Demand Diagrams}

A portion of the elastic response spectrum for Vancouver is shown in Figure (3.3) in acceleration-displacement format. The inelastic spectrum or the demand diagram for a global displacement ductility of 1.87 , obtained by using the Krawinler Nassar $R_{\mathrm{y}}-\mu-T$ relationships, is also shown; this spectrum represents the demand diagram. The performance point is given by the intersection of the ultimate displacement and the demand diagram. The capacity curve is obtained by drawing a horizontal line from the performance point to the yield displacement and from the latter to the origin. The spectral acceleration at yield is found to be $A_{y}=0.043 \mathrm{~g}$, and the corresponding design base shear works out to;

$V_{b}=A_{y} M^{*}=0.043 \times 9.81 \times 2642=1114 \mathrm{kN}$

This shear is distributed across the height in proportion to the product of the floor mass, $W / g$, and the height of floor above the base, $h$. The resulting forces are given by:

$\mathbf{f}^{T}=V_{b} \times \frac{W h}{\sum W h}=\left\{\begin{array}{llllllllllll}19.4 & 33.1 & 47.3 & 61.5 & 75.7 & 869 & 97.4 & 1108 & 1241 & 137.4 & 1506 & 1697\end{array}\right\} \mathrm{kN}$

\subsubsection{Design of Frames}

A static analysis is carried out for the combination $\mathrm{D}+0.5 \mathrm{~L}+\mathrm{E}$. In the analysis the effective inertias for beams is assumed to be $70 \%$ of the gross inertia based on the dimensions 400 (width) x 600 (depth). For the columns as well, the effective inertia is taken as $70 \%$ the gross inertia. This assumption will be verified later on the basis of the 
computed moment-curvature relationships for the selected sections. A summary of the results of analysis is shown in Table (3.1).

The load combination $\mathrm{D}+0.5 \mathrm{~L}+\mathrm{E}$ produces the governing design forces. All beams in floors 1 to 6 are designed for a negative moment of $893 \mathrm{kNm}$ and a positive moment of half that value, that is, $446 \mathrm{kNm}$. Note that in the latter case the beam acts as a $\mathrm{T}$ beam. A 400 by $600 \mathrm{~mm}$ beam with $60 \mathrm{~mm}$ cover to the center of the first layer of reinforcement is used. In the selected design the first layer from the top has 4 No. 35 bars and the second layer has 4 No. 25 , while the bottom layer has 4 No. 30 bars. The resulting moment capacity is $900 \mathrm{kNm}$ in negative moment and $546 \mathrm{kNm}$ in positive moment. For floors 7 , 8 , and 9 the design negative moment is $751.8 \mathrm{kNm}$, and the positive design moment can be taken as half that value, namely $375.9 \mathrm{kNm}$. Using an identical beam section, reinforcement consisting of 2 No. 35 and 2 No. 30 bars for the first layer from top, 4 No. 25 bars for the second layer, and 4 No. 25 bars for the bottom layer is found to be adequate. The negative moment capacity works out to $804 \mathrm{kNm}$ and the positive moment capacity as $399 \mathrm{kNm}$. For floors 10,11 , and 12 the design negative moment is 536.7 $\mathrm{kNm}$, and the positive design moment can be taken as $268.4 \mathrm{kNm}$. Again, with the same section size, 4 No. 25 bars for the first layer from top, 2 No. 25 and 2 No. 20 bars for the second layer, and 2 No. 25 and 2 No. 20 bars for the bottom layer are found to provide adequate strength, the negative moment capacity being $565 \mathrm{kNm}$ and the positive moment capacity $322 \mathrm{kNm}$. 
Included in the design process of the columns, is the check for capacity design principles, to the extent that the sum of columns resisting moments at a joint must be larger than the sum of beams resisting moments. For the interior columns in the lowest story, the design axial force is $5261 \mathrm{kN}$ and the design moment is $1329 \mathrm{kN}-\mathrm{m}$. Capacity design will require the moment to be at least $(900+546) / 2=723 \mathrm{kN}-\mathrm{m}$. A $700 \times 700 \mathrm{~mm}$ column with 4 No. 45 bars and 8 No. 35 bars is selected. The cover to the centers of the bars is $70 \mathrm{~mm}$. For stories 2 to 4 the design axial force is $4816 \mathrm{kN}$ and the design moment is $809 \mathrm{kNm}$. A 700 by 700 column with 4 No. 30 bars and 8 No. 20 bars is selected. For stories 5, 6, 7, and 8 the design axial force is $3496 \mathrm{kN}$ and the design moment is $590 \mathrm{kNm}$. The selected column is 600 by 600 with 4 No. 30 bars and 8 No. 20 bars, the cover to the center of bars being $60 \mathrm{~mm}$. Finally, for stories $9,10,11$, and 12 the design axial force is $1739 \mathrm{kN}$ and the design moment is $352 \mathrm{kNm}$. The selected column is 500 by 500 with 4 No. 20 bars and 8 No.15 bars. The moment-curvature analyses of the designed beams and columns show that in a majority of the cases, stiffness of the fist portion of the bi-linear curves fitted on the moment-curvature curves is close to the $60 \%$ of the stiffness of the un-cracked section. Thus effective moment of inertia for both columns and beams will be considered as $60 \%$ of the gross moment of inertia hereafter.

\subsubsection{Pushover Analysis}

A modal analysis of the preliminary design is now carried out. The effective moment of inertia is assumed to be $60 \%$ of the gross moment of inertia for both beams and columns. The following properties are obtained for the first mode not taking into account the P- $\Delta$ effect. 
$\mathrm{T}_{1}=4.69 \mathrm{~s}$

$\phi_{1}^{T}=\left\{\begin{array}{llllllllllll}0.079 & 0.181 & 0.289 & 0.396 & 0.508 & 0.611 & 0.704 & 0.785 & 0.867 & 0.930 & 0.975 & 1\end{array}\right\}$

$\Gamma_{1}=1.3187$

$\mathrm{M}_{1}{ }^{*}=2650.6$ tonnes $(79.3 \%$ of total mass $)$

Pushover analysis including P- $\Delta$ effect is carried out for forces distributed according to Equation (2.27). The resulting pushover curve is shown in Figure (3.4). At a roof displacement of $\Delta=56.3 \mathrm{~cm}$, drift of the 2 nd floor reaches the $2.5 \%$ limit. However on the descending branch of the pushover curve the lateral strength reaches $95 \%$ of its maximum value at $\Delta=49.4 \mathrm{~cm}$. This displacement value may be considered as the stability limit; it also becomes the governing value of the ultimate roof displacement. A bi-linear idealization of the pushover curve gives $\Delta_{\mathrm{y}}=34.2 \mathrm{~cm}$.

\subsubsection{Subsequent Design Iterations}

Based on the results obtained from pushover analysis the system global displacement ductility capacity works out to $\mu=49.4 / 34.2=1.44$ and the updated yield and the ultimate displacements for the equivalent SDOF system are,

$\delta_{\mathrm{y}}=34.2 / 1.3187=25.93 \mathrm{~cm}$

$\delta_{\mathrm{u}}=49.4 / 1.3187=37.46 \mathrm{~cm}$ 
The revised capacity and demand curves are shown in Figure (3.5). The spectral acceleration at yield is found to be $0.0592 \mathrm{~g}$, and the corresponding design base shear works out to,

$V_{b}=A_{y} M^{*}=0.0592 \times 9.81 \times 2650.6=1539.3 \mathrm{kN}$

Thus, the difference between the two successive estimates, $\delta V_{b}$, is given by,

$\delta V_{b}=\frac{V_{b 2}-V_{b 1}}{V_{b 1}}=38 \%$

which is fairly large. Therefore, a new design will be performed with the revised base shear.

The calculated design shear is distributed across the height in proportion to the product $\mathbf{M} \phi_{1}$. The resulting forces are given by

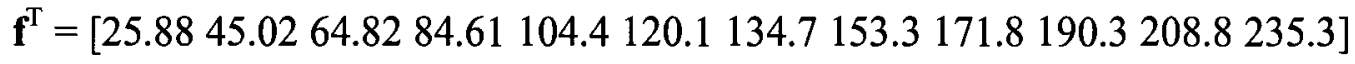

A static analysis is carried out for the lateral forces given above and the appropriate loads. The combination $\mathrm{D}+0.5 \mathrm{~L}+\mathrm{E}$ governs the design.

All beams in floors 1 to 6 are designed for a negative moment of $1270 \mathrm{kNm}$ and a positive moment of half that value or $635 \mathrm{kNm}$. The selected beam size and reinforcement are shown in Figure (3.6). The negative moment capacity of the selected beam is $1287 \mathrm{kNm}$ and the positive moment capacity is $800 \mathrm{kNm}$. For floors 7,8 , and 9 the design negative moment is $1018 \mathrm{kNm}$, and the positive design moment is taken as $509 \mathrm{kNm}$. The negative moment capacity of the selected beam section shown in Figure (3.6) is $1035 \mathrm{kN}-\mathrm{m}$ and the positive moment capacity is $529 \mathrm{kNm}$. For floors 10 , 
11 and 12 the design negative moment is $652 \mathrm{kNm}$ and the positive design moment can be taken as $326 \mathrm{kNm}$. The selected design section is again shown in Figure (3.6), The negative moment capacity of the section is $724 \mathrm{kNm}$ and the positive moment capacity is $384 \mathrm{kNm}$.

Details of the designed columns are shown in Figure (3.6). For the interior columns in the lowest story, the design axial force is $5331 \mathrm{kN}$ and the design moment is $1828 \mathrm{kNm}$. The designed column fails by crushing of concrete and yielding of steel at $2030 \mathrm{kNm}$, when the concrete strain is 0.0035 . For stories 2 to 4 the design axial force is $4878 \mathrm{kN}$ and the design moment is moment is $1144 \mathrm{kN}-\mathrm{m}$. The selected column fails by crushing of concrete at a moment of $1247 \mathrm{kNm}$. For stories 5, 6, 7, and 8 the design axial force is $3542 \mathrm{kN}$ and the design moment is $890 \mathrm{kNm}$. The selected column also fails by crushing of concrete at a moment of $920 \mathrm{kNm}$. For stories $9,10,11$, and 12 the design axial force is $1766 \mathrm{kN}$ and the design moment is $516 \mathrm{kNm}$. The designed column fails by yielding of steel and crushing of concrete at a moment of $537 \mathrm{kNm}$.

A modal analysis of this design is carried out. The effective moment of inertia is assumed to be $60 \%$ of the gross moment of inertia for both the beams and the columns. The following properties are obtained for the first mode not taking into account the P- $\Delta$ effect. $\mathrm{T}_{1}=4.06 \mathrm{~s}$ $\phi_{1}^{T}=\left\{\begin{array}{llllllllllll}0.058 & 0.143 & 0.234 & 0.325 & 0.424 & 0.519 & 0.618 & 0.719 & 0.825 & 0.909 & 0.966 & 1\end{array}\right\}$ 
$\Gamma_{1}=1.3639$

$\mathrm{M}_{1}^{*}=2520$ tonnes $\quad(75.4 \%$ of total mass $)$

Figures (3.7) and (3.8) show the pushover curve and inter-story drifts for the new design. At a roof displacement of $59.5 \mathrm{~cm}$, drift in the first floor reaches the $2.5 \%$ limit. The instability limit on the ultimate roof displacement is $\Delta_{\mathrm{u}}=51.0 \mathrm{~cm}$, and is again the governing value. The yield displacement at roof level is estimated as $\Delta_{\mathrm{y}}=39.5 \mathrm{~cm}$ and global displacement ductility capacity works out to: $\mu=51.0 / 39.5=1.30$. The yield and ultimate displacements of the equivalent SDOF system will be $28.96 \mathrm{~cm}$ and $37.39 \mathrm{~cm}$, respectively.

Figure (3.9) shows the $3^{\text {rd }}$ DBD try in which demand acceleration of $A_{y}=0.0657 \mathrm{~g}$ is obtained and design base shear works out to $\mathrm{V}_{\mathrm{b}}=1624 \mathrm{kN}$. Since the pushover diagram shows strength of $1618 \mathrm{kN}$ and also the design base shear has converged, design is considered satisfactory.

In order to calculate the performance of the structure in the first mode, capacity diagram of the equivalent SDOF system is obtained by dividing the base shear value in the pushover curve by $\mathrm{M}^{*} \mathrm{~g}$,

$A_{y}=V_{y} / M^{*} g=1618 /(2520 * 9.81)=0.0654 g$ 
The analytical period of the structure considering the P- $\Delta$ is $T=4.21 \mathrm{~s}$; it is substituted in Equation (2.35) to calculate the demand acceleration from the elastic design spectrum for Vancouver,

$\mathrm{S}_{\mathrm{a}}(4.21)=2 \times 0.18 \mathrm{~g} / 4.21=0.0855 \mathrm{~g}$

The demand force reduction factor is,

$\mathrm{R}=\mathrm{S}_{\mathrm{a}} / \mathrm{A}_{\mathrm{y}}=0.0855 / 0.0654=1.30$

The demand global displacement ductility calculated using Equations (2.37) and (2.38) works out to $\quad \mu_{\text {Demand }}=1.30$, which is equal to the ductility capacity of 1.30 , and is therefore satisfactory.

The demand roof displacement in the first mode works out to,

$\Delta_{1}^{\mathrm{Roof}}=\mu_{\text {Demand }} \mathrm{X} \Delta_{\mathrm{y}}=1.30 \times 39.5=51.3 \mathrm{~cm}$

\subsubsection{Multi-Mode Pushover Analysis}

As shown earlier, the mass participation in the first mode is $75.4 \%$ of the total mass, which means that the higher modes may make significant contributions. In the present example modes 2 and 3 are included in order to capture 90\% mass participation. In regular structures it is expected that the structure would remain elastic under higher mode demand. A dynamic analysis of the designed structure gives the vibration period and mode shape for mode 2 ,

$\mathrm{T}_{2}=1.54 \mathrm{~s}$

$\phi_{2}{ }^{\mathrm{T}}=\{0.185,0.431,0.657,0.823,0.913,0.883,0.719,0.432,-0.001,-0.438,-0.789,-1\}$ 
$\Gamma_{2}=0.533$

$\mathrm{M}_{2}^{*}=433.0$ tonnes $\quad(12.9 \%$ of total mass $)$

From the elastic design spectrum of Vancouver, displacement of the SDOF system with a period of $1.54 \mathrm{~s}$ is obtained and then the demand roof displacement is calculated,

$\delta(1.54)=\mathrm{S}_{\mathrm{a}}(1.54) \times(1.54)^{2} / 4 \pi^{2}=14.94 \mathrm{~cm}$

$\Delta_{2}^{\text {Roof }}=\delta \times \Gamma_{2}=14.94 \times 0.533=7.96 \mathrm{~cm}$

For mode 3 similar parameters are calculated,

$\mathrm{T}_{3}=0.87 \mathrm{~s}$

$\phi_{3}{ }^{\mathrm{T}}=\{0.309,0.657,0.847,0.801,0.464,-0.058,-0.616,-1,-0.946,-0.366,0.411,0.991\}$

$\Gamma_{3}=0.299$

$\mathrm{M}_{3}^{*}=140.0$ tonnes $\quad(4.2 \%$ of total mass $)$

$\delta(0.87)=5.70 \mathrm{~cm}$

$\Delta_{3}^{\text {Roof }}=1.70 \mathrm{~cm}$

The total mass for first 3 modes is $92.5 \%$, which is a substantial portion of the total mass and no additional modes need be included. For each of the three modes, a pushover analysis using the lateral force distribution of Equation (2.27) is carried out. The calculated demand roof displacements are considered as the target displacements and the inter-story drifts, story shears and member forces corresponding to the target displacement are extracted. As expected, in each of the $2^{\text {nd }}$ and $3^{\text {rd }}$ modes, the structure remains elastic until the demand displacement is reached. Results for the key 
displacements and forces and their combination are discussed briefly in the following sections.

\section{Inter-story drifts}

Table (3.2) shows the inter-story drifts in the first 3 modes as well as their SRSS combination. Higher modes do not make a major contribution to the displacements and the drifts are still within the acceptable limit of $2.5 \%$.

\section{Story shears}

Modal story shears are presented in Table (3.3). The SRSS combination of the base shear $(=1983 \mathrm{kN})$ is almost $22 \%$ higher than the design base shear $(=1624 \mathrm{kN})$. The extra shear force is resisted by adding shear reinforcements in columns and no change in dimensions is necessary.

The results presented here show that higher modes make more contribution to the story shears than to the inter-story drifts. This can be explained by the fact that the structural response in the first mode enters the inelastic range, so that the drifts increase even as the shears remain virtually constant. On the other hand, the structural response in the higher modes is still elastic, so that the shears are proportional to the drifts.

\section{Beam moments}

End moments in the interior-span beams are listed in Tables (3.4a) and (3.4b). Wherever a plastic hinge is formed, the plastic rotation is also given. The positive plastic moment 
capacity is $800 \mathrm{kNm}$ for the 6 lower story beams, $529 \mathrm{kNm}$ for beams of stories 7 to 9 and $384 \mathrm{kNm}$ for beams of stories 10 to 12 . The negative moment capacity is $1287 \mathrm{kNm}$ for the 6 lower story beams, $1035 \mathrm{kNm}$ for beams of stories 7 to 9 and $724 \mathrm{kNm}$ for beams of stories 10 to 12 . In order to properly account for the gravity moments, modal moments excluding gravity are combined by SRSS method and then the gravity moments are added. Results of the SRSS combination of the positive moments in Table (3.4a) show that beams in stories 5 to 12 still remain elastic and no design change is necessary. For the first 4 story beams, it is necessary to ensure that the local ductility capacities of the beams are not exceeded, otherwise the design needs to be revised. Figure (3.10) shows the positive moment-curvature relationship for these beams. At a curvature of 54.98E-6 $1 / \mathrm{mm}$, concrete strain reaches the limit of 0.0035 , thus it could be considered as the maximum allowable curvature for the beam. Curvature ductility capacity of the beam considering the yield curvature of $3.94 \mathrm{E}-061 / \mathrm{mm}$ is: $\mu_{\text {curvature }}=54.98 / 3.94=13.95$.

Plastic hinge length is calculated using Equation (2.23), $L_{p}=0.5 d+0.05 z=0.5 \times 640+0.05 \times 4000=520 \mathrm{~mm}$ and the plastic curvature of the first mode $\phi_{\mathrm{p}}$ is obtained from plastic hinge rotation $\theta_{\mathrm{p}}$, $\phi_{\mathrm{p}}{ }^{\mathrm{model}}=\theta_{\mathrm{p}} / \mathrm{L}_{\mathrm{p}}=6.06 \mathrm{E}-3 / 520=11.65 \mathrm{E}-61 / \mathrm{mm}$ $\phi_{\text {total }}^{\text {model }}=\phi_{\mathrm{y}}+\phi_{\mathrm{p}}=15.59 \mathrm{E}-6$

From Figure (3.11), the curvature corresponding to the gravity moment of $-295 \mathrm{kNm}$ is obtained, $\phi_{\text {gravity }}=-1.22 \mathrm{E}-6$ 
and the net total curvature excluding the gravity load effect will be,

$\phi_{\text {net }}^{\text {mode1 }}=\phi_{\text {total }}-\phi_{\text {gravity }}=16.81 \mathrm{E}-6$

For modes 2 and 3 , the net curvatures for the net positive moments ( +483 and $+166 \mathrm{kN}-\mathrm{m}$ in columns 6 and 8) are also obtained from Figure (3.11),

$\phi_{\text {net }}^{\text {mode2 }}=2.72 \mathrm{E}-6$

$\phi_{\text {net }}{ }^{\text {mode3 }}=0.9 \mathrm{E}-6$

The net curvatures are combined using the SRSS method and then the gravity curvature is added to obtain the demand curvature,

$\phi_{\text {SRSS }}=17.05 \mathrm{E}-6$

$\phi_{\text {Demand }}=\phi_{\text {SRSS }}+\phi_{\text {gravity }}=15.83 \mathrm{E}-6$

The curvature ductility demand is,

$\mu_{\text {Demand }}=\phi_{\text {Demand }} / \phi_{y}=4.0$

The above calculations show that the local ductility demand $(=4.0)$ is well below the curvature ductility capacity $(=13.95)$. This procedure is applied for all other beams and it is concluded that beam design is satisfactory even considering the effect of higher modes. The same analogy is used to calculate the demand local ductility for negative moments using the results of Table (3.4b) and Figure (3.11).

$\mu_{\text {curvature }}=12.61 / 5.53=2.28$

$\phi_{\mathrm{p}}{ }^{\text {model }}=17.08 \mathrm{E}-61 / \mathrm{mm}$

$\phi_{\text {total }}{ }^{\text {model }}=22.61 \mathrm{E}-6$

$\phi_{\text {net }}^{\text {model }}=21.39 \mathrm{E}-6$ 
$\phi_{\text {net }}^{\text {mode2 }}=2.04 \mathrm{E}-6$

$(\mathrm{M}=-483 \mathrm{kN}-\mathrm{m})$

$\phi_{\text {net }}^{\text {mode3 }}=0.7 \mathrm{E}-6$

$(\mathrm{M}=-166 \mathrm{kN}-\mathrm{m})$

$\phi_{\mathrm{SRSS}}=21.50 \mathrm{E}-6$

$\phi_{\text {Demand }}=22.72 \mathrm{E}-6$

$\mu_{\text {Demand }}=4.11>2.28$

The curvature ductility demand is higher than the ductility capacity. Since degradation of the negative moment capacity is negligible until curvature of the $24 \mathrm{E}-6 \mathrm{1} / \mathrm{mm}$, design is considered satisfactory.

\section{Beam shear forces}

The shear forces in the middle span beams, at their end farther from the applied lateral forces (j-end as shown in Figure (3.1b)), are presented in Table (3.5). Similar to the procedure used for combination of the moments, the gravity shear force is added after the SRSS combination of modal shear forces. However, if a plastic hinge has formed at either end of the beam (as is the case in stories 1 to 4,7 and 10), the shear force is calculated using the method proposed by Goel and Chopra (2005). Extra shear reinforcements are used to carry the excess shear forces and no change in the dimensions is required.

\section{Column moments}

The moment-curvature relationship for first story column is shown in Figure (3.12). The confined concrete model of Figure (3.2a) is used to calculate the moment capacities up to the concrete strain of $1.5 \%$. UBC 1997 allows this strain limit for well-confined concrete. 
At the first mode demand level, plastic hinges form at the base of the first story columns. Column plastic hinge length is calculated using Equation (2.23),

$L_{p}=0.5 d+0.05 z=0.5 \times 750+0.05 \times 2425=496 \mathrm{~mm}$ (say $\left.500 \mathrm{~mm}\right)$

From the plastic hinge rotation in the first mode, the corresponding curvature is calculated,

$\phi_{\mathrm{p}}{ }^{\mathrm{model}}=\theta_{\mathrm{p}} / \mathrm{L}_{\mathrm{p}}=1.165 \mathrm{E}-2 / 500=2.33 \mathrm{E}-5$

The yield curvature is estimated from the moment-curvature diagram of the column shown in Figure (3.12) and then the total curvature is calculated,

$\phi_{\text {total }}^{\text {model }}=\phi_{\mathrm{y}}+\phi_{\mathrm{p}}=6.0 \mathrm{E}-6+23.3 \mathrm{E}-6=29.3 \mathrm{E}-6$

From the same figure the curvatures corresponding to the $2^{\text {nd }}$ and $3^{\text {rd }}$ mode moments of $1,179 \mathrm{kNm}$ and $440 \mathrm{kNm}$, respectively, are obtained,

$\phi_{\text {total }}{ }^{\text {mode2 }}=2.09 \mathrm{E}-6$

$\phi_{\text {total }}{ }^{\text {mode3 }}=0.73 \mathrm{E}-6$

Note that the gravity curvature is negligible, thus the total curvatures are equal to their net values. The demand curvature, calculated from SRSS of the 3 modes, is equal to, $\phi_{\text {Demand }}=29.38 \mathrm{E}-6$

This curvature is less than the maximum limit of 31.0E-6 shown in Figure (3.12) and is accepted. This procedure is repeated to for other columns of the first story and the results are found to be acceptable.

The above discussion shows that performance of the designed structure at the near collapse level is satisfactory. 


\subsubsection{Operational level performance}

The performance of the designed structure at operational level is evaluated next. The uniform hazard spectrum of Vancouver for the frequent earthquakes (50 percent probability of being exceeded in 50 years) prepared by the Geological Survey of Canada (2006), is Shown in Figure (3.13). The demand base shear in a frequent earthquake can be calculated for this structure as follows.

For the first mode period of $4.28 \mathrm{~s}$, the demand acceleration obtained using Equation (2.35) is equal to,

$\mathrm{S}_{\mathrm{a}}(4.21)=2 \times 0.034 \mathrm{~g} / 4.21=0.0162 \mathrm{~g}$

$\mathrm{V}=\mathrm{S}_{\mathrm{a}} \mathrm{M}=0.0162 \times 9.81 \times 3343=530 \mathrm{kN}$

Referring to the pushover curve of Figure (3.7), the corresponding roof displacement for the calculated base shear is equal to $13 \mathrm{~cm}$. At this roof displacement the maximum interstory drift reaches $0.38 \%$ as shown in Figure (3.8), which is less than the $0.5 \%$ limit. Thus, the design is satisfactory.

\subsection{DBD of other RC frame buildings}

A similar procedure is used for DBD of 6,15 and 20-story buildings with similar geometry and loading. As shown in plan view of Figure (3.1a), the lateral load resisting frames are located at every $16 \mathrm{~m}$. Dimensions and properties of these buildings that are located in Vancouver are shown in Table (3.7). The details of the design of six-story building are presented in Appendix A 
A similar set of RC frame buildings, located in Montreal are designed with the same procedure. In these buildings, lateral load resisting frames are located at every $32 \mathrm{~m}$ so the load combinations including the earthquake force will be more critical in design. Dimensions and properties of these frames are shown in Table (3.8).

\subsection{DBD of 12-story Steel Moment Resisting Frame}

\subsubsection{Layout of the building}

The DBD of a 12-story steel moment resisting frame is considered in this section. Geometry and arrangement of the lateral load resisting frames are identical to the RC frame of Section 3.2 and are shown in Figure (3.1a).

The dead loads consist of the following: weight of floor slab $4.8 \mathrm{kN} / \mathrm{m}^{2}$; partitions $0.5 \mathrm{kN} / \mathrm{m}^{2}$; electrical, mechanical, ceiling $0.5 \mathrm{kN} / \mathrm{m}^{2}$; and roof insulation and water proofing $0.5 \mathrm{kN} / \mathrm{m}^{2}$ giving a total of $5.8 \mathrm{kN} / \mathrm{m}^{2}$ for both the floor and roof levels. The live load is comprised of snow on roof at $2.2 \mathrm{kN} / \mathrm{m}^{2}$, and floor load at $2.4 \mathrm{kN} / \mathrm{m}^{2}$. The following material properties are assumed: steel yield strength $f_{y}=350 \mathrm{MPa}$ Steel modulus of elasticity $\mathrm{E}=200,000 \mathrm{MPa}$ and performance factor for steel $\phi=0.9$.

The building is designed for earthquake forces in the N-S direction neglecting the accidental torsion effect. The contribution of simple (gravity) frames to lateral resistance is ignored. The total dead load of the building including the estimated weight of frames works out to $88,467 \mathrm{kN}$, so that the inertia mass is 9,018 tonnes. In average, a uniform 
distributed load of $0.6 \mathrm{kN} / \mathrm{m}^{2}$ is considered as self-weight of columns, beams and connections. For each lateral load resisting frame (LLRF), the floor mass is equal to $250.5 \mathrm{t}$ at each floor, giving a total of $3006 \mathrm{t}$.

The reduced live load and also the P- $\Delta$ gravity loads are calculated and applied to the structure using a procedure similar to that presented in Section 3.2.1

\subsubsection{Equivalent static procedure of NBCC 2005}

The design base shear according to NBCC 2005 is calculated as follows:

Effective mass tributary to each frame, $M=3,006$ tonnes

$\mathrm{R}_{\mathrm{d}}=5.0, \mathrm{R}_{\mathrm{o}}=1.5 \quad$ (Ductile moment resisting frame)

$\mathrm{T}=0.085(\mathrm{H})^{3 / 4} \times 1.5=2.22 \mathrm{~s}$

Note that when the period obtained analytically is larger than the empirical period, which is true in this case, NBCC permits the use of a period equal to 1.5 times the empirical period but not larger than the analytical period. From the UHS for Vancouver; the elastic spectral acceleration is

$\mathrm{S}_{\mathrm{a}}(2.22)=0.163 \mathrm{~g}$ and the base shear in each frame is given by

$$
V=\frac{S_{a} M_{1}}{R_{d} R_{o}}=\frac{0.163 \times 9.81 \times 3006}{5.0 \times 1.5}=641 \mathrm{kN}
$$




\subsubsection{Displacement Estimates}

The DBD is performed for two performance levels. Design for near collapse level is considered first. Again we assume that $\beta$ is equal to 0.5 for the steel moment resisting frame. Assuming a beam depth of $600 \mathrm{~mm}$, yield displacement at roof level is estimated using Equations (2.10);

$$
\Delta_{y}=0.532 \frac{F_{y} l}{E d_{b}} H \beta=0.532 \times \frac{350 \times 8000}{200000 \times 600} \times 4500 \times 0.5=27.93 \mathrm{~cm}
$$

In order to meet the code requirements, the maximum inter-story drift is taken as $2.5 \%$. The ultimate displacement at roof is thus given by

$\Delta_{u}^{R o o f}=\Delta_{u} \beta=\frac{0.025 \times 4500}{2}=56.25 \mathrm{~cm}$

and the global ductility requirement works out to $\mu=\frac{\Delta_{u}}{\Delta_{y}}=2.01$

\subsubsection{Equivalent SDOF system}

Assuming a linear displaced shape, the properties of the equivalent SDOF system are calculated as shown in Section 3.2.4;

$\mathrm{M}^{*}=2394$ tonnes

$\delta_{\mathrm{y}}=27.93 / 1.4378=19.43 \mathrm{~cm}$

$\delta_{\mathrm{u}}=56.25 / 1.4378=39.12 \mathrm{~cm}$ 


\subsubsection{Capacity and Demand Diagrams}

The inelastic spectrum or the demand diagram for a global ductility of 2.01 is shown in Figure (3.15). The spectral acceleration at yield is found to be $A_{y}=0.039 \mathrm{~g}$, and the corresponding design base shear works out to;

$V_{b}=A_{y} M^{*}=0.039 \times 9.81 \times 3006=916 \mathrm{kN}$

This shear is distributed across the height in proportion to the product of the floor mass, $W / g$, and the height of floor above the base, $h$. The resulting forces are given by:

$\mathbf{f}^{T}=V_{b} \times \frac{W h}{\sum W h}=\left\{\begin{array}{llllllllllll}15 & 26 & 37 & 48 & 60 & 71 & 82 & 93 & 104 & 115 & 127 & 138\end{array}\right\} \mathrm{kN}$

\subsubsection{Design of Frames}

A static analysis is carried out for the combination $\mathrm{D}+0.5 \mathrm{~L}+\mathrm{E}$. This load combination produces the governing design forces. Included in the design process of the columns, is the check for capacity design principles, to the extent that the sum of columns resisting moments at a joint must be larger than the sum of beams resisting moments. Selected steel sections are shown in Table (3.9).

\subsubsection{Pushover Analysis}

A modal analysis of the preliminary design is now carried out. The following properties are obtained for the first mode taking into account the P- $\Delta$ effect.

$\mathrm{T}_{1}=4.66 \mathrm{~s}$

$\boldsymbol{\varphi}_{1}^{\top}=\left\{\begin{array}{llllllllllll}0.089 & 0.189 & 0.288 & 0.383 & 0.476 & 0.575 & 0.665 & 0.753 & 0.836 & 0.914 & 0.969 & 1\end{array}\right\}$ 
$\Gamma_{1}=1.343$

$\mathrm{M}_{1}{ }^{*}=2402$ tonnes $\quad(79.9 \%$ of total mass $)$

Pushover analysis including P- $\Delta$ effect is carried out for forces distributed according to Equation (2.27). The resulting pushover curve is shown in Figure (3.15). The capacity of the structure is seen to be $1170 \mathrm{kN}$, even though it was designed for a base shear of 916 $\mathrm{kN}$. This is because only discrete section sizes are available and because, for facility in construction, similar beam and column sizes are used for a number of floors, instead of using a large number of different sections. At a roof displacement of $\Delta=64.5 \mathrm{~cm}$, drift of the 2nd floor reaches the $2.5 \%$ limit. However on the descending branch of the pushover curve the lateral strength reaches $95 \%$ of its maximum value at $\Delta=63.0 \mathrm{~cm}$. This displacement value may be considered as the stability limit; it also becomes the governing value of the ultimate roof displacement. A bi-linear idealization of the pushover curve gives $\Delta_{\mathrm{y}}=36.1 \mathrm{~cm}$. Inter-story drifts are shown in Figure (3.16).

\subsubsection{Subsequent Design Iterations}

Based on the results obtained from pushover analysis the system ductility capacity works out to $\mu=63.0 / 36.1=1.745$ and the updated yield and the ultimate displacements for the equivalent SDOF system are,

$\delta_{\mathrm{y}}=36.1 / 1.343=26.88 \mathrm{~cm}$

$\delta_{\mathrm{u}}=63.0 / 1.343=46.91 \mathrm{~cm}$ 
The revised capacity and demand curves are shown in Figure (3.17). The spectral acceleration at yield is found to be $0.0385 \mathrm{~g}$, and the corresponding design base shear works out to,

$V_{b}=A_{y} M^{*}=0.0385 \times 9.81 \times 2402=907 \mathrm{kN}$

Since the design base shear has converged, the design is considered satisfactory.

In order to calculate the performance of the structure in the first mode, capacity diagram of the equivalent SDOF system is obtained by dividing the base shear value in the pushover curve by $\mathrm{M}^{*} \mathrm{~g}$,

$A_{y}=V_{y} / M^{*} g=1170 /(2402 * 9.81)=0.0497 g$

Substituting the period of the structure, $T=4.66$ in Equation (2.35), the demand acceleration from the elastic design spectrum for Vancouver is calculated,

$\mathrm{S}_{\mathrm{a}}(4.66)=2 \times 0.18 \mathrm{~g} / 4.66=0.0773 \mathrm{~g}$

The demand force reduction factor is,

$\mathrm{R}=\mathrm{S}_{\mathrm{a}} / \mathrm{A}_{\mathrm{y}}=0.0773 / 0.0497=1.556$

The demand global ductility calculated using Equations (2.37) and (2.38) works out to $\mu_{\text {Demand }}=1.56$, which is less than the ductility capacity of 1.745 , and is therefore satisfactory.

The demand roof displacement in the first mode works out to,

$\Delta_{1}^{\mathrm{Roof}}=\mu_{\text {Demand }} \times \Delta_{\mathrm{y}}=1.56 \times 36.1=56.3 \mathrm{~cm}$ 


\subsubsection{Multi-Mode Pushover Analysis}

The mass participation in the first mode is $79.9 \%$ of the total mass. In the present example only two modes need to be included in order to capture $90 \%$ mass participation. A dynamic analysis of the designed structure gives the vibration period and mode shape for mode 2,

$\mathrm{T}_{2}=1.677 \mathrm{~s}$

$\phi_{2}{ }^{\mathrm{T}}=\{0.246,0.498,0.698,0.823,0.860,0.797,0.631,0.355,-0.016,-0.455,-0.793,-1\}$

$\Gamma_{2}=0.508$

$\mathrm{M}_{2}{ }^{*}=336.0$ tonnes $\quad(11.2 \%$ of total mass $)$

From the elastic design spectrum of Vancouver, displacement of the SDOF system with a period of $1.677 \mathrm{~s}$ is obtained and then the demand roof displacement is calculated, $\delta(1.677)=\mathrm{S}_{\mathrm{a}}(1.677) \times(1.677)^{2} / 4 \pi^{2}=16.2 \mathrm{~cm}$ $\Delta_{2}^{\mathrm{Roof}}=\delta \times \Gamma_{2}=16.2 \times 0.508=8.22 \mathrm{~cm}$

The total mass for first 2 modes is $91.1 \%$, which is a substantial portion of the total mass tributary to the frame and no additional modes need be included. For both modes, a pushover analysis using the lateral force distribution of Equation (2.27) is carried out. The calculated demand roof displacements are considered as the target displacements and the inter-story drifts, story shears and member forces corresponding to the target displacement are extracted. As expected, in the $2^{\text {nd }}$ mode, the structure remains elastic until the demand displacement is reached. Results for the key displacements and forces and their combination are discussed next. 


\section{Inter-story drifts}

Table (3.11) shows the inter-story drifts in the first 2 modes as well as their SRSS combination. Second mode does not make a major contribution to the displacements and the drifts are still within the acceptable limit of $2.5 \%$.

\section{Story shears}

Modal story shears are presented in Table (3.12). The SRSS combination of the base shear $(=1323 \mathrm{kN})$ is almost $44 \%$ higher than the design base shear $(=916 \mathrm{kN})$. Selected column sections have sufficient capacity to resist the extra shear force.

\section{Beam moments}

End moments in the middle-span beams in first mode response of the designed structure are listed in Table (3.13). Plastic hinges form in 11 stories, for which the plastic hinge rotations are also given in column (4). For each beam, the yield rotation is calculated using Equation (2.7). For example the yield rotation of the section W610x101 will be,

$$
\theta_{y b}=\frac{M_{P b} l}{6 E I_{b}}=\frac{Z F_{y} l}{6 E I_{b}}=\frac{2,900,000 \times 350 \times 8000}{6 \times 200,000 \times 764,000,000}=8.857 \times 10^{-3}
$$

The rotational ductility demand for first story beam is calculated as follows,

$\mu_{\text {DEMAND }}=\left(\theta_{\mathrm{P}}+\theta_{\mathrm{y}}\right) / \theta_{\mathrm{y}}=(1.105 \mathrm{E}-2+8.857 \mathrm{E}-3) / 8.857 \mathrm{E}-3=2.25$

For beams of stories 2 to 12 , demand ductility is calculated and shown in column (6) of the same table. 
The rotational ductility capacity is obtained from Table (2.2). For section W610x101 the width to thickness ratios are calculated as follows,

$$
\begin{aligned}
\frac{b_{f}}{2 t_{f}}=\frac{228}{2 \times 14.9}=7.65 & >\frac{52}{\sqrt{F_{y}}}=\frac{52}{\sqrt{50.8}}=7.3 \\
& <\frac{65}{\sqrt{F_{y}}}=9.1 \quad\left(F_{\mathrm{y}} \text { in } \mathrm{ksi}\right)
\end{aligned}
$$

Considering the beam as primary element and for the life safety objective, the rotational ductility capacity is calculated from interpolation between the values of 3 and 7 and works out to,

$\mu_{\mathrm{CAPACITY}}=6.2$

The rotational ductility capacities are calculated for upper beams and listed in column (7). Since in all cases the demand is less than the capacity, design of the beams is considered satisfactory.

\section{Column moments}

Maximum moments in the interior columns in modes 1 and 2 and also their SRSS combinations are shown in Table (3.14). The plastic hinge formed at the base of the column shows a plastic rotation of $\theta_{\mathrm{P}}=5.853 \mathrm{E}-3$ radians at the demand roof displacement. For column section of $\mathrm{W} 360 \times 314$, the yield rotation is calculated as follows: 
$\theta_{y c}=\frac{Z F_{y} l}{E I}\left(1-\frac{P}{A F_{y}}\right)=\frac{6,370,000 \times 350 \times 4850}{200,000 \times 11 \times 10^{7}}\left(1-\frac{5,188,000}{350 \times 39,900}\right)=30.81 \times 10^{-3}$

and the rotational ductility demand works out to,

$\mu_{\text {DEMAND }}=\left(\theta_{\mathrm{P}}+\theta_{\mathrm{y}}\right) / \theta_{\mathrm{y}}=(5.853 \mathrm{E}-3+30.81 \mathrm{E}-3) / 30.81 \mathrm{E}-3=1.19$

To obtain the rotational ductility capacity, first the axial force capacity of column, $\mathrm{P}_{\mathrm{CL}}$ is calculated. Following the CISC code procedure, the column strength will be,

$\mathrm{P}_{\mathrm{CL}}=10,425 \mathrm{kN}$

The width-to-thickness ratios are calculated for the column,

$\mathrm{P} / \mathrm{P}_{\mathrm{CL}}=5,188 / 10,425=0.498<0.5$

$\frac{b_{f}}{2 t_{f}}=\frac{401}{2 \times 39.6}=5.06<\frac{52}{\sqrt{F_{y}}}=\frac{52}{\sqrt{50.8}}=7.3$

$\frac{h}{t_{w}}=\frac{227}{24.9}=11.1<\frac{260}{\sqrt{F_{y}}}=36.5$

For life safety objective the rotational ductility capacity is calculated as follows,

$\mu_{\mathrm{CAPACITY}}=8\left(1-1.7 \mathrm{P} / \mathrm{P}_{\mathrm{CL}}\right)+1=2.23>\mu_{\mathrm{DEMAND}}=1.19$

Thus, column design is satisfactory. 


\subsubsection{Operational level performance}

For the first mode period of $4.66 \mathrm{~s}$, the demand acceleration obtained using Equation (2.35) is equal to,

$\mathrm{S}_{\mathrm{a}}(4.66)=2 \times 0.034 \mathrm{~g} / 4.66=0.0146 \mathrm{~g}$

$\mathrm{V}=\mathrm{S}_{\mathrm{a}} \mathrm{M}=0.0146 \times 9.81 \times 3006=430 \mathrm{kN}$

Referring to the pushover curve of Figure (3.15), the corresponding roof displacement for the calculated base shear is equal to $13.4 \mathrm{~cm}$. At this roof displacement the maximum inter-story drift reaches $0.38 \%$ as shown in Figure (3.16), which is less than the $0.5 \%$ limit. Thus, the design is satisfactory.

\subsection{DBD of other SMRF buildings}

A similar procedure is used for DBD of 6,15 and 20 -story buildings with similar geometry and loading. The lateral load resisting frames are located at every $16 \mathrm{~m}$. Detail of steel sections and properties of these buildings that are located in Vancouver are shown in Table (3.9).

A similar set of SMRF buildings, located in Montreal are designed with the same procedure. In these buildings, lateral load resisting frames are located at every $32 \mathrm{~m}$ so the load combinations including the earthquake force will be more critical in design. Details of the steel sections and properties of these frames are shown in Table (3.10). 


\subsection{DBD of 12-story Concentrically-braced frame (CBF) building}

\subsubsection{Layout of the building}

The DBD of a 12-story CBF building is considered in this section. Geometry and arrangement of the lateral load resisting braced frames are shown in Figure (3.18a). Assumed hysterisis model of the bracing elements is presented in Figure (3.18b). It is assumed that these elements yield in tension and buckle in compression with zero strain hardening. The dead and live loads are identical to those of the steel frame building presented in Section 3.4.1. The total dead load works out to be $5.8 \mathrm{kN} / \mathrm{m}^{2}$ for both the floor and roof levels and the live load is comprised of snow on roof at $2.2 \mathrm{kN} / \mathrm{m}^{2}$, and floor load at $2.4 \mathrm{kN} / \mathrm{m}^{2}$. The following material properties are assumed: steel yield strength $f_{y}=350 \mathrm{MPa}$ Steel modulus of elasticity $\mathrm{E}=200,000 \mathrm{MPa}$ and performance factor for steel $\phi=0.9$.

The building is designed for earthquake forces in the N-S direction neglecting the accidental torsion effect. The contribution of simple (gravity) frames to lateral resistance is ignored. For each interior lateral load resisting frame (LLRF), the floor mass is equal to $125 \mathrm{t}$ at each floor, giving a total of $1500 \mathrm{t}$.

The P- $\Delta$ gravity loads are calculated using the reduced live load and applied to the structure using a procedure similar to that presented in Section 3.2.1

\subsubsection{Equivalent static procedure of NBCC 2005}

The design base shear according to NBCC 2005 is calculated as follows: 
Effective mass tributary to each frame, $M=1,500$ tonnes

$\mathrm{R}_{\mathrm{d}}=3.0, \mathrm{R}_{\mathrm{o}}=1.3 \quad$ (Moderately ductile concentrically braced frame, tension only)

$\mathrm{T}=0.05(\mathrm{H})^{3 / 4} \times 2.0=1.74 \mathrm{~s}$

Note that in braced frames, when the period obtained analytically is larger than the empirical period, which is true in this case, NBCC permits the use of a period equal to 2.0 times the empirical period but not larger than the analytical period. From UHS of Vancouver; the elastic spectral acceleration is

$\mathrm{S}_{\mathrm{a}}(1.74)=0.222 \mathrm{~g}$ and the base shear in each frame is given by

$$
V=\frac{S_{a} M_{1}}{R_{d} R_{o}}=\frac{0.222 \times 9.81 \times 1500}{3.0 \times 1.3}=838 \mathrm{kN}
$$

\subsubsection{Displacement Estimates}

The DBD is performed for two performance levels. Design for near collapse level is considered first. We assume that $\beta$ is equal to 0.45 for this building. Yield displacement at roof level is estimated using equations (2.11);

$$
\Delta_{y}=\frac{F_{y} l_{b}}{E \times \operatorname{Cos}(\theta)}\left(\frac{H}{h}\right) \beta=\frac{350 \times 879}{200000 \times 0.91} \times \frac{4500}{365} \times 0.45=9.38 \mathrm{~cm}
$$

In order to meet the code requirements, the maximum inter-story drift is taken as $2.5 \%$. The ultimate displacement at roof is thus given by

$\Delta_{u}^{R o o f}=\Delta_{u} \beta=0.025 \times 4500 \times 0.45=50.62 \mathrm{~cm}$

and the global displacement ductility requirement works out to 
$\mu=\frac{\Delta_{u}}{\Delta_{y}}=5.39$

In this case the global ductility capacity specified by the NBCC code $\left(R_{d}=3\right)$ governs.

\subsubsection{Equivalent SDOF system}

Assuming a linear displaced shape, the properties of the equivalent SDOF system are calculated as shown in Section 3.2.4;

$\mathrm{M}^{*}=1194$ tonnes

$\delta_{\mathrm{y}}=9.38 / 1.4378=6.52 \mathrm{~cm}$

$\delta_{u}=\mu \times \delta_{y}=3.0 \times 6.52=19.56 \mathrm{~cm}$

\subsubsection{Capacity and Demand Diagrams}

The inelastic spectrum or the demand diagram for a global ductility of 3.0 is shown in Figure (3.19). The spectral acceleration at yield is found to be $A_{y}=0.0494 \mathrm{~g}$, and the corresponding design base shear works out to;

$V_{b}=A_{y} M^{*}=0.0494 \times 9.81 \times 1194=580 \mathrm{kN}$

This shear is distributed across the height in proportion to the product of the floor mass, $W / g$, and the height of floor above the base, $h$. The resulting forces are given by:

$\mathbf{f}^{T}=V_{b} \times \frac{W h}{\sum W h}=\left\{\begin{array}{llllllllllll}10 & 17 & 24 & 30 & 38 & 45 & 52 & 58 & 66 & 73 & 80 & 87\end{array}\right\} k N$ 


\subsubsection{Design of braces}

A static analysis considering the P- $\Delta$ loads is carried out to obtain the earthquake forces in braces. Steel sections with a cross sectional area of $2280 \mathrm{~mm}^{2}$ (HSS $152 \times 102 \times 4.8$ ),

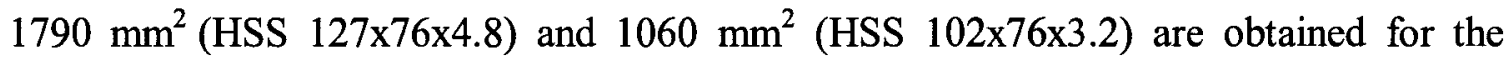
braces of stories 1-4, 5-8 and 9-12 respectively.

\subsubsection{Pushover Analysis}

A modal analysis of the preliminary design is now carried out. The following properties are obtained for the first mode taking into account the P- $\Delta$ effect.

$\mathrm{T}_{1}=3.25 \mathrm{~s}$

$\phi_{1}^{T}=\left\{\begin{array}{llllllllllll}0.115 & 0.197 & 0.279 & 0.359 & 0.464 & 0.563 & 0.654 & 0.736 & 0.831 & 0.908 & 0.965 & 1\end{array}\right\}$

$\Gamma_{1}=1.358$

$\mathrm{M}_{1}{ }^{*}=1200$ tonnes $\quad(80.0 \%$ of total mass $)$

Pushover analysis including P- $\Delta$ effect is carried out for forces distributed according to Equation (2.27). In the prepared finite element model, tension-only truss elements are used for bracings and once a minor compressive force is developed in these elements they buckle and become ineffective in the model. The resulting pushover curve is shown in Figure (3.20). The capacity of the structure is seen to be $430 \mathrm{kN}$. On the descending branch of the pushover curve the lateral strength reaches $95 \%$ of its maximum value at 
$\Delta=16.0 \mathrm{~cm}$. This displacement becomes the governing value of the ultimate roof displacement. A bi-linear idealization of the pushover curve gives $\Delta_{\mathrm{y}}=13.0 \mathrm{~cm}$.

\subsubsection{Subsequent Design Iterations}

Based on the results obtained from pushover analysis the system ductility capacity works out to $\mu=16.0 / 13.0=1.23$ and the updated yield and the ultimate displacements for the equivalent SDOF system are,

$\delta_{\mathrm{y}}=13.0 / 1.358=9.6 \mathrm{~cm}$

$\delta_{\mathrm{u}}=16.0 / 1.358=11.8 \mathrm{~cm}$

The revised capacity and demand curves are shown in Figure (3.21). The spectral acceleration at yield is found to be $0.24 \mathrm{~g}$, and the corresponding design base shear works out to,

$V_{b}=A_{y} M^{*}=0.24 \times 9.81 \times 1200=2825 \mathrm{kN}$

Due to the drastic change in the design base shear, design procedure should be repeated.

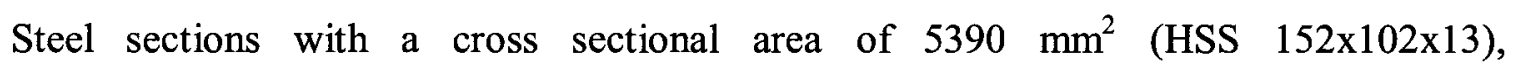
$4240 \mathrm{~mm}^{2}$ (HSS $152 \times 102 \times 9.5$ ) and $2960 \mathrm{~mm}^{2}$ (HSS $152 \times 102 \times 6.4$ ) are selected for the braces of stories 1-4, 5-8 and 9-12 respectively. It should be noted that braces of the first story are not sufficient for the calculated base shear, however since it is expected that the demand base shear will be lower in the next step, weaker sections are chosen. Modal analysis of the revised taking into account the P- $\Delta$ effect gives the following properties for the first mode, 
$\mathrm{T}_{1}=2.25 \mathrm{~s}$

$\phi_{1}^{T}=\left\{\begin{array}{llllllllllll}0.080 & 0.152 & 0.229 & 0.309 & 0.405 & 0.500 & 0.591 & 0.678 & 0.779 & 0.868 & 0.942 & 1\end{array}\right\}$

$\Gamma_{1}=1.406$

$\mathrm{M}_{1}{ }^{*}=1148$ tonnes $\quad(76.5 \%$ of total mass $)$

The resulting pushover curve and the Inter-story drift curves are shown in Figures (3.22) and (3.23) respectively. At $\Delta=26.0 \mathrm{~cm}$ the inter-story drift of $5^{\text {th }}$ story reaches the $2.5 \%$ limit so this displacement becomes the governing value of the ultimate roof displacement. A bi-linear idealization of the pushover curve gives $\Delta_{\mathrm{y}}=18.5 \mathrm{~cm}$. Based on the results obtained from pushover analysis the system ductility capacity works out to $\mu=26.0 / 18.5=1.405$ and the updated yield and the ultimate displacements for the equivalent SDOF system are,

$\delta_{\mathrm{y}}=18.5 / 1.406=13.2 \mathrm{~cm}$

$\delta_{\mathrm{u}}=26.0 / 1.406=18.5 \mathrm{~cm}$

The revised capacity and demand curves are shown in Figure (3.24). The spectral acceleration at yield is found to be $0.122 \mathrm{~g}$, and the corresponding design base shear works out to,

$V_{b}=A_{y} M^{*}=0.122 \times 9.81 \times 1148=1374 \mathrm{kN}$

The selected braces are sufficient to carry the induced earthquake forces due to this demand base shear, thus the design process is converged. 
In order to calculate the performance of the structure in the first mode, capacity diagram of the equivalent SDOF system is obtained by dividing the base shear value in the pushover curve by $\mathrm{M}^{*} \mathrm{~g}$,

$A_{y}=V_{y} / M^{*} g=1500 /(1148 * 9.81)=0.133 g$

Substituting the period of the structure, $T=2.25$ in Equation (2.35), the demand acceleration from the elastic design spectrum for Vancouver is calculated,

$\mathrm{S}_{\mathrm{a}}(2.25)=2 \times 0.18 \mathrm{~g} / 2.25=0.16 \mathrm{~g}$

The demand force reduction factor is,

$\mathrm{R}=\mathrm{S}_{\mathrm{a}} / \mathrm{A}_{\mathrm{y}}=0.16 / 0.133=1.2$

The demand global ductility calculated using Equations (2.37) and (2.38) works out to $\mu_{\text {Demand }}=1.2$, which is less than the system ductility capacity of 1.405 , and is therefore satisfactory.

The demand roof displacement in the first mode works out to,

$\Delta_{1}^{\text {Roof }}=\mu_{\text {Demand }} \times \Delta_{\mathrm{y}}=1.2 \times 18.5=22.2 \mathrm{~cm}$

\subsubsection{Multi-Mode Pushover Analysis}

The mass participation in the first mode is $76.5 \%$ of the total mass. In the present example only two modes need to be included in order to capture $90 \%$ mass participation. A dynamic analysis of the designed structure gives the vibration period and mode shape for mode 2 , 
$\mathrm{T}_{2}=0.75 \mathrm{~s}$

$\phi_{2}{ }^{\mathrm{T}}=\{0.325,0.561,0.744,0.856,0.902,0.841,0.680,0.436,0.027,-0.392,-0.754,-1\}$

$\Gamma_{2}=0.576$

$\mathrm{M}_{2}{ }^{*}=232.0$ tonnes $\quad(15.5 \%$ of total mass $)$

From the elastic design spectrum of Vancouver, displacement of the SDOF system with a period of $0.75 \mathrm{~s}$ is obtained and then the demand roof displacement is calculated,

$\delta(0.75)=\mathrm{S}_{\mathrm{a}}(0.75) \times(0.75)^{2} / 4 \pi^{2}=6.98 \mathrm{~cm}$

$\Delta_{2}^{\mathrm{Roof}}=\delta \times \Gamma_{2}=6.98 \times 0.576=4.0 \mathrm{~cm}$

The total mass for first 2 modes is $92.0 \%$, thus no additional modes need be included. For both modes, a pushover analysis using the lateral force distribution of Equation (2.27) is carried out. The calculated demand roof displacements are considered as the target displacements and the inter-story drifts, bracing tensile forces corresponding to the target displacement are extracted. As expected, in the $2^{\text {nd }}$ mode, the structure remains elastic until the demand displacement is reached. Results for the inter-story drifts and bracing forces are discussed next.

\section{Inter-story drifts}

Table (3.15) shows the inter-story drifts in the first 2 modes as well as their SRSS combination. Contribution of the second mode in some stories is major however; the drifts are still within the acceptable limit of $2.5 \%$. 


\section{Tensile forces in bracings}

Tensile forces in bracings in first and second modes and also their SRSS combinations are presented in Table (3.16). Plastic tensile forces of the designed bracings are equal to 1700,1336 and $932 \mathrm{kN}$ in stories $1-4,5-8$ and $9-12$ respectively. Where the modal combination values exceeded the bracing plastic tensile force, they are replaced by the latter value, as is the case in stories $1,2,3,5,9$ and 10.

In the first mode, bracing of the $5^{\text {th }}$ story yields. When the roof displacement reaches its demand value, the yield and plastic elongation of the this bracing will be equal to $\Delta_{\mathrm{y}}=13.85$ and $\Delta_{\mathrm{p}}=30.44 \mathrm{~mm}$ respectively. The displacement ductility demand for this bracing is calculated as follows,

$\mu_{\text {DEMAND }}=\left(\Delta_{\mathrm{P}}+\Delta_{\mathrm{y}}\right) / \Delta_{\mathrm{y}}=(13.85+30.44) / 13.85=3.2$

The displacement ductility capacity is obtained from Table (2.2). Considering the bracing as primary element and for the life safety objective, the displacement ductility capacity for braces in tension is equal to,

$\mu_{\text {CAPACITY }}=8$

It could be shown that in all braces the demand is less than the capacity, thus design of the bracings is considered satisfactory. 


\subsubsection{Operational level performance}

For the first mode period of $2.25 \mathrm{~s}$, the demand acceleration obtained using Equation (2.35) is equal to,

$\mathrm{S}_{\mathrm{a}}(2.25)=2 \times 0.034 \mathrm{~g} / 2.25=0.03 \mathrm{~g}$

$\mathrm{V}=\mathrm{S}_{\mathrm{a}} \mathrm{M}=0.03 \times 9.81 \times 1500=441 \mathrm{kN}$

Referring to the pushover curve of Figure (3.22), the corresponding roof displacement for the calculated base shear is equal to $5.0 \mathrm{~cm}$. At this roof displacement the maximum inter-story drift reaches $0.14 \%$ as shown in Figure (3.23), which is less than the $0.5 \%$ limit. Thus, the design is satisfactory. 
Table (3.1): Results of the Static Analysis for design of 12-story RC frame in Vancouver

\begin{tabular}{|c|c|c|c|c|c|c|}
\hline & \multicolumn{2}{|c|}{$1.25 \mathrm{D}+1.5 \mathrm{~L}$} & \multicolumn{2}{|c|}{$\mathrm{D}+0.5 \mathrm{~L}+\mathrm{E}$} \\
\hline & & & $\mathrm{P}(\mathrm{kN})$ & $\mathrm{M}(\mathrm{kN}-\mathrm{m})$ & $\mathrm{P}(\mathrm{kN})$ & $\mathrm{M}(\mathrm{kN}-\mathrm{m})$ \\
\hline \multirow{12}{*}{ Columns } & \multirow{6}{*}{ Interior } & $1-2$ & 7503 & 1 & 5261 & 1329 \\
\hline & & $3-4$ & 6258 & 12 & 4367 & 664 \\
\hline & & $5-6$ & 5022 & 25 & 3492 & 627 \\
\hline & & $7-8$ & 3791 & 18 & 2618 & 490 \\
\hline & & $9-10$ & 2556 & 22 & 1748 & 381 \\
\hline & & $11-12$ & 1327 & 29 & 876 & 237 \\
\hline & \multirow{6}{*}{ Exterior } & $1-2$ & 3857 & 258 & 3891 & 1305 \\
\hline & & $3-4$ & 3231 & 222 & 3191 & 528 \\
\hline & & $5-6$ & 2596 & 291 & 2453 & 494 \\
\hline & & $7-8$ & 1957 & 230 & 1738 & 426 \\
\hline & & $9-10$ & 1321 & 233 & 1084 & 370 \\
\hline & & $11-12$ & 679 & 437 & 500 & 348 \\
\hline \multirow{12}{*}{ Beams } & \multirow{6}{*}{ Middle Span } & $1-2$ & - & 416 & - & 867 \\
\hline & & $3-4$ & - & 416 & - & 820 \\
\hline & & $5-6$ & - & 415 & - & 757 \\
\hline & & $7-8$ & - & 415 & - & 700 \\
\hline & & $9-10$ & - & 414 & - & 530 \\
\hline & & $11-12$ & - & 474 & - & 400 \\
\hline & \multirow{6}{*}{ Side Spans } & $1-2$ & - & 410 & - & 877 \\
\hline & & $3-4$ & - & 438 & - & 892 \\
\hline & & $5-6$ & - & 446 & - & 847 \\
\hline & & $7-8$ & - & 436 & - & 752 \\
\hline & & $9-10$ & - & 441 & - & 537 \\
\hline & & $11-12$ & - & 462 & - & 429 \\
\hline
\end{tabular}


Table (3.2): Inter-story drifts (\%)

\begin{tabular}{|c|c|c|c|c|}
\hline Story & Mode 1 & Mode 2 & Mode 3 & SRSS \\
\hline 1 & 1.54 & 0.30 & 0.11 & 1.57 \\
\hline 2 & 1.75 & 0.53 & 0.16 & 1.84 \\
\hline 3 & 1.57 & 0.49 & 0.09 & 1.65 \\
\hline 4 & 1.32 & 0.36 & 0.02 & 1.37 \\
\hline 5 & 1.21 & 0.20 & 0.16 & 1.24 \\
\hline 6 & 1.05 & 0.06 & 0.25 & 1.08 \\
\hline 7 & 1.06 & 0.36 & 0.26 & 1.15 \\
\hline 8 & 1.08 & 0.62 & 0.18 & 1.26 \\
\hline 9 & 1.13 & 0.94 & 0.03 & 1.47 \\
\hline 10 & 0.88 & 0.96 & 0.27 & 1.33 \\
\hline 11 & 0.61 & 0.77 & 0.37 & 1.05 \\
\hline 12 & 0.34 & 0.46 & 0.27 & 0.63 \\
\hline
\end{tabular}


Table (3.3): Story Shears $(\mathrm{kN})$

\begin{tabular}{|c|c|c|c|c|}
\hline Story & Mode 1 & Mode 2 & Mode 3 & SRSS \\
\hline 1 & 1618 & 1066 & 423 & 1983 \\
\hline 2 & 1603 & 995 & 341 & 1917 \\
\hline 3 & 1567 & 832 & 171 & 1782 \\
\hline 4 & 1508 & 584 & 48 & 1618 \\
\hline 5 & 1426 & 274 & 256 & 1474 \\
\hline 6 & 1320 & 70 & 376 & 1374 \\
\hline 7 & 1193 & 392 & 361 & 1307 \\
\hline 8 & 1048 & 645 & 212 & 1249 \\
\hline 9 & 879 & 798 & 30 & 1188 \\
\hline 10 & 685 & 798 & 259 & 1083 \\
\hline 11 & 471 & 643 & 348 & 870 \\
\hline 12 & 244 & 365 & 248 & 504 \\
\hline
\end{tabular}


Table (3.4a): Moments and plastic hinge rotations - middle span beam, Positive Moment (moments in $\mathrm{kN}-\mathrm{m}$ and rotations in radians)

\begin{tabular}{|c|c|c|c|c|c|c|c|c|c|}
\hline $\begin{array}{c}(1) \\
\text { Story }\end{array}$ & $\begin{array}{c}(2) \\
\text { Gravity }\end{array}$ & $\begin{array}{c}\text { Mode1 } \\
\text { and } \\
\text { Gravity }\end{array}$ & $\begin{array}{c}(4) \\
\text { Mode1 } \\
(3)-(2)\end{array}$ & $\begin{array}{c}(5) \\
\text { Mode2 } \\
\text { and } \\
\text { Gravity }\end{array}$ & $\begin{array}{c}(6) \\
\text { Mode2 } \\
(5)-(2)\end{array}$ & $\begin{array}{c}(7) \\
\text { Mode3 } \\
\text { and } \\
\text { Gravity }\end{array}$ & $\begin{array}{c}(8) \\
\text { Mode3 } \\
(7)-(2)\end{array}$ & $\begin{array}{c}(9) \\
\text { SRSS } \\
\text { Moment }\end{array}$ & $\begin{array}{c}(10) \\
\text { Total } \\
\text { Moment } \\
(9)+(2)\end{array}$ \\
\hline 1 & -295 & $\begin{array}{c}800 \\
\theta=6.06 \mathrm{E}-3\end{array}$ & - & $-778^{* *} / 188$ & \pm 483 & $-129 /-461$ & \pm 166 & - & 800 \\
\hline 2 & -295 & $\begin{array}{c}800 \\
\theta=4.86 \mathrm{E}-3\end{array}$ & - & $-810 / 222$ & \pm 515 & $-162 /-422$ & \pm 133 & - & 800 \\
\hline 3 & -295 & $\begin{array}{c}800 \\
\theta=2.63 \mathrm{E}-3\end{array}$ & - & $-717 / 129$ & \pm 422 & $-260 /-328$ & \pm 35 & - & 800 \\
\hline 4 & -295 & 799 & 1094 & $-565 /-21$ & \pm 570 & $-366 /-221$ & \pm 71 & 1235 & 800 \\
\hline 5 & -295 & 624 & 919 & $-345 /-241$ & \pm 50 & $-467 /-120$ & \pm 172 & 936 & 641 \\
\hline 6 & -295 & 555 & 850 & $-129 /-457$ & \pm 166 & $-503 /-80$ & \pm 208 & 890 & 596 \\
\hline 7 & -295 & 373 & 668 & $11 /-598$ & \pm 306 & $-438 /-150$ & \pm 143 & 749 & 453 \\
\hline 8 & -295 & 312 & 607 & $121 / 707$ & \pm 416 & $-352 /-235$ & \pm 57 & 738 & 443 \\
\hline 9 & -295 & 183 & 478 & $164 /-750$ & \pm 459 & $-217 /-364$ & \pm 78 & 667 & 372 \\
\hline 10 & -295 & 65 & 360 & $128 /-716$ & \pm 423 & $-134 /-452$ & \pm 161 & 578 & 283 \\
\hline 11 & -295 & -59 & 237 & $7 /-589$ & \pm 302 & $-132 /-450$ & \pm 163 & 417 & 122 \\
\hline 12 & -295 & -185 & 110 & $-158 /-426$ & \pm 137 & $-211 /-372$ & \pm 84 & 195 & -100 \\
\hline
\end{tabular}

*Maximum positive moment capacity is $800 \mathrm{kN}-\mathrm{m}$ for 6 lower story beams, $529 \mathrm{kN}-\mathrm{m}$ for beams of stories 7 to 9 and $384 \mathrm{kN}-\mathrm{m}$ for beams of stories 10 to 12 .

**Maximum negative moment capacity is $1287 \mathrm{kN}$-m for 6 lower story beams, $1035 \mathrm{kN}$ $\mathrm{m}$ for beams of stories 7 to 9 and $724 \mathrm{kN}-\mathrm{m}$ for beams of stories 10 to 12 . 
Table (3.4b): Moments and plastic hinge rotations - middle span beam, Negative Moment (moments in $\mathrm{kN}-\mathrm{m}$ and rotations in radians)

\begin{tabular}{|c|c|c|c|c|c|c|c|c|c|}
\hline $\begin{array}{l}(1) \\
\text { Story }\end{array}$ & $\begin{array}{c}(2) \\
\text { Gravity }\end{array}$ & $\begin{array}{c}(3) \\
\text { Model } \\
\text { and } \\
\text { Gravity } \\
\end{array}$ & $\begin{array}{c}(4) \\
\text { Mode1 } \\
(3)-(2)\end{array}$ & $\begin{array}{c}(5) \\
\text { Mode2 } \\
\text { and } \\
\text { Gravity } \\
\end{array}$ & $\begin{array}{c}(6) \\
\text { Mode2 } \\
(5)-(2)\end{array}$ & $\begin{array}{c}(7) \\
\text { Mode3 } \\
\text { and } \\
\text { Gravity } \\
\end{array}$ & $\begin{array}{c}(8) \\
\text { Mode3 } \\
(7)-(2)\end{array}$ & $\begin{array}{c}(9) \\
\text { SRSS } \\
\text { Moment }\end{array}$ & $\begin{array}{l}(10) \\
\text { Total } \\
\text { Moment } \\
(9)+(2)\end{array}$ \\
\hline 1 & -295 & $\begin{array}{c}-1287 \\
\theta=8.54 \mathrm{E}-3 \\
\end{array}$ & - & $-778 / 188$ & \pm 483 & $-129 /-461 \mid$ & \pm 166 & - & -1287 \\
\hline 2 & -295 & $\begin{array}{c}-1287 \\
\theta=7.36 \mathrm{E}-3\end{array}$ & - & $-810 / 222$ & \pm 515 & $-162 /-422$ & \pm 133 & - & -1287 \\
\hline 3 & -295 & $\begin{array}{c}-1287 \\
\theta=5.12 \mathrm{E}-3\end{array}$ & - & $-717 / 129$ & \pm 422 & $-260 /-328$ & \pm 35 & - & -1287 \\
\hline 4 & -295 & $\begin{array}{c}-1287 \\
\theta=2.49 \mathrm{E}-3\end{array}$ & - & $-565 /-21$ & \pm 570 & $-366 /-221$ & \pm 71 & - & -1287 \\
\hline 5 & -295 & -1212 & -917 & $-345 /-241$ & \pm 50 & $-467 /-120$ & \pm 172 & -934 & -1229 \\
\hline 6 & -295 & -1139 & -884 & $-129 /-457$ & \pm 166 & $-503 /-80$ & \pm 208 & -923 & -1218 \\
\hline 7 & -295 & -960 & -665 & $11 /-598$ & \pm 306 & $-438 /-150$ & \pm 143 & -746 & $-1035^{\mathrm{P}}$ \\
\hline 8 & -295 & -898 & -603 & $121 / 707$ & \pm 416 & $-352 /-235$ & \pm 57 & -735 & -1030 \\
\hline 9 & -295 & -769 & -474 & $164 /-750$ & \pm 459 & $-217 /-364$ & \pm 78 & -664 & -959 \\
\hline 10 & -295 & -651 & -356 & $128 /-716$ & \pm 423 & $-134 /-452$ & \pm 161 & -576 & $-724^{P}$ \\
\hline 11 & -295 & -523 & -228 & $7 /-589$ & \pm 302 & $-132 /-450$ & \pm 163 & -412 & -707 \\
\hline 12 & -295 & -397 & -104 & $-158 /-426$ & \pm 137 & $-211 /-372$ & \pm 84 & -191 & -486 \\
\hline
\end{tabular}


Table (3.5): Shear Forces - middle span beam, j-end (Forces in $\mathrm{kN}$ )

\begin{tabular}{|c|c|c|c|c|c|c|c|c|c|}
\hline $\begin{array}{c}(1) \\
\text { Story }\end{array}$ & $\begin{array}{c}(2) \\
\text { Gravity }\end{array}$ & $\begin{array}{c}\text { Mode1 } \\
\text { and } \\
\text { Gravity }\end{array}$ & $\begin{array}{c}(4) \\
\text { Mode1 } \\
(3)-(2)\end{array}$ & $\begin{array}{c}\text { Mode2 } \\
\text { and } \\
\text { Gravity }\end{array}$ & $\begin{array}{c}(6) \\
\text { Mode2 } \\
(5)-(2)\end{array}$ & $\begin{array}{c}\text { Mode3 } \\
\text { and } \\
\text { Gravity }\end{array}$ & $\begin{array}{c}(8) \\
\text { Mode1 } \\
(7)-(2)\end{array}$ & $\begin{array}{c}\text { SRSS } \\
\text { Shear }\end{array}$ & $\begin{array}{c}\text { Total } \\
\text { Shear } \\
(9)+(2)\end{array}$ \\
\hline 1 & 221 & $* *$ & - & - & - & - & - & - & 482 \\
\hline 2 & 221 & $* *$ & - & - & - & - & - & - & 482 \\
\hline 3 & 221 & $* *$ & - & - & - & - & - & - & 482 \\
\hline 4 & 221 & $* *$ & - & - & - & - & - & - & 482 \\
\hline 5 & 221 & 451 & 230 & 208 & -13 & 178 & -43 & 234 & 455 \\
\hline 6 & 221 & 433 & 212 & 263 & 42 & 168 & -53 & 223 & 444 \\
\hline 7 & 221 & $*$ & - & - & - & - & - & - & 407 \\
\hline 8 & 221 & 372 & 151 & 324 & 103 & 207 & -14 & 183 & 404 \\
\hline 9 & 221 & 340 & 119 & 336 & 115 & 240 & 19 & 167 & 388 \\
\hline 10 & 221 & $*$ & - & - & - & - & - & - & 347 \\
\hline 11 & 221 & 279 & 58 & 296 & 75 & 261 & 40 & 103 & 324 \\
\hline 12 & 221 & 245 & 69 & 252 & 31 & 239 & 18 & 78 & 299 \\
\hline
\end{tabular}

* Plastic hinge at one end

** Plastic hinge at both ends

The shear force in above cases is calculated using, $\mathrm{V}_{\text {TOTAL }}=\left(\mathrm{M}_{\mathrm{I}}+\mathrm{M}_{\mathrm{J}}\right) / \mathrm{L}+\mathrm{V}_{\mathrm{GRAVTT}}$ 
Table (3.6): Moments and plastic hinge rotations - the interior column (moments in $\mathrm{kN}-\mathrm{m}$ and rotations in radians)

\begin{tabular}{|c|c|c|c|c|c|c|c|c|c|}
\hline $\begin{array}{c}(1) \\
\text { Story }\end{array}$ & $\begin{array}{c}(2) \\
\text { Gravity }\end{array}$ & $\begin{array}{c}\text { Mode1 } \\
\text { and } \\
\text { Gravity }\end{array}$ & $\begin{array}{c}(4) \\
\text { Model } \\
(3)-(2)\end{array}$ & $\begin{array}{c}\text { Mode2 } \\
\text { and } \\
\text { Gravity }\end{array}$ & $\begin{array}{c}(6) \\
\text { Mode2 } \\
(5)-(2)\end{array}$ & $\begin{array}{c}\text { Mode3 } \\
\text { and } \\
\text { Gravity }\end{array}$ & $\begin{array}{c}(8) \\
\text { Mode1 } \\
(7)-(2)\end{array}$ & $\begin{array}{c}(9) \\
\text { SRSS } \\
\text { Moment }\end{array}$ & $\begin{array}{c}\text { Total } \\
\text { Moment } \\
(9)+(2)\end{array}$ \\
\hline 1 & 0 & $\begin{array}{c}1933^{*} \\
\theta=1.165 \mathrm{E}-2\end{array}$ & - & -1179 & - & 440 & - & - & 1933 \\
\hline 2 & 1 & 1017 & 1016 & -635 & -636 & 184 & 183 & 1213 & 1214 \\
\hline 3 & 6 & 884 & 878 & -575 & -581 & 49 & 43 & 1054 & 1060 \\
\hline 4 & 11 & 849 & 838 & -272 & -283 & -87 & -98 & 890 & 901 \\
\hline 5 & 9 & 823 & 814 & -82 & 91 & -178 & -187 & 840 & 849 \\
\hline 6 & 13 & 845 & 832 & 137 & 124 & -230 & -243 & 876 & 889 \\
\hline 7 & 16 & 843 & 827 & 371 & 355 & -208 & -224 & 927 & 943 \\
\hline 8 & 14 & 660 & 646 & 487 & 473 & -69 & -83 & 805 & 819 \\
\hline 9 & 9 & 509 & 500 & 495 & 486 & 62 & 53 & 699 & 708 \\
\hline 10 & 9 & 405 & 396 & 487 & 478 & 183 & 174 & 645 & 654 \\
\hline 11 & 12 & 266 & 254 & 362 & 350 & 213 & 201 & 477 & 489 \\
\hline 12 & 11 & 137 & 126 & 195 & 184 & 139 & 128 & 257 & 268 \\
\hline
\end{tabular}

* Maximum moment capacity of the first story column at the gravity axial load of $5331 \mathrm{kN}$ is equal to $1933 \mathrm{kN}-\mathrm{m}$. 
Table (3.7): Dimensions and Properties of the RC frames located in Vancouver and Designed with the proposed DBD method

\begin{tabular}{|c|c|c|c|c|c|c|c|c|c|}
\hline \multirow{2}{*}{$\begin{array}{l}\text { No. of } \\
\text { Stories }\end{array}$} & \multirow{2}{*}{ Height, m } & \multirow{2}{*}{$\begin{array}{c}\text { Total } \\
\text { mass, } \mathrm{t}\end{array}$} & \multirow{2}{*}{ Periods, S } & \multirow{2}{*}{ Stories } & \multicolumn{2}{|c|}{ Columns } & \multirow{2}{*}{ Stories } & \multicolumn{2}{|r|}{ Beams } \\
\hline & & & & & Size, $\mathrm{mm}$ & Reinforcements & & Size, $\mathrm{mm}$ & Reinforcements \\
\hline \multirow{2}{*}{6} & \multirow{2}{*}{$\begin{array}{c}\text { Total }=23 \\
\text { 1st level }=4.75 \\
\text { upper levels }=3.65\end{array}$} & \multirow{2}{*}{1604} & \multirow{2}{*}{$\begin{array}{l}\mathrm{T} 1=2.67 \\
\mathrm{~T} 2=0.87\end{array}$} & $1-3$ & $600 \times 600$ & 12 No. 25 bars & $1-3$ & $h=600 b=400$ & $\begin{array}{c}4 \text { No. } 30 \& 2 \text { No. } 25 \text { Top } \\
4 \text { No. } 25 \text { Bottom }\end{array}$ \\
\hline & & & & $4-6$ & $500 \times 500$ & 8 No. 25 bars & $4-6$ & $h=600 b=400$ & $\begin{array}{l}2 \text { No. } 35 \& 2 \text { No. } 30 \text { Top } \\
4 \text { No. } 20 \text { Bottom }\end{array}$ \\
\hline \multirow{4}{*}{12} & \multirow{4}{*}{$\begin{array}{c}\text { Total }=45 \\
1 \text { st level }=4.85 \\
\text { upper levels }=3.65\end{array}$} & \multirow{4}{*}{3343} & \multirow{4}{*}{$\begin{array}{l}\mathrm{T} 1=4.21 \\
\mathrm{~T} 2=1.54 \\
\mathrm{~T} 3=0.87\end{array}$} & 1 & $800 \times 800$ & 12 No. 35 bars & $1-6$ & $h=700 \mathrm{~b}=400$ & $\begin{array}{c}6 \text { No. } 35 \& 2 \text { No. } 30 \text { Top } \\
4 \text { No. } 30 \text { Bottom }\end{array}$ \\
\hline & & & & $2-4$ & $700 \times 700$ & 12 No. 30 bars & $7-9$ & $h=600 b=400$ & $\begin{array}{c}6 \text { No. } 35 \& 2 \text { No. } 30 \text { Top } \\
4 \text { No. } 30 \text { Bottom }\end{array}$ \\
\hline & & & & $5-8$ & $600 \times 600$ & 12 No. 30 bars & \multirow[b]{2}{*}{$10-12$} & \multirow[b]{2}{*}{$h=600 \mathrm{~b}=400$} & \multirow{2}{*}{$\begin{array}{c}6 \text { No. } 30 \& 4 \text { No. } 25 \text { Top } \\
4 \text { No. } 25 \text { Bottom }\end{array}$} \\
\hline & & & & $9-12$ & $500 \times 500$ & $\begin{array}{c}8 \text { No. } 25 \& \\
4 \text { No. } 20 \text { bars } \\
\end{array}$ & & & \\
\hline \multirow{4}{*}{15} & \multirow{4}{*}{$\begin{array}{c}\text { Total }=56 \\
1 \text { st level }=4.90 \\
\text { upper levels }=3.65\end{array}$} & \multirow{4}{*}{4176} & \multirow{4}{*}{$\begin{array}{l}\mathrm{T} 1=5.16 \\
\mathrm{~T} 2=1.89 \\
\mathrm{~T} 3=1.10\end{array}$} & $1-2$ & $900 \times 900$ & 12 No. 35 bars & $1-7$ & $\mathrm{~h}=700 \mathrm{~b}=400$ & $\begin{array}{c}6 \text { No. } 35 \& 2 \text { No. } 30 \text { Top } \\
4 \text { No. } 30 \text { Bottom }\end{array}$ \\
\hline & & & & $3-6$ & $800 \times 800$ & 12 No. 35 bars & $8-11$ & $h=600 \mathrm{~b}=400$ & $\begin{array}{c}6 \text { No. } 35 \& 2 \text { No. } 30 \text { Top } \\
4 \text { No. } 30 \text { Bottom }\end{array}$ \\
\hline & & & & $7-11$ & $600 \times 600$ & 12 No. 30 bars & \multirow{2}{*}{$12-15$} & \multirow{2}{*}{$h=600 b=400$} & 4 No. $30 \& 4$ No. 25 Top \\
\hline & & & & $12-15$ & $500 \times 500$ & 12 No. 25 bars & & & 4 No. 25 Bottom \\
\hline \multirow{4}{*}{20} & \multirow{4}{*}{$\begin{array}{c}\text { Total }=74 \\
\text { 1st level }=4.65 \\
\text { upper levels }=3.65\end{array}$} & \multirow{4}{*}{5577} & \multirow{4}{*}{$\begin{array}{l}\mathrm{T} 1=6.00 \\
\mathrm{~T} 2=2.27 \\
\mathrm{~T} 3=1.33\end{array}$} & $1-3$ & $900 \times 900$ & 20 No. 30 bars & $1-6$ & $\mathrm{~h}=800 \mathrm{~b}=500$ & $\begin{array}{c}6 \text { No. } 35 \text { \& } 2 \text { No. } 30 \text { Top } \\
4 \text { No. } 30 \text { Bottom }\end{array}$ \\
\hline & & & & $4-11$ & $800 \times 800$ & 12 No. 35 bars & $7-12$ & $h=700 b=400$ & $\begin{array}{c}6 \text { No. } 35 \& 2 \text { No. } 30 \text { Top } \\
4 \text { No. } 30 \text { Bottom }\end{array}$ \\
\hline & & & & $12-16$ & $600 \times 600$ & 12 No. 30 bars & $13-16$ & $h=600 b=400$ & $\begin{array}{c}6 \text { No. } 35 \& 2 \text { No. } 30 \text { Top } \\
4 \text { No. } 30 \text { Bottom }\end{array}$ \\
\hline & & & & $17-20$ & $500 \times 500$ & 12 No. 25 bars & $17-20$ & $\mathrm{~h}=600 \mathrm{~b}=400$ & $\begin{array}{c}4 \text { No. } 30 \& 4 \text { No. } 25 \text { Top } \\
4 \text { No. } 25 \text { Bottom }\end{array}$ \\
\hline
\end{tabular}

- Lateral load resisting frames are located at $16 \mathrm{~m}$ spacing and gravity load frames at every $8 \mathrm{~m}$ as shown in Figure (3.1a) 
Table (3.8): Dimensions and Properties of the RC frames located in Montreal and Designed with the proposed DBD method

\begin{tabular}{|c|c|c|c|c|c|c|c|c|c|}
\hline \multirow{2}{*}{$\begin{array}{l}\text { No. of } \\
\text { Stories }\end{array}$} & \multirow{2}{*}{ Height, $m$} & \multirow{2}{*}{$\begin{array}{c}\text { Total } \\
\text { mass, } \mathrm{t}\end{array}$} & \multirow{2}{*}{ Periods, S } & \multirow{2}{*}{ Stories } & \multicolumn{2}{|c|}{ Columns } & \multirow{2}{*}{ Stories } & \multicolumn{2}{|r|}{ Beams } \\
\hline & & & & & Size, $\mathrm{mm}$ & Reinforcements & & Size, $\mathrm{mm}$ & Reinforcements \\
\hline \multirow{2}{*}{6} & \multirow{2}{*}{$\begin{array}{c}\text { Total }=23 \\
\text { 1st level }=4.75 \\
\text { upper levels }=3.65\end{array}$} & \multirow{2}{*}{3209} & \multirow{2}{*}{$\begin{array}{l}\mathrm{T} 1=3.72 \\
\mathrm{~T} 2=1.25\end{array}$} & $1-3$ & $600 \times 600$ & 8 No. 30 bars & $1-3$ & $h=600 b=400$ & $\begin{array}{c}2 \text { No. } 35 \text { \& } 2 \text { No. } 30 \text { Top } \\
4 \text { No. } 20 \text { Bottom }\end{array}$ \\
\hline & & & & $4-6$ & $500 \times 500$ & 8 No. 25 bars & $4-6$ & $h=600 \mathrm{~b}=400$ & \begin{tabular}{|c|}
4 No. 30 Top \\
4 No. 20 Bottom \\
\end{tabular} \\
\hline \multirow{4}{*}{12} & \multirow{4}{*}{$\begin{array}{c}\text { Total }=45 \\
\text { 1st level }=4.85 \\
\text { upper levels }=3.65\end{array}$} & \multirow{4}{*}{6686} & \multirow{4}{*}{$\begin{array}{l}\mathrm{T} 1=6.86 \\
\mathrm{~T} 2=2.33 \\
\mathrm{~T} 3=1.33\end{array}$} & 1 & $800 \times 800$ & 12 No. 30 bars & $1-6$ & $h=600 b=400$ & $\begin{array}{c}6 \text { No. } 35 \text { \& } 2 \text { No. } 30 \text { Top } \\
4 \text { No. } 30 \text { Bottom }\end{array}$ \\
\hline & & & & $2-4$ & $700 \times 700$ & 12 No. 25 bars & $7-9$ & $h=600 b=400$ & $\begin{array}{c}4 \text { No. } 30 \& 4 \text { No. } 25 \text { Top } \\
4 \text { No. } 25 \text { Bottom }\end{array}$ \\
\hline & & & & $5-8$ & $600 \times 600$ & 12 No. 25 bars & \multirow{2}{*}{$10-12$} & \multirow{2}{*}{$h=600 \mathrm{~b}=400$} & 2 No. $35 \& 2$ No. 30 Top \\
\hline & & & & $9-12$ & $500 \times 500$ & 8 No. 25 bars & & & 4 No. 25 Bottom \\
\hline \multirow{4}{*}{15} & \multirow{4}{*}{$\begin{array}{c}\text { Total }=56 \\
\text { 1st level }=4.90 \\
\text { upper levels }=3.65\end{array}$} & \multirow{4}{*}{8348} & \multirow{4}{*}{$\begin{array}{l}\mathrm{T} 1=7.32 \\
\mathrm{~T} 2=2.69 \\
\mathrm{~T} 3=1.56\end{array}$} & $1-2$ & $900 \times 900$ & $\begin{array}{c}4 \text { No. } 35 \& \\
8 \text { No. } 30 \text { bars }\end{array}$ & $1-7$ & $\mathrm{~h}=700 \mathrm{~b}=400$ & $\begin{array}{c}6 \text { No. } 30 \& 2 \text { No. } 35 \text { Top } \\
4 \text { No. } 30 \text { Bottom }\end{array}$ \\
\hline & & & & $3-6$ & $800 \times 800$ & $\begin{array}{c}4 \text { No. } 35 \& \\
8 \text { No. } 30 \text { bars }\end{array}$ & $8-11$ & $\mathrm{~h}=600 \mathrm{~b}=400$ & $\begin{array}{c}6 \text { No. } 30 \& 2 \text { No. } 35 \text { Top } \\
4 \text { No. } 30 \text { Bottom }\end{array}$ \\
\hline & & & & $7-11$ & $600 \times 600$ & $\begin{array}{c}4 \text { No. } 30 \& \\
8 \text { No. } 25 \text { bars } \\
\end{array}$ & \multirow[t]{2}{*}{$12-15$} & \multirow[t]{2}{*}{$h=600 \mathrm{~b}=400$} & \multirow{2}{*}{$\begin{array}{c}4 \text { No. } 35 \text { Top } \\
4 \text { No. } 25 \text { Bottom }\end{array}$} \\
\hline & & & & $12-15$ & $500 \times 500$ & 8 No. 30 bars & & & \\
\hline \multirow{4}{*}{20} & \multirow{4}{*}{$\begin{array}{c}\text { Total }=74 \\
\text { 1st level }=4.65 \\
\text { upper levels }=3.65\end{array}$} & \multirow{4}{*}{11142} & \multirow{4}{*}{$\begin{array}{l}\mathrm{T} 1=8.51 \\
\mathrm{~T} 2=3.22 \\
\mathrm{~T} 3=1.89\end{array}$} & $1-3$ & $900 \times 900$ & 16 No. 35 bars & $1-6$ & $\mathrm{~h}=800 \mathrm{~b}=500$ & $\begin{array}{c}8 \text { No. } 35 \text { Top } \\
4 \text { No. } 30 \text { Bottom } \\
\end{array}$ \\
\hline & & & & $4-11$ & $800 \times 800$ & 12 No. 35 bars & $7-12$ & $\mathrm{~h}=700 \mathrm{~b}=400$ & $\begin{array}{c}8 \text { No. } 35 \text { Top } \\
4 \text { No. } 30 \text { Bottom } \\
\end{array}$ \\
\hline & & & & $12-16$ & $600 \times 600$ & 12 No. 30 bars & $13-16$ & $\mathrm{~h}=600 \mathrm{~b}=400$ & $\begin{array}{c}6 \text { No. } 35 \& 2 \text { No. } 30 \text { Top } \\
4 \text { No. } 30 \text { Bottom }\end{array}$ \\
\hline & & & & $17-20$ & $500 \times 500$ & 12 No. 25 bars & $17-20$ & $\mathrm{~h}=600 \mathrm{~b}=400$ & $\begin{array}{c}4 \text { No. } 30 \& 4 \text { No. } 25 \text { Top } \\
4 \text { No. } 25 \text { Bottom }\end{array}$ \\
\hline
\end{tabular}

- Lateral load resisting frames are located at $32 \mathrm{~m}$ spacing and gravity load frames at every $8 \mathrm{~m}$ 
Table (3.9): Dimensions and properties of the steel frames located in Vancouver and designed with the proposed DBD method

\begin{tabular}{|c|c|c|c|c|c|c|c|c|}
\hline \multirow{2}{*}{$\begin{array}{l}\text { No. of } \\
\text { Stories }\end{array}$} & \multirow{2}{*}{ Height, $\mathrm{m}$} & \multirow{2}{*}{$\begin{array}{c}\text { Total } \\
\text { mass, } t\end{array}$} & \multirow{2}{*}{ Periods, S } & \multirow{2}{*}{ Stories } & \multicolumn{2}{|c|}{ Columns } & \multirow{2}{*}{ Stories } & \multirow{2}{*}{ Beams } \\
\hline & & & & & Interior & Exterior & & \\
\hline \multirow{3}{*}{6} & \multirow{3}{*}{$\begin{array}{c}\text { Total }=23 \\
\text { 1st level }=4.75 \\
\text { upper levels }=3.65\end{array}$} & \multirow{3}{*}{1503} & \multirow{3}{*}{$\begin{array}{l}\mathrm{T} 1=2.64 \\
\mathrm{~T} 2=0.92\end{array}$} & 1 & W310X202 & W310X202 & $1-3$ & W610X91 \\
\hline & & & & $2-3$ & W310X202 & W310X143 & \multirow{2}{*}{$4-6$} & \multirow{2}{*}{ W530X74 } \\
\hline & & & & $4-6$ & W310X143 & W310X97 & & \\
\hline \multirow{5}{*}{12} & \multirow{5}{*}{$\begin{array}{c}\text { Total }=45 \\
\text { 1st level }=4.85 \\
\text { upper levels }=3.65\end{array}$} & \multirow{5}{*}{3006} & \multirow{5}{*}{$\begin{array}{l}\mathrm{T} 1=4.66 \\
\mathrm{~T} 2=1.68 \\
\mathrm{~T} 3=0.97\end{array}$} & 1 & W360X314 & W310X283 & $1-4$ & W610X101 \\
\hline & & & & $2-5$ & W310X283 & $\mathrm{W} 310 \times 202$ & \multirow{2}{*}{$5-8$} & \multirow{2}{*}{ W610X91 } \\
\hline & & & & $6-7$ & W310X202 & W310X143 & & \\
\hline & & & & $8-9$ & W310X143 & W310X143 & 010 & we $50 \mathrm{Y} 74$ \\
\hline & & & & $10-12$ & W310X143 & W310X97 & $9-12$ & W $530 \times / 4$ \\
\hline \multirow{7}{*}{15} & \multirow{7}{*}{$\begin{array}{c}\text { Total }=56 \\
\text { 1st level }=4.90 \\
\text { upper levels }=3.65\end{array}$} & \multirow{7}{*}{3758} & \multirow{7}{*}{$\begin{array}{l}\mathrm{T} 1=5.71 \\
\mathrm{~T} 2=2.04\end{array}$} & 1 & WWF400X362 & WWF400X362 & \multirow{2}{*}{$1-6$} & \multirow{2}{*}{ W610X101 } \\
\hline & & & & 2 & WWF400X362 & W310X283 & & \\
\hline & & & & 3 & W310X283 & W310X283 & \multirow{2}{*}{$7-11$} & \multirow{2}{*}{ W610X91 } \\
\hline & & & & $4-7$ & W310X283 & W310X202 & & \\
\hline & & & & $8-10$ & W310X202 & W310X143 & \multirow{3}{*}{$12-15$} & \multirow{3}{*}{ W530X74 } \\
\hline & & & & 11 & W310X143 & W310X143 & & \\
\hline & & & & $12-15$ & W310X143 & W310X97 & & \\
\hline \multirow{8}{*}{20} & \multirow{8}{*}{$\begin{array}{c}\text { Total }=74 \\
\text { 1st level }=4.65 \\
\text { upper levels }=3.65\end{array}$} & & & 1 & WWF450X409 & WWF400X362 & $1-8$ & W610X101 \\
\hline & & & & $2-3$ & WWF450X409 & W310X283 & $1-8$ & W010 101 \\
\hline & & & & $4-6$ & WWF400X362 & W310X283 & & \\
\hline & & 5010 & $\begin{array}{l}11=1.50 \\
\mathrm{~T} 2=272\end{array}$ & 7 & WWF400X362 & W310X202 & $9-14$ & W610X91 \\
\hline & & & $\begin{array}{l}12=2.12 \\
\mathrm{~T} 3=159\end{array}$ & $8-11$ & W310X283 & W310X202 & & \\
\hline & & & & $12-14$ & W310X202 & W310X143 & & \\
\hline & & & & 15 & W310X143 & W310X143 & $15-20$ & W530X74 \\
\hline & & & & $16-20$ & W310X143 & W310X97 & & \\
\hline
\end{tabular}

- Lateral load resisting frames are located at $16 \mathrm{~m}$ spacing and gravity load frames at every $8 \mathrm{~m}$ as shown in Figure (3.1a) 
Table (3.10): Dimensions and Properties of the Steel frames located in Montreal and Designed with the proposed DBD method

\begin{tabular}{|c|c|c|c|c|c|c|c|c|}
\hline \multirow{2}{*}{$\begin{array}{l}\text { No. of } \\
\text { Stories }\end{array}$} & \multirow{2}{*}{ Height, m } & \multirow{2}{*}{$\begin{array}{c}\text { Total } \\
\text { mass, } t\end{array}$} & \multirow{2}{*}{ Periods, S } & \multirow{2}{*}{ Stories } & \multicolumn{2}{|c|}{ Columns } & \multirow{2}{*}{ Stories } & \multirow{2}{*}{ Beams } \\
\hline & & & & & Interior & Exterior & & \\
\hline \multirow{2}{*}{6} & \multirow{2}{*}{$\begin{array}{c}\text { Total }=23 \\
\text { 1st level }=4.75 \\
\text { upper levels }=3.65\end{array}$} & \multirow{2}{*}{3006} & \multirow{2}{*}{$\begin{array}{l}\mathrm{T} 1=4.69 \\
\mathrm{~T} 2=1.46\end{array}$} & 1 & W310X202 & W310X97 & \multirow{2}{*}{$1-6$} & \multirow{2}{*}{ W530X74 } \\
\hline & & & & $2-6$ & W310X143 & W310X97 & & \\
\hline \multirow{6}{*}{12} & \multirow{6}{*}{$\begin{array}{c}\text { Total }=45 \\
\text { 1st level }=4.85 \\
\text { upper levels }=3.65\end{array}$} & \multirow{6}{*}{6012} & \multirow{6}{*}{$\begin{array}{l}\mathrm{T} 1=6.91 \\
\mathrm{~T} 2=2.48\end{array}$} & 1 & W360X314 & W310X283 & \multirow{2}{*}{$1-2$} & \multirow{2}{*}{ W610X101 } \\
\hline & & & & $2-3$ & W310X283 & W310X202 & & \\
\hline & & & & 4 & W310X283 & W310X143 & \multirow{2}{*}{$3-7$} & \multirow{2}{*}{ W610X91 } \\
\hline & & & & $5-7$ & W310X202 & W310X143 & & \\
\hline & & & & 8 & W310X143 & W310X143 & \multirow{2}{*}{$8-12$} & \multirow{2}{*}{ W530X74 } \\
\hline & & & & $9-12$ & W310X143 & W310X97 & & \\
\hline \multirow{7}{*}{15} & \multirow{7}{*}{$\begin{array}{c}\text { Total }=56 \\
\text { 1st level }=4.90 \\
\text { upper levels }=3.65\end{array}$} & \multirow{7}{*}{7515} & \multirow{7}{*}{$\begin{array}{l}T 1=7.99 \\
T 2=2.87\end{array}$} & 1 & WWF400X362 & WWF400X362 & \multirow{2}{*}{$1-3$} & \multirow{2}{*}{ W610X113 } \\
\hline & & & & 2 & WWF400X362 & W310X283 & & \\
\hline & & & & 3 & W310X283 & W310X283 & \multirow{2}{*}{$4-7$} & \multirow{2}{*}{ W610X101 } \\
\hline & & & & 4-7 & W310X283 & W310X202 & & \\
\hline & & & & $8-10$ & W310X202 & W310X143 & $8-11$ & W61 \\
\hline & & & & 11 & W310X143 & W310X143 & $8-11$ & W610X91 \\
\hline & & & & $12-15$ & W310X143 & W310X97 & $12-15$ & W530X74 \\
\hline & & & & 1 & WWF500X456 & WWF450X409 & & \\
\hline & & & & 2 & WWF450X409 & WWF400X362 & $1-8$ & W610X113 \\
\hline & & & & 3 & WWF450X409 & W310X283 & $0-11$ & w610X101 \\
\hline 20 & Total $=74$ & 10020 & $\mathrm{~T} 1=9.95$ & $4-8$ & WWF400X362 & W310X283 & $9-11$ & W610X101 \\
\hline 20 & $\begin{array}{c}\text { Ist level }=4.65 \\
\text { unner levels }=365\end{array}$ & 10020 & $\begin{array}{l}12=3.05 \\
\mathrm{~T} 3=2.14\end{array}$ & $9-11$ & W310X283 & W310X202 & 12,15 & X/610X01 \\
\hline & & & & 12 & W310X283 & W310X143 & $12-15$ & W010XY1 \\
\hline & & & & $13-15$ & W310X202 & W310X143 & & X/530X74 \\
\hline & & & & $16-20$ & W310X143 & W310X97 & & W530X/4 \\
\hline
\end{tabular}

- Lateral load resisting frames are located at $32 \mathrm{~m}$ spacing and gravity load frames at every $8 \mathrm{~m}$ 
Table (3.11): Inter-story drifts (\%)

12-story SMRF building in Vancouver

\begin{tabular}{|c|c|c|c|}
\hline Story & Mode 1 & Mode 2 & SRSS \\
\hline 1 & 1.25 & 0.23 & 1.27 \\
\hline 2 & 1.73 & 0.31 & 1.76 \\
\hline 3 & 1.68 & 0.25 & 1.70 \\
\hline 4 & 1.58 & 0.15 & 1.58 \\
\hline 5 & 1.52 & 0.05 & 1.52 \\
\hline 6 & 1.50 & 0.08 & 1.50 \\
\hline 7 & 1.24 & 0.22 & 1.26 \\
\hline 8 & 1.09 & 0.35 & 1.14 \\
\hline 9 & 1.15 & 0.47 & 1.24 \\
\hline 10 & 1.17 & 0.55 & 1.29 \\
\hline 11 & 0.74 & 0.44 & 0.86 \\
\hline 12 & 0.36 & 0.26 & 0.44 \\
\hline
\end{tabular}


Table (3.12): Story shears $(\mathrm{kN})$

12-story SMRF building in Vancouver

\begin{tabular}{|c|c|c|c|}
\hline Story & Mode 1 & Mode 2 & SRSS \\
\hline 1 & 1254 & 423 & 1323 \\
\hline 2 & 1238 & 383 & 1296 \\
\hline 3 & 1205 & 303 & 1243 \\
\hline 4 & 1155 & 192 & 1171 \\
\hline 5 & 1088 & 60 & 1090 \\
\hline 6 & 1004 & 77 & 1007 \\
\hline 7 & 903 & 205 & 926 \\
\hline 8 & 786 & 306 & 843 \\
\hline 9 & 653 & 363 & 747 \\
\hline 10 & 507 & 360 & 622 \\
\hline 11 & 346 & 287 & 450 \\
\hline 12 & 176 & 160 & 238 \\
\hline
\end{tabular}


Table (3.13): Moments and ductilities of the Middle span beams, 1st mode response of 12-story SMRF building in Vancouver

(Moments in $\mathrm{kN}-\mathrm{m}$, rotations in radians)

\begin{tabular}{|c|c|c|c|c|c|c|}
\hline $\begin{array}{l}(1) \\
\text { Story }\end{array}$ & $\begin{array}{c}(2) \\
\text { Section }\end{array}$ & $\begin{array}{c}(3) \\
\text { Moment }\end{array}$ & $\begin{array}{c}(4) \\
\text { Plastic } \\
\text { hinge } \\
\text { rotation }\end{array}$ & $\begin{array}{c}(5) \\
\text { Yield } \\
\text { rotation }\end{array}$ & $\begin{array}{c}\text { (6) } \\
\text { Ductility } \\
\text { demand }\end{array}$ & $\begin{array}{c}(7) \\
\text { Ductility } \\
\text { capacity }\end{array}$ \\
\hline 1 & W610x101 & 914 & $1.105 \mathrm{E}-2$ & $8.857 \mathrm{E}-3$ & 2.25 & 6.2 \\
\hline 2 & W610x101 & 914 & $1.205 \mathrm{E}-2$ & $8.857 \mathrm{E}-3$ & 2.36 & 6.2 \\
\hline 3 & W610x101 & 914 & $1.069 \mathrm{E}-2$ & $8.857 \mathrm{E}-3$ & 2.21 & 6.2 \\
\hline 4 & W610x101 & 914 & $9.324 \mathrm{E}-3$ & 8.857E-3 & 2.05 & 6.2 \\
\hline 5 & W610x91 & 806 & $1.012 \mathrm{E}-2$ & $8.956 \mathrm{E}-3$ & 2.13 & 3.4 \\
\hline 6 & W610x91 & 806 & $7.332 \mathrm{E}-3$ & $8.956 \mathrm{E}-3$ & 1.82 & 3.4 \\
\hline 7 & W610x91 & 806 & $3.462 \mathrm{E}-3$ & $8.956 \mathrm{E}-3$ & 1.39 & 3.4 \\
\hline 8 & W610x91 & 806 & $3.615 \mathrm{E}-4$ & $8.956 \mathrm{E}-3$ & 1.04 & 3.4 \\
\hline 9 & W530x74 & 488 & $1.022 \mathrm{E}-2$ & $10.276 \mathrm{E}-3$ & 1.99 & 7 \\
\hline 10 & W530x74 & 488 & $6.177 \mathrm{E}-3$ & $10.276 \mathrm{E}-3$ & 1.60 & 7 \\
\hline 11 & W530x74 & 488 & $2.011 \mathrm{E}-4$ & $10.276 \mathrm{E}-3$ & 1.02 & 7 \\
\hline 12 & W530x74 & 382 & 0 & $10.276 \mathrm{E}-3$ & 1 & 7 \\
\hline
\end{tabular}


Table (3.14): Moments and plastic hinge rotations - the interior column of 12-story SMRF building in Vancouver (Moments in $\mathrm{kN}-\mathrm{m}$ and rotations in radians)

\begin{tabular}{|c|c|c|c|}
\hline $\begin{array}{c}(1) \\
\text { Story }\end{array}$ & $\begin{array}{c}(2) \\
\text { Mode1 }\end{array}$ & $\begin{array}{c}(3) \\
\text { Mode2 }\end{array}$ & $\begin{array}{c}(4) \\
\text { SRSS } \\
\text { moment }\end{array}$ \\
\hline 1 & $\begin{array}{c}1386^{*} \\
\theta=5.853 \mathrm{E}-3\end{array}$ & - & 1386 \\
\hline 2 & 948 & 241 & 978 \\
\hline 3 & 814 & 176 & 833 \\
\hline 4 & 777 & 92 & 782 \\
\hline 5 & 761 & 2 & 761 \\
\hline 6 & 632 & 80 & 637 \\
\hline 7 & 544 & 165 & 568 \\
\hline 8 & 462 & 207 & 506 \\
\hline 9 & 512 & 260 & 574 \\
\hline 10 & 283 & 232 & 366 \\
\hline 11 & 151 & 169 & 227 \\
\hline 12 & 90 & 85 & 124 \\
\hline
\end{tabular}

* Maximum moment capacity of the first story column at the gravity axial load of $5188 \mathrm{kN}$ is equal to $1386 \mathrm{kN}-\mathrm{m}$. Gravity moments are negligible. 
Table (3.15): Inter-story drifts (\%)

12-story CBF building in Vancouver

\begin{tabular}{|c|c|c|c|}
\hline Story & Mode 1 & Mode 2 & SRSS \\
\hline 1 & 0.37 & 0.31 & 0.48 \\
\hline 2 & 0.41 & 0.29 & 0.50 \\
\hline 3 & 0.42 & 0.23 & 0.48 \\
\hline 4 & 0.43 & 0.14 & 0.45 \\
\hline 5 & 1.43 & 0.07 & 1.43 \\
\hline 6 & 0.49 & 0.04 & 0.50 \\
\hline 7 & 0.47 & 0.16 & 0.49 \\
\hline 8 & 0.43 & 0.26 & 0.50 \\
\hline 9 & 0.52 & 0.46 & 0.69 \\
\hline 10 & 0.43 & 0.68 & 0.81 \\
\hline 11 & 0.34 & 0.40 & 0.52 \\
\hline 12 & 0.23 & 0.24 & 0.34 \\
\hline
\end{tabular}


Table (3.16): Tensile force in bracings $(\mathrm{kN})$

12-story CBF building in Vancouver ( $\mathrm{P}=$ Plastic elongation)

\begin{tabular}{|c|c|c|c|}
\hline Story & Mode 1 & Mode 2 & SRSS \\
\hline 1 & 1685 & 1559 & $1700^{\mathrm{P}}$ \\
\hline 2 & 1577 & 1260 & $1700^{\mathrm{P}}$ \\
\hline 3 & 1538 & 1005 & $1700^{\mathrm{P}}$ \\
\hline 4 & 1482 & 667 & 1625 \\
\hline 5 & 1336 & 290 & $1336^{\mathrm{P}}$ \\
\hline 6 & 1313 & 37 & 1314 \\
\hline 7 & 1186 & 411 & 1255 \\
\hline 8 & 1037 & 720 & 1262 \\
\hline 9 & 880 & 923 & $932^{\mathrm{P}}$ \\
\hline 10 & 682 & 925 & $932^{\mathrm{P}}$ \\
\hline 11 & 462 & 766 & 895 \\
\hline 12 & 223 & 423 & 478 \\
\hline
\end{tabular}


(a)
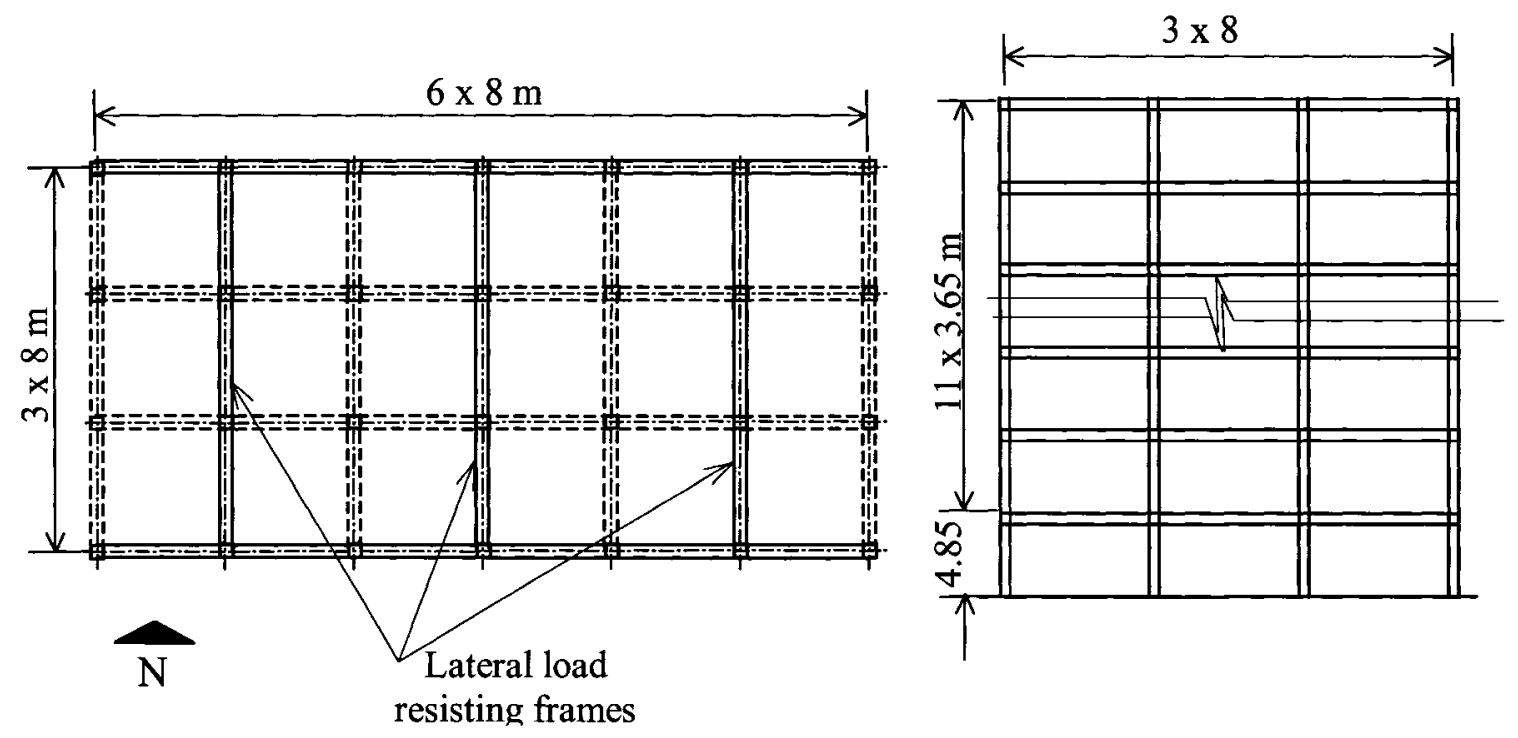

(b)

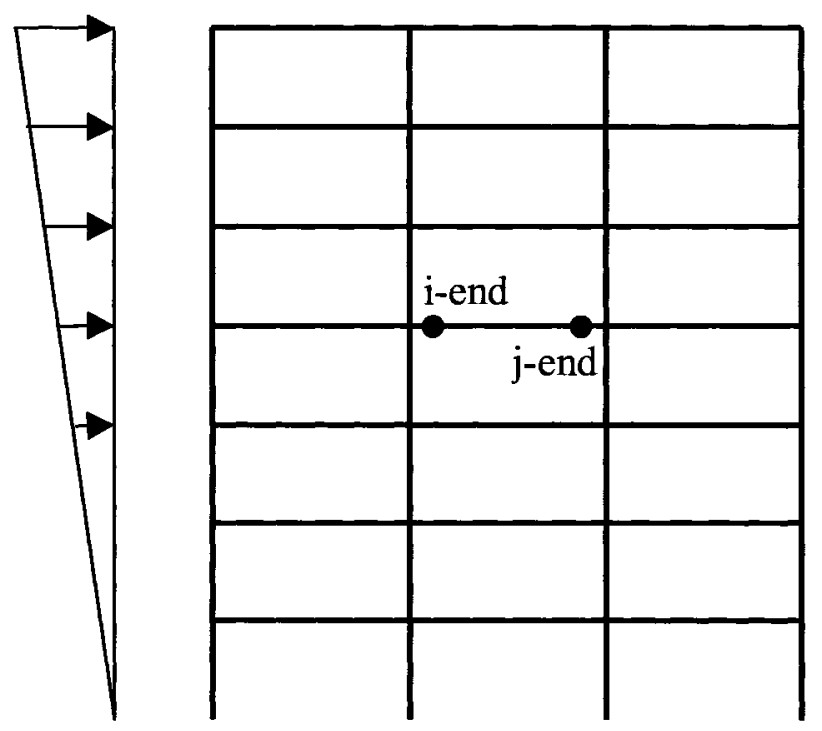

Figure (3.1): (a) Plan and Elevation of the frame structure

(b) Definition of $i$ and $j$ ends of the beams 
(a)

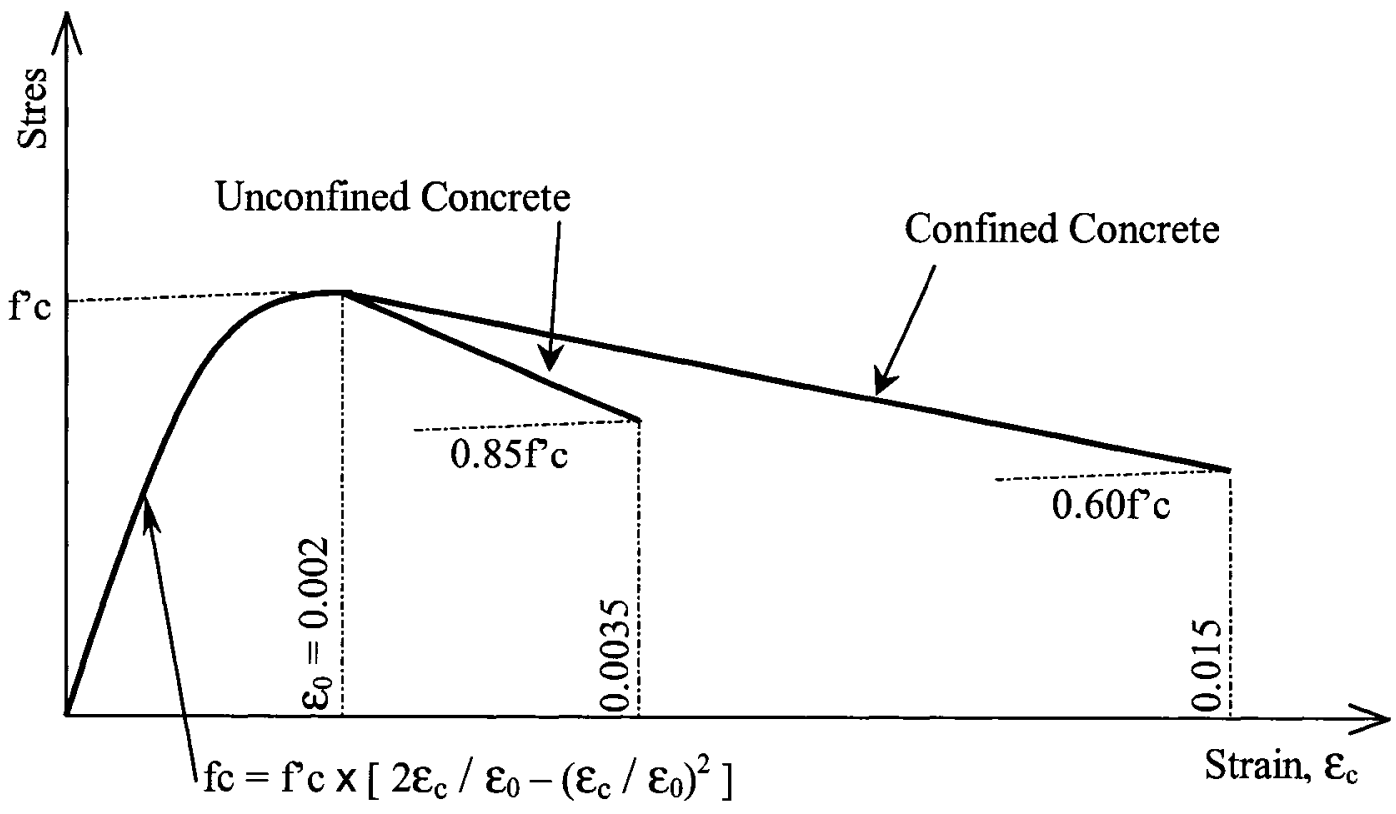

(b)

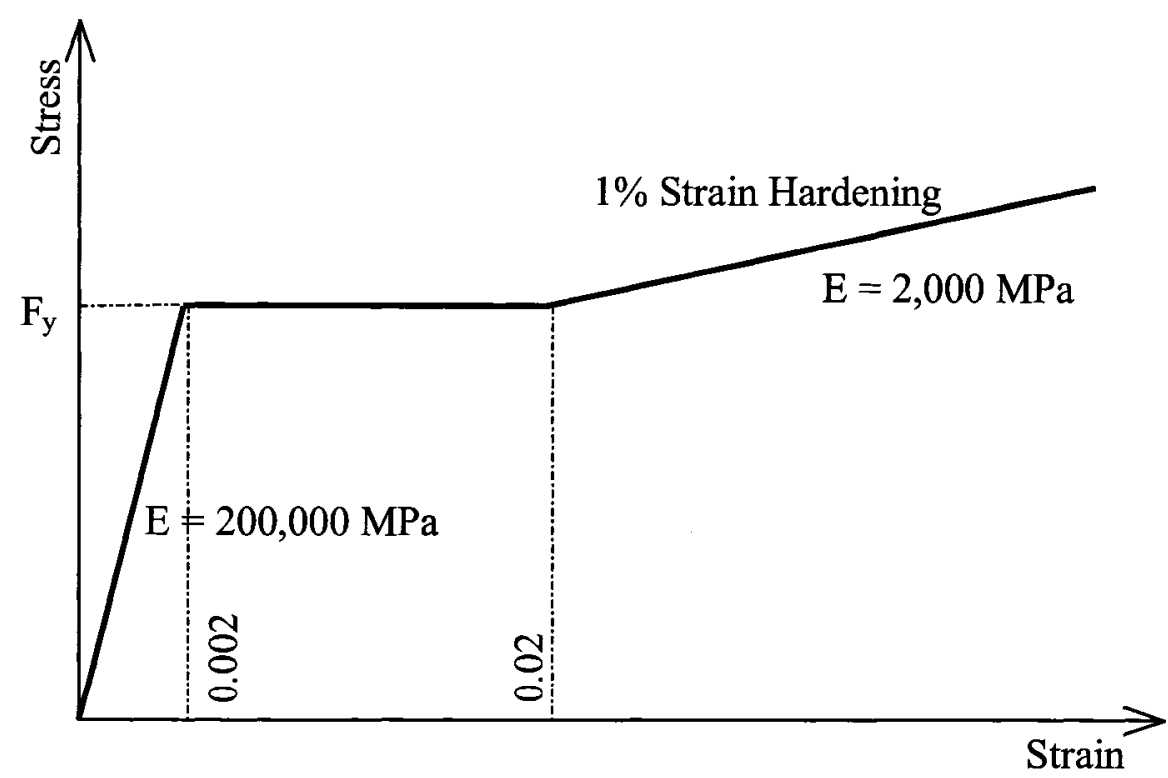

Figure (3.2): Stress-Strain relationships for (a) Concrete and (b) Reinforcing Steel 


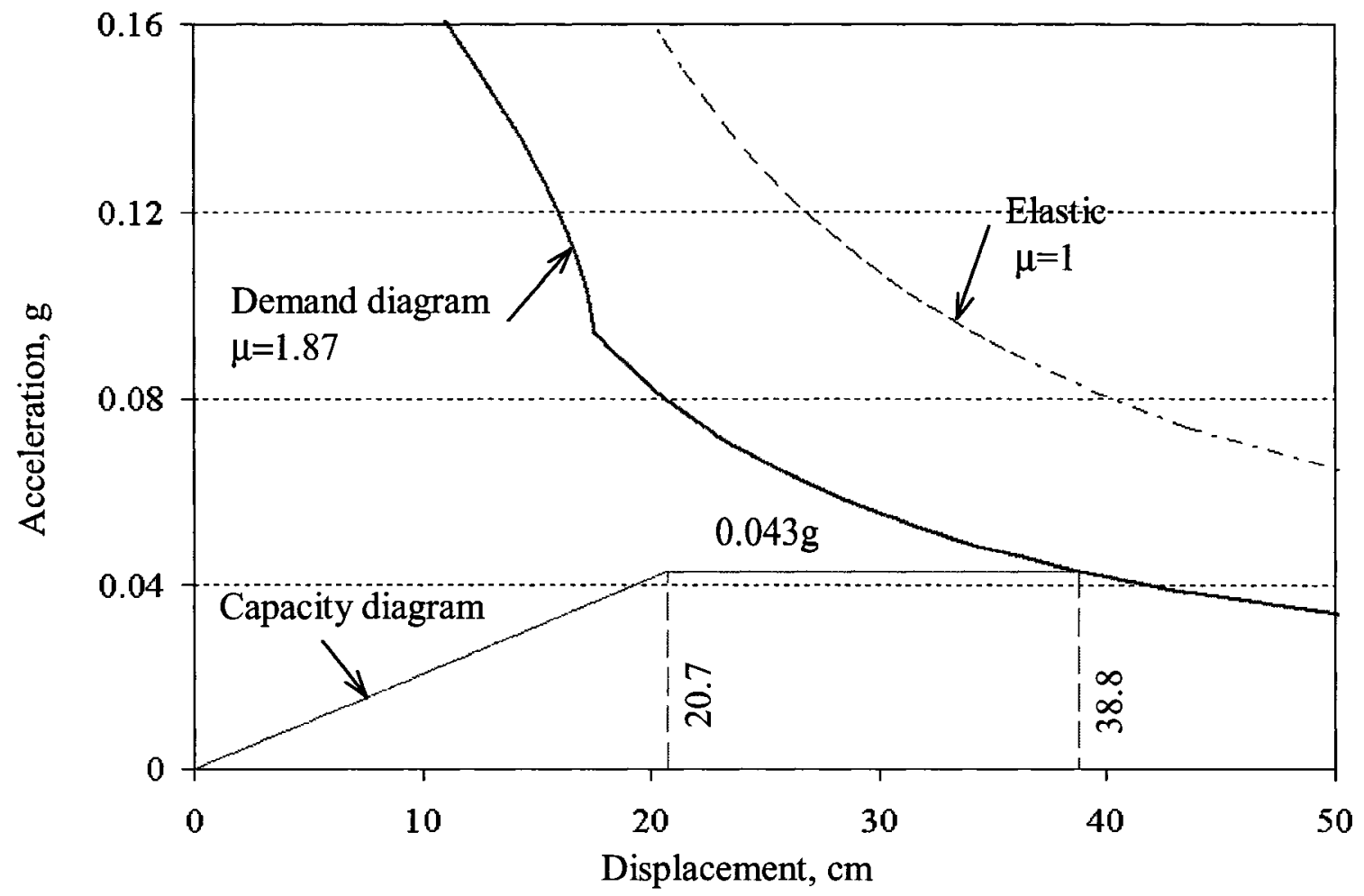

Figure (3.3): Displacement Based Design of 12-Story RC Frame In Vancouver - first try

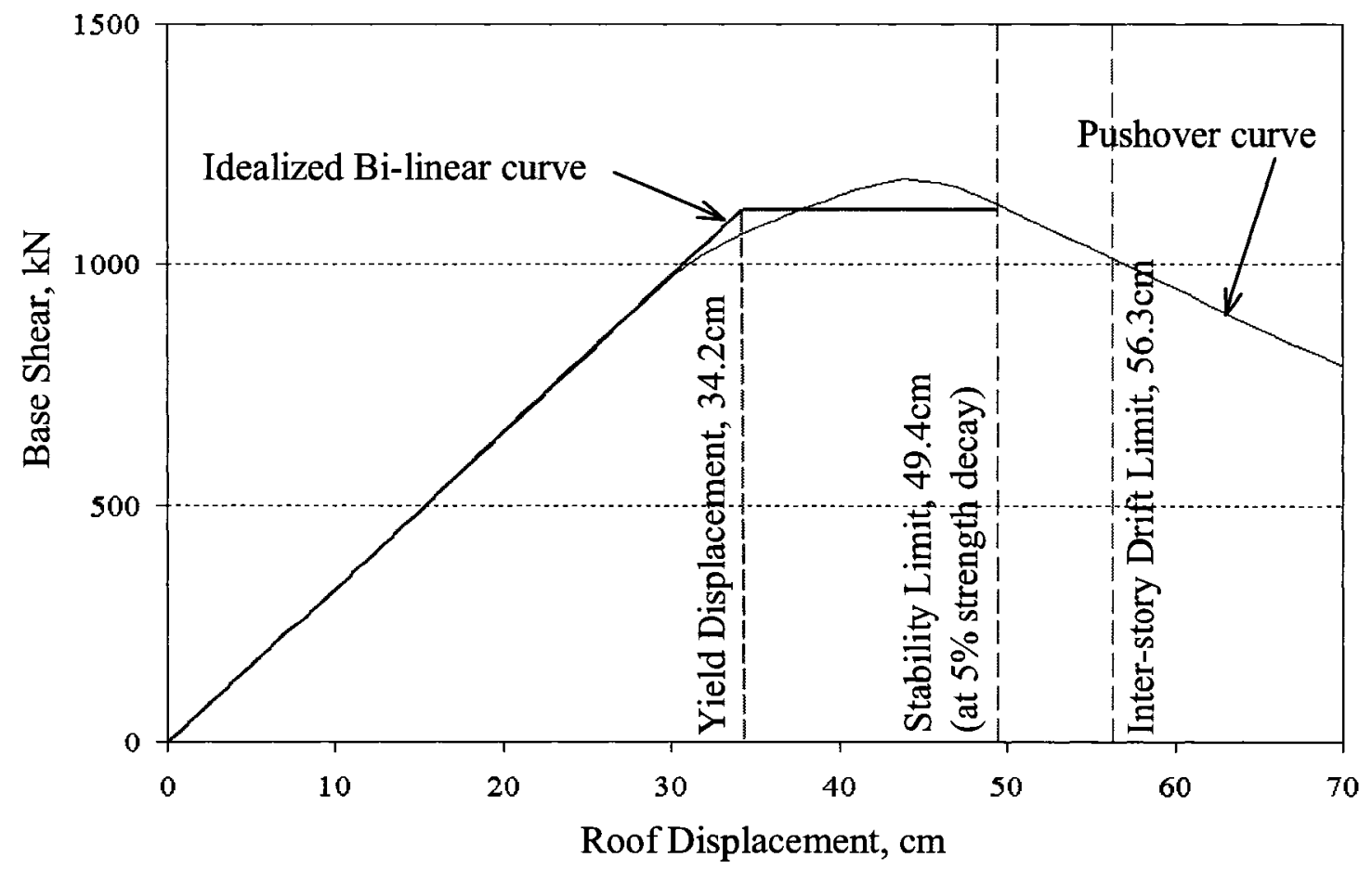

Figure (3.4): Pushover Curve - Initial design 


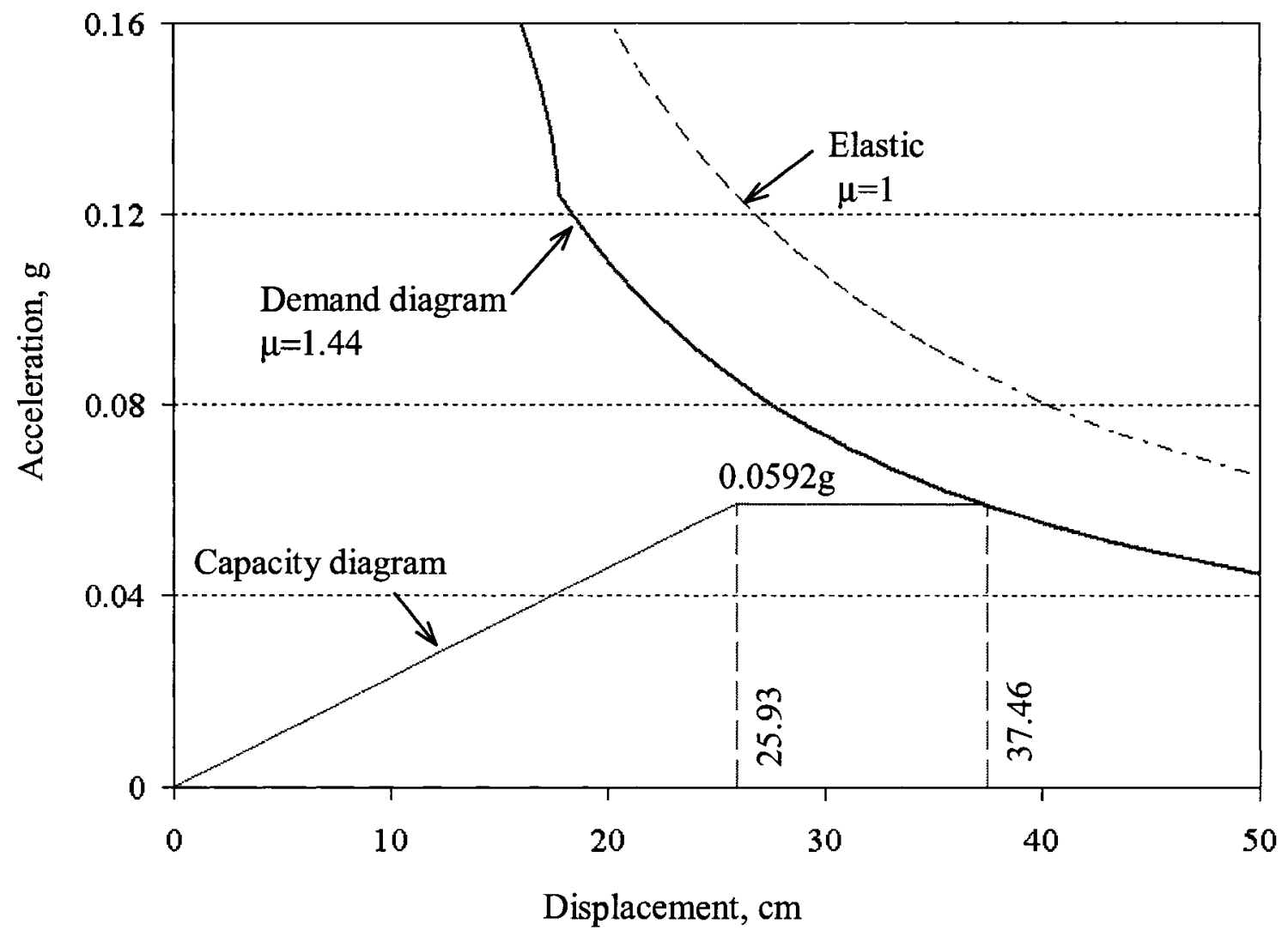

Figure (3.5): Displacement Based Design of 12-Story RC Frame In Vancouver - second try 


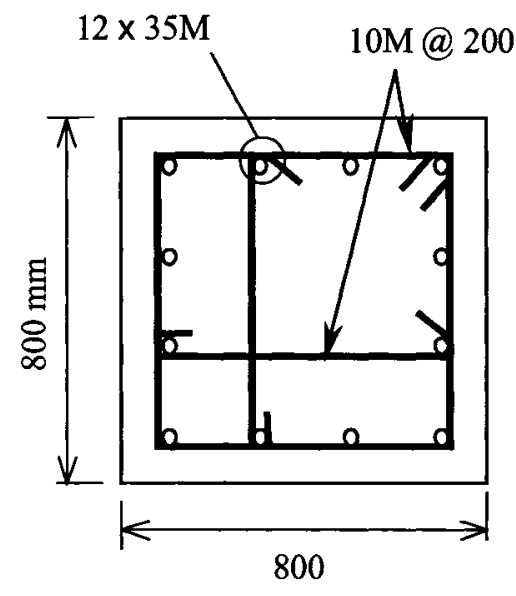

Columns of the $1^{\text {st }}$ story

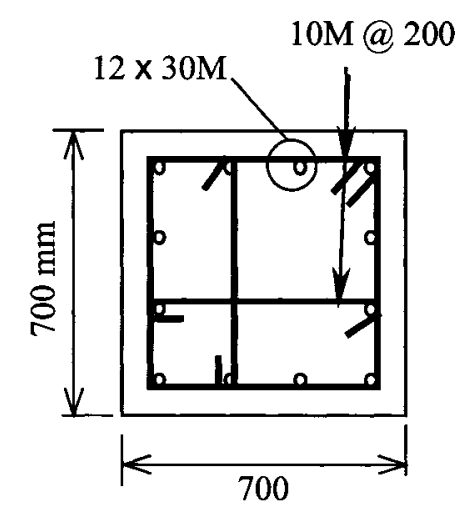

Columns of stories 2 to 4

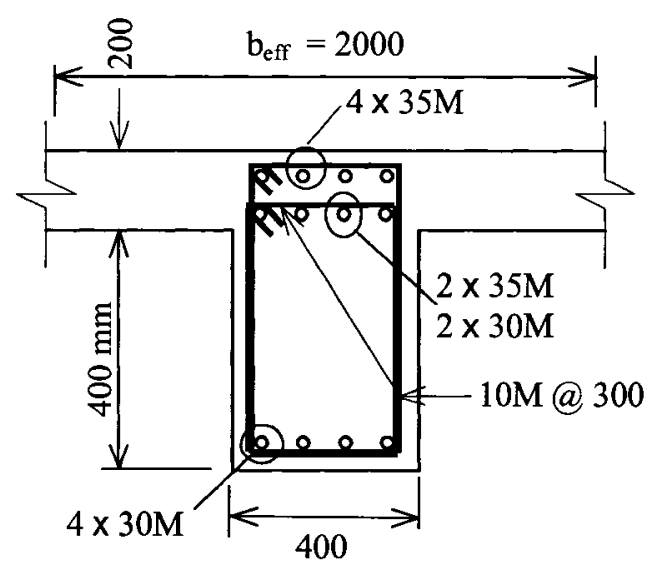

Beams of stories 7 to 9

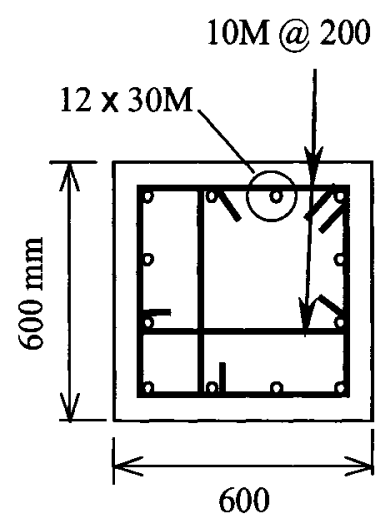

Columns of stories 5 to 8 Columns of stories 9 to 12

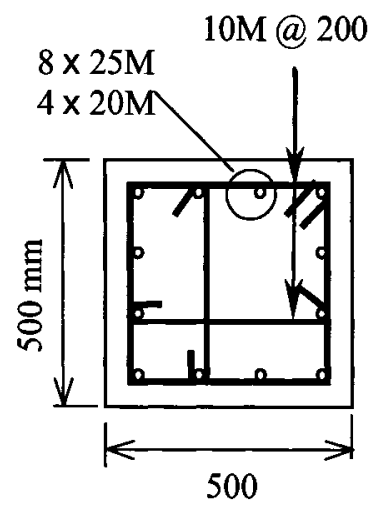

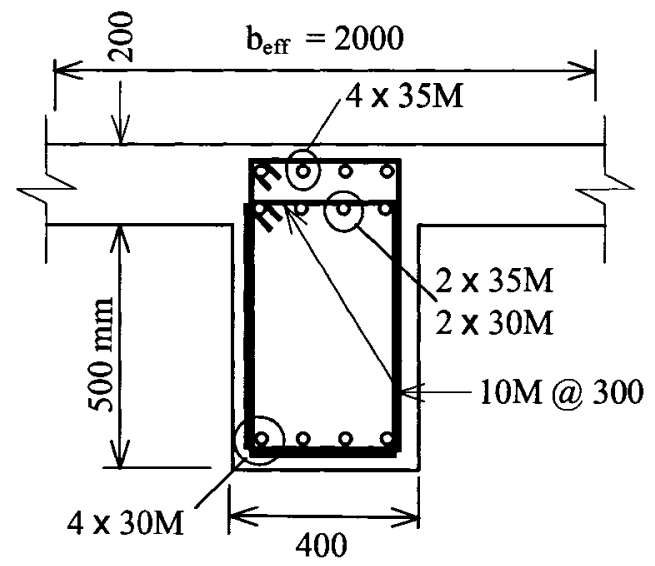

Beams of stories 1 to 6

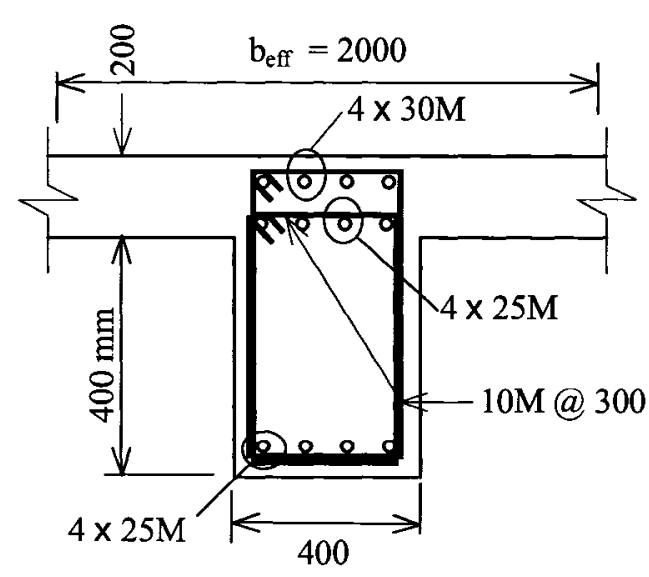

Beams of stories 10 to 12

Figure (3.6): Columns and beams of the final design 


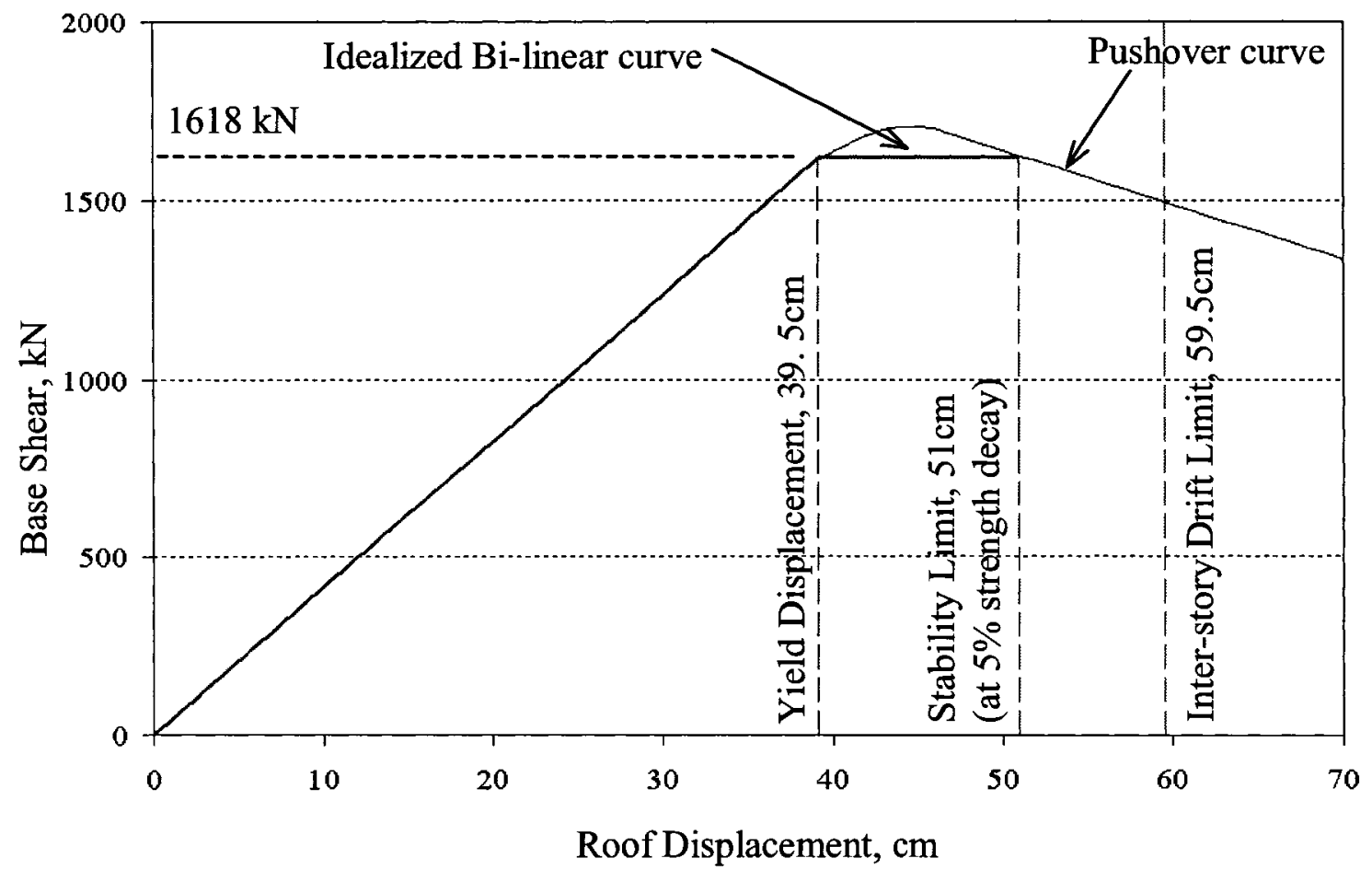

Figure (3.7): Pushover Curve - Second design

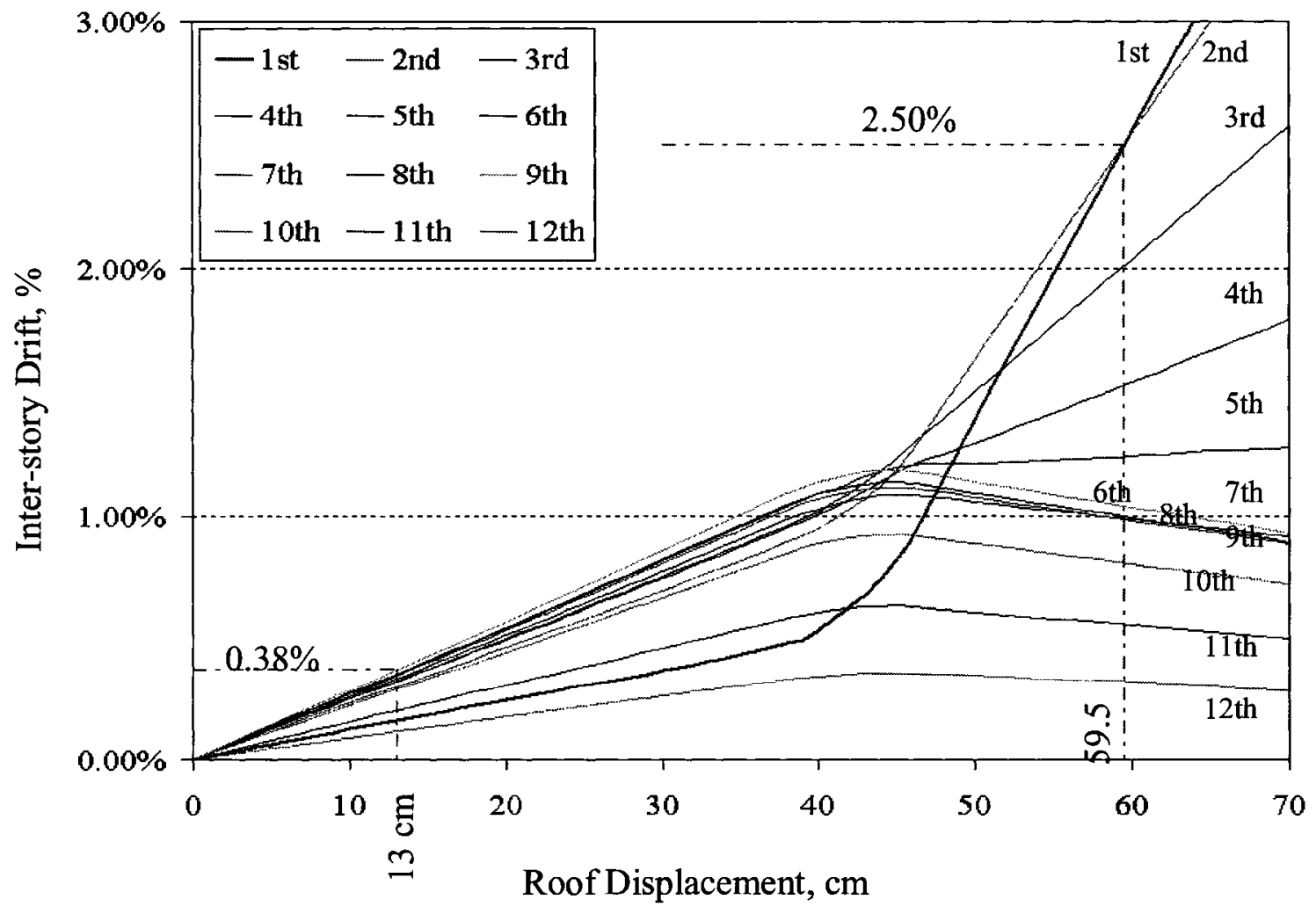

Figure (3.8): Inter-story drifts 


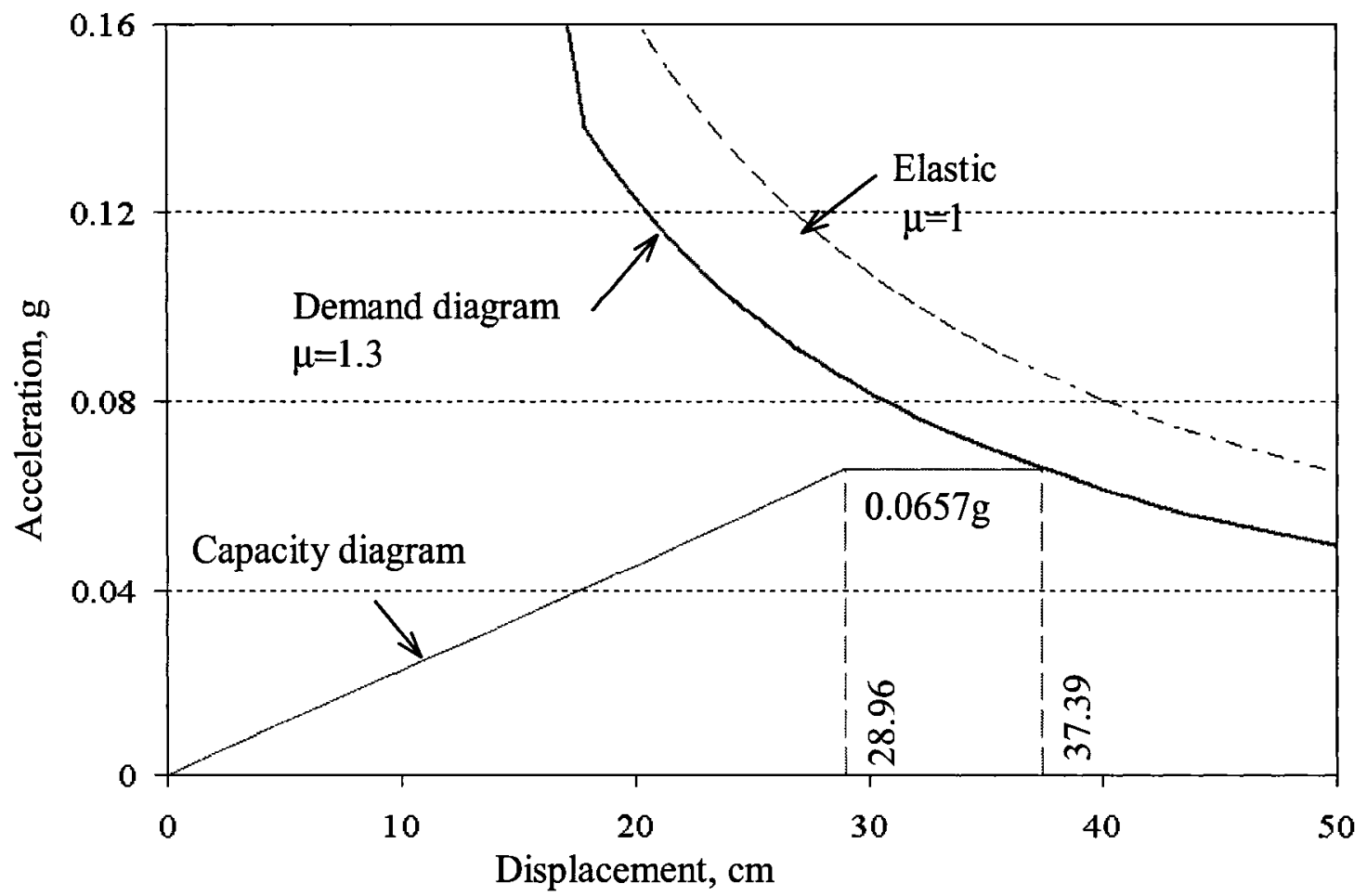

Figure (3.9): Displacement Based Design of 12-Story RC Frame in Vancouver - third try

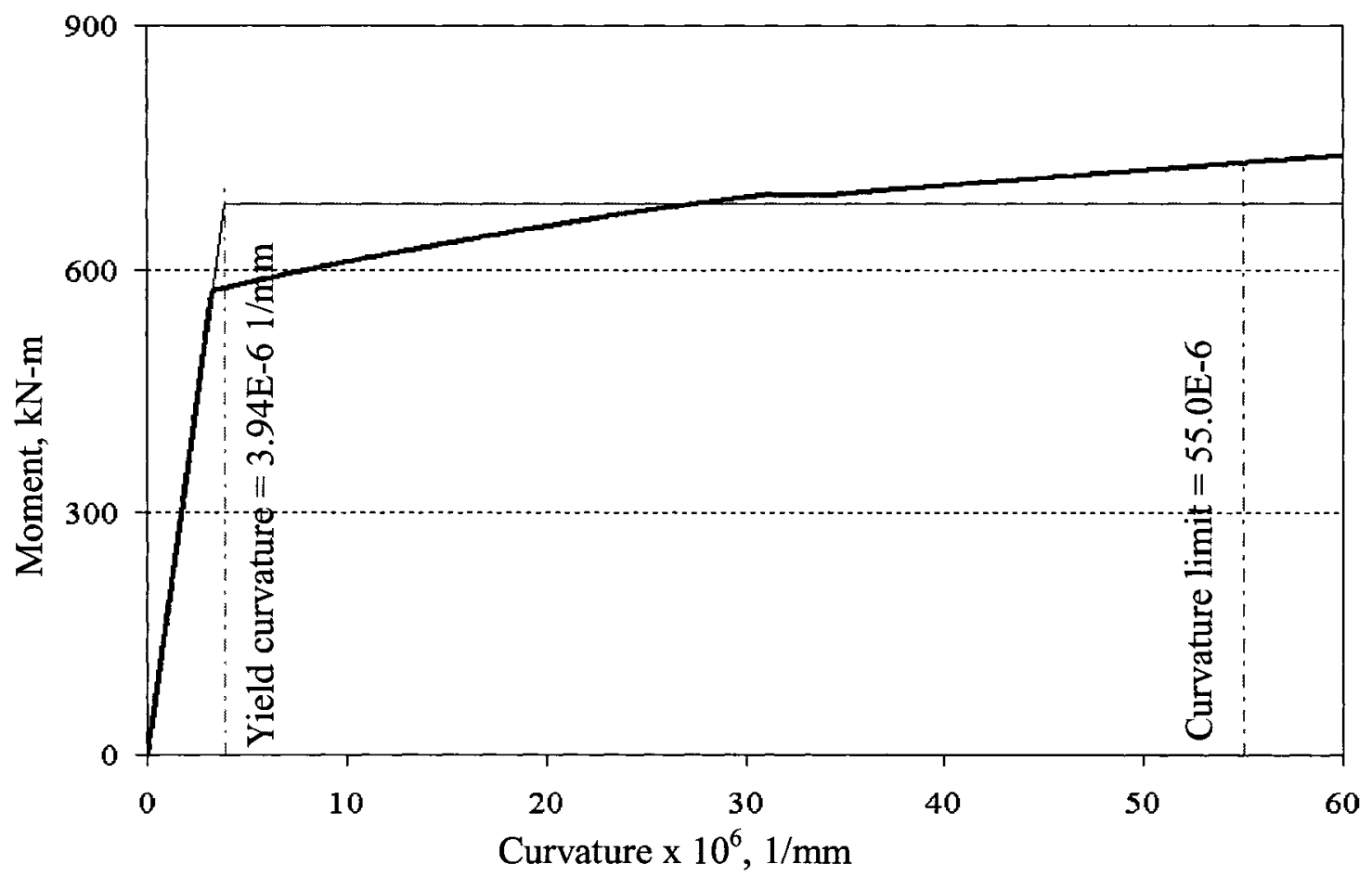

Figure (3.10): Moment-Curvature relationship for first floor interior beam, positive moment 


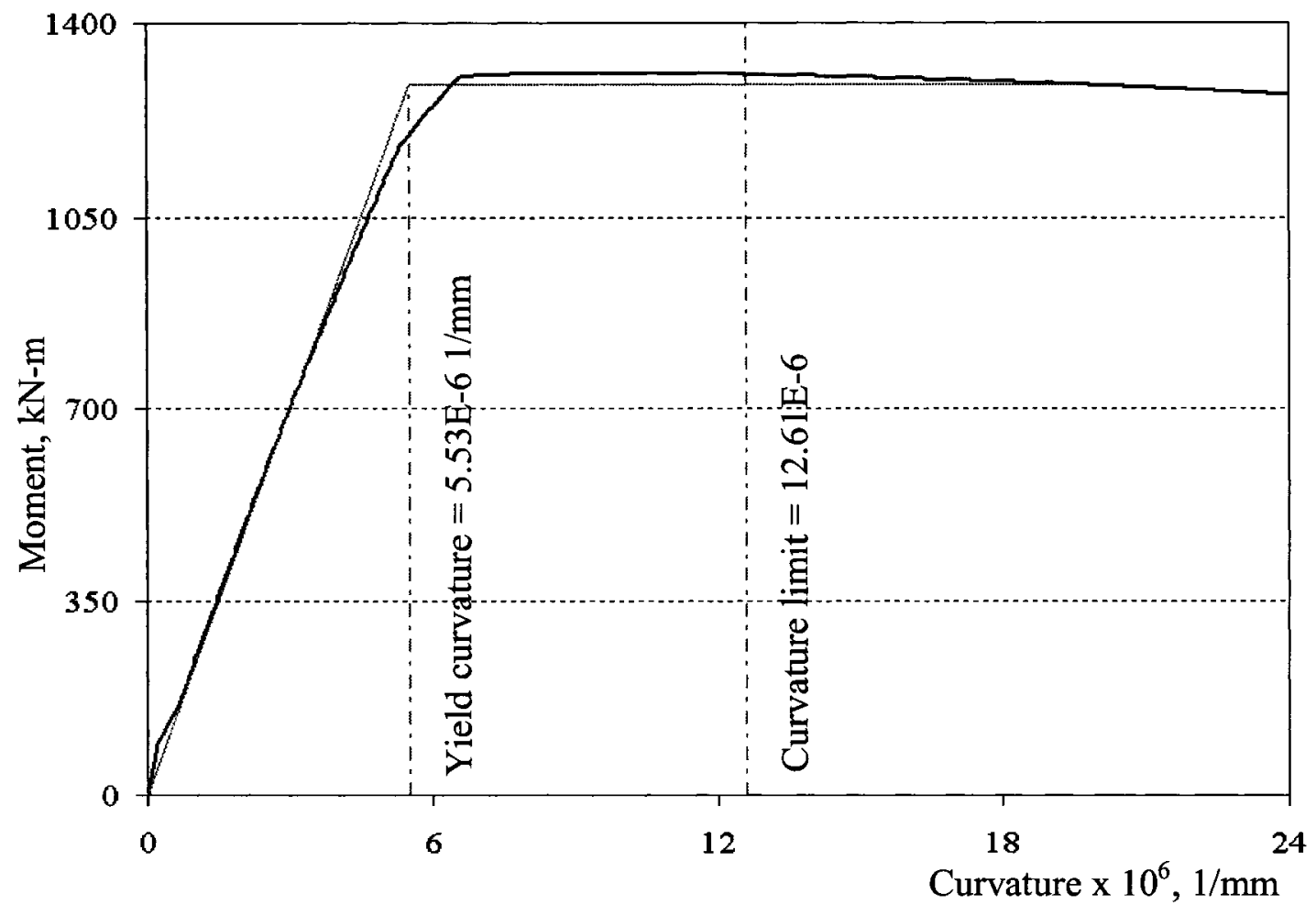

Figure (3.11): Moment-Curvature relationship for first floor interior beam, negative moment

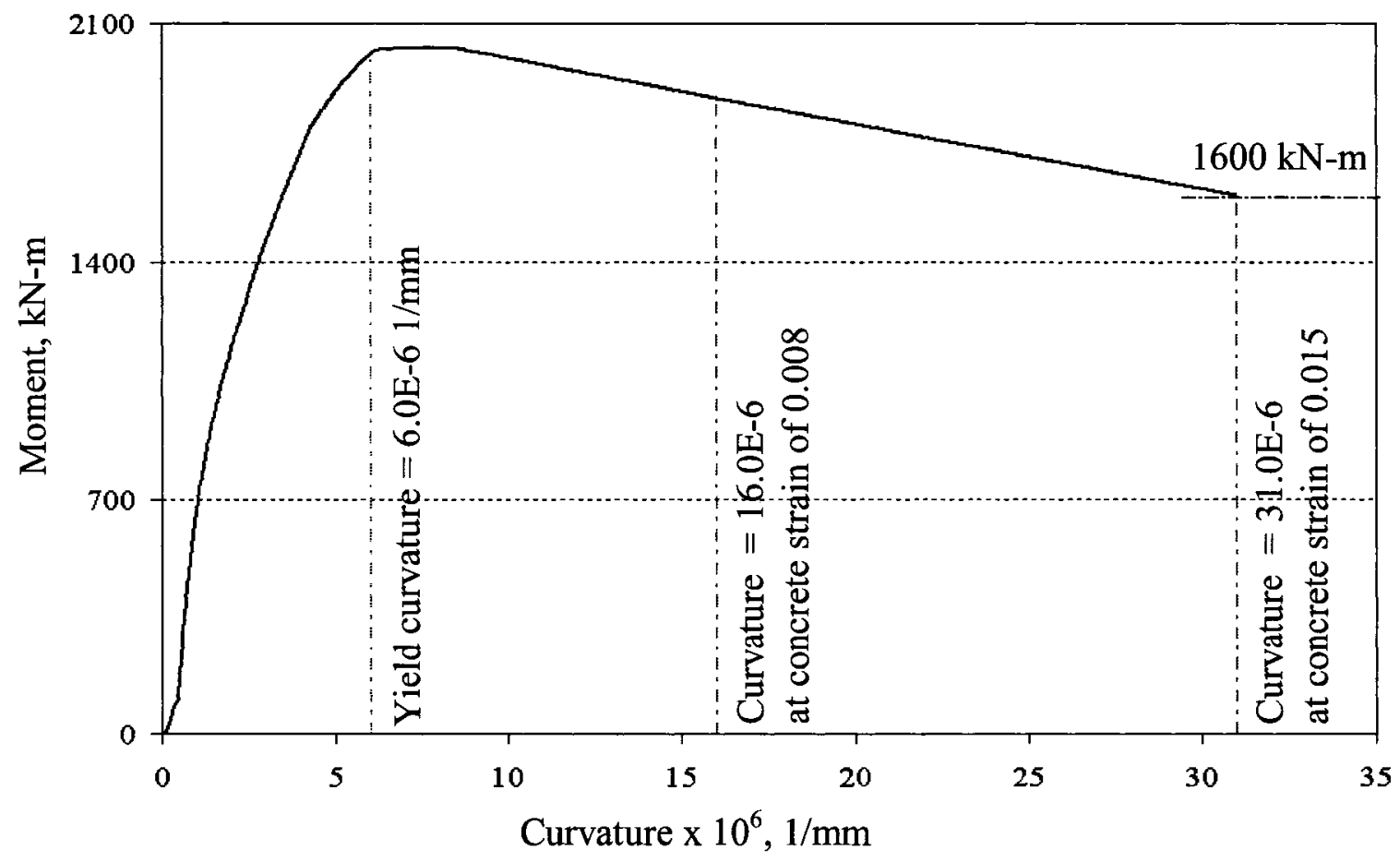

Figure (3.12): Moment-Curvature relationship for first floor interior column, Under gravity axial force 


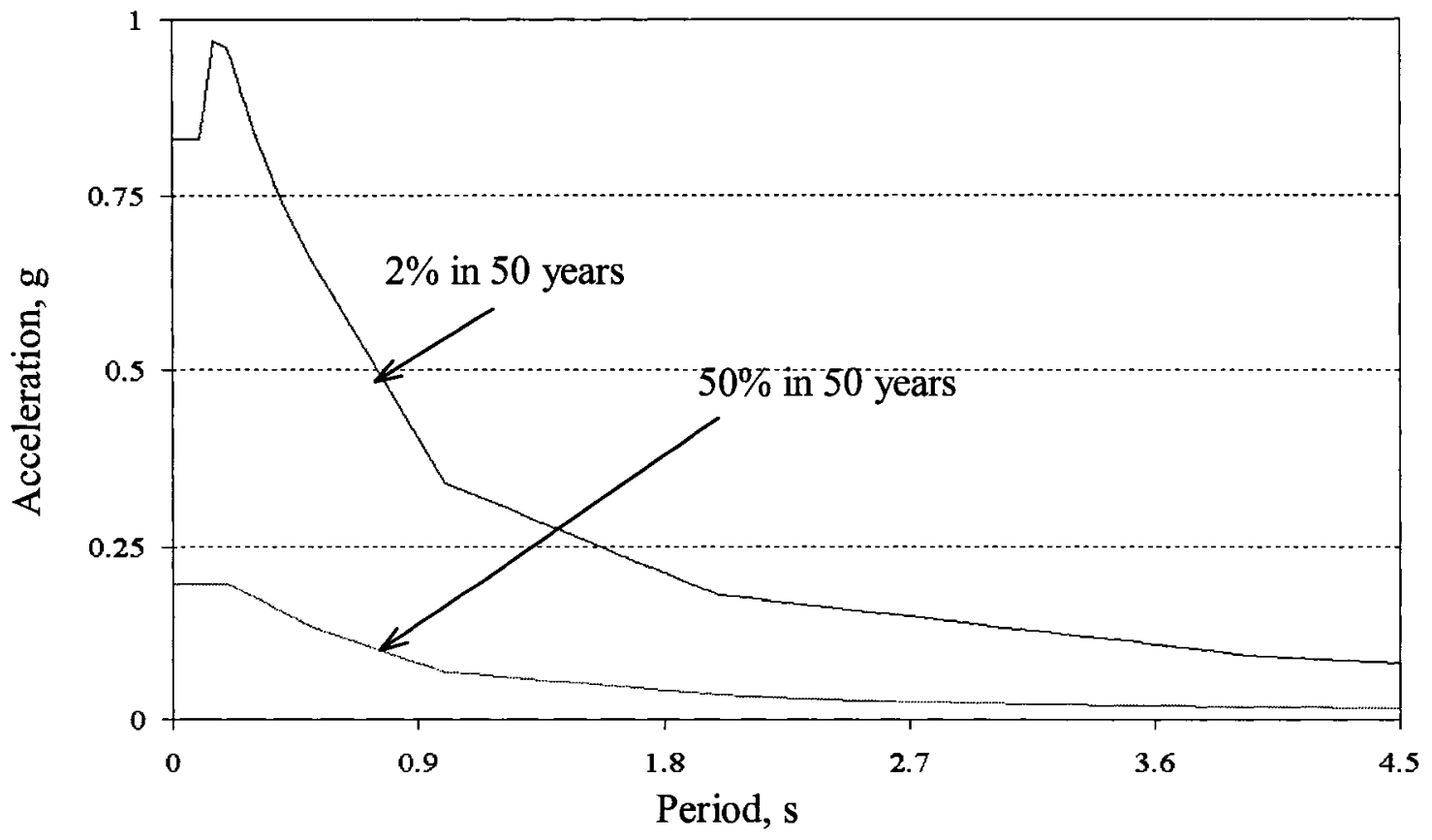

Figure (3.13): Uniform Hazard Spectra for Vancouver

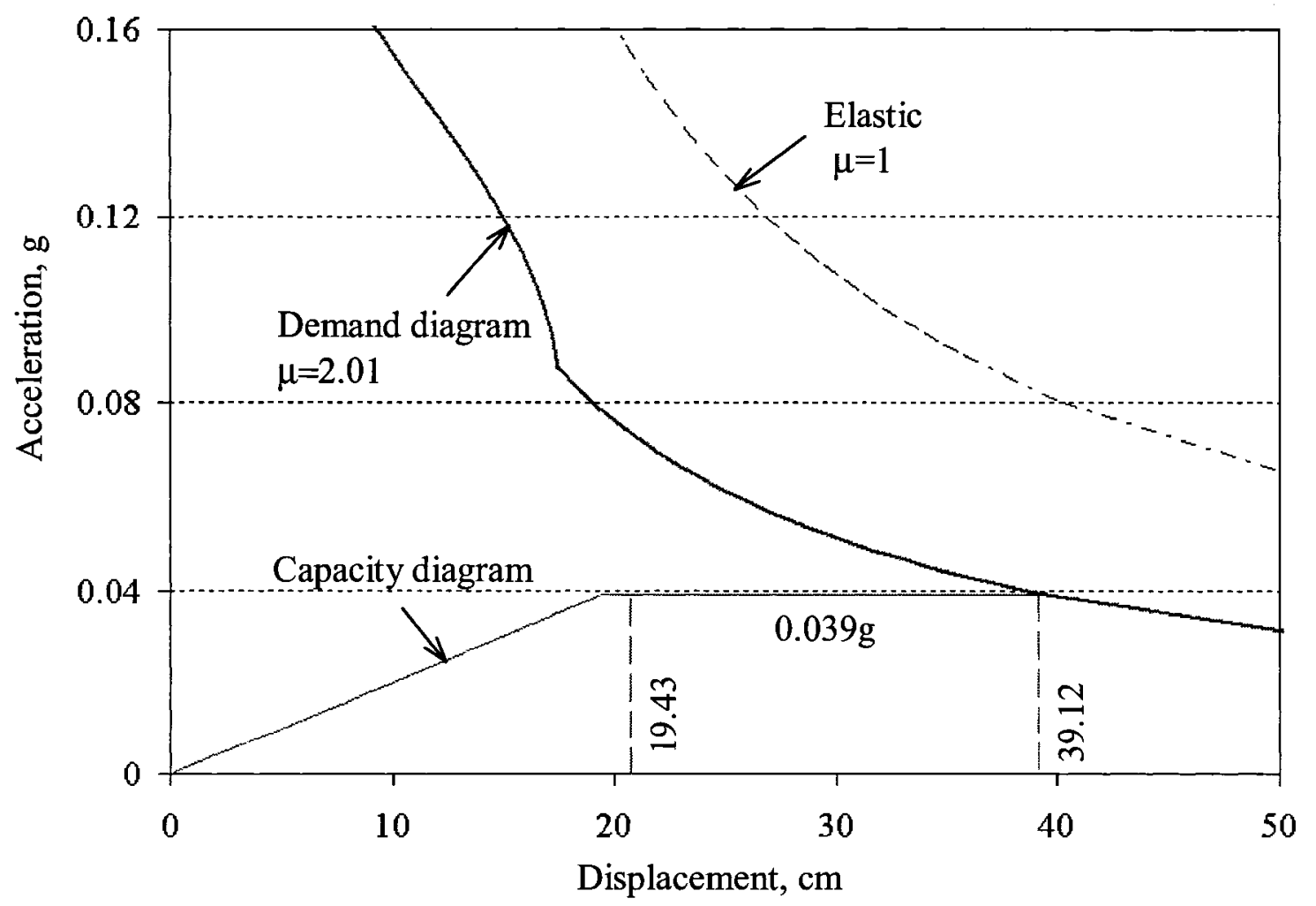

Figure (3.14): Displacement Based Design of 12-Story Steel Frame In Vancouver - first try 


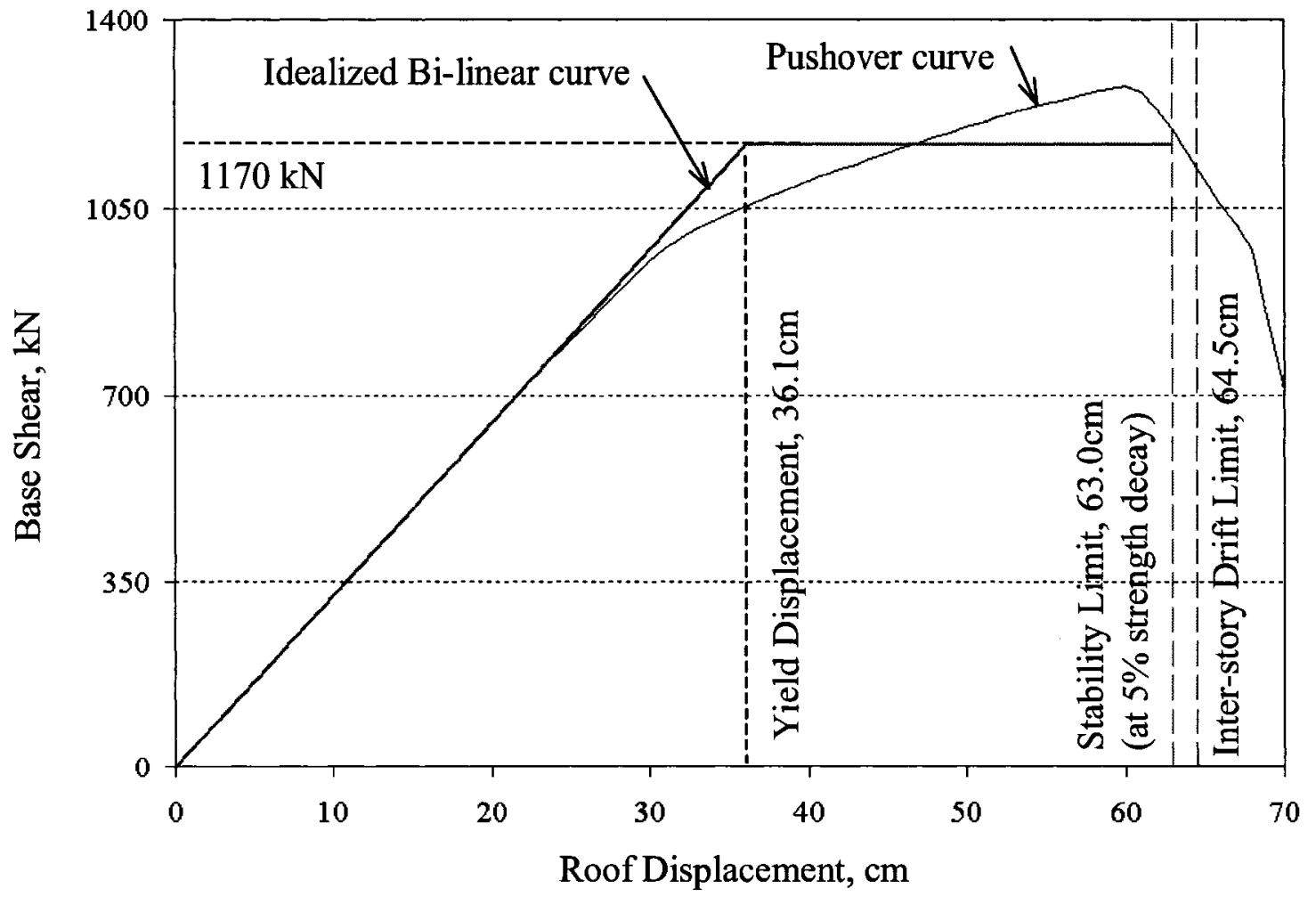

Figure (3.15): Pushover Curve - first design

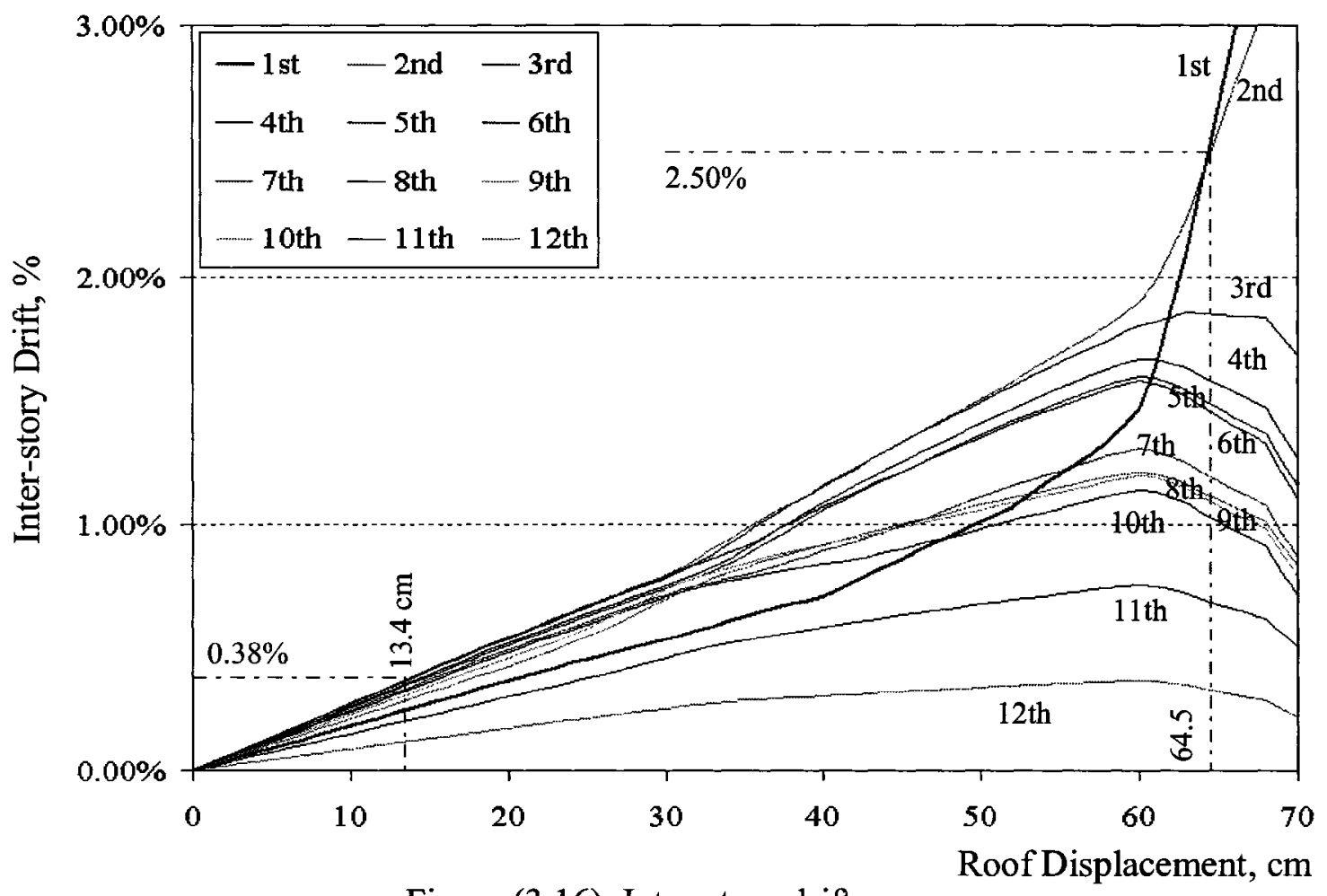

Figure (3.16): Inter-story drifts 


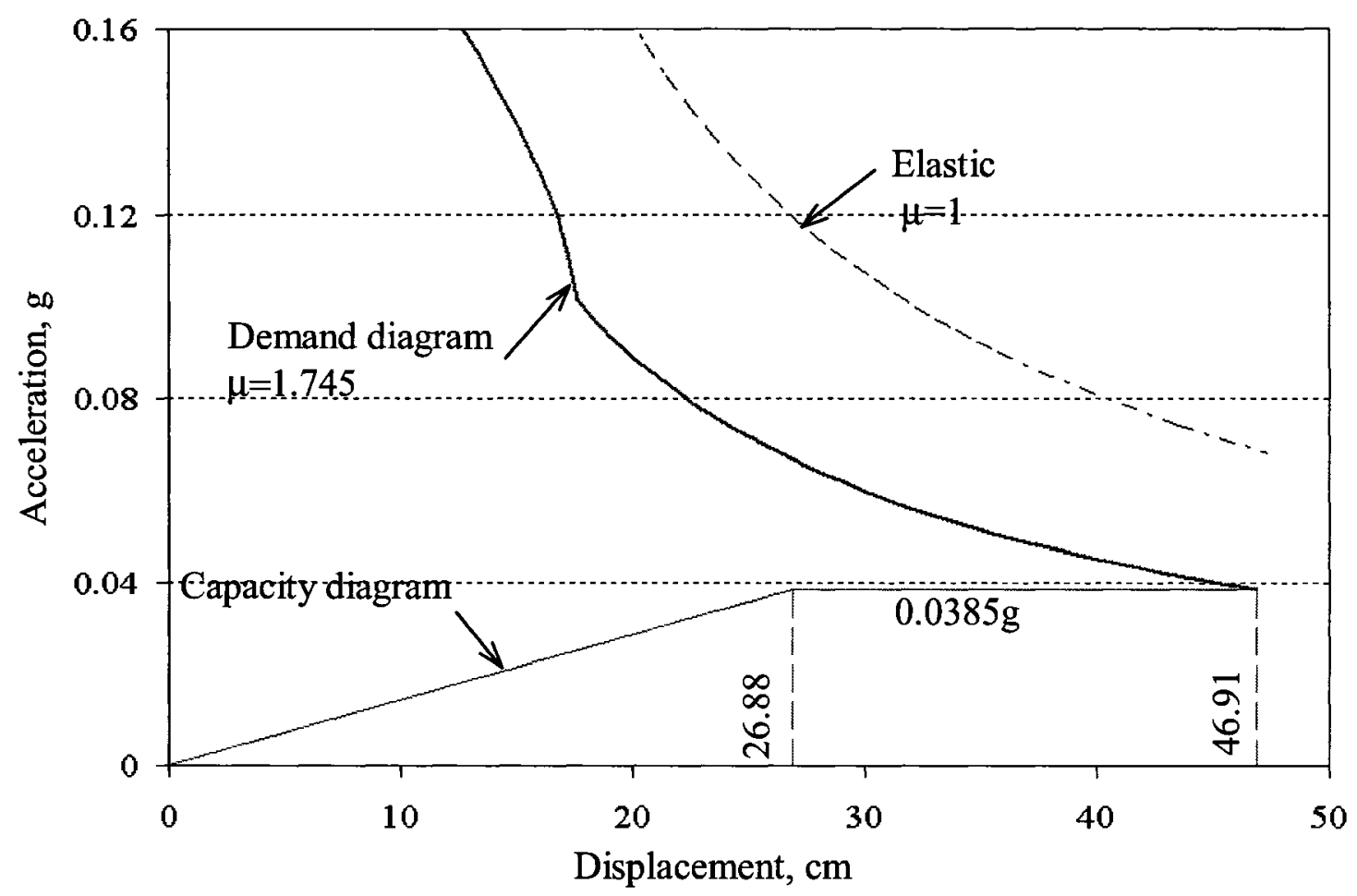

Figure (3.17): Displacement Based Design of 12-Story Steel Frame in Vancouver second try 

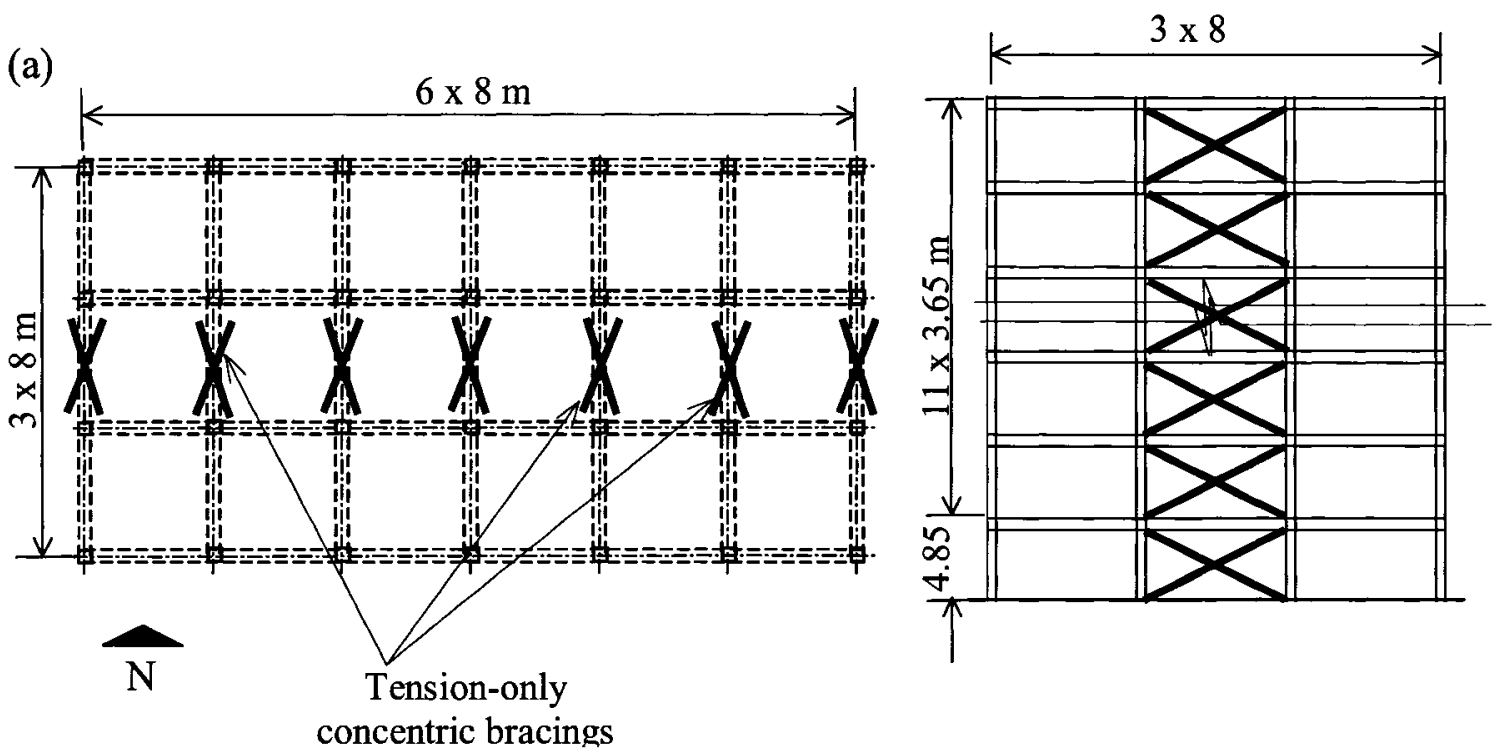

(b)

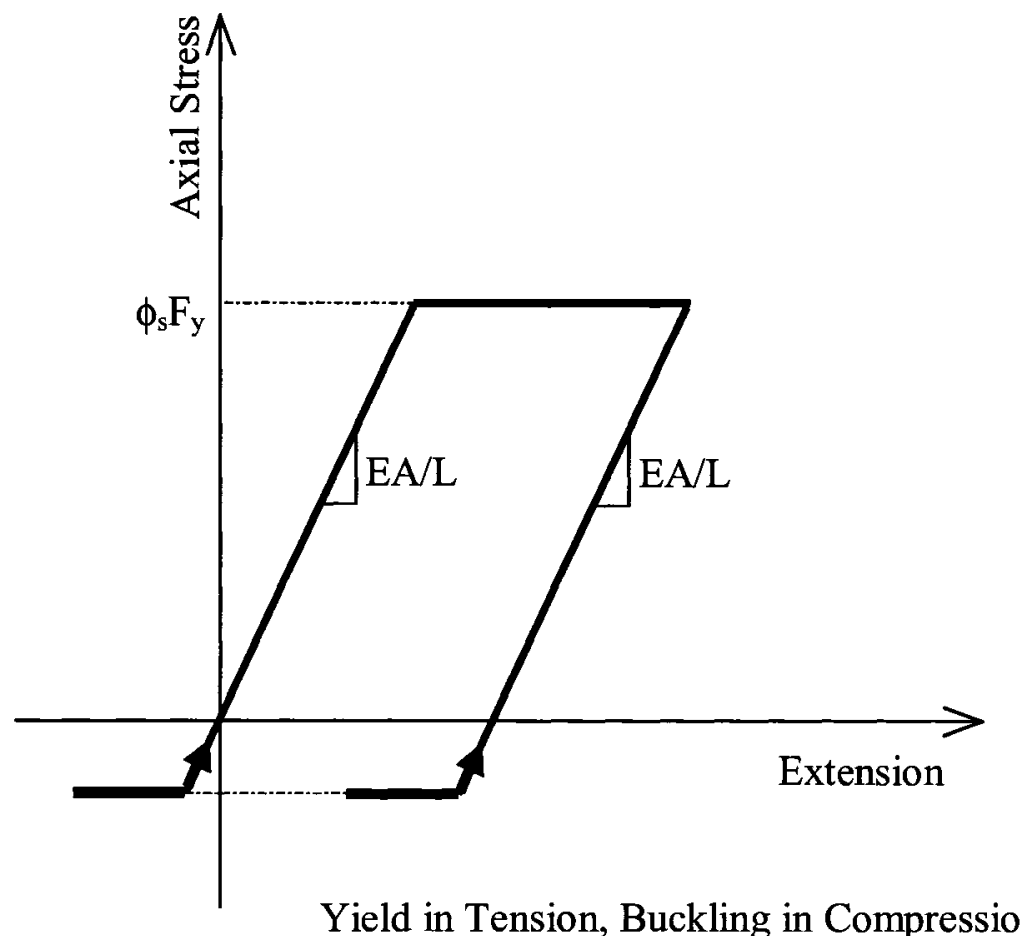

Figure (3.18): (a) Plan and Elevation of the concentrically braced frame (CBF) structure (b) Hysterisis behavior of the brace elements 


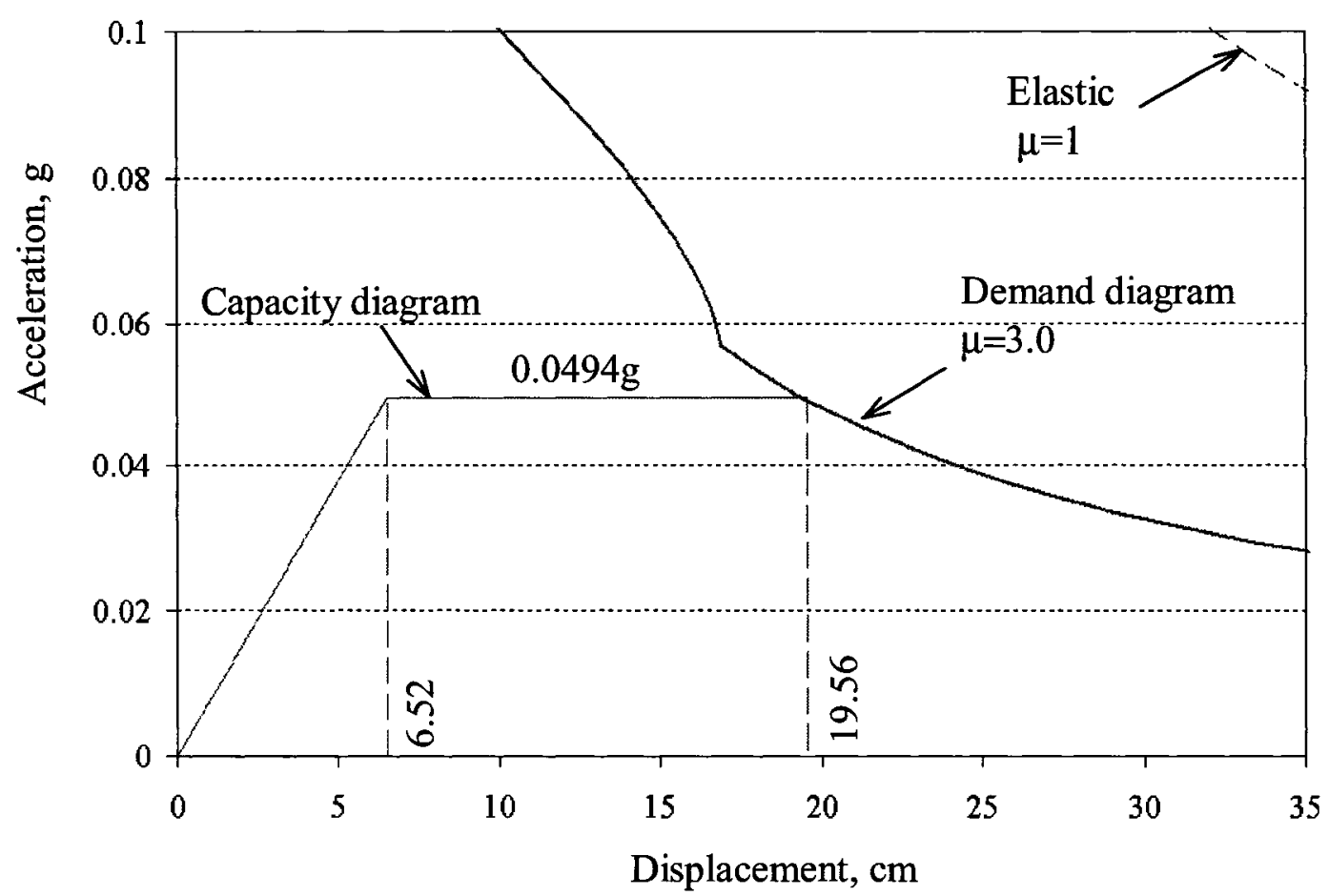

Figure (3.19): Displacement Based Design of 12-Story CBF in Vancouver - first try

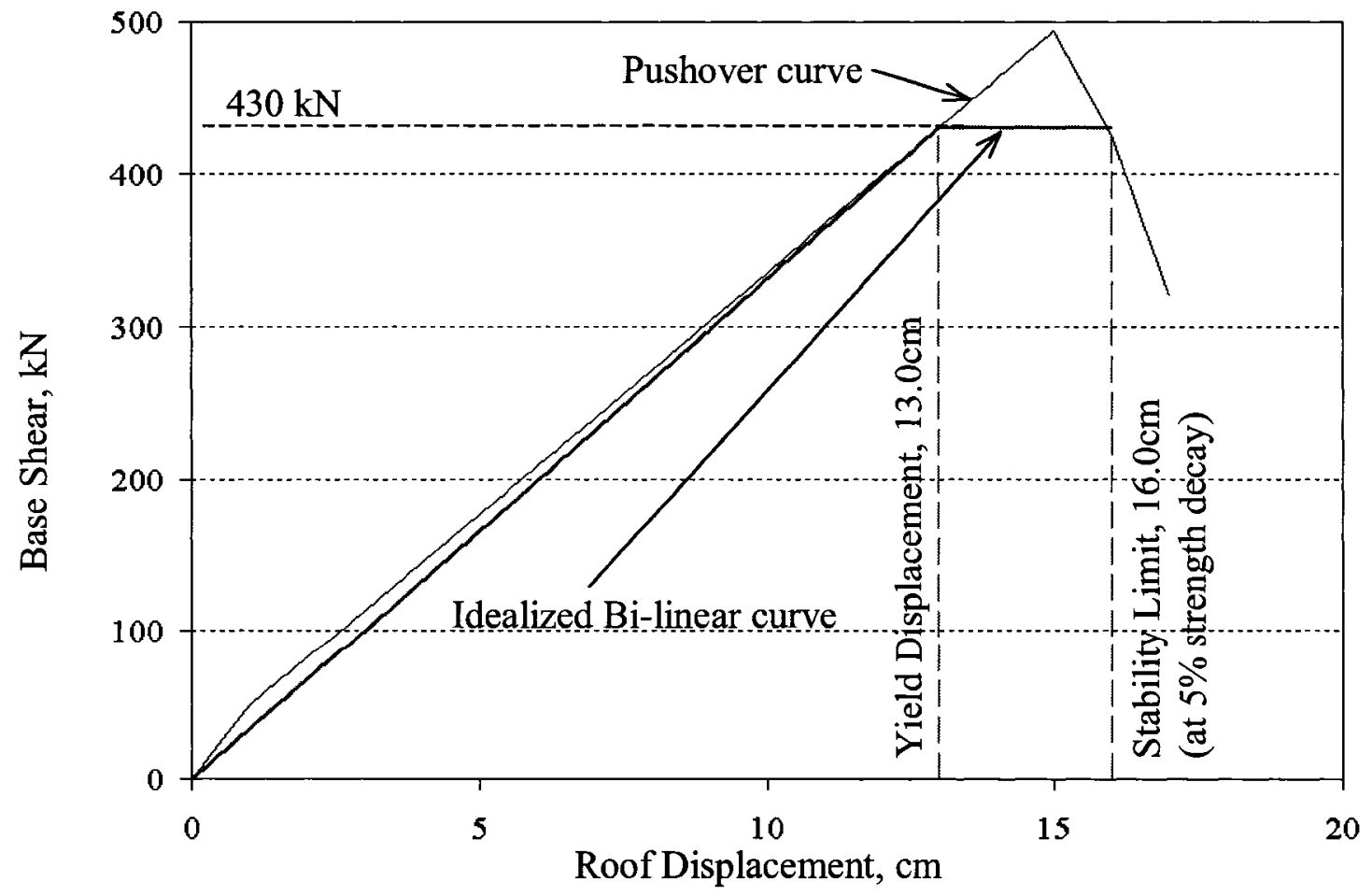

Figure (3.20): Pushover Curve - first design 


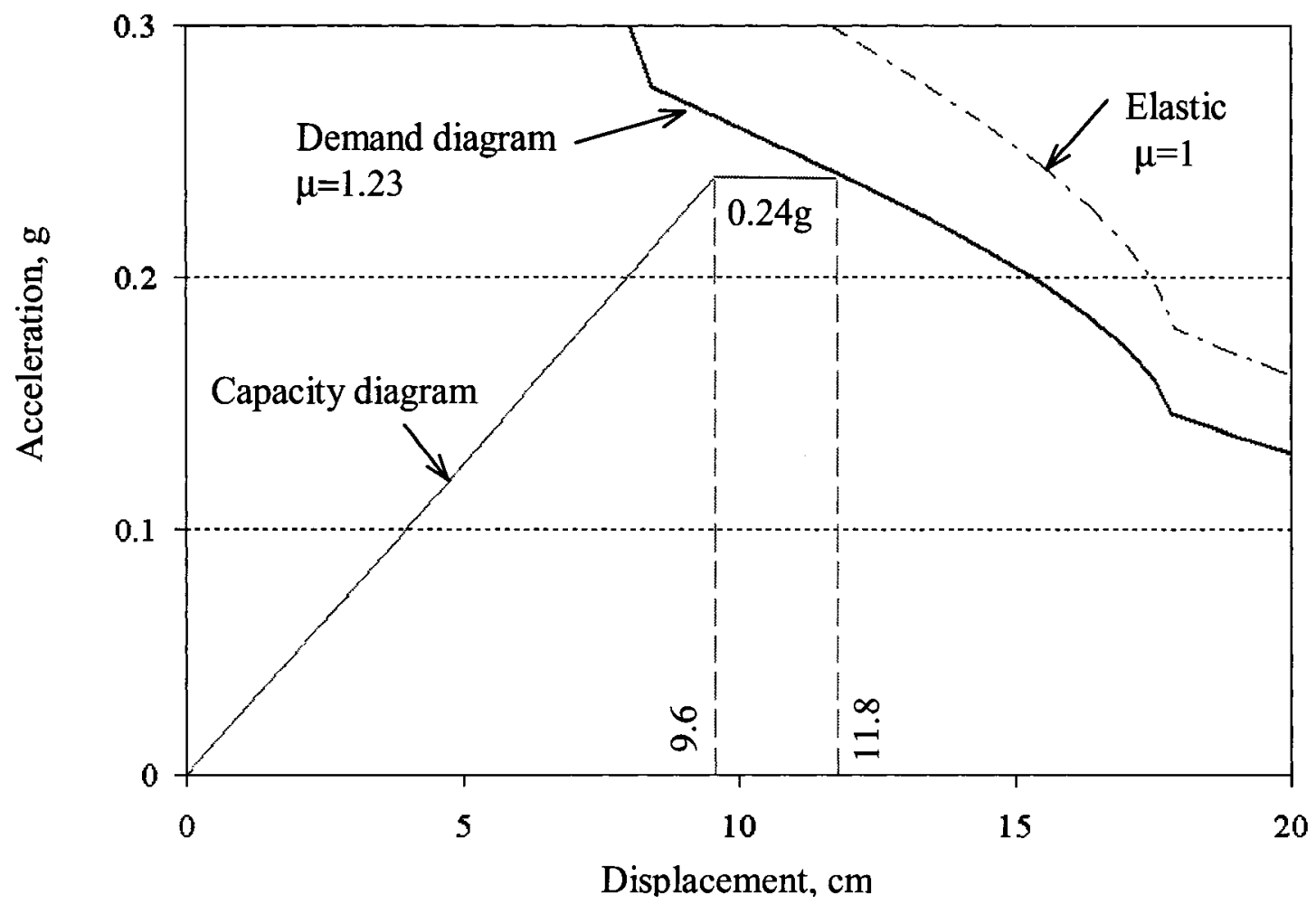

Figure (3.21): Displacement Based Design of 12-Story CBF in Vancouver - second try

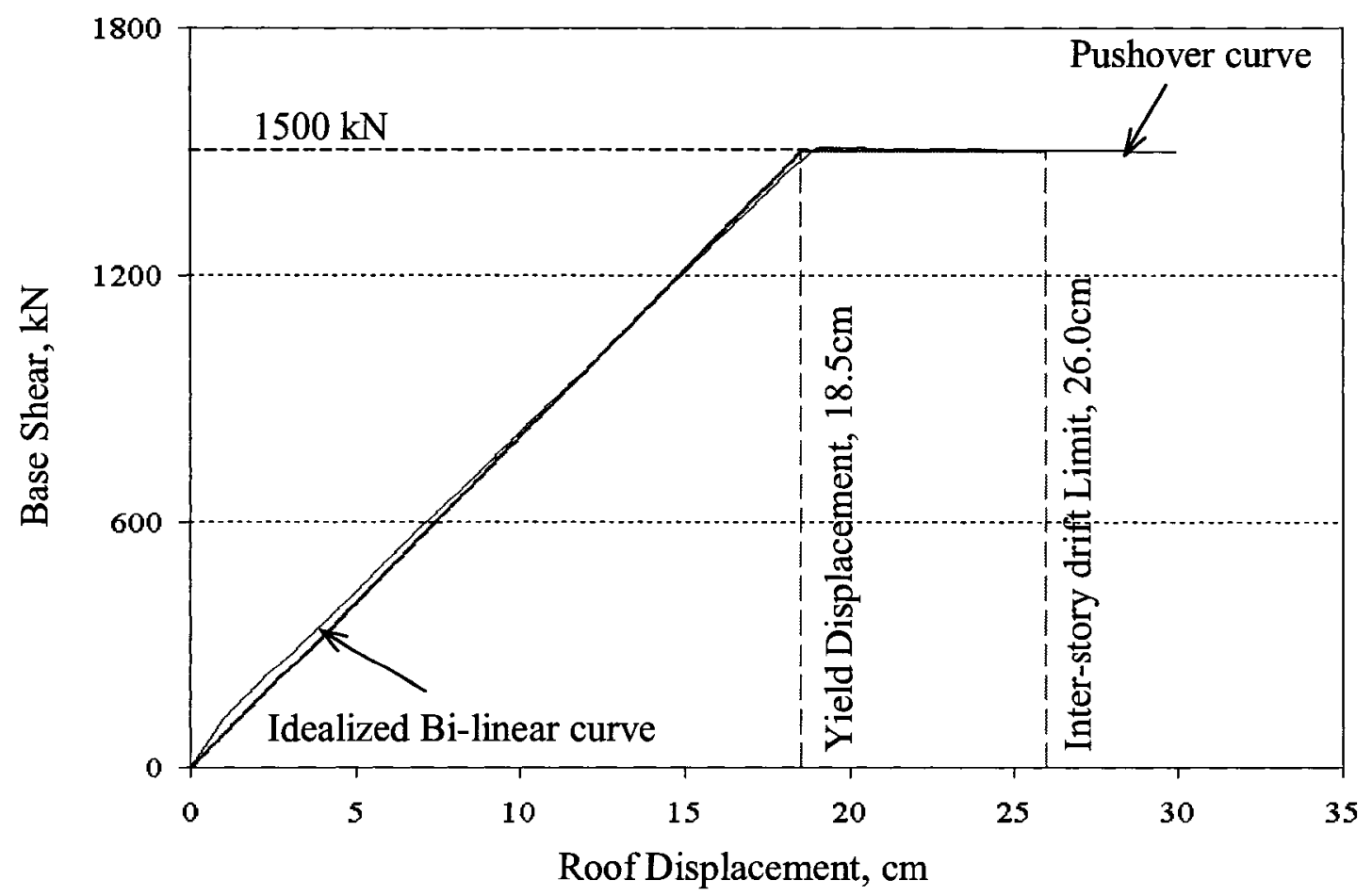

Figure (3.22): Pushover Curve - second design 


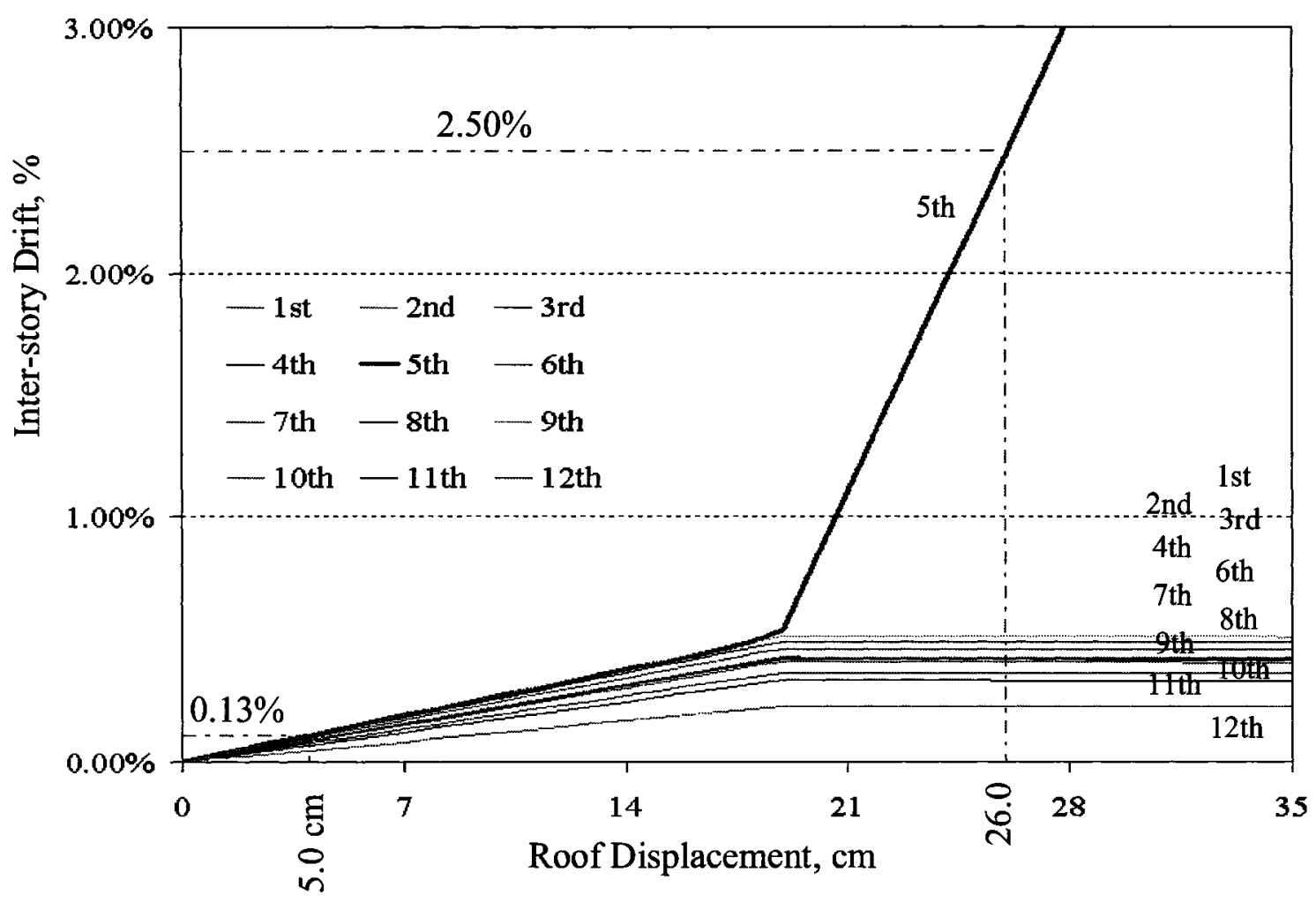

Figure (3.23): Inter-story drifts

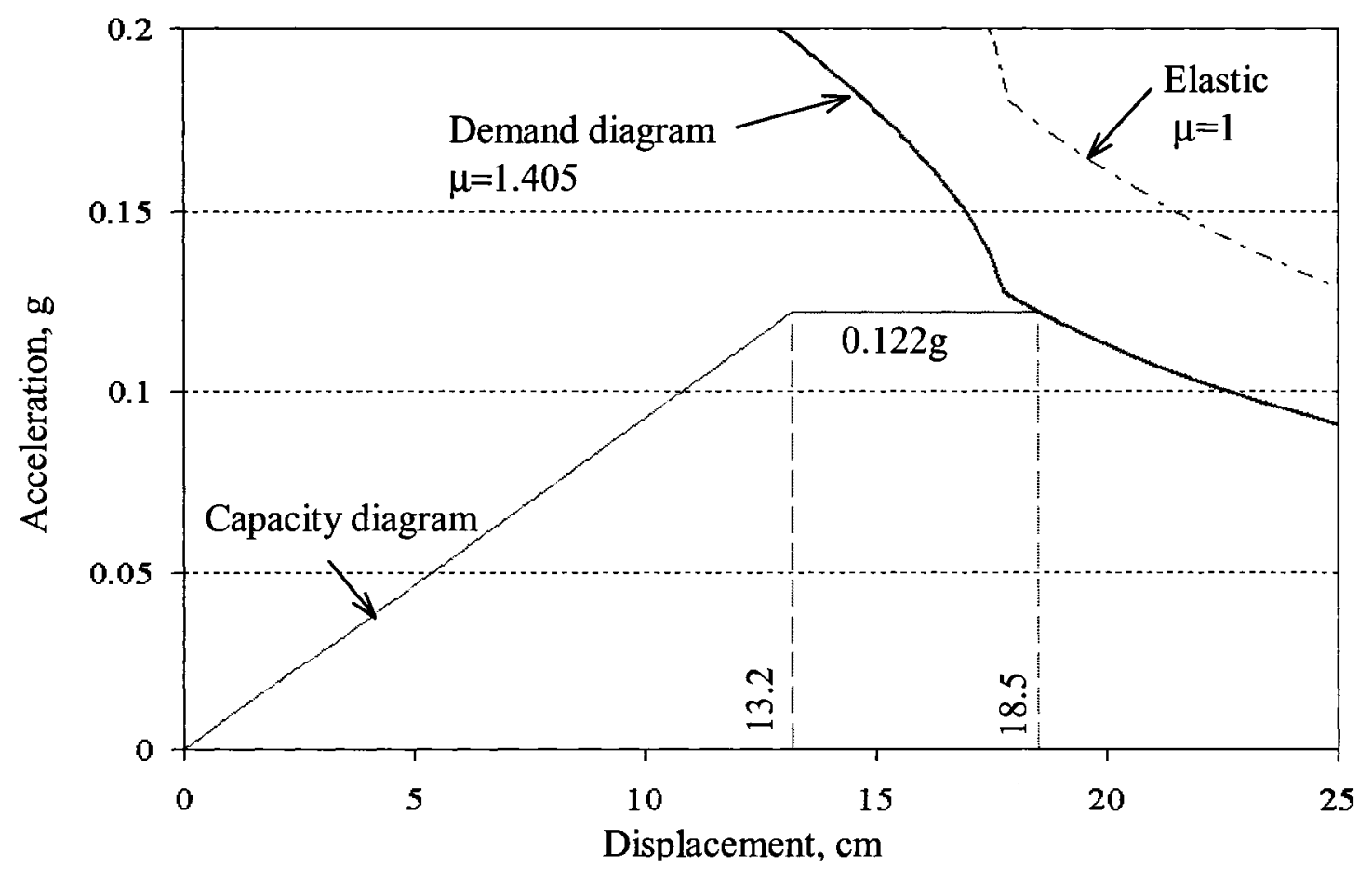

Figure (3.24): Displacement Based Design of 12-Story CBF in Vancouver - third try 


\section{Chapter 4}

\section{Selection and Scaling of Ground Motions for Canada}

\subsection{Introduction}

The nonlinear response of structures depends strongly on the characteristics of the input ground motion including its frequency content and phase angles. The linear response of a structure can often be obtained from a single time history matched to a target spectrum, whereas, the use of multiple realistic time histories with phasing and response spectral peaks and troughs that are appropriate for the magnitude, distance, site conditions and wave propagation characteristics of the region is necessary for an appropriate measure of the nonlinear response of the structure. The purpose of providing suites of time histories is to provide a statistical sample of this variability in phasing and response spectra through a set of time histories that are realistic not only in their average properties, but also in their individual characteristics.

One of the objectives of this study is to develop relationships between the maximum inter-story drift and roof drift for various structural systems. Another objective is to validate the proposed displacement-based design method by studying the behaviour of the designed structure when subjected to appropriate ground motions and determining the statistical properties of certain demand parameters. To achieve these objectives, quantification of the demand imposed on these systems through analysis of the structural 
response to spectrum compatible ground motions is necessary. The focus of this chapter is on the demand side of equation and not on evaluating the influence of structural system and proportioning and ground motion character and intensity on the global response of structure.

To fit within a reliability framework and be appropriate for implementation in Canadian building code, ground motion used for these analyses must be based on probabilistic estimates of seismic hazard appropriate to Canada's geographic regions.

Development of ground motions for two of Canada's largest urban centres at high risk, Vancouver in the west and Montreal in the east, and for a hazard corresponding to probability of exceedence of $2 \%$ in 50 years will be considered.

\subsection{Review of Literature Related to Selection and Scaling of Ground Motions}

\subsubsection{Ground Motion Scaling Methods}

Design spectrum compatible time histories are widely used in analysis and design of structures. Scaling ground motions in frequency domain is a technique that is often employed to develop spectrum compatible time histories. In this method, the maximum response of a SDOF system to the ground motion is compared to the target spectrum ordinate at selected periods. The computed spectral ordinate at a given period is modified so as to match the target spectrum by reducing or increasing the Fourier coefficient of the ground motion at the same period. These coefficients are obtained by Fourier analysis of 
the time history. Inverse Fourier transformation is carried out using the modified coefficients and a modified accelerogram is obtained. This time history is used for the next iteration and the procedure is repeated until computed and target spectra match. Program SYNTH (Naumoski 1998) uses this method for the scaling of ground motions.

Naeim and Marshall (1995) examined the use of frequency-domain scaled ground motions. It was shown that this method of scaling was based on an unrealistic understanding of the concept of design spectra and could lead to major problems. The modified time histories may produce velocities, displacements and energy content that are not realistic. Use of frequency-domain-scaled design-spectrum-compatible time histories in the design of earthquake resistant structures, therefore, requires extreme caution.

An alternative approach for spectral matching is to adjust the time history in the timedomain by adding wavelets to the original time history. In this method, considering the time of peak response $t_{i}$, an adjustment time history $\delta a(t)$ is added to the reference time history $a(t)$, such that at time $t_{i}$, the response of $a(t)+\delta a(t)$ is equal to that represented by the target spectrum, assuming that the time of peak response of $a(t)$ will not be affected by this adjustment. Program RSPMATCH (Abrahamson 1993) uses this procedure to produce non-stationary spectrum compatible ground motions. 
In both frequency and time-domain scaling, the shape of the response of reference time history is modified to match the target spectrum. However, such modification may change the characteristics of the ground motion. In order to preserve the individual characteristics of the ground motions, it is essential that the original shape of response spectrum is maintained. This is achieved in the scaling method proposed by Somerville (1997), where a scaling factor is found which minimizes the weighted sum of the squared error between the response spectrum of the scaled time history and the target spectrum at selected periods. Lognormal distribution of amplitudes is assumed and a smaller weight is given to the error at short reference period. For example, weights of $0.1,0.3,0.3$ and 0.3 are used for errors at periods of $0.3,1.0,2.0$ and 4.0 seconds, respectively. This method of scaling preserves the shape of response spectrum.

Shome et al (1998) investigated the use of different methods of scaling and compared their relative advantages. Several alternative scaling measures were considered in his study including scaling to the peak ground acceleration (PGA) level, scaling to the spectral acceleration level averaged over a period interval, scaling to the spectral acceleration at a higher level of damping etc. It was observed that the scaling of groundmotion records to match the 5\%-damped spectral acceleration at the fundamental period of the structure was the best. The scaling to the PGA was not recommended and the results from other cases showed that some marginal reduction in variance may exist but that it was not worth the effort. 


\subsubsection{Selection of Ground Motions for US}

Somerville et al (1997) developed ground motion time histories for use in SAC Phase 2 steel project. Ground motion estimates were provided for three cities of the United States (Boston, Seattle and Los Angeles) corresponding to seismic zones 2, 3 and 4, respectively. In each of these locations, suites of ground motions were provided at two probabilities of occurrences, $2 \%$ in 50 years and $10 \%$ in 50 years, for firm soil conditions.

For generating the ground motion histories Somerville et al used USGS (United States geological survey) response spectra for site category $\mathrm{S}_{\mathrm{B}} / \mathrm{S}_{\mathrm{C}}$ boundary (soft rock conditions) with four return periods. Previously recorded ground motions from earthquakes having magnitude and distance characteristics similar to those of the events contributing to the seismic hazard at the site under consideration were used. Since deaggregations of probabilistic seismic hazard for the selected cities were not available at the time of study, approximate ranges of magnitude and distance were selected based on the deaggregation of seismic hazard in other projects. Ground motions recorded in the region were preferred but recordings from similar source categories and seismic regions were also considered. Broadband strong ground motion simulations were generated in cases where sufficient recorded time histories were not available. The selected ground motions were modified for site condition, rotation to strike-normal and strike-parallel (in near-fault ground motions), low pass filtering and base line correction. Finally they were scaled to the target spectra. In order to maintain the original characteristics of the selected ground motions, the shapes of the response spectra of the individual time histories were 
not modified in the scaling procedure. Assuming lognormal distribution of amplitudes, a single scaling factor was calculated to minimize the weighted sum of squared error between the target spectrum and the average response spectrum of the two horizontal components of time history. To generate soft soil records, six soil profiles were chosen and selected time histories were applied at the underlying rock. SHAKE program was used for the dynamic analysis required to obtain the ground motion at the surface.

\subsection{Deaggregation results for Eastern Canada}

Open file 4459 of the Geological Survey of Canada (2003) presents the hazard values for the NBCC 2005 in the table entitled "Design Data for Selected Locations in Canada". Also provided are the full Uniform Hazard Spectra (UHS) for 23 cities, prepared for sites on firm soil at the $2 \%$ in 50 years probability of being exceeded ( 0.000404 per annum). As an example, Table (4.1) shows the probabilistic seismic hazard estimates for Montreal.

Halchuk and Adams (2004) have deaggregated the seismic hazard results for several cities and presented the relative contributions of the earthquake sources defined in terms of distance and magnitude. To examine the hazard for two of Canada's large cities at high risk, Vancouver in the western Canada and Montreal in the east, deaggregation for range of spectral accelerations for periods ranging from 0.1 to $2.0 \mathrm{~s},\left(\mathrm{~S}_{\mathrm{a}}(0.1)\right.$ to $\left.\mathrm{S}_{\mathrm{a}}(2.0)\right)$, and for several probabilities was performed. Deaggregation results of Montreal for a probability of $2 \%$ in 50 years are shown in Figures (4.1) through (4.4) (Halchuk and 
Adams 2004). Moderate and large earthquakes of the IRM (Iapetan Rift Margin) zone dominate short- and long-period hazard, although there is some contribution from GAT (Gatineau) zone. The mean and mode values of magnitude and distance are summarized in Table (4.2).

\subsection{Deaggregation results for Western Canada}

Probabilistic seismic hazard estimates of Vancouver for probability of $2 \%$ in 50 years are shown in Table (4.3). Deaggregation results are presented in Figures (4.5) through (4.8)(Halchuk and Adams 2004). The contribution of the great earthquakes on the Cascadia Subduction zone are excluded from the deaggregation process. These earthquakes are treated deterministically by Adams and Halchuk in Open File Report 4459 (2003), where it is shown that the uniform hazard spectrum for Vancouver is not governed by Cascadia zone (Figure (4.9)). In Vancouver crustal and subcrustal earthquake sources have very different activities and produce ground motions with different characteristics at the surface. For all period ranges the largest contribution to hazard comes from earthquakes at distances above $50 \mathrm{~km}$. This is the result of the dominant contribution of subcrustal zones PUG (Puget Sound) and GSP (Georgia Strait/ Puget Sound). The subcrustal earthquakes could not occur within a hypocentral distance less than $50 \mathrm{~km}$ in Vancouver, because they happen at a depth greater than $50 \mathrm{~km}$. Earthquakes at distances less than $50 \mathrm{~km}$ and located in the crustal zone do make significant contribution to the long period hazard, which leads to a bimodal 
deaggregation. The mean and mode values of magnitude and distance are shown in Table (4.4) (Halchuk and Adams 2004).

\subsection{Ground motions of Eastern Canada}

Major earthquakes are rare in the eastern region of Canada and northeastern US and very few of them have been recorded in the last decade. The available ground motions of this region are from the few events that occurred between 1982 and 2002 with magnitudes 4 to 5.9 and were recorded at distances between 4 and $800 \mathrm{~km}$. Some of these ground motions are shown in Table (4.5a). Considering the results of deaggregation for Montreal, many of these records cannot be used as spectrum compatible ground motions. At the same time, for each region at least 20 ground motions must be selected. This quantity usually gives satisfactory result in representing all of the earthquake source characteristics. In order to provide more records, ground motions of other Stable Continental Regions (SCR) could be used. One possible source is the SCR earthquake database developed by Johnston (1990). In that database all known earthquakes of magnitude 5 or greater that have occurred in stable continental crust of Africa, Antarctica, Australia, China, Europe, India, North America and South America are listed (Table (4.6)). According to Johnston's study, the stable continental regions of the earth are similar in geological and geophysical characteristics, so that their earthquakes may be considered in one data set. Figure (4.10) taken from Johnston's work shows regression curve between Unified Magnitude, $M_{u}$ and seismic Static Moment, $M_{0}$ for stable continental regions data set. $\mathrm{M}_{\mathrm{u}}$ is weighted average of $\mathrm{M}_{\mathrm{b}}$ (Body Wave Magnitude) and 
$M_{s}$ (Surface Wave Magnitude) and $M_{o}$ is a function of the area of rupture, rupture strength and average lateral displacement of fault. The conclusion reached in Johnston's study is confirmed since no systematic intra-SCR differences are observed in this figure.

An updated earthquakes catalog for stable continental regions that includes date, time, magnitude and coordinates of events, is presented by Schulte and Mooney (2004). This catalog contains crustal events with depth less than $45 \mathrm{~km}$ and magnitude greater than 4.5, from the historic era up until 2003. Around 1373 events from stable parts of North and South America, India, Eurasia (Europe and Russia), China, Australia and Africa are listed in this database.

The information in the two catalogs mentioned above is used to search for the earthquake records from reliable sources including GSC (Geological Survey of Canada), USGS (United States Geological Survey), Cosmos (Consortium of Organizations for StrongMotion Observation System), McMaster University, Columbia University, NGDC (National Geophysical Data Center) and ESD (European Strong-Motion Data) databanks. Some of the available ground motions are listed in Table (4.5b). The 5\% damped elastic response spectra of all ground motions listed in Tables (4.5a) and (4.5b) and the UHS of Montreal for $2 \%$ probability of being exceeded in 50 years are plotted in Figure (4.11). Substantial scatter exists in the response spectra of these records. 


\subsection{Selection of spectrum-compatible ground motions for Eastern Canada}

The 5\% damped spectral response acceleration values of NBCC 2005 are given for the reference ground condition, site class C. Soil profile of this site class in top $30 \mathrm{~m}$ is defined as very dense soil or soft rock with average shear wave velocity in range of 360 to $760 \mathrm{~m} / \mathrm{s}$. In selection of earthquake records, preference is given to the ground motions that are recorded in the same type of soil. Also, in order to develop design spectrum compatible ground motions with less bias, four criteria are considered as follows.

\subsubsection{Compatibility with the deaggregation results}

The most important factor for a ground motion to be accepted is compatibility with the results of deaggregation for Montreal. This means that at the first step any earthquake record whose magnitude or distance is not in the acceptable range is excluded. Compatibility results for all records are shown in column 16 of Tables (4.5a) and (4.5b).

\subsubsection{Smaller scaling factor}

Selected ground motions are scaled to match the design response spectrum. In order to maintain the original characteristics of the records, scaling methods that do not change the shape of response spectrum, are preferred. Two scaling methods are used at this stage. In the first scaling method, a single scaling factor is found which minimizes the weighted squared error between the target spectrum and the average response spectrum of the two horizontal components of the time history at selected periods assuming lognormal 
distribution of amplitudes. The weights used are $0.1,0.3,0.3$ and 0.3 for periods of $0.3,1$, 2 and 4 seconds respectively (Somerville 1997).

In the second scaling method, ground-motion records are scaled to the 5\%-damped spectral acceleration at the fundamental period of the structure (Shome et al 1998). This scaling factor is calculated for a period of $\mathrm{T}=1.0$ second, which is reasonable for a midrise structure. For all ground motions both, Somerville and Shome, scaling factors are shown in columns 13 and 14 of Tables (4.5a) and (4.5b). Somerville scaling factors are calculated for the average of two records in orthogonal directions. These factors range between 0.74 (record No. 44 of India) to over 2000 (record No.18 of Quebec). At this step, ground motions for which either of the two scaling factors is larger than 30 are excluded.

\subsubsection{Spectral intensity of ground motions}

The modified spectral intensity ( $\mathrm{SIb}$ ), as defined by Lestuzzi et al (2004), is calculated for all ground motions. This parameter is defined based on the Pseudo-Velocity spectrum $\left(\mathrm{P}_{\mathrm{sv}}\right)$ at damping ratio of $\zeta=5 \%$,

$\mathrm{SIb}=\frac{1}{\Delta \mathrm{T}} \int_{\mathrm{T}_{0}}^{\mathrm{T}_{\mathrm{S}}} \mathrm{P}_{\mathrm{SV}}(\xi=5 \%) \cdot \mathrm{dt}$

where, the periods $T_{0}$ and $T_{s}$, which define the range of integration, are chosen as 1 and 2 seconds, respectively. It is expected that the first few modal periods of the many 
buildings of 10 to 20 stories would lie in this range. Calculated SIb factors are compared to that for the design spectrum of Montreal; the differences between the two are shown in column 15 of Table (4.5a) and (4.5b). As the third criterion, ground motions whose spectral intensity differs by more than $50 \%$ from that for the Montreal design response spectrum are excluded.

\subsubsection{Spectral shape}

Similarity between the spectral shape of ground motions and the target design spectrum is used as the final criterion. Considering that the period of highest significant mode varies between 0.3 to 0.5 second, 20 of the remaining ground motions that show least bias in this range are chosen. The final list of the records for Montreal (Eastern Canada) is shown in Table (4.7). In this table, Somerville scale factors are calculated for each record independently. Response spectra of the selected records that have been scaled using Somerville factor are compared to Montreal design spectrum in Figure (4.12).

\subsection{Filtering of the records}

In order to achieve reliable results from non-linear time history analysis, it is necessary to use corrected records. Majority of the selected ground motions are originally filtered and no extra processing is required. Some of the selected ground motions that had been already filtered had been subjected to $8^{\text {th }}$ order elliptical band pass filter with limits of $0.25 \mathrm{~Hz}$ and $25 \mathrm{~Hz}$. In other cases Butterworth filters with high pass frequency limit of $0.65-2 \mathrm{~Hz}$ and low pass frequency limit of $25-27 \mathrm{~Hz}$ were used. The uncorrected ground 
motions were filtered as a part of this study using high pass Butterworth filter with frequency limit of $0.5 \mathrm{~Hz}$ and low pass filter with limit of $50 \mathrm{~Hz}$.

\subsection{Baseline Correction of the records}

The baseline correction procedure presented by Iwan et al (1985) and Boore (2001) is used in this study for the processing of uncorrected ground motions. In this method it is assumed that the baseline offset after and before the strong shaking are different. To correct ground motions with baseline shifts, two baseline shifts are calculated and removed, one from the strong shaking part of the acceleration time history (say acceleration more than $50 \mathrm{~cm} / \mathrm{sec}^{2}$ ) and one from the rest of the record. Zero velocity constraint at the end of record is applied to the correction process.

\subsection{Ground motions of Western Canada}

Uniform hazard spectrum for Vancouver is not governed by Cascadia subduction zone as shown in open file report 4459 by Adams and Halchuk (2003). Subcrustal earthquakes at distance larger than $50 \mathrm{~km}$ and crustal earthquakes at distance less than $50 \mathrm{~km}$ both make significant contribution in this region. Since the number of suitable ground motions recorded on crustal and subcrustal sources in western Canada and north western US is not adequate, similar sources from other regions of the world including Japan, New Zealand, south and Central America are considered. 
Pina (2006) selected spectrum compatible ground motions for Western Canada, specifically for the city of Vancouver. A methodology similar to that described here was followed by Pina for the selection and scaling of the records. The 20 ground motions finally selected are from Tokachi Oki earthquake in Japan 2003, regional Olympia 1949, Puget Sound 1965 and Nisqually 2001 ground motions. The selected records along with the associated calculated Somerville scale factors are shown in Table (4.8). The response spectra of the scaled records are compared to Vancouver design spectrum in Figure (4.13). 
Table (4.1): Probabilistic Seismic Hazard Estimates for Montreal, 2\% in 50 years (Open file 4459- Geological Survey of Canada 2003)

\begin{tabular}{|c|c|c|c|c|}
\hline \multirow{2}{*}{} & \multicolumn{2}{|c|}{ H Model } & \multicolumn{2}{c|}{ R Model } \\
\cline { 2 - 5 } & $50 \%$ ile & $84 \%$ ile & $50 \%$ ile & $84 \%$ ile \\
\hline $\mathrm{S}_{\mathrm{a}}(0.1)$ & 0.57 & 0.89 & 0.65 & 0.95 \\
\hline $\mathrm{S}_{\mathrm{a}}(0.15)$ & 0.58 & 0.97 & 0.71 & 1.1 \\
\hline $\mathrm{S}_{\mathrm{a}}(0.2)$ & 0.58 & 1.0 & 0.69 & 1.2 \\
\hline $\mathrm{S}_{\mathrm{a}}(0.3)$ & 0.43 & 0.86 & 0.50 & 1.1 \\
\hline $\mathrm{S}_{\mathrm{a}}(0.4)$ & 0.35 & 0.86 & 0.39 & 0.95 \\
\hline $\mathrm{S}_{\mathrm{a}}(0.5)$ & 0.29 & 0.71 & 0.34 & 0.83 \\
\hline $\mathrm{S}_{\mathrm{a}}(1.0)$ & 0.13 & 0.38 & 0.14 & 0.44 \\
\hline $\mathrm{S}_{\mathrm{a}}(2.0)$ & 0.038 & - & 0.048 & - \\
\hline PGA & 0.37 & 0.59 & 0.43 & 0.63 \\
\hline PGV & 0.17 & 0.43 & 0.18 & 0.48 \\
\hline
\end{tabular}

Spectral accelerations and peak Ground Accelerations (PGA) are in terms of $\mathrm{g}$. Peak Ground Velocities (PGV) are in $\mathrm{m} / \mathrm{s}$.

$\mathrm{H}$ Model is based on historic earthquakes.

$\mathrm{R}$ Model is based on regional tectonics.

Table (4.2): Mean and Mode Magnitude and distance values for Montreal $2 \% / 50$ years (Halchuk and Adams, 2004)

\begin{tabular}{|c|c|c|c|c|}
\hline & \multicolumn{2}{|c|}{ Mean } & \multicolumn{2}{c|}{ Mode } \\
\cline { 2 - 5 } & Magnitude & Distance $(\mathrm{km})$ & Magnitude & Distance $(\mathrm{km})$ \\
\hline $\mathrm{S}_{\mathrm{a}}(0.2)$ & 6.5 & 39 & 6.875 & 30 \\
\hline $\mathrm{S}_{\mathrm{a}}(0.5)$ & 6.8 & 55 & 7.125 & 50 \\
\hline $\mathrm{S}_{\mathrm{a}}(1.0)$ & 6.9 & 64 & 7.125 & 50 \\
\hline $\mathrm{S}_{\mathrm{a}}(2.0)$ & 6.9 & 69 & 7.125 & 50 \\
\hline
\end{tabular}


Table (4.3): Probabilistic Seismic Hazard Estimates for Vancouver, 2\% in 50 years (Open file 4459- Geological Survey of Canada 2003)

\begin{tabular}{|c|c|c|c|c|}
\hline & \multicolumn{2}{|c|}{ H Model } & \multicolumn{2}{c|}{ R Model } \\
\cline { 2 - 5 } & $50 \%$ ile & $84 \%$ ile & $50 \%$ ile & $84 \%$ ile \\
\hline $\mathrm{S}_{\mathrm{a}}(0.1)$ & 0.83 & 1.7 & 0.80 & 1.6 \\
\hline $\mathrm{S}_{\mathrm{a}}(0.15)$ & 0.97 & 1.9 & 0.95 & 1.9 \\
\hline $\mathrm{S}_{\mathrm{a}}(0.2)$ & 0.96 & 1.9 & 0.96 & 1.9 \\
\hline $\mathrm{S}_{\mathrm{a}}(0.3)$ & 0.83 & 1.7 & 0.84 & 1.7 \\
\hline $\mathrm{S}_{\mathrm{a}}(0.4)$ & 0.72 & 1.4 & 0.74 & 1.5 \\
\hline $\mathrm{S}_{\mathrm{a}}(0.5)$ & 0.65 & 1.3 & 0.66 & 1.3 \\
\hline $\mathrm{S}_{\mathrm{a}}(1.0)$ & 0.30 & 0.60 & 0.34 & 0.68 \\
\hline $\mathrm{S}_{\mathrm{a}}(2.0)$ & 0.014 & 0.27 & 0.18 & 0.35 \\
\hline $\mathrm{PGA}$ & 0.48 & 0.96 & 0.47 & 0.94 \\
\hline
\end{tabular}

Peak Ground Accelerations (PGA) are in terms of $\mathrm{g}$.

$\mathrm{H}$ Model is based on historic earthquakes.

$\mathrm{R}$ Model is based on regional tectonics.

Table (4.4): Mean and Mode Magnitude and distance values for Vancouver $2 \% / 50$ years (Halchuk and Adams, 2004)

\begin{tabular}{|c|c|c|c|c|}
\hline \multirow{2}{*}{} & \multicolumn{2}{|c|}{ Mean } & \multicolumn{2}{c|}{ Mode } \\
\cline { 2 - 5 } & Magnitude & Distance $(\mathrm{km})$ & Magnitude & Distance $(\mathrm{km})$ \\
\hline $\mathrm{S}_{\mathrm{a}}(0.2)$ & 6.5 & 67 & 7.125 & 62.5 \\
\hline $\mathrm{S}_{\mathrm{a}}(0.5)$ & 6.7 & 52 & 6.875 & 62.5 \\
\hline $\mathrm{S}_{\mathrm{a}}(1.0)$ & 6.9 & 47 & 6.875 & 62.5 \\
\hline $\mathrm{S}_{\mathrm{a}}(2.0)$ & 7.0 & 48 & 7.375 & 62.5 \\
\hline
\end{tabular}


Table (4.5a): Available Ground Motions of Eastern Canada / North Eastern US

\begin{tabular}{|c|c|c|c|c|c|c|c|c|c|c|c|c|c|c|c|c|}
\hline & $\begin{array}{l}\text { No. } \\
\text { (1) }\end{array}$ & $\begin{array}{c}\text { Event } \\
(2)\end{array}$ & $\begin{array}{l}\text { Location } \\
\text { (3) }\end{array}$ & $\begin{array}{c}\text { Mag. } \\
(4)\end{array}$ & $\begin{array}{l}\text { Date } \\
(5)\end{array}$ & $\begin{array}{l}\text { Time } \\
(6)\end{array}$ & $\begin{array}{l}\text { Station } \\
(7)\end{array}$ & $\begin{array}{c}\text { Longit. } \\
(8)\end{array}$ & $\begin{array}{c}\text { Latit. } \\
(9)\end{array}$ & $\begin{array}{c}\text { Azim } \\
(10)\end{array}$ & $\begin{array}{l}\text { Dist. } \\
\text { (km) } \\
\text { (11) }\end{array}$ & $\begin{array}{l}\text { Data Source } \\
\text { (12) }\end{array}$ & $\begin{array}{c}\text { Somervill e } \\
\text { Factor } \\
\text { (13) }\end{array}$ & $\begin{array}{l}\text { Shome } \\
\text { Factor } \\
\text { (14) }\end{array}$ & $\begin{array}{c}\text { SIb Error } \\
\text { (Montreal) } \\
\text { (15) }\end{array}$ & $\begin{array}{c}\text { Match } \\
\text { Deagg. } \\
\text { (16) }\end{array}$ \\
\hline \multirow{24}{*}{$\left|\begin{array}{l}\mathrm{C} \\
\mathrm{A} \\
\mathrm{N} \\
\mathrm{A} \\
\mathrm{D} \\
\mathrm{A}\end{array}\right|$} & 1 & $A-1$ & New Brunswick & 4.8 & $03 / 31 / 82$ & $21: 02$ & Miramichi-Holmes L. & -66.6 & 47 & 18 & 6 & USGS & 20.10 & 38.00 & $-28 \%$ & Yes \\
\hline & 2 & A-2 & \begin{tabular}{|l|} 
New Brunswick \\
\end{tabular} & 4.8 & $03 / 31 / 82$ & $21: 02$ & Miramichi-Holmes L. & -66.6 & 47 & 288 & 6 & USGS & 20.10 & 20.80 & $-16 \%$ & Yes \\
\hline & 3 & $\mathrm{~A}-3$ & \begin{tabular}{|l|} 
New Brunswick \\
\end{tabular} & 4.8 & $03 / 31 / 82$ & $21: 02$ & Miramichi-Indian B. & -66.6 & 47 & 321 & 3 & USGS & 9.60 & 27.10 & $-19 \%$ & Yes \\
\hline & 4 & $\mathrm{~A}-4$ & \begin{tabular}{|l|} 
New Brunswick \\
\end{tabular} & 4.8 & $03 / 31 / 82$ & $21: 02$ & Miramichi-Indian B. & -66.6 & 47 & 231 & 3 & USGS & 9.60 & 8.00 & $-17 \%$ & Yes \\
\hline & 5 & A-5 & \begin{tabular}{|l|} 
New Brunswick \\
\end{tabular} & 4.8 & $03 / 31 / 82$ & $21: 02$ & Miramichi-Loggie L. & -66.6 & 47 & 189 & 6 & USGS & 7.80 & 18.00 & $-33 \%$ & Yes \\
\hline & 6 & A-6 & New Brunswick & 4.8 & $03 / 31 / 82$ & $21: 02$ & Miramichi-Loggie L. & -66.6 & 47 & 99 & 6 & USGS & 7.80 & 7.10 & $-19 \%$ & Yes \\
\hline & 7 & A-7 & New Brunswick & 4.8 & $03 / 31 / 82$ & $21: 02$ & Miramichi-Mitchell L. & -66.6 & 47 & 118 & 4 & USGS & 16.10 & 25.60 & $-21 \%$ & Yes \\
\hline & 8 & A-8 & \begin{tabular}{|l|} 
New Brunswick \\
\end{tabular} & 4.8 & $03 / 31 / 82$ & $21: 02$ & Miramichi-Mitchell L. & -66.6 & 47 & 28 & 4 & USGS & 16.10 & 24.60 & $-31 \%$ & Yes \\
\hline & 9 & B-1 & \begin{tabular}{|l|} 
New Brunswick \\
\end{tabular} & 4 & \begin{tabular}{|l|}
$05 / 06 / 82$ \\
\end{tabular} & $16: 28$ & Miramichi-Loggie L. & -66.6 & 47 & 189 & 7 & USGS & 17.10 & 36.60 & $-14 \%$ & Yes \\
\hline & 10 & $\mathrm{~B}-2$ & \begin{tabular}{|l|} 
New Brunswick \\
\end{tabular} & 4 & $05 / 06 / 82$ & $16: 28$ & Miramichi-Loggie L. & -66.6 & 47 & 99 & 7 & USGS & 17.10 & 13.70 & $-14 \%$ & Yes \\
\hline & 11 & B-3 & New Brunswick & 4 & $05 / 06 / 82$ & $16: 28$ & S3-Miramichi-Hickey L. & -66.6 & 47 & 99 & 4.1 & Cosmos & 27.22 & 25.80 & $1 \%$ & Yes \\
\hline & 12 & B-4 & New Brunswick & 4 & $05 / 06 / 82$ & $16: 28$ & S3-Miramichi-Hickey L. & -66.6 & 47 & 189 & 4.1 & Cosmos & 27.22 & 24.90 & $16 \%$ & Yes \\
\hline & 13 & C-1 & Saguenay & 5.9 & $11 / 25 / 88$ & $23: 46$ & S8-La Malbaie, $P Q$ & -71.2 & 48.1 & 63 & 93 & McMaster U. & 8.73 & 4.20 & $28 \%$ & Yes \\
\hline & 14 & $\mathrm{C}-2$ & \begin{tabular}{|l|} 
Saguenay \\
\end{tabular} & 5.9 & $11 / 25 / 88$ & $23: 46$ & S20,Elboulements,PQ & -71.2 & 48.1 & 0 & 90 & McMaster U. & 8.73 & 7.20 & $40 \%$ & Yes \\
\hline & 15 & $\mathrm{D}-1$ & Queb,Mt.Laurier & 4.6 & $10 / 19 / 90$ & $7: 02$ & Dickey & -75.6 & 46.5 & 0 & $727^{*}$ & Columbia U. & 815.90 & 745.00 & $26 \%$ & No \\
\hline & 16 & D-2 & Queb,Mt.Laurier & 4.6 & $10 / 19 / 90$ & $7: 02$ & Dickey & -75.6 & 46.5 & 90 & $727^{*}$ & Columbia U. & 815.90 & 1000.00 & $20 \%$ & No \\
\hline & 17 & D-3 & Queb,Mt.Laurier & 4.6 & $10 / 19 / 90$ & $7: 02$ & Island Falls & -75.6 & 46.5 & 177 & $822^{*}$ & Columbia U. & 1092.80 & 1324.20 & $-12 \%$ & No \\
\hline & 18 & D-4 & Queb,Mt.Laurier & 4.6 & $10 / 19 / 90$ & $7: 02$ & Island Falls & -75.6 & 46.5 & 267 & $822^{*}$ & Columbia U. & 1092.80 & 2032.10 & $-8 \%$ & No \\
\hline & 19 & D-5 & Queb,Mt.Laurier & 4.6 & $10 / 19 / 90$ & $7: 02$ & Massena & -75.6 & 46.5 & 335 & $186^{*}$ & Columbia U. & 460.50 & 626.10 & $-1 \%$ & No \\
\hline & 20 & D-6 & Queb,Mt.Laurier & 4.6 & $10 / 19 / 90$ & $7: 02$ & Massena & -75.6 & 46.5 & 245 & $186^{*}$ & Columbia U. & 460.50 & 626.10 & $-1 \%$ & No \\
\hline & 21 & D-7 & Queb,Mt.Laurier & 4.6 & $10 / 19 / 90$ & $7: 02$ & Lyon Mont. & -75.6 & 46.5 & 210 & $270^{*}$ & Columbia U. & 359.50 & 800.60 & $-14 \%$ & No \\
\hline & 22 & D-8 & Queb,Mt.Laurier & 4.6 & $10 / 19 / 90$ & 7:02 & Lyon Mont. & -75.6 & 46.5 & 300 & $270^{*}$ & Columbia U. & 359.50 & 296.20 & $-4 \%$ & No \\
\hline & 23 & $\mathrm{E}-1$ & \begin{tabular}{|l|} 
Southern Queb. \\
\end{tabular} & 4.5 & $12 / 31 / 90$ & $3: 53$ & Hebertville & -72.5 & 47.6 & 0 & $124^{*}$ & Columbia U. & 370.90 & 503.40 & $7 \%$ & No \\
\hline & 24 & $\mathrm{E}-2$ & Southern Queb. & 4.5 & $12 / 31 / 90$ & $3: 53$ & Hebertville & -72.5 & 47.6 & 90 & $124^{*}$ & Columbia U. & 370.90 & 368.10 & $9 \%$ & No \\
\hline $\mathrm{N}$ & 25 & F-1 & New Hampshire & 4.5 & $01 / 19 / 82$ & $14: 42$ & Franklin Falls Dam & & & 45 & 10.4 & Cosmos & 9.58 & 15.20 & $-14 \%$ & Yes \\
\hline $\mathrm{o}$ & 26 & F-2 & New Hampshire & 4.5 & $01 / 19 / 82$ & $14: 42$ & Franklin Falls Dam & & & 315 & 10.4 & Cosmos & 9.58 & 9.90 & $-22 \%$ & Yes \\
\hline $\mathrm{R}$ & $27 \mid$ & $\mathrm{F}-3$ & Vermont & 4.5 & $01 / 19 / 82$ & $14: 42$ & Ball Mountain Dam & & & 30 & 103.2 & Cosmos & 57.17 & 57.40 & $-38 \%$ & No \\
\hline $\mathrm{T}$ & 28 & $\mathrm{~F}-4$ & Vermont & 4.5 & $01 / 19 / 82$ & $14: 42$ & Ball Mountain Dam & & & 300 & 103.2 & Cosmos & 57.17 & 138.30 & $-60 \%$ & No \\
\hline $\mathrm{H}$ & 29 & F-5 & Vermont & 4.5 & $01 / 19 / 82$ & $14: 42$ & North Hartland Dam & & & 15 & 82.4 & Cosmos & 32.49 & 42.80 & $-6 \%$ & No \\
\hline $\mathrm{E}$ & \begin{tabular}{|l|}
30 \\
\end{tabular} & $\mathrm{~F}-6$ & Vermont & 4.5 & $01 / 19 / 82$ & $14: 42$ & North Hartland Dam & & & 285 & 82.4 & Cosmos & 32.49 & 37.20 & $-28 \%$ & No \\
\hline A & \begin{tabular}{|l|}
31 \\
\end{tabular} & F-7 & Vermont & 4.5 & $01 / 19 / 82$ & $14: 42$ & Union Village Dam & & & 245 & - & Cosmos & 58.93 & 80.60 & $-32 \%$ & \\
\hline s & 32 (32 & F-8 & Vermont & 4.5 & $01 / 19 / 82$ & $14: 42$ & Union Village Dam & & & 155 & - & Cosmos & 58.93 & 91.10 & $-44 \%$ & \\
\hline \multirow[t]{2}{*}{$\mathrm{T}$} & 33 & F-9 & Vermont & 4.5 & $01 / 19 / 82$ & $14: 42$ & North Springfield Dam & & & 185 & 74.6 & Cosmos & 65.10 & 109.70 & $-60 \%$ & No \\
\hline & 34 & $\mathrm{~F}-10$ & Vermont & 4.5 & $01 / 19 / 82$ & $14: 42$ & North Springfield Dam & & & 275 & 74.6 & Cosmos & 65.10 & 80.10 & $-23 \%$ & No \\
\hline $\mathrm{U}$ & 35 & $\mathrm{~F}-11$ & Vermont & 4.5 & $01 / 19 / 82$ & $14: 42$ & White River Jct. Hosp. & & & 270 & 59.1 & Cosmos & 47.40 & 108.50 & $-37 \%$ & \\
\hline \multirow[t]{3}{*}{ s } & 36 & $\mathrm{~F}-12$ & Vermont & 4.5 & $01 / 19 / 82$ & $14: 42$ & White River Jct. Hosp. & & & 180 & 59.1 & Cosmos & 47.40 & 45.90 & $-13 \%$ & \\
\hline & \begin{tabular}{|l|}
37 \\
\end{tabular} & G-1 & Evansville & 4.5 & $06 / 18 / 02$ & $17: 37$ & St. Louis & -87.7 & 38.1 & 106 & 228 & Cosmos & 201.20 & 260.60 & $39 \%$ & No \\
\hline & 38 & G-2 & Evansville & 4.5 & $06 / 18 / 02$ & $17: 37$ & St. Louis & -87.7 & 38.1 & 16 & 228 & Cosmos & 201.20 & 69.50 & $24 \%$ & No \\
\hline
\end{tabular}


Table (4.5b): Available Ground Motions of Other Stable Continental Regions

\begin{tabular}{|c|c|c|c|c|c|c|c|c|c|c|c|c|c|c|c|c|}
\hline & $\begin{array}{l}\text { No. } \\
\text { (1) }\end{array}$ & $\begin{array}{c}\text { Event } \\
\text { (2) }\end{array}$ & $\begin{array}{l}\text { Location } \\
\text { (3) }\end{array}$ & $\begin{array}{l}\text { Mag. } \\
\text { (4) }\end{array}$ & $\begin{array}{l}\text { Date } \\
(5)\end{array}$ & $\begin{array}{c}\text { Time } \\
(6)\end{array}$ & $\begin{array}{l}\text { Station } \\
(7)\end{array}$ & $\begin{array}{l}\text { Longit. } \\
\text { (8) }\end{array}$ & $\begin{array}{l}\text { Latit. } \\
\text { (9) }\end{array}$ & $\begin{array}{l}\text { Azim. } \\
(10)\end{array}$ & $\begin{array}{l}\text { Dist. } \\
\text { (km) } \\
\text { (11) }\end{array}$ & $\begin{array}{c}\text { Data } \\
\text { Source } \\
(12)\end{array}$ & $\begin{array}{c}\text { Somervill } \\
\text { Factor } \\
\text { (13) }\end{array}$ & $\begin{array}{l}\text { Shome } \\
\text { Factor } \\
\text { (14) }\end{array}$ & $\begin{array}{c}\text { SIb Error } \\
\text { (Montreal } \\
\text { ) } \\
(15) \\
\end{array}$ & $\begin{array}{c}\text { Match } \\
\text { Deagg. } \\
(16)\end{array}$ \\
\hline \multirow{23}{*}{$\begin{array}{l}\mathrm{I} \\
\mathrm{N} \\
\mathrm{D} \\
\mathrm{I} \\
\mathrm{A}\end{array}$} & 39 & $\mathrm{H}-1$ & Koyna Dam & 4.6 & $09 / 13 / 67$ & $6: 23$ & Shear Gallery & 73.75 & 17.4 & Long. & & NGDC & 16.30 & 7.20 & \begin{tabular}{|l|}
$59 \%$ \\
\end{tabular} & \\
\hline & 40 & $\mathrm{H}-2$ & Koyna Dam & 4.6 & $09 / 13 / 67$ & $6: 23$ & Shear Gallery & 73.75 & 17.4 & Trans. & & NGDC & 57.10 & 80.10 & $-15 \%$ & \\
\hline & 41 & $\mathrm{H}-3$ & Koyna Dam & 4.6 & $09 / 13 / 67$ & $6: 23$ & Shear Gallery & 73.75 & 17.4 & Trans. & & NGDC & 16.30 & 17.20 & $19 \%$ & \\
\hline & 42 & $\mathrm{I}-1$ & Koyna Dam & 6.3 & $12 / 10 / 67$ & $22: 51$ & 1A Gallery & 73.4 & 17.2 & Long. & 12 & NGDC & 1.07 & 1.34 & $-13 \%$ & Yes \\
\hline & 43 & $\mathrm{I}-2$ & Koyna Dam & 6.3 & $12 / 10 / 67$ & $22: 51$ & Shear Gallery & 73.4 & 17.2 & Long. & 14 & NGDC & 15.90 & 29.14 & $-45 \%$ & Yes \\
\hline & 44 & $\mathrm{I}-3$ & Koyna Dam & 6.3 & $12 / 10 / 67$ & $22: 51$ & 1A Gallery & 73.4 & 17.2 & Trans. & 12 & NGDC & 1.07 & 0.74 & $-12 \%$ & Yes \\
\hline & 45 & $\mathrm{I}-4$ & Koyna Dam & 6.3 & $12 / 10 / 67$ & $22: 51$ & Shear Gallery & 73.4 & 17.2 & Trans. & 14 & NGDC & 15.90 & 8.40 & $13 \%$ & Yes \\
\hline & 46 & $\mathrm{~J}-1$ & Koyna Dam & 5.1 & $12 / 11 / 67$ & $20: 49$ & 1A Gallery & 73.53 & 17.2 & Long. & 18 & NGDC & 23.00 & 33.40 & $-25 \%$ & Yes \\
\hline & 47 & $\mathrm{~J}-2$ & Koyna Dam & 5.1 & $12 / 11 / 67$ & $20: 49$ & 1A Gallery & 73.53 & 17.2 & Trans. & 18 & NGDC & 23.00 & 17.10 & $21 \%$ & Yes \\
\hline & 48 & K-1 & Koyna Dam & 5.2 & $10 / 29 / 68$ & 10:00 & 1A Gallery & 73.84 & 17.4 & Long. & 5 & NGDC & 15.20 & 7.10 & $61 \%$ & Yes \\
\hline & 49 & K-2 & Koyna Dam & 5.2 & $10 / 29 / 68$ & $10: 00$ & 1A Gallery & 73.84 & 17.4 & Trans. & 5 & NGDC & 15.20 & 18.70 & $39 \%$ & Yes \\
\hline & 50 & $\mathrm{~K}-3$ & Koyna Dam & 5.2 & $10 / 29 / 68$ & $10: 00$ & Shear Gallery & 73.84 & 17.4 & Long. & 5 & NGDC & 15.70 & 10.00 & $26 \%$ & Yes \\
\hline & 51 & $\mathrm{~K}-4$ & Koyna Dam & 5.2 & $10 / 29 / 68$ & $10: 00$ & Shear Gallery & 73.84 & 17.4 & Trans. & 5 & NGDC & 15.70 & 13.40 & $30 \%$ & Yes \\
\hline & 52 & $\mathrm{~K}-5$ & Koyna Dam & 5.2 & $10 / 29 / 68$ & $10: 00$ & Downstream & 73.84 & 17.4 & Long. & 5 & NGDC & 13.20 & 16.20 & $-6 \%$ & Yes \\
\hline & 53 & K-6 & Koyna Dam & 5.2 & $10 / 29 / 68$ & $10: 00$ & Downstream & 73.84 & 17.4 & Trans. & 5 & NGDC & 13.20 & 7.70 & $-8 \%$ & Yes \\
\hline & 54 & $\mathrm{~L}-1$ & Koyna Dam & 5.5 & $09 / 02 / 80$ & $16: 39$ & Kirnos & 73.71 & 17.2 & Long. & 18 & NGDC & 51.20 & 85.10 & $-25 \%$ & Yes \\
\hline & 55 & $\mathrm{~L}-2$ & Koyna Dam & 5.5 & $09 / 02 / 80$ & $16: 39$ & Kirnos & 73.71 & 17.2 & Trans. & 18 & NGDC & 51.20 & 33.90 & $59 \%$ & Yes \\
\hline & 56 & L-3 & Koyna Dam & 5.5 & $09 / 02 / 80$ & $16: 39$ & Operation Gal. & 73.71 & 17.2 & Long. & 18 & NGDC & 27.70 & 50.90 & $-23 \%$ & Yes \\
\hline & 57 & $\mathrm{~L}-4$ & Koyna Dam & 5.5 & $09 / 02 / 80$ & $16: 39$ & Operation Gal. & 73.71 & 17.2 & Trans. & 18 & NGDC & 27.70 & 22.20 & $46 \%$ & Yes \\
\hline & 58 & M-1 & Koyna Dam & 5.1 & $09 / 20 / 80$ & $10: 45$ & & 73.58 & 17.3 & Long. & 17 & NGDC & 44.80 & 26.60 & $56 \%$ & Yes \\
\hline & 59 & M-2 & Koyna Dam & 5.1 & $09 / 20 / 80$ & $10: 45$ & Kirnos & 73.58 & 17.3 & Trans. & 17 & NGDC & 44.80 & 50.00 & $-13 \%$ & Yes \\
\hline & 60 & $\mathrm{M}-3$ & Koyna Dam & 5.1 & $09 / 20 / 80$ & $10: 45$ & Operation Gal. & 73.58 & 17.3 & Long. & 17 & NGDC & 23.99 & 13.50 & $23 \%$ & Yes \\
\hline & 61 & M-4 & Koyna Dam & 5.1 & $09 / 20 / 80$ & $10: 45$ & Operation Gal. & 73.58 & 17.3 & Trans. & 17 & NGDC & 23.99 & 35.00 & $-39 \%$ & Yes \\
\hline \multirow{12}{*}{$\begin{array}{l}\mathrm{E} \\
\mathrm{U} \\
\mathrm{R} \\
\mathrm{O} \\
\mathrm{P} \\
\mathrm{E}\end{array}$} & 62 & $\mathrm{~N}-1$ & Norwegian Sea & 5.6 & $08 / 08 / 88$ & $19: 59$ & Molde & 2.4 & 63.7 & $\mathrm{EW}$ & 289 & ESD & 412.80 & 408.80 & $18 \%$ & No \\
\hline & 63 & $\mathrm{~N}-2$ & Norwegian Sea & 5.6 & $08 / 08 / 88$ & 19:59 & Molde & 2.4 & 63.7 & NS & 289 & ESD & 412.80 & 450.30 & $-38 \%$ & No \\
\hline & 64 & $\mathrm{~N}-3$ & Norwegian Sea & 5.6 & $08 / 08 / 88$ & $19: 59$ & Sulen & 2.4 & 63.7 & EW & 314 & ESD & 51.70 & 28.00 & $41 \%$ & No \\
\hline & 65 & $\mathrm{~N}-4$ & Norwegian Sea & 5.6 & $08 / 08 / 88$ & $19: 59$ & Sulen & 2.4 & 63.7 & NS & 314 & ESD & 51.70 & 34.10 & $51 \%$ & No \\
\hline & 66 & $0-1$ & South of Bergen & 4.8 & $01 / 29 / 89$ & $16: 38$ & Sulc & 5.9 & 59.5 & EW & 190 & ESD & 243.60 & 145.80 & $-13 \%$ & No \\
\hline & 67 & $\mathrm{O}-2$ & South of Bergen & 4.8 & $01 / 29 / 89$ & $16: 38$ & Sulen & 5.9 & 59.5 & $\mathrm{NS}$ & 190 & ESD & 243.60 & 746.40 & $15 \%$ & No \\
\hline & 68 & P-1 & Becerrea & 5.3 & $05 / 21 / 97$ & $23: 50$ & Lisboa & -7.16 & 42.9 & Long. & 486 & ESD & 125.60 & 87.50 & $-3 \%$ & No \\
\hline & 69 & P-2 & Becerrea & 5.3 & $05 / 21 / 97$ & $23: 50$ & Lisboa & -7.16 & 42.9 & Trans. & 486 & ESD & 125.60 & 98.80 & $-9 \%$ & No \\
\hline & 70 & Q-1 & Sarria Becerrea & 4.5 & $05 / 23 / 97$ & 18:14 & Becerrea & -7.1 & 42.9 & $\mathrm{EW}$ & 5 & ESD & 42.80 & 24.00 & $16 \%$ & Yes \\
\hline & 71 & Q-2 & Sarria Becerrea & 4.5 & $05 / 23 / 97$ & 18:14 & Becerrea & -7.1 & 42.9 & NS & 5 & ESD & 42.80 & 57.20 & $26 \%$ & Yes \\
\hline & 72 & R-1 & $\begin{array}{l}\text { Polkowice } \\
\end{array}$ & 4.8 & $02 / 20 / 02$ & $11: 27$ & Rudna & 16.08 & 51.6 & EW & 12 & ESD & 50.10 & 20.80 & $26 \%$ & Yes \\
\hline & 73 & $\mathrm{R}-2$ & Polkowice & 4.8 & $02 / 20 / 02$ & $11: 27$ & Rudna & 16.08 & 51.6 & NS & 12 & ESD & 50.10 & 36.60 & $14 \%$ & Yes \\
\hline
\end{tabular}


Table (4.6): Events of Stable Continental Regions

(Johnston 1990)

\begin{tabular}{|c|c|c|c|c|c|}
\hline Region & Date & Magnitude & Region & Date & Magnitude \\
\hline \multirow{19}{*}{ Africa } & $1990-03-13$ & 5.53 & \multirow{3}{*}{ China } & 1963-09-07 & 5.82 \\
\hline & $1989-05-09$ & 5.04 & & $1963-09-06$ & 5.86 \\
\hline & $1987-06-28$ & 5.38 & & $1962-03-18$ & 6.02 \\
\hline & $1987-01-26$ & 4.93 & \multirow{42}{*}{$\begin{array}{l}\text { North } \\
\text { America }\end{array}$} & $1989-12-25$ & 6.00 \\
\hline & $1986-10-05$ & 5.37 & & $1988-11-25$ & 5.77 \\
\hline & $1986-07-18$ & 5.23 & & 1988-09-07 & 4.17 \\
\hline & 1985-10-04 & 5.57 & & $1987-12-13$ & 5.38 \\
\hline & 1984-10-26 & 5.34 & & 1987-06-10 & 4.96 \\
\hline & $1983-12-22$ & 6.29 & & 1986-07-12 & 4.40 \\
\hline & 1981-11-18 & 5.57 & & 1986-01-31 & 4.88 \\
\hline & 1976-07-01 & 5.81 & & 1983-10-07 & 4.89 \\
\hline & $1974-09-23$ & 5.93 & & $1982-01-21$ & 4.42 \\
\hline & 1974-09-04 & 5.70 & & 1982-01-19 & 4.36 \\
\hline & $1972-12-18$ & 5.63 & & 1982-01-09 & 5.57 \\
\hline & 1969-09-29 & 6.4 & & 1962-02-02 & 4.23 \\
\hline & $1968-12-02$ & 5.68 & & $1940-12-24$ & 5.62 \\
\hline & 1968-05-15 & 5.89 & & $1940-12-20$ & 5.46 \\
\hline & 1965-05-18 & 5.42 & & $1939-10-19$ & 5.30 \\
\hline & $1963-09-25$ & 5.81 & & 1935-11-01 & 6.35 \\
\hline Antarctica & $1984-05-19$ & 4.96 & & $1933-11-20$ & 7.70 \\
\hline \multirow{18}{*}{ Australia } & 1989-10-13 & 5.51 & & 1929-11-18 & 7.38 \\
\hline & 1989-0618 & 5.24 & & $1929-08-12$ & 4.90 \\
\hline & $1988-0206$ & 5.13 & & $1925-03-01$ & 6.86 \\
\hline & $1988-01-22$ & 6.23 & & $1980-07-27$ & 5.05 \\
\hline & $1988-01-22$ & 6.29 & & $1979-08-19$ & 4.75 \\
\hline & $1988-01-22$ & 6.57 & & $1979-06-27$ & 5.00 \\
\hline & 1987-01-09 & 5.44 & & $1978-06-16$ & 4.51 \\
\hline & 1986-03-30 & 5.78 & & $1978-02-18$ & 3.90 \\
\hline & $1985-10-23$ & 5.79 & & 1978-02-05 & 5.12 \\
\hline & 1982-11-21 & 4.65 & & 1976-03-25 & 4.63 \\
\hline & 1979-07-14 & 5.06 & & $1975-10-06$ & 5.10 \\
\hline & 1979-06-02 & 6.10 & & $1975-07-12$ & 4.12 \\
\hline & $1979-04-23$ & 6.13 & & $1975-07-09$ & 4.31 \\
\hline & 1973-03-09 & 5.14 & & $1974-02-15$ & 4.37 \\
\hline & $1972-08-28$ & 5.30 & & $1973-11-30$ & 4.08 \\
\hline & $1970-03-24$ & 6.04 & & $1973-06-15$ & 4.49 \\
\hline & $1968-10-14$ & 6.58 & & $1972-12-28$ & 5.86 \\
\hline & $1966-05-03$ & $4 . \overline{46}$ & & $1972-12-27$ & 6.28 \\
\hline \multirow{7}{*}{ China } & 1986-08-15 & 4.98 & & $1972-11-21$ & 5.97 \\
\hline & 1984-05-21 & 6.03 & & $1972-11-19$ & 5.94 \\
\hline & 1982-10-27 & 5.23 & & 1972-09-15 & 4.12 \\
\hline & $1980-02-10$ & 5.10 & & $1972-01-21$ & 4.61 \\
\hline & 1979-07-09 & 5.52 & & $1971-12-07$ & 5.57 \\
\hline & $1974-04-22$ & 5.33 & & $1971-10-02$ & 4.69 \\
\hline & 1969-07-25 & 5.77 & & $1970-11-17$ & 4.10 \\
\hline
\end{tabular}


Table (4.6): Continued

\begin{tabular}{|c|c|c|}
\hline Region & Date & Magnitude \\
\hline \multirow{5}{*}{$\begin{array}{c}\text { North } \\
\text { America }\end{array}$} & $1969-11-20$ & 4.54 \\
\cline { 2 - 3 } & $1969-01-01$ & 4.34 \\
\cline { 2 - 3 } & $1968-11-09$ & \\
\cline { 2 - 3 } & $1967-06-13$ & 4.08 \\
\cline { 2 - 3 } & $1967-06-04$ & 4.29 \\
\cline { 2 - 3 } & $1965-10-21$ & 4.62 \\
\cline { 2 - 3 } & $1963-09-04$ & 6.11 \\
\cline { 2 - 3 } & $1963-03-03$ & 4.66 \\
\cline { 2 - 3 } South & $1944-09-05$ & 5.77 \\
\hline \multirow{4}{*}{ America } & $1986-11-30$ & 5.12 \\
\cline { 2 - 3 } & $1985-04-12$ & 5.13 \\
\cline { 2 - 3 } & $1983-08-05$ & 5.47 \\
\cline { 2 - 3 } & $1980-11-20$ & 5.20 \\
\hline
\end{tabular}

\begin{tabular}{|c|c|c|}
\hline Region & Date & Magnitude \\
\hline \multirow{4}{*}{ India } & $1989-06-12$ & 5.77 \\
\cline { 2 - 3 } & $1980-09-20$ & 5.05 \\
\cline { 2 - 3 } & $1967-12-10$ & 6.30 \\
\hline \multirow{5}{*}{ Europe } & $1989-01-23$ & 5.15 \\
\cline { 2 - 3 } & $1988-08-08$ & 5.59 \\
\cline { 2 - 3 } & $1986-02-05$ & 4.71 \\
\cline { 2 - 3 } & $1985-12-21$ & \\
\cline { 2 - 3 } & $1984-07-19$ & \\
\cline { 2 - 3 } & $1983-11-08$ & 4.77 \\
\cline { 2 - 3 } & $1983-03-08$ & \\
\cline { 2 - 3 } & $1978-09-03$ & 5.21 \\
\cline { 2 - 3 } & $1975-06-23$ & 4.79 \\
\hline
\end{tabular}


Table (4.7): Final Selection of Ground Motions, Eastern Region of Canada

\begin{tabular}{|c|c|c|c|c|c|c|c|c|c|c|c|c|c|c|c|}
\hline No. & $\begin{array}{c}\text { Event } \\
\text { (2) }\end{array}$ & $\begin{array}{l}\text { Location } \\
\text { (3) }\end{array}$ & $\begin{array}{c}\text { Mag. } \\
(4)\end{array}$ & $\begin{array}{c}\text { Date } \\
(5)\end{array}$ & $\begin{array}{c}\text { Time } \\
(6)\end{array}$ & $\begin{array}{l}\text { Station } \\
(7)\end{array}$ & $\begin{array}{c}\text { Longit. } \\
(8)\end{array}$ & $\begin{array}{l}\text { Latit. } \\
(9)\end{array}$ & $\begin{array}{c}\text { Azim. } \\
(10)\end{array}$ & $\begin{array}{l}\text { Dist. } \\
(\mathrm{km}) \\
(11)\end{array}$ & $\begin{array}{c}\text { Depth } \\
\text { (km) } \\
(12)\end{array}$ & $\begin{array}{l}\text { No. of } \\
\text { Data } \\
(13)\end{array}$ & $\begin{array}{c}\text { Time } \\
\text { Interval } \\
(\mathrm{S}) \\
(14)\end{array}$ & $\begin{array}{l}\text { Filename } \\
\text { (15) }\end{array}$ & $\begin{array}{l}\text { Somervil } \\
\text { le Factor } \\
\text { (16) }\end{array}$ \\
\hline 2 & $\mathrm{~A}-2$ & New Brunswick & 4.8 & $03 / 31 / 82$ & $21: 02$ & Miramichi-Holmes L. & -66.6 & 47 & 288 & 6 & 4 & 1549 & 0.005 & $\mathrm{~m} 02 . \mathrm{txt}$ & 17.3 \\
\hline 3 & $A-3$ & New Brunswick & 4.8 & $03 / 31 / 82$ & 21:02 & Miramichi-Indian B. & -66.6 & 47 & 321 & 3 & 4 & 937 & 0.005 & $\mathrm{~m} 03 . \mathrm{txt}$ & 15.4 \\
\hline 4 & $\mathrm{~A}-4$ & New Brunswick & 4.8 & $03 / 31 / 82$ & $21: 02$ & Miramichi-Indian B. & -66.6 & 47 & 231 & 3 & 4 & 955 & 0.005 & m04.txt & 6 \\
\hline $\begin{array}{ll}\mathrm{A} \\
\end{array}$ & $A-5$ & New Brunswick & 4.8 & $03 / 31 / 82$ & 21:02 & Miramichi-Loggie L. & -66.6 & 47 & 189 & 6 & 4 & 975 & 005 & m05.txt & 11.2 \\
\hline N 6 & $\mathrm{~A}-6$ & New Brunswick & 4.8 & $03 / 31 / 82$ & $21: 02$ & Miramichi-Loggie L. & -66.6 & 47 & 99 & 6 & 4 & 983 & 0.005 & m06.txt & 5.4 \\
\hline 7 & $\mathrm{~A}-7$ & New Brunswick & 4.8 & $03 / 31 / 82$ & $21: 02$ & Miramichi-Mitchell L. & -66.6 & 47 & 118 & 4 & 4 & 1676 & .005 & m07.txt & 18.8 \\
\hline 10 & B-2 & New Brunswick & 4 & $05 / 06 / 82$ & $16: 28$ & Miramichi-Loggie L. & -66.6 & 47 & 99 & 7 & 5 & 1818 & 0.005 & m10.txt & 10.8 \\
\hline 11 & B-3 & New Brunswick & 4 & $05 / 06 / 82$ & $16: 28$ & S3-Miramichi-Hickey L. & -66.6 & 47 & 99 & 4.1 & 5 & 1818 & 0.005 & m099.ACC & 24.9 \\
\hline 12 & $\mathrm{~B}-4$ & New Brunswick & 4 & $05 / 06 / 82$ & $16: 28$ & S3-Miramichi-Hickey L. & -66.6 & 47 & 189 & 4.1 & 5 & 1820 & 0.005 & m189.ACC & 29.8 \\
\hline 42 & $\mathrm{I}-1$ & \begin{tabular}{|l|} 
Koyna Dam \\
\end{tabular} & 6.3 & $12 / 10 / 67$ & $22: 51$ & $1 \mathrm{~A}$ Gallery & 73.4 & 17.2 & Long. & 12 & 4.5 & 536 & 0.02 & B-1o-1.acc & 1.25 \\
\hline 43 & $\mathrm{I}-2$ & Koyna Dam & 6.3 & $12 / 10 / 67$ & $22: 51$ & Shear Gallery & 73.4 & 17.2 & Long. & 14 & 4.5 & 435 & 0.02 & B-1o-2.acc & 19.5 \\
\hline 44 & $\mathrm{I}-3$ & Koyna Dam & 6.3 & $12 / 10 / 67$ & $22: 51$ & 1A Gallery & 73.4 & 17.2 & Trans. & 12 & 4.5 & 551 & 0.02 & B-tr-1.acc & 0.92 \\
\hline I 45 & $\mathrm{I}-4$ & Koyna Dam & 6.3 & $12 / 10 / 67$ & $22: 51$ & Shear Gallery & 73.4 & 17.2 & Trans. & 14 & 4.5 & 435 & 0.02 & B-tr-2.acc & 13 \\
\hline 47 & $\mathrm{~J}-2$ & Koyna Dam & 5.1 & $12 / 11 / 67$ & $20: 49$ & 1А Gallery & 73.53 & 17.2 & Trans. & 18 & 1 & 193 & 0.02 & C-tr-1.acc & 23.2 \\
\hline 49 & $\mathrm{~K}-2$ & Koyna Dam & 5.2 & $10 / 29 / 68$ & $10: 00$ & 1A Gallery & 73.84 & 17.4 & Trans. & 5 & 1 & 330 & 0.02 & D-tr-1.acc & 21.6 \\
\hline 50 & $\mathrm{~K}-3$ & Koyna Dam & 5.2 & $10 / 29 / 68$ & $10: 00$ & Shear Gallery & 73.84 & 17.4 & Long. & 5 & 1 & 433 & 0.02 & D-lo-2.acc & 12.8 \\
\hline 51 & $\mathrm{~K}-4$ & Koyna Dam & 5.2 & $10 / 29 / 68$ & $10: 00$ & Shear Gallery & 73.84 & 17.4 & Trans. & 5 & 1 & 437 & 0.02 & D-tr-2.acc & 19.1 \\
\hline 53 & $\mathrm{~K}-6$ & Koyna Dam & 5.2 & $10 / 29 / 68$ & 10:00 & Downstream & 73.84 & 17.4 & Trans. & 5 & 1 & 205 & 0.02 & D-tr-3.acc & 11.6 \\
\hline 57 & $\mathrm{~L}-4$ & Koyna Dam & 5.5 & $09 / 02 / 80$ & $16: 39$ & Operation Gal. & 73.71 & 17.2 & Trans. & 18 & 33 & 332 & 0.02 & E-tr-2.acc & 23.9 \\
\hline 60 & M-3 & Koyna Dam & 5.1 & $09 / 20 / 80$ & $10: 45$ & Operation Gal. & 73.58 & 17.3 & Long. & 17 & 33 & 332 & 0.02 & F-1o-2.acc & 18.6 \\
\hline
\end{tabular}


Table (4.8): Final Selection of Ground Motions for Western Region of Canada

\begin{tabular}{|c|c|c|c|c|c|c|c|c|c|c|}
\hline $\begin{array}{l}\text { No. } \\
\text { (1) }\end{array}$ & $\begin{array}{l}\text { Location } \\
\text { (2) }\end{array}$ & $\begin{array}{c}\text { Mag. } \\
\text { (3) }\end{array}$ & $\begin{array}{l}\text { Date } \\
(4)\end{array}$ & $\begin{array}{c}\text { Station } \\
\text { (5) }\end{array}$ & $\begin{array}{c}\text { Dist. } \\
(\mathrm{km}) \\
(6)\end{array}$ & $\begin{array}{c}\text { Depth } \\
(\mathrm{km}) \\
(7)\end{array}$ & $\begin{array}{c}\text { No. of } \\
\text { Data } \\
(8)\end{array}$ & \begin{tabular}{|c|} 
Time \\
Interval (S) \\
$(9)$ \\
\end{tabular} & $\begin{array}{l}\text { Filename } \\
\text { (10) }\end{array}$ & $\begin{array}{c}\text { Somerville } \\
\text { Factor } \\
(11)\end{array}$ \\
\hline 1 & Tokachi Oki & 8 & $09 / 25 / 03$ & & 120 & 30 & 15709 & 0.01 & van0la & 0.988 \\
\hline 2 & Tokachi Oki & 8 & $09 / 25 / 03$ & & 120 & 30 & 15709 & 0.01 & $\operatorname{van} 01 b$ & 0.988 \\
\hline 3 & Olympia & 6.9 & $04 / 13 / 49$ & Washington Hwy Lab & 75 & 70 & 4454 & 0.02 & $\operatorname{van} 03 a$ & 1.855 \\
\hline 4 & Olympia & 6.9 & $04 / 13 / 49$ & Washington Hwy Lab & 75 & 70 & 4454 & 0.02 & $\operatorname{van} 03 b$ & 1.855 \\
\hline 6 & Tokachi Oki & 8 & $09 / 30 / 03$ & & 120 & 30 & 18509 & 0.01 & van $04 b$ & 1.711 \\
\hline 7 & Nisqually & 6.8 & $02 / 28 / 2001$ & & 111 & 52 & 17900 & 0.01 & $\operatorname{van} 09 a$ & 3.555 \\
\hline 8 & Nisqually & 6.8 & $02 / 28 / 2001$ & & 111 & 52 & 17900 & 0.01 & $\operatorname{van} 09 \mathrm{~b}$ & 3.555 \\
\hline 9 & Nisqually & 6.8 & $02 / 28 / 2001$ & & 111 & 52 & 20600 & 0.01 & $\operatorname{van} 12 \mathrm{a}$ & 4.16 \\
\hline 10 & Nisqually & 6.8 & $02 / 28 / 2001$ & & 111 & 52 & 20600 & 0.01 & $\operatorname{van} 12 b$ & 4.16 \\
\hline 14 & Nisqually & 6.8 & $02 / 28 / 2001$ & & 111 & 52 & 48001 & 0.01 & $\operatorname{van} 16 b$ & 4.774 \\
\hline 15 & Nisqually & 6.8 & $02 / 28 / 2001$ & & 111 & 52 & 94800 & 0.01 & $\operatorname{van} 19 a$ & 4.871 \\
\hline 16 & Nisqually & 6.8 & $02 / 28 / 2001$ & & 111 & 52 & 94800 & 0.01 & $\operatorname{van} 19 b$ & 4.871 \\
\hline 17 & Puget Sound & 6.7 & $04 / 29 / 1965$ & Seattle Federal Bldg. & 63 & 59 & 3706 & 0.02 & $\operatorname{van} 23 a$ & 4.89 \\
\hline 18 & Puget Sound & 6.7 & $04 / 29 / 1965$ & Seattle Federal Bldg. & 63 & 59 & 3706 & 0.02 & $\operatorname{van} 23 b$ & 4.89 \\
\hline 19 & Nisqually & 6.8 & $02 / 28 / 2001$ & & 111 & 52 & 48001 & 0.01 & $\operatorname{van} 25 \mathrm{a}$ & 5.093 \\
\hline 20 & Nisqually & 6.8 & $02 / 28 / 2001$ & & 111 & 52 & 48000 & 0.01 & $\operatorname{van} 25 b$ & 5.093 \\
\hline
\end{tabular}




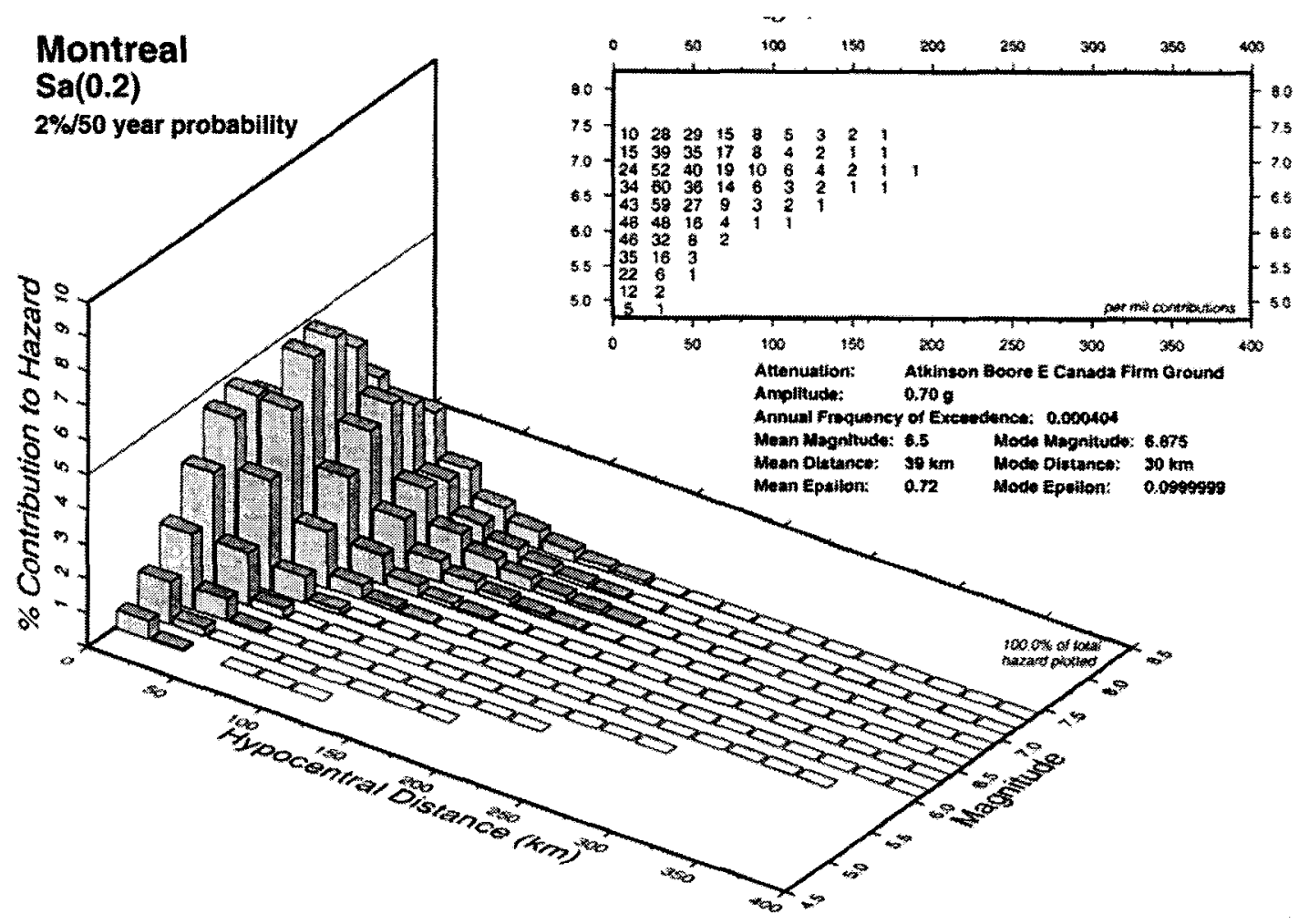

Figure (4.1): Deaggregation of seismic hazard for Montreal defined in terms of $\mathrm{S}_{\mathrm{a}}(0.2)$ for a probability of exceedance $2 \% / 50$ years

(Halchuk and Adams, 2004) 


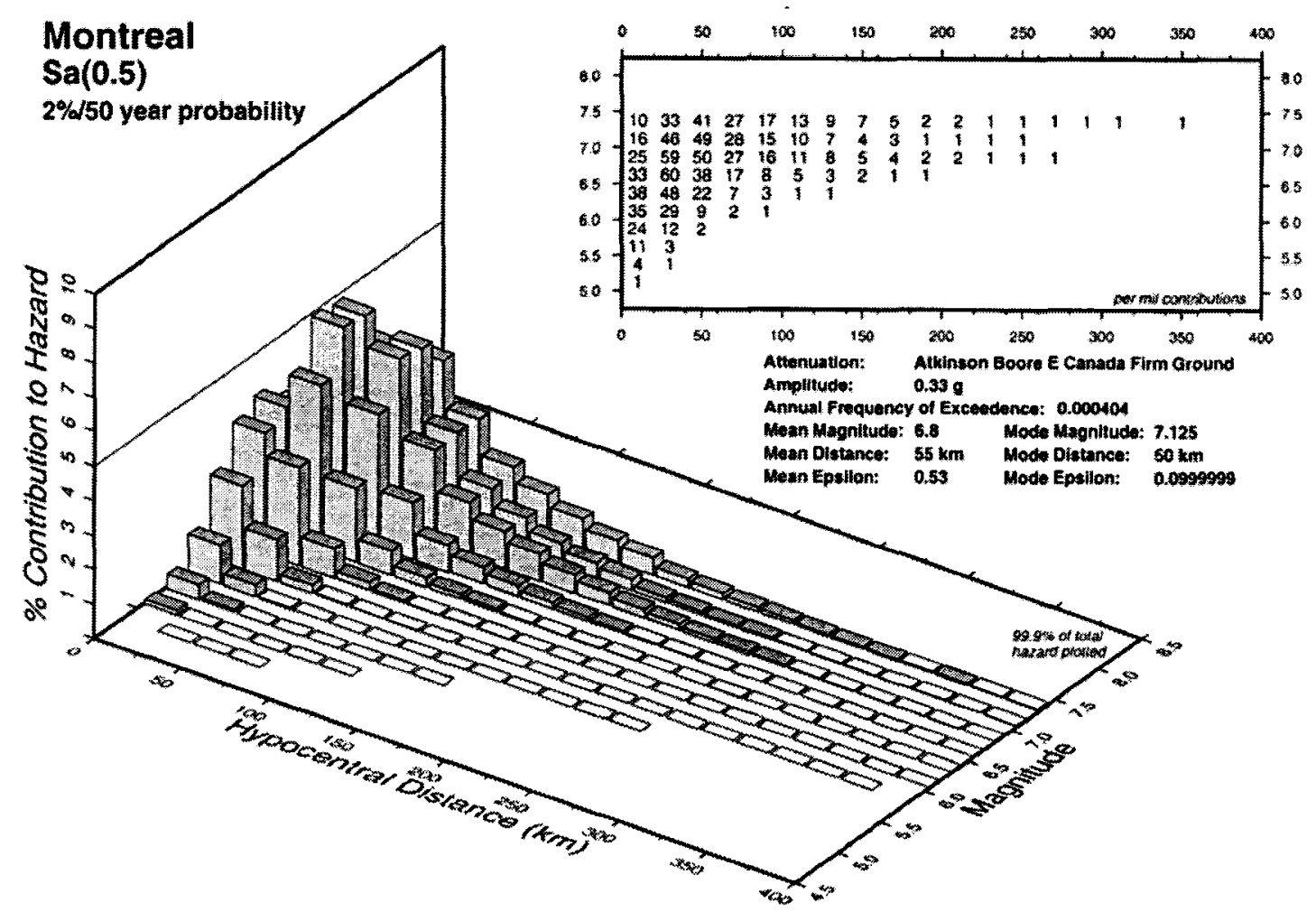

Figure (4.2): Deaggregation of seismic hazard for Montreal defined in terms of $\mathrm{S}_{\mathrm{a}}(0.5)$ for a probability of exceedance $2 \% / 50$ years

(Halchuk and Adams, 2004) 


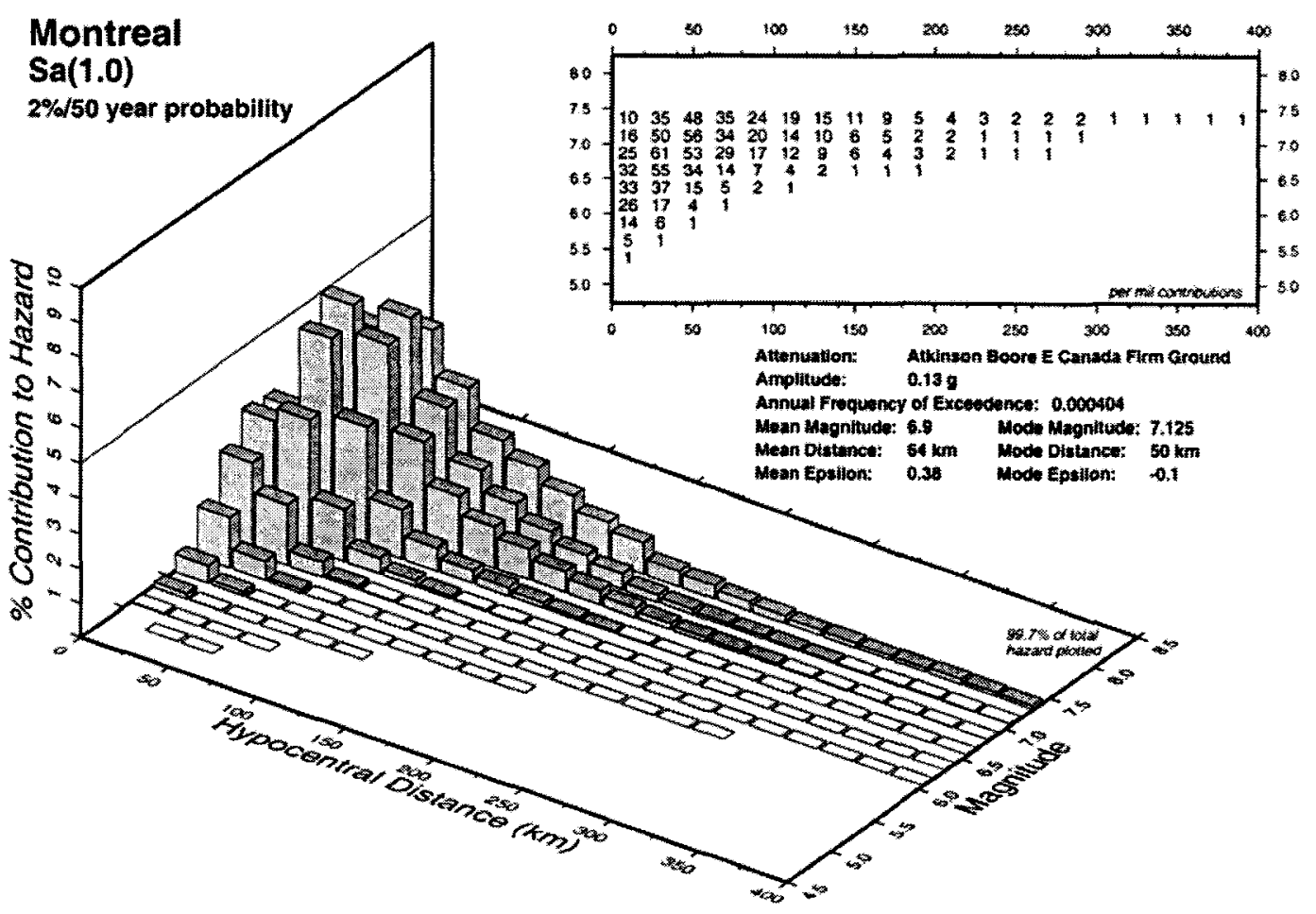

Figure (4.3): Deaggregation of seismic hazard for Montreal defined in terms of $S_{a}(1.0)$ for a probability of exceedance $2 \% / 50$ years

(Halchuk and Adams, 2004) 


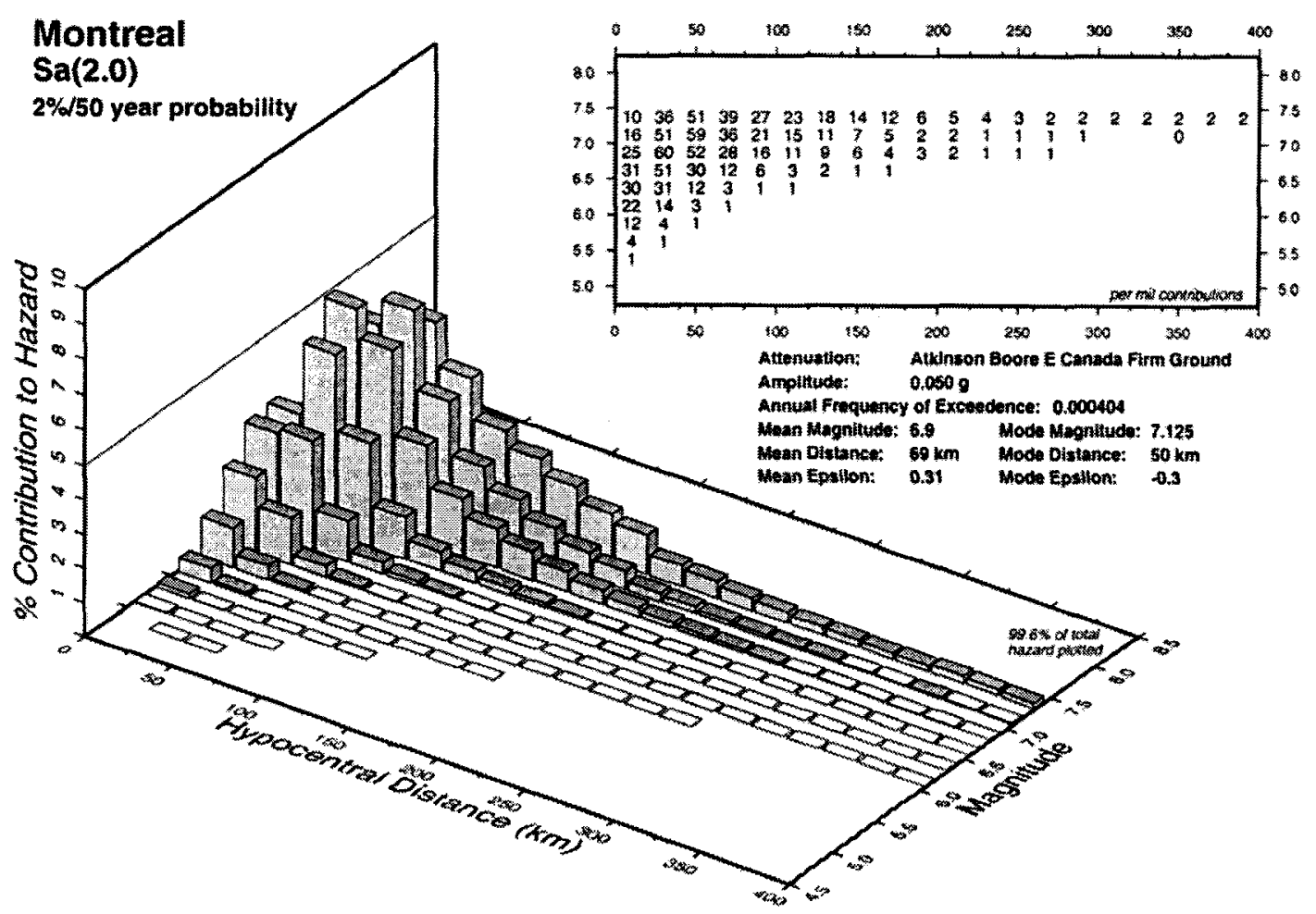

Figure (4.4): Deaggregation of seismic hazard for Montreal defined in terms of $S_{a}(2.0)$ for a probability of exceedance $2 \% / 50$ years

(Halchuk and Adams, 2004) 


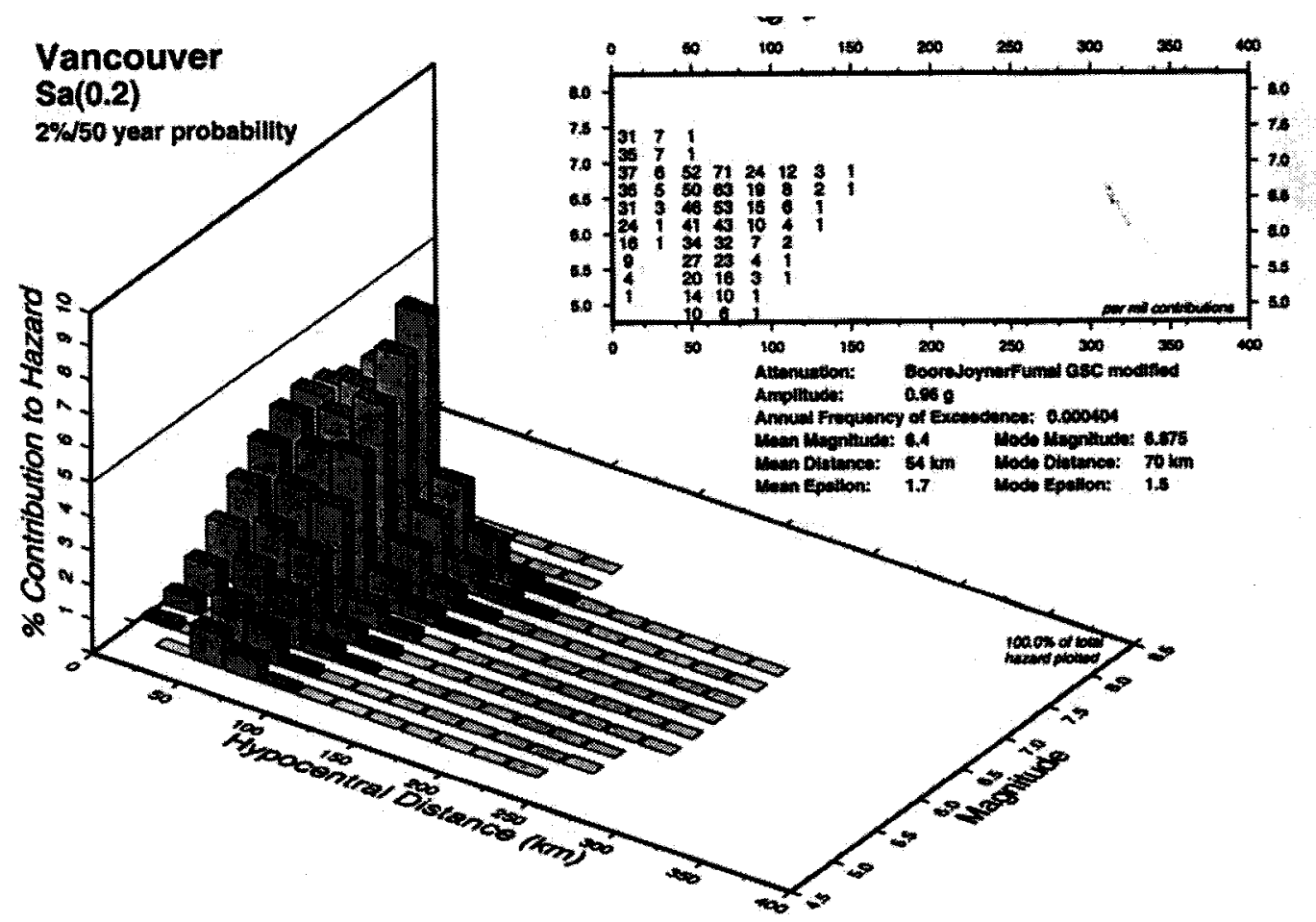

Figure (4.5): Deaggregation of seismic hazard for Vancouver defined in terms of $S_{a}(0.2)$ for a probability of exceedance $2 \% / 50$ years

(Halchuk and Adams, 2004) 


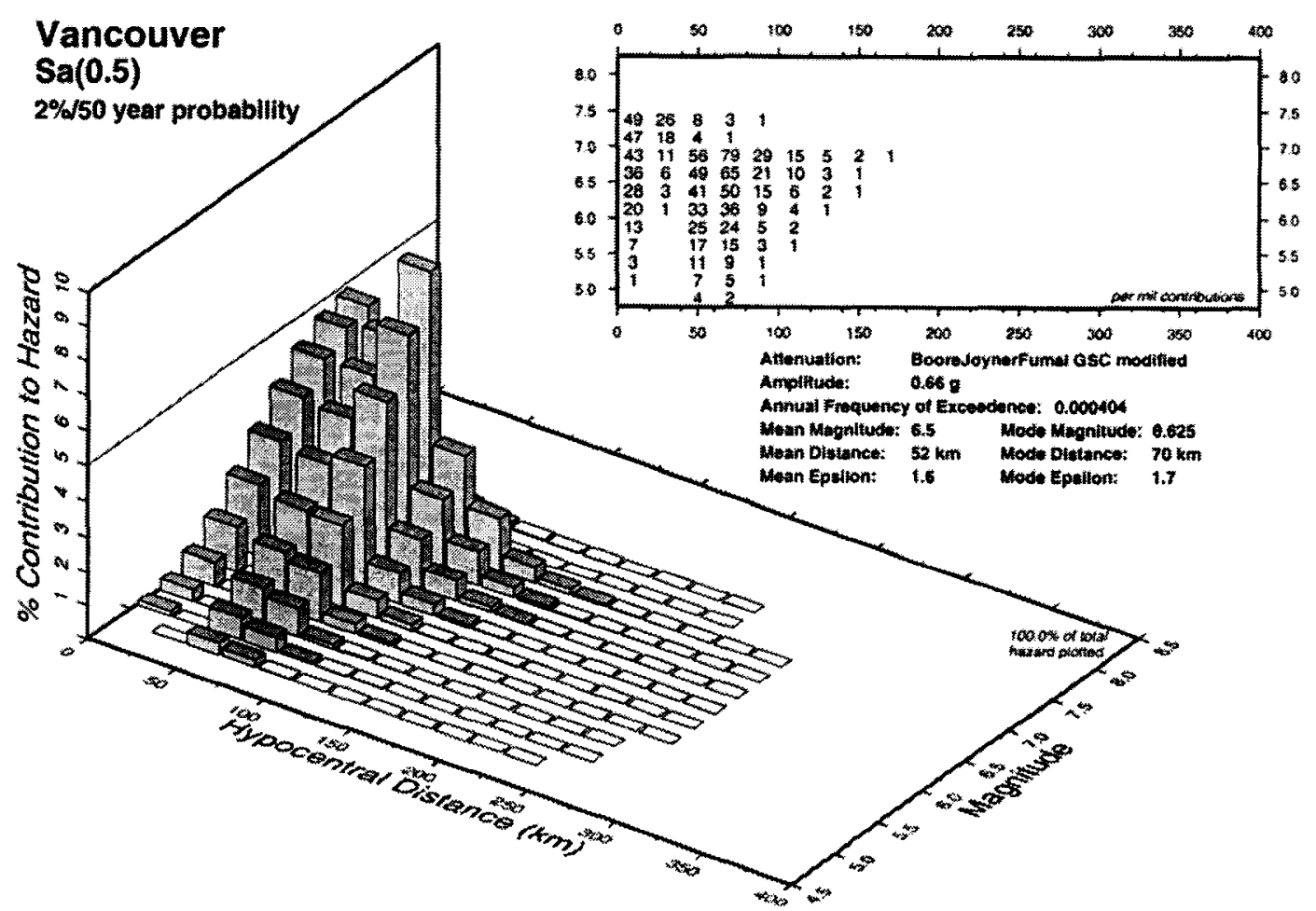

Figure (4.6): Deaggregation of seismic hazard for Vancouver defined in terms of $S_{a}(0.5)$ for a probability of exceedance $2 \% / 50$ years

(Halchuk and Adams, 2004) 


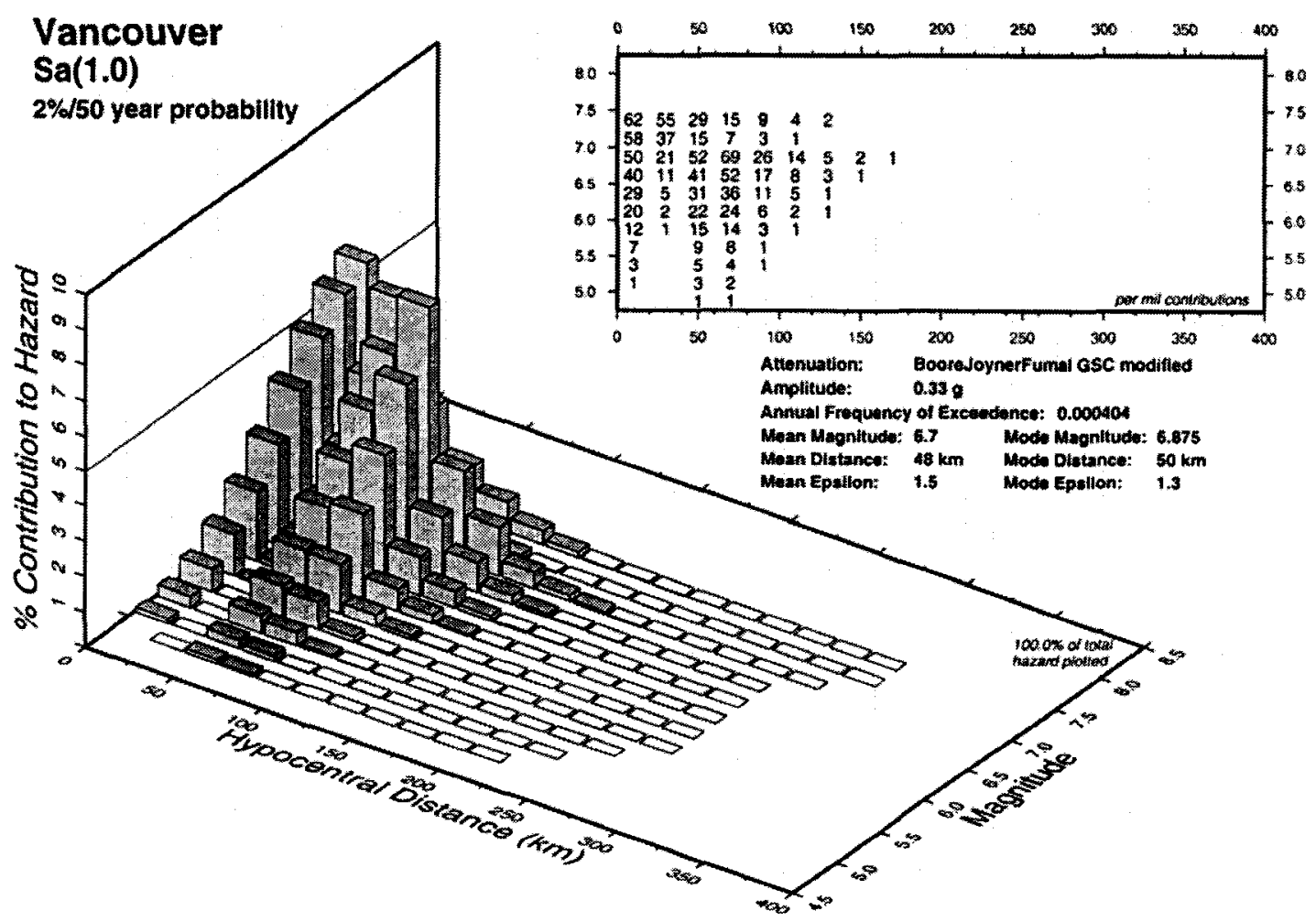

Figure (4.7): Deaggregation of seismic hazard for Vancouver defined in terms of $S_{a}(1.0)$ for a probability of exceedance $2 \% / 50$ years

(Halchuk and Adams, 2004) 


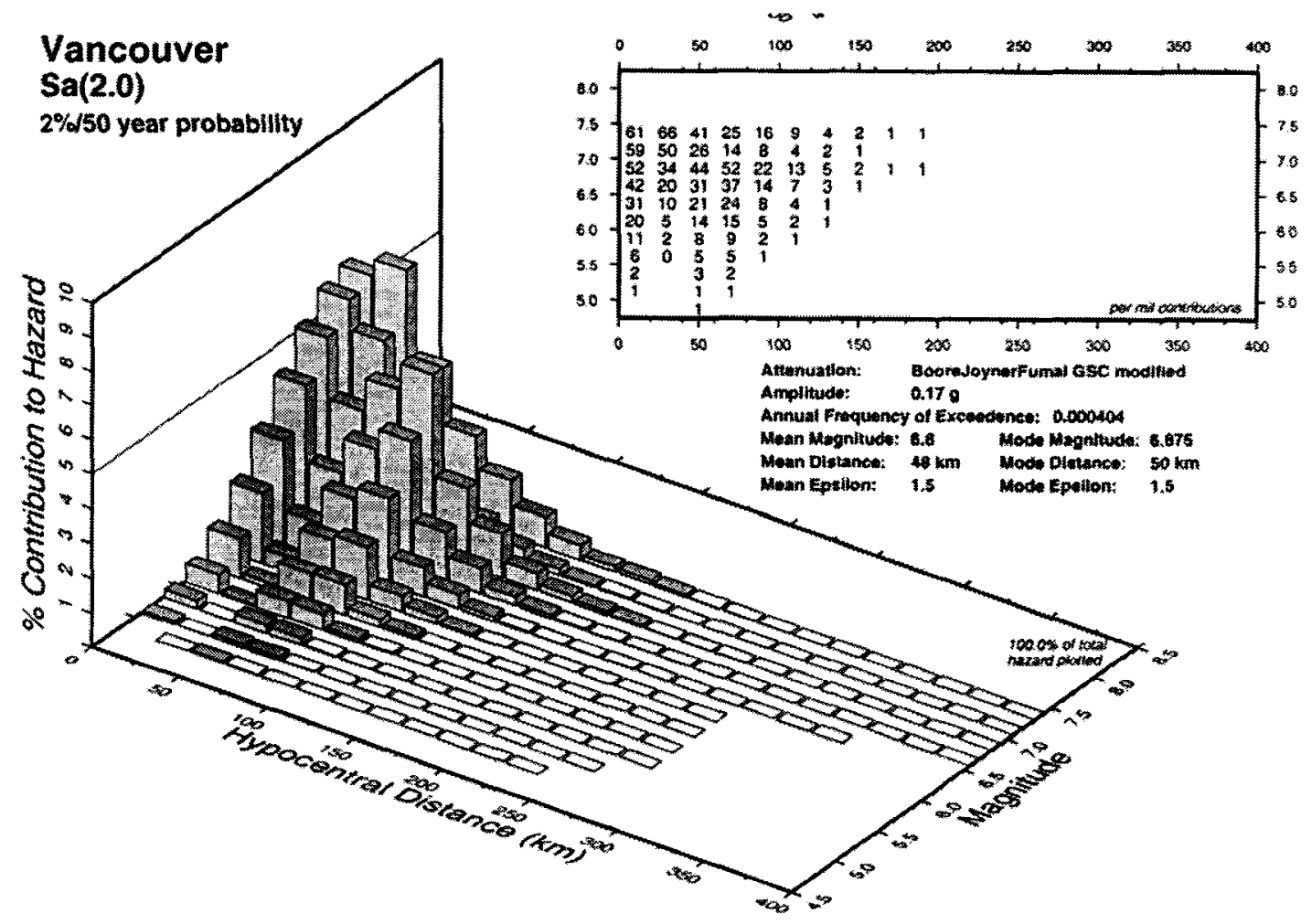

Figure (4.8): Deaggregation of seismic hazard for Vancouver defined in terms of $S_{a}(2.0)$ for a probability of exceedance $2 \% / 50$ years

(Halchuk and Adams, 2004) 


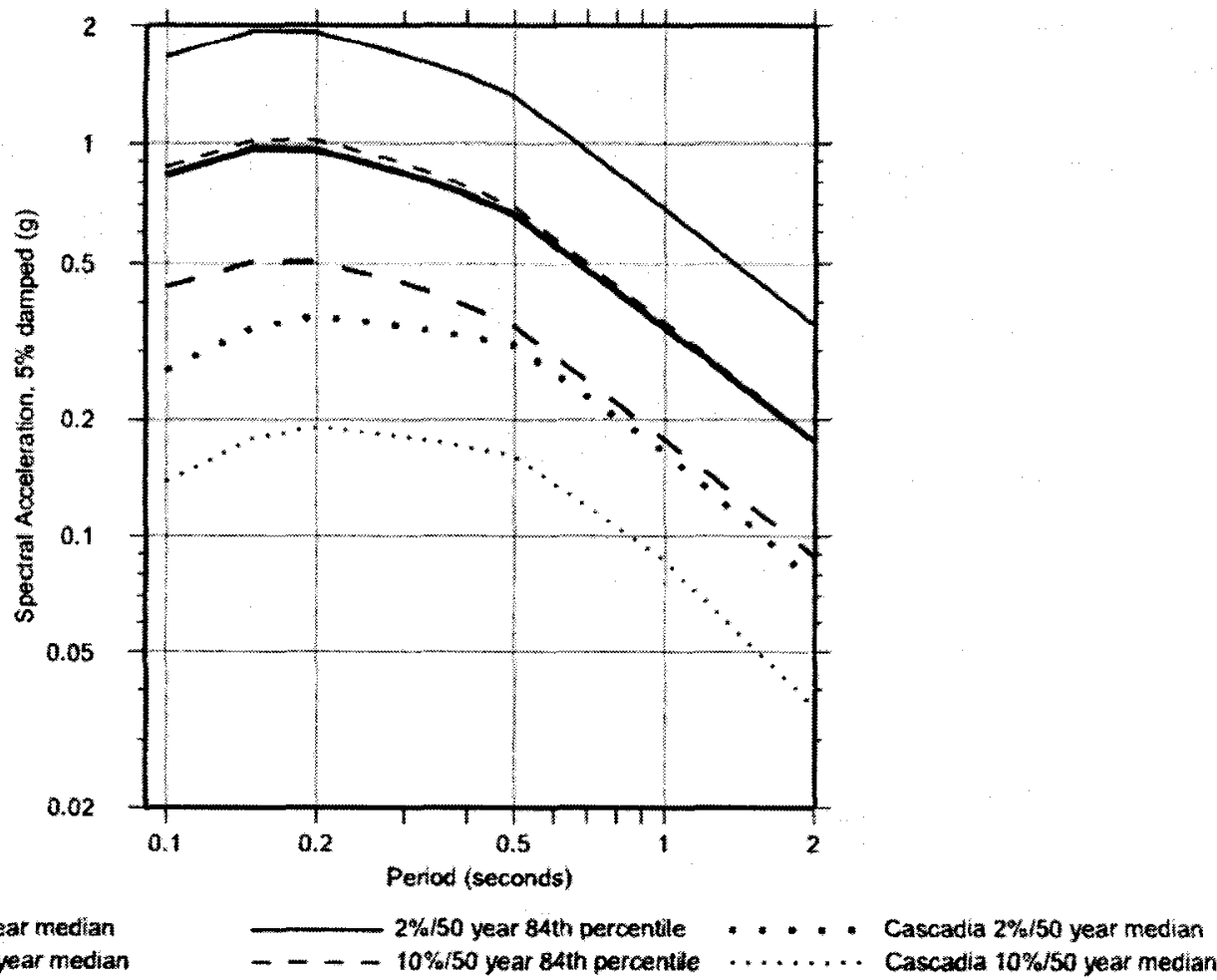

Figure (4.9): Robust Uniform Hazard Spectra for Vancouver

(Open file 4459- Geological Survey of Canada 2003) 


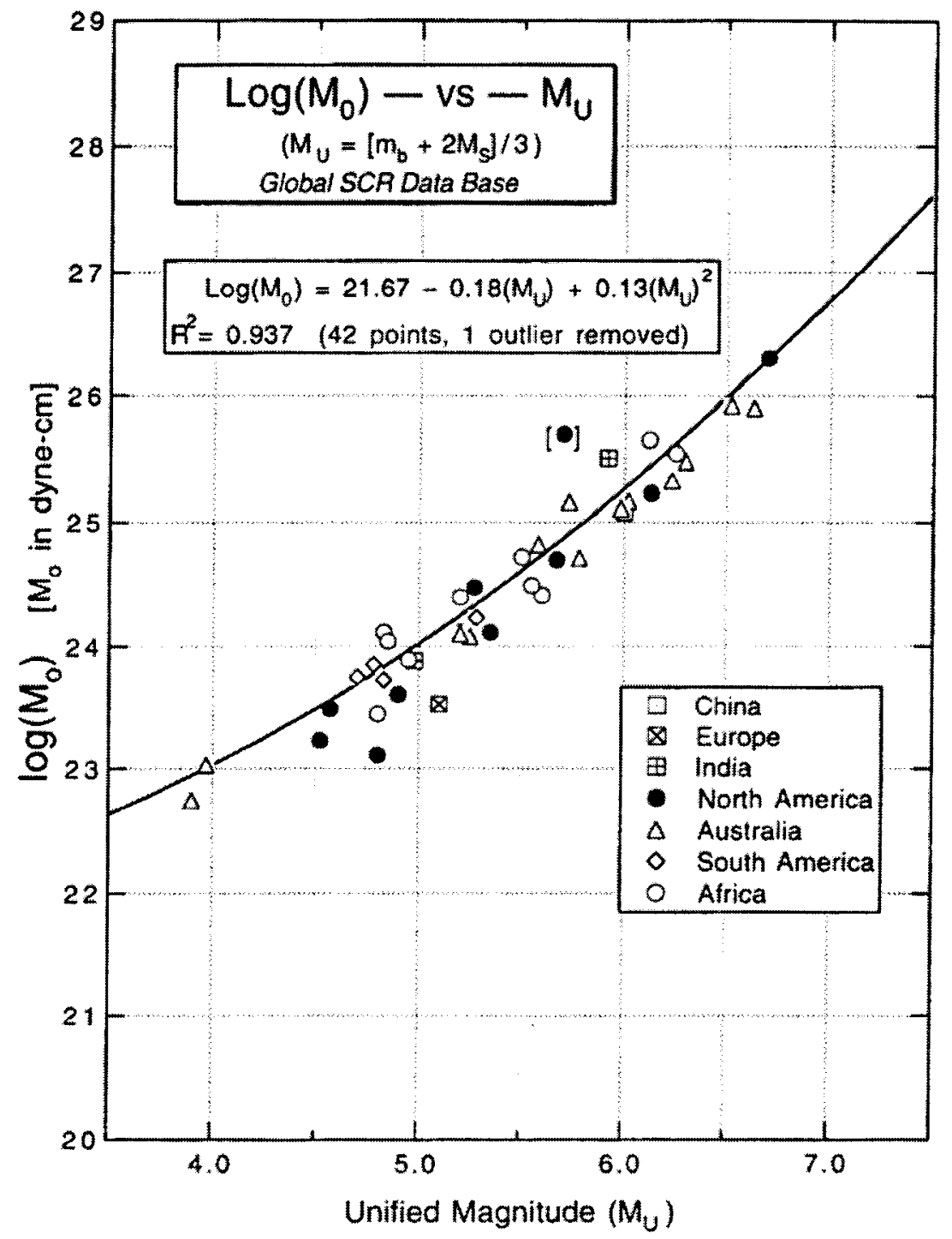

Figure (4.10): The Stable Continental Region Data Set and Regression Curve (Johnston, 1990) 


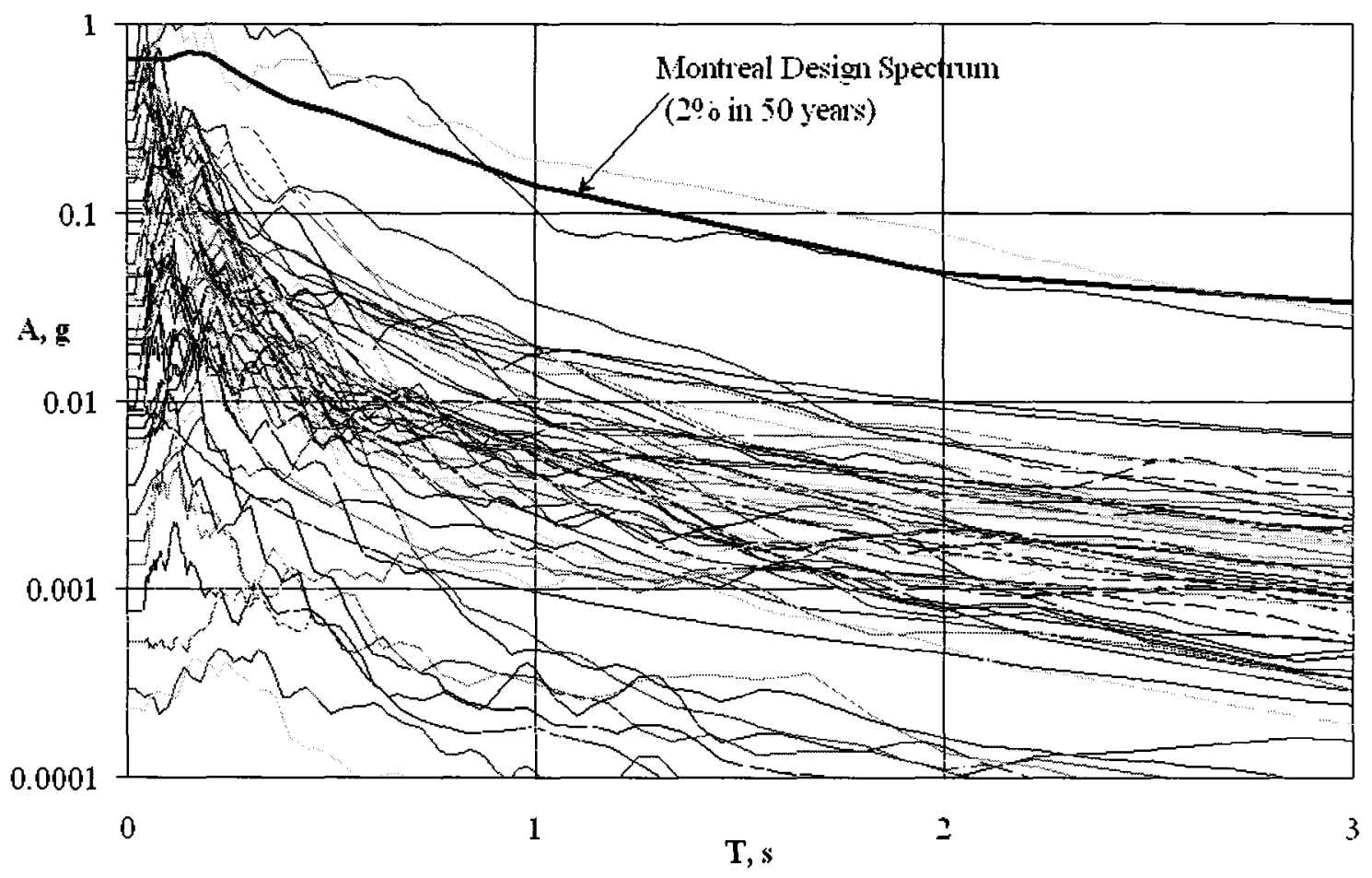

Figure (4.11): Acceleration spectra for all un-scaled SCR Ground motions compared to Montreal Design Spectrum 


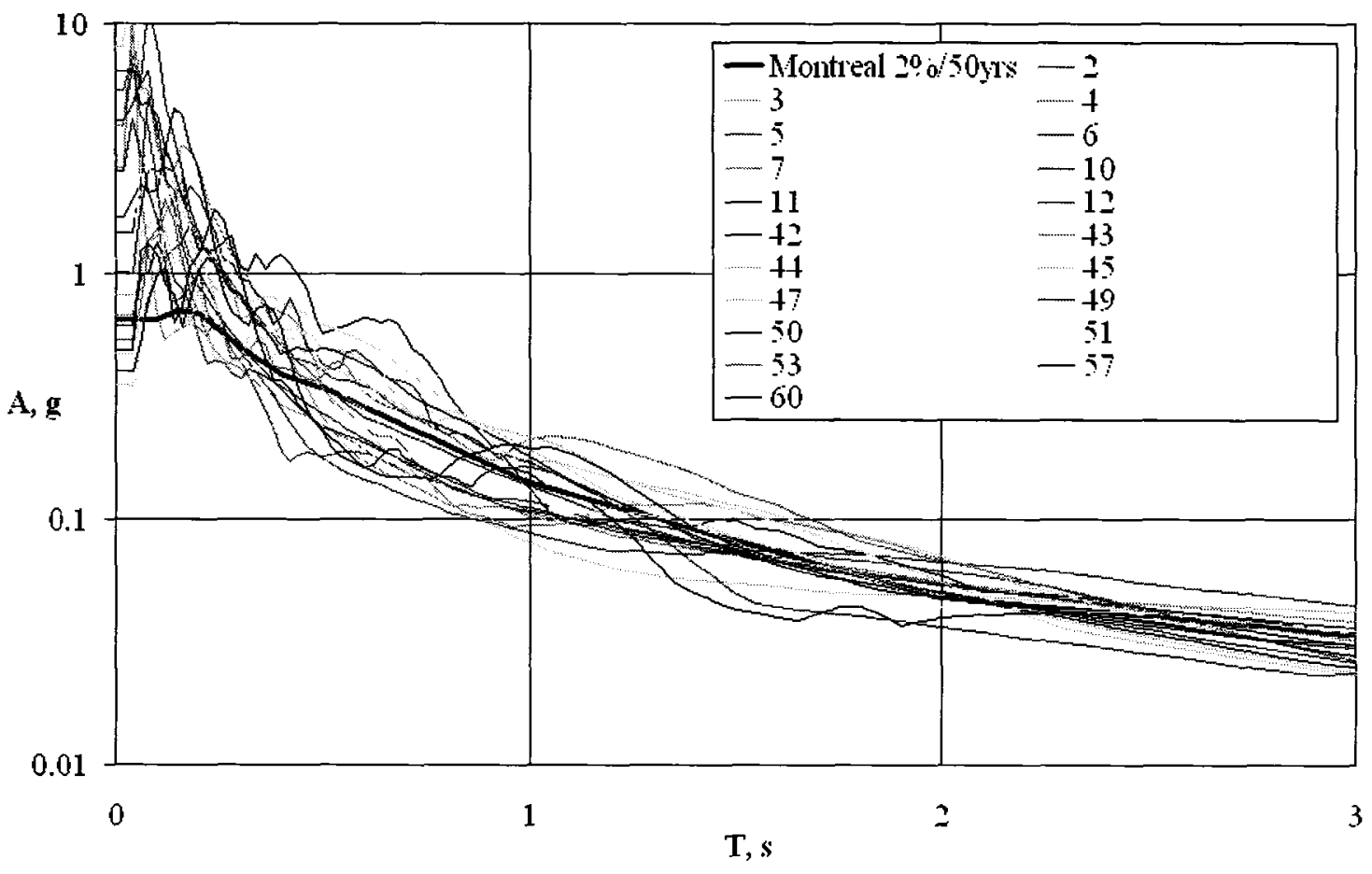

Figure (4.12): Acceleration Spectra for Eastern Canada Ground motions (Scaled by the "Least Sum of Squared Error" Method) 


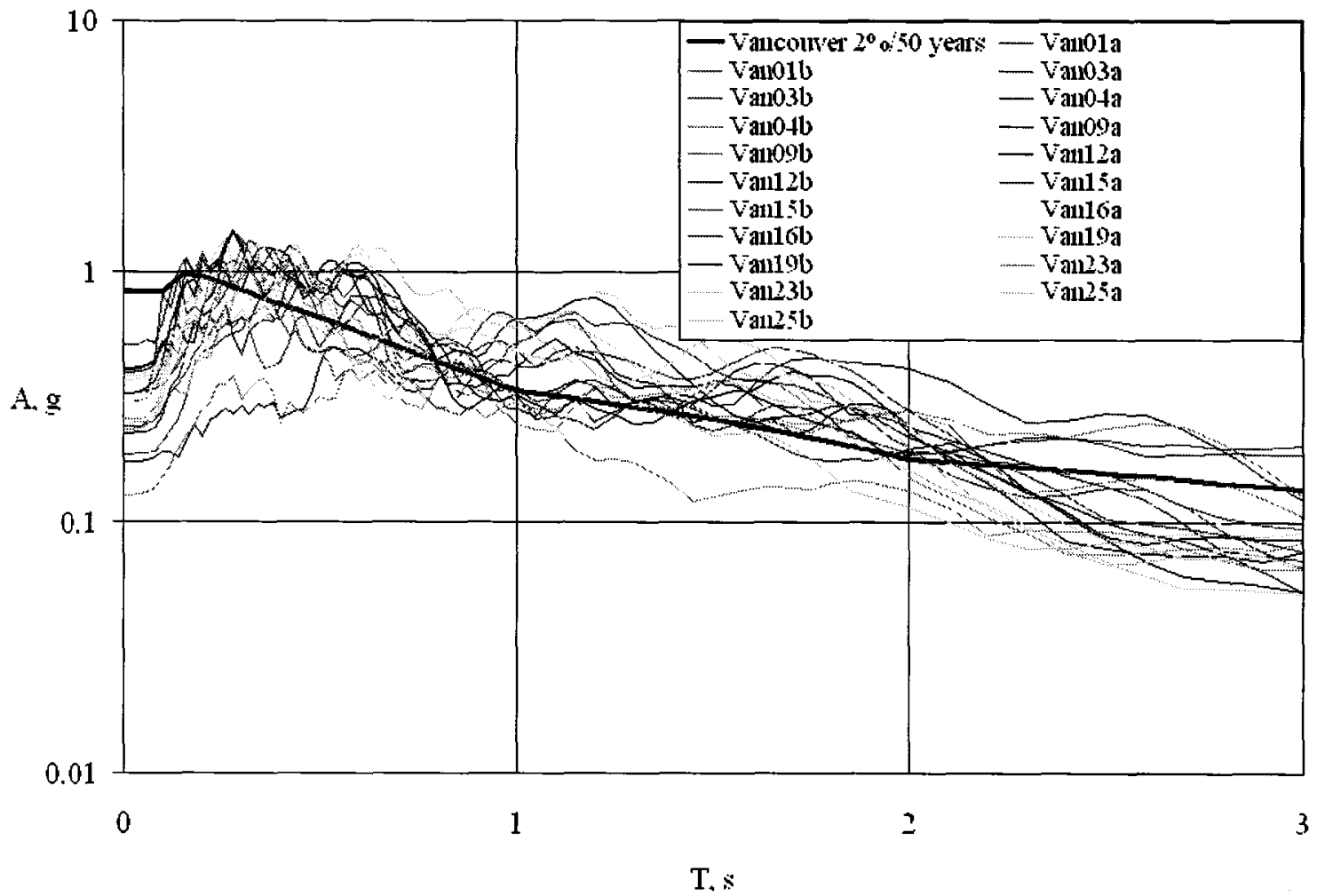

Figure (4.13): Acceleration Spectra for Western Canada Ground motions (Scaled by the "Least Sum of Squared Error" Method) 


\section{Chapter 5}

\section{Validation of the Displacement-based Design Method}

\subsection{Introduction}

In this chapter results of an extended numerical and statistical study of the nonlinear response of building models to selected ground motions are presented. The study is carried out to evaluate the accuracy of the proposed displacement-based design method for several buildings and a wide range of ground motions. Also, based on the results obtained, a relationship between the maximum inter-story drift and the maximum roof drift is developed. Structural steel and reinforced concrete frames of 4 different heights, $6,12,15$ and 20 stories, designed using the proposed displacement based method are used in this study. Nonlinear time history analyses of these frames are carried out to obtain their response to 20 spectrum compatible ground motions. The selection, processing and scaling of these ground motions for eastern and western regions of Canada are discussed in Chapter 4.

For each building, the median and dispersion values of the structural response parameters, which include the inter-story drifts, story shears, beam and column moments and shear forces, and local ductility demands, are calculated and then compared to the respective 
estimated demands, obtained from displacement based method of design using the first mode or several lower order modes.

Equations (5.1) and (5.2) are used in this study to calculate the median value $\hat{x}$, and the dispersion measure $\delta$, for the $\mathrm{x}_{\mathrm{i}}$ results obtained for the $\mathrm{n}=20$ ground motions.

$\hat{x}=\exp \left(\frac{\sum_{i=1}^{n} \ln x_{i}}{n}\right)$

$\delta=\left(\frac{\sum_{i=1}^{n}\left(\ln x_{i}-\ln \hat{x}\right)^{2}}{n-1}\right)^{1 / 2}$

It may be noted that the geometric mean and standard deviation of the logarithm of the results have been calculated since a lognormal distribution is assumed for the data. In the next section, detailed results of the dynamic analyses of the 12-story RC frame building, whose design has been described in Section 3.2, are presented. Summary of the results for 6,15 and 20 storey buildings located in Vancouver, and buildings of all four heights located in Montreal are presented in subsequent sections of the chapter. Nonlinear time history analyses are carried out using Drain-2DX program (Prakash et al. 1993). 


\subsection{Time history analysis of the 12 story $\mathrm{RC}$ frame building}

The layout, applied loads, and material properties of this 12 story RC frame building have been presented in Section 3.2.1 and Figure (3.1). This building is located in Vancouver and has been designed for both near collapse and operational level performance objectives. Twenty spectrum compatible time histories, selected for Western Canada, are used in the nonlinear dynamic analyses of this building. Details of the selected ground motions are presented in Table (4.8). Results of the Nonlinear Time History (NL-TH) analyses follow.

\section{Roof Displacement}

The roof displacements obtained from the analyses are presented in Figure (5.1). In several cases residual displacements remain at the end of the response history; however, the structure remains stable under all 20 records. All of the analytical results will therefore be included in the calculation of statistical parameters.

\section{Inter-story drifts}

The inter-story drift ratios of the structure for 20 records are shown in Table (5.1). The median and dispersion measures are calculated and listed in the last two columns. Maximum drift is observed to be at the $9^{\text {th }}$ and $10^{\text {th }}$ levels and is equal to $1.64 \%$, which is within the acceptable limit of $2.5 \%$. Dispersions are generally less than 0.3 , which shows a limited scatter of the data. Maximum roof displacements are also shown in this table. 
The median value is equal to $36.3 \mathrm{~cm}$ and the maximum value is $54.4 \mathrm{~cm}$ under the first ground motion. The demand roof displacement in the first mode was conservatively estimated by DBD as $53.1 \mathrm{~cm}$

The ratio of the roof drift to the maximum inter-story drift $\beta$, as defined in Section 2.6 and Equation (2.5) is presented in the last row of the Table (5.1) for each ground motion and the median and dispersion are calculated for this parameter. The median value of $\beta$ is found to be 0.46 .

\section{Story shears}

The story shear forces obtained from the dynamic analyses as well as the calculated values of median and dispersion are presented in Table (5.2). The maximum median story shear is in the first story and is equal to $1748 \mathrm{kN}$. Note that the proposed DBD method estimated the design base shear as $1624 \mathrm{kN}$.

\section{Beam moments and shears}

The negative moments at the ends of the middle span beams are shown in the Table (5.3). Under a majority of ground motions, plastic hinges form in the beams of lower 11 floors. Note that the plastic moment capacity of the beams in negative moment is equal to 1287 $\mathrm{kNm}$ for beams of lower 6 floors, $1035 \mathrm{kNm}$ in beams of stories 7 to 9 and $724 \mathrm{kNm}$ for stories 10 to 12 . 
The positive moments at the ends of the middle span beams are shown in Table (5.4). Plastic hinges form in only a few cases. The plastic moment capacity of the beams in positive moment is equal to $800 \mathrm{kNm}$ for beams of lower 6 floors, $529 \mathrm{kNm}$ in beams of stories 7 to 9 and $384 \mathrm{kNm}$ for stories 10 to 12 .

Shear forces for the middle span beams are shown in Table (5.5). The median values show a rather uniform distribution of the shear forces at all levels.

\section{Column Moments}

The column moments are presented in Table (5.6). A plastic hinge forms at the base of the interior columns in all cases for all 20 ground motions. Plastic hinge rotations are shown in the last row of the same table. The median value for this parameter is equal to $2.13 \times 10^{-3}$ radians, whereas the estimated demand value from the first mode pushover analysis presented in Table (3.6) is equal to $11.65 \times 10^{-3}$ radians, which is considerably higher than the median value. Only in two cases under ground motions 2 and 18, the plastic rotation in column base is higher than the estimated demand value. It could be concluded that the proposed design method provides safe and reliable performance in a majority of cases. 


\subsection{Validation of the proposed DBD method}

Demand values for the structural response parameters calculated for the first mode response and by taking the SRSS of the responses in the first 3 modes, presented in Tables (3.2) through (3.6), are compared to the median values obtained from NL-TH analyses in Figures (5.2) through (5.4). In these figures, ratios of the response obtained from superposition of modes, referred to herein as modal response, to NL-TH response, and the first mode response to NL-TH response, represented by $\delta_{\mathrm{SRSS}}$ and $\delta_{\mathrm{FIRST}}$, respectively, are plotted at each story level. Values greater than one for these parameters indicate that DBSD provides an overestimate, whereas values smaller than one indicate an underestimate.

The results presented in Figure (5.2a) show that the inter-story drift demand estimates obtained using both the SRSS combination and the 1st mode are non-conservative in the upper stories, while being quite conservative in the lower stories. A comparison of the estimated inter-story drifts in Table (3.2) and median values of Table (5.1) shows that maximum modal values are in the lower half of the structure, whereas in the exact analysis maximum drifts are observed in the upper half of the structure. Significant effect of higher modes that can be seen only using a NL-TH analysis causes this difference between the estimated and observed results. Even the SRSS combination used in the DBD is unable to capture the effect of higher mode on the inter-story drift. 
The story shear values are compared in Figure (5.2b). The SRSS estimates of the story shears are fairly close to the results of the NL-TH analyses.

Figures (5.3a) and (5.3b) present similar comparisons for the positive and negative bending moments in the beams. The multi mode estimates are very close to the nonlinear analyses results for negative moments, but for positive moments considerable variation is observed in the results. Since local ductility demand values calculated for positive moments are quite low, the underestimated values are not considered critical. Figure (5.4a) compares the results for shear forces in the beams. Both the first mode and the modal estimates are close to the values obtained from NL-TH analyses.

Finally, the estimated bending moment values at the base of the interior columns are compared to the nonlinear analysis values in Figure (5.4b). For all response parameters, the modal method gives better estimates compared to the estimates based on first mode alone.

The results presented here show that in most cases, superposition of modes, which captures the higher modes effect, gives a better estimate of the structural response parameters including inter-story drifts, story shears and member forces compared to the first mode response. 


\subsection{Dynamic analyses of 6, 15 and 20 story $\mathrm{RC}$ frames designed for Vancouver}

The selected ground motions are used in the NL-TH of 6, 15 and 20 story RC frames designed with the proposed DBD method. Details of the designed structures are presented in Table (3.7). Modal and first mode response of these structures for inter-story drifts, story shears, beam negative moments and column moments are compared to the median values obtained from the Nonlinear Time History analyses in Figures (5.5) through (5.10).

\section{Inter-story drifts}

Both, the first mode and modal responses, overestimate the inter-story drifts in lower stories and underestimate them in the upper stories. This difference is less in the 15- and 20 -story frames as compared to the 6-story frame. In all 3 cases, the modal response is closer to the results of NL-TH analyses. Higher modes effect is the main reason for this difference.

\section{Story shears}

The first mode response underestimates the story shear in all 3 buildings. The modal estimate of the base shear is always on the safe side. Comparatively, the story shear estimates obtained by modal analysis are more reliable for the mid-rise and high-rise frames. 


\section{Beam moments}

Results of both the first mode and modal responses are close to the NL-TH analyses. Where a plastic hinge is developed in beams, the modal and $1^{\text {st }}$ mode responses are equal. Since beam local ductility is relied upon during the earthquake excitation, it is important to use a method that produces reliable results for this parameter.

\section{Column moments}

As a result of "strong column-weak beam" criterion that was utilized during the design process, plastic hinges are formed only at the base of first story columns. It was shown earlier that in most cases local ductility estimates based on the first mode are conservative compared to the results of NL-TH analyses. In upper stories of the 6-story frame both responses underestimate the column moments. However, since no plastic hinges from in the upper level columns, this under estimation is not critical. In the case of 15 and 20 story frames, modal method gives fairly good estimates of column moments.

\subsection{Dynamic analyses of 6, 12, 15 and 20 story $\mathrm{RC}$ frames designed for Montreal}

Four reinforced concrete frame buildings of 6, 12, 15 and 20 stories, located in Montreal and designed for both near collapse and operational level performance objectives, are considered. Details of these buildings are shown in Table (3.8). Twenty spectrum compatible time histories, selected for eastern Canada, are used in the nonlinear dynamic analyses of this building. Details of the selected ground motions are presented in Table (4.9). Modal and first mode response of these structures for inter-story drifts, story 
shears, beam negative moments and column moments are compared to the median values obtained from the Nonlinear Time History analyses in Figures (5.11) through (5.18).

\section{Inter-story drifts}

The first mode and modal responses for the inter-story drifts are close, showing low contribution from modes 2 and 3. In all four frames, both responses overestimate the inter-story drifts. The ratios of the modal and first mode response to NL-TH results are maximum in the lower stories and close to unit at roof level.

\section{Story shears}

At the base and in upper portions of the frames, the story shear estimates are close to the results of NL-TH. In the middle section both responses over estimate the story shear forces even up to $100 \%$. Both methods provide a reliable estimate for base shear value, which usually is the starting point in earthquake design.

\section{Beam and column moments}

First mode and modal responses both equally overestimate the moments in the beams and columns in lower stories. This difference is more for taller structures. This could be a direct result of overestimation in story shears as mentioned in the preceding section. 


\subsection{Dynamic analyses of 6, 12, 15 and 20 story steel moment-resisting frames} designed for Vancouver

Four steel moment-resisting frame buildings of $6,12,15$ and 20 stories, located in Vancouver are considered. Details of these buildings, which are designed for two performance objectives (near collapse and operational level), are shown in Table (3.9). Spectrum compatible time histories of the western Canada listed in Table (4.8) are used in the nonlinear dynamic analyses of these buildings. Modal and first mode response of these structures for inter-story drifts, story shears, beam negative moments and column moments are compared to the median values obtained from the nonlinear time history analyses in Figures (5.19) through (5.26).

In all four buildings both the first mode and modal responses overestimate the inter-story drifts in lower stories and underestimate it in upper stories. The ratios of the modal and first mode response to NL-TH results, generally increase with the height of the structure and is maximum in 20 -story building. The first mode and modal responses estimates of the story shears follow a pattern similar to the inter-story drift estimates, except that the estimates are closer to the results of the NL-TH analyses. This bias in the estimation of both inter-story drifts and story shears could be attributed to the effect of higher modes, phenomena that is only captured through the NL-TH analysis. 
The ratios $\delta_{\text {SRSS }}$ and $\delta_{\text {FIRST }}$ for the beams of almost all floors and also moment at the base of the first story columns in all four buildings are close to unity. This indicates that both first mode and modal response methods, estimate the plastic hinge formation in the structures with acceptable precision. The moments of the upper story columns are overestimated because the strong column criterion has governed the design of these columns.

\subsection{Dynamic analyses of 6, 12, 15 and 20 story steel moment-resisting frames} designed for Montreal

Spectrum compatible time histories of the Eastern Canada listed in Table (4.9) are used in the nonlinear dynamic analyses of four steel moment-resisting frame buildings of 6,12 , 15 and 20 stories, located in Montreal. Details of these buildings are shown in Table (3.9). Modal and first mode response of these structures for major response parameters are compared to the median values obtained from the Nonlinear Time History analyses in Figures (5.27) through (5.34).

Results of the NL-TH analyses for these buildings represent considerable difference between the exact and estimated values. Following a pattern similar to that of the steel moment-resisting frames of western Canada, inter-story drifts, story shears, column and beam moments are overestimated in all buildings with maximum bias in middle stories. This overestimation of the response quantities increases with the increase in the number 
of the stories. As discussed in previous section, a part of this bias is initiated from the effect of higher modes that is larger in taller buildings.

\subsection{Dynamic analyses of 12 story concentrically-braced frame building designed for} Vancouver

The 12-story CBF building located in Vancouver is considered. Details of the DBD of this building are presented in Section 3.6. Spectrum compatible time histories of the western Canada are used in the nonlinear dynamic analyses of this building. Modal and first mode response of this structure for inter-story drifts and tensile forces in bracings are compared to the median values obtained from the nonlinear time history analyses in Figures (5.35a) and (5.35b). The median value of the roof displacement resulted from the NL-TH analyses works out to $23.4 \mathrm{~cm}$, which is fairly estimated by the presented DBD method as $22.2 \mathrm{~cm}$. The ratio of the roof drift to maximum inter-story drift $(\beta)$ is calculated as 0.304 .

As presented in Figure (5.35a), except in the $5^{\text {th }}$ story the inter-story drift estimates of both the modal and first mode responses are within acceptable range. During the pushover analysis, bracing of the $5^{\text {th }}$ story yields before the target displacement is reached. This produces larger inter-story drift in the first mode response that is the reason for this over estimation. Figure (5.35b) shows a good compatibility between the results of dynamic analyses and estimated values for the tensile forces of bracings. Modal response 
detects the yielding of braces through the height of the structure with a good precision which is indicate by $\delta_{\mathrm{SRSS}}=1$ values in this figure.

\subsection{Ratio of the roof drift to maximum inter-story drift, $\beta$}

Results of the dynamic analyses are also used to establish a relationship between the ratios of roof drift and maximum inter story drifts, defined in Section 2.6 as $\beta$ factor. Median and dispersion and also the recommended values for $6,12,15$ and 20 story frames located in eastern and western Canada are shown in Table (5.7). This factor is around 0.6 for 6 -story frame and decreases to 0.35 for 20 -story frames.

\subsection{Conclusions}

Results of the NL-TH analyses of the buildings designed for Western Canada prove the effectiveness of the presented DBD method in the design of both steel and reinforced concrete moment-resisting frames. In general, the modal estimates of the critical response parameters are slightly above the median values obtained from exact NL-TH analyses providing a reasonable over-strength factor. It is successful in predicting the distribution pattern of the plastic hinges while providing sufficient ductility capacity. The designed structures remain stable under all ground motions with the median roof displacement close to the target displacement. The inter-story drifts are exceeded under the individual ground motions; however, the median values generally are within the maximum allowable drift of $2.5 \%$. 
There is a certain bias between the results of the NL-TH analyses and first mode or modal response estimates. Higher modes effect that is captured only through the NL-TH analysis is one of the reasons for this bias. This effect is more significant in taller structures.

For Eastern Canada the estimated structural response parameters show higher discrepancy with the results of NL-TH analyses. However, the estimates of the basic design parameters still are acceptable. For example, both responses give a good estimate of the base story shear in majority of cases.

In addition to the error sources discussed for the buildings of Western Canada, larger errors for the buildings in Eastern Canada could be attributed to following sources. In the structures designed for the Eastern Canada, fewer frames are included in the lateral load resisting system, so that inertia masses tributary to such frames are larger. This is done, so that earthquake loads, rather than gravity loads, would govern the design. In spite of this, for some elements the gravity loads are still critical resulting in an over-designed section for earthquake forces. In other words, the earthquake-induced forces are smaller than gravity forces and ductility capacity of these members are not utilized during the earthquake excitation. 
The Somerville scaling method of ground motions that is implemented in this study works well where ground motions are used for a structure with natural period of less than $5 \mathrm{~s}$ (as was the case for most of the buildings designed for Western Canada). However this method has shortcomings when the scaled ground motions are used for buildings designed for Eastern Canada that have considerably longer periods. The selected records are scaled based on their spectral values at $0.3,1,2$ and 4 seconds. The natural period of the structures studied here are well above 4 seconds where the selected records are not scaled properly, so that a high scatter in the results is expected. If instead of the above-mentioned periods, sampling points of the Somerville scaling methods are selected to be in the range of the first few natural periods of the structure, this source of error could be eliminated.

The Geological Survey of Canada has provided the elastic design spectra for Vancouver and Montreal for periods ranging from 0.1 to 2.0 seconds. In designing the buildings for Western Canada, the design spectrum is assumed to vary according to Equation (2.35) for periods larger than $2.0 \mathrm{~s}$, so that the spectral values decline as the period becomes longer. For Eastern Canada too the spectral acceleration is assumed to vary inversely as the period according to Equation (2.35) for periods between 2.0 and $4.0 \mathrm{~s}$. However, for periods larger than $4.0 \mathrm{~s}$ the ordinate of the design spectrum is kept constant. This choice was made to ensure that earthquake forces governed the design. A constant value of the design spectrum for periods larger than $4.0 \mathrm{~s}$ could not be accounted for in the Somerville's scaling method, unless, as stated above, sampling points of the Somerville 
scaling methods are selected to cover periods beyond $4 \mathrm{~s}$. Because sampling points beyond $4 \mathrm{~s}$ were not included in the evaluation studies reported here a significant bias between the estimated performance parameters and results of the NL-TH analyses is expected for buildings designed for Eastern Canada. As a comparison between the buildings designed for Eastern and Western Canada, the estimated and median roof displacements for 15 -story RC frames are examined. The demand roof displacement in first mode is estimated as $63.0 \mathrm{~cm}$ for the building in Vancouver. The median value of the roof displacement obtained from $20 \mathrm{NL}-\mathrm{TH}$ analyses is equal to $40.7 \mathrm{~cm}$, so that there is a 35\% difference between the two values. For the Montreal building the corresponding values of the roof displacements are 43.7 and $13,8 \mathrm{~cm}$ respectively, showing a difference of $68 \%$ difference.

To demonstrate the impact of the choice of scaling method, an alternative scaling method, ground motions are scaled to match just the target spectral value at $\mathrm{T}=4.0 \mathrm{~s}$. Figure (5.36) shows the modal and first mode responses for inter story drifts and story shears compared to the results of the NL-TH analyses of the 12 story RCFR in Montreal. Considerable improvement is observed in the results. It could be concluded that the scaling methods, which account for the natural period of the designed structures, are more effective. 
Table (5.1): Inter-story drifts produced in the 12-story frame by 20 ground motions for Western Canada; drifts are in \%

\begin{tabular}{|c|c|c|c|c|c|c|c|c|c|c|c|c|c|c|c|c|c|c|c|c|c|c|}
\hline \multirow{2}{*}{ Story } & \multicolumn{20}{|c|}{ Ground motions } & \multirow{2}{*}{ Median } & \multirow{2}{*}{$\begin{array}{c}\text { Dispersio } \\
\mathbf{n}\end{array}$} \\
\hline & 1 & 2 & 3 & 4 & 5 & 6 & 7 & 8 & 9 & 10 & 11 & 12 & 13 & 14 & 15 & 16 & 17 & 18 & 19 & 20 & & \\
\hline 1 & 0.97 & 1.49 & 0.60 & 0.63 & 0.44 & 1.17 & 0.76 & 0.55 & 0.57 & 0.71 & 0.58 & 0.50 & 0.56 & 0.85 & 0.91 & 0.75 & 0.56 & 1.32 & 0.70 & 0.84 & 0.73 & 0.33 \\
\hline 2 & 1.24 & 1.72 & 0.91 & 1.07 & 0.82 & 1.53 & 1.15 & 0.94 & 1.03 & 0.96 & 0.91 & 0.83 & 0.95 & 1.08 & 1.17 & 0.99 & 1.00 & 1.39 & 1.00 & 1.20 & 1.07 & 0.19 \\
\hline 3 & 1.23 & 1.50 & 1.00 & 1.20 & 0.85 & 1.50 & 1.20 & 0.93 & 1.09 & 0.97 & 0.8 & 0.77 & 0.94 & 1.05 & 1.24 & 0.83 & 1.10 & 1.23 & 0.94 & 1.18 & 1.06 & 0.19 \\
\hline 4 & 1.18 & 1.17 & 1.04 & 1.17 & 0.79 & 1.29 & 1.10 & 0.82 & 0.97 & 0.86 & 0.87 & 0.61 & 0.82 & 0.90 & 1.11 & 0.82 & 1.10 & 1.25 & 0.88 & 1.09 & 0.98 & 0.19 \\
\hline 5 & 1.23 & 1.13 & 1.15 & 1.16 & 0.81 & 1.18 & 1.19 & 0.80 & 0.86 & 0.88 & 1.04 & 0.63 & 0.71 & 0.98 & 1.02 & 0.95 & 1.16 & 1.40 & 0.91 & 0.98 & 0.99 & 0.20 \\
\hline 6 & 1.34 & 1.13 & 1.04 & 1.20 & 0.79 & 1.27 & 1.06 & 0.78 & 1.02 & 1.00 & 0.93 & 0.81 & 0.77 & 1.13 & 0.96 & 0.93 & 1.07 & 1.37 & 0.85 & 1.00 & 1.01 & 0.18 \\
\hline 7 & 1.93 & 1.36 & 1.01 & 1.30 & 1.01 & 1.52 & 0.97 & 0.83 & 1.32 & 1.18 & 1.20 & 1.12 & 0.94 & 1.39 & 1.04 & 1.08 & 1.15 & 1.36 & 0.95 & 1.11 & 1.17 & 0.20 \\
\hline 8 & 2.33 & 1.58 & 1.19 & 1.31 & 1.19 & 1.83 & 0.90 & 1.01 & 1.57 & 1.43 & 1.44 & 1.41 & 1.10 & 1.70 & 1.22 & 1.28 & 1.21 & 1.34 & 1.20 & 1.17 & 1.34 & 0.22 \\
\hline 9 & 2.45 & 1.65 & 1.51 & 1.51 & 1.59 & 2.07 & 1.22 & 1.34 & 1.65 & 1.80 & 1.61 & 1.64 & 1.60 & 1.92 & 1.67 & 1.66 & 1.27 & 1.50 & 1.89 & 1.75 & 1.64 & 0.16 \\
\hline 10 & 2.27 & 1.75 & 1.38 & 1.28 & 1.74 & 1.85 & 1.38 & 1.41 & 1.52 & 1.88 & 1.41 & 1.91 & 2.15 & 1.78 & 1.60 & 1.62 & 1.00 & 1.36 & 2.02 & 2.16 & 1.64 & 0.21 \\
\hline 11 & 1.66 & 1.49 & 1.21 & 1.11 & 1.41 & 1.33 & 1.23 & 1.15 & 1.40 & 1.47 & 1.05 & 1.77 & 2.05 & 1.44 & 1.39 & 1.43 & 0.87 & 1.09 & 1.46 & 1.75 & 1.36 & 0.20 \\
\hline 12 & 0.82 & 0.81 & 0.71 & 0.79 & 0.72 & 0.68 & 0.65 & 0.64 & 0.81 & 0.80 & 0.72 & 0.96 & 1.11 & 0.85 & 0.87 & 0.83 & 0.62 & 0.79 & 0.74 & $0.95 \mid$ & 0.79 & 0.15 \\
\hline
\end{tabular}

\begin{tabular}{|c|c|c|c|c|c|c|c|c|c|c|c|c|c|c|c|c|c|c|c|c|c|c|}
\hline $\begin{array}{c}\Delta_{\text {Roof }} \\
(\mathrm{cm})\end{array}$ & 54.4 & 53.1 & 31.6 & 39.4 & 32.2 & 48.3 & 27.6 & 31.6 & 34.2 & 35.3 & 33.9 & 25.0 & 33.0 & 41.9 & 36.3 & 38.9 & 40.6 & 47.1 & 34.7 & 24.7 & 36.3 & 0.22 \\
\hline $\boldsymbol{\beta}$ & 0.49 & 0.67 & 0.46 & 0.58 & 0.41 & 0.52 & 0.44 & 0.50 & 0.46 & 0.42 & 0.47 & 0.29 & 0.34 & 0.48 & 0.48 & 0.52 & 0.71 & 0.70 & 0.38 & 0.25 & 0.46 & 0.26 \\
\hline
\end{tabular}


Table (5.2): Story shear forces in the 12-story RC frame under 20 ground motions of Western Canada, shear forces in $\mathrm{kN}$

\begin{tabular}{|c|c|c|c|c|c|c|c|c|c|c|c|c|c|c|c|c|c|c|c|c|c|c|}
\hline \multirow{2}{*}{ Story } & \multicolumn{20}{|c|}{ Ground motions } & \multirow{2}{*}{ Median } & \multirow{2}{*}{ Dispersion } \\
\hline & 1 & 2 & 3 & 4 & 5 & 6 & 7 & 8 & 9 & 10 & 11 & 12 & 13 & 14 & 15 & 16 & 17 & 18 & 19 & 20 & & \\
\hline 1 & 1770 & 1860 & 1713 & 1706 & 1476 & 1771 & 1744 & 1675 & 1637 & 1811 & 1704 & 1687 & 1790 & 1875 & 1852 & 1821 & 1764 & 1928 & 1757 & 1680 & 1748 & 0.06 \\
\hline 2 & 1761 & 1843 & 1611 & 1779 & 1474 & 1824 & 1776 & 1684 & 1846 & 1680 & 1574 & 1533 & 1687 & 1796 & 1876 & 1723 & 1680 & 1885 & 1704 & 1797 & 1723 & 0.07 \\
\hline 3 & 1714 & 1707 & 1684 & 1765 & 1383 & 1772 & 1792 & 1540 & 1794 & 1575 & 1420 & 1296 & 1549 & 1664 & 1828 & 1389 & 1667 & 1843 & 1512 & 1844 & 1628 & 0.11 \\
\hline 4 & 1691 & 1575 & 1676 & 1671 & 1236 & 1653 & 1722 & 1382 & 1562 & 1374 & 1483 & 991 & 1318 & 1480 & 1637 & 1336 & 1627 & 1818 & 1388 & 1690 & 1501 & 01 \\
\hline 5 & 1601 & 1499 & 1596 & 1553 & 1070 & 1592 & 1625 & 1170 & 1231 & $\mid 1270$ & 1539 & 976 & 1008 & 1393 & 1460 & 1341 & 1523 & 1829 & 1245 & 1381 & 1376 & 0.11 \\
\hline 6 & 1497 & 1489 & 1488 & 1570 & 1074 & 1511 & 1416 & 1068 & 1120 & 1384 & 1297 & 1095 & 1051 & 1521 & 1306 & 1253 & 1414 & 1663 & 1145 & 1369 & 1323 & 0.10 \\
\hline 7 & 1498 & 1405 & 1271 & 1443 & 1176 & 1454 & 1182 & 973 & 1456 & 1372 & 1386 & 1353 & 1086 & 1488 & 1216 & 1251 & 1314 & 1452 & 1089 & 1328 & 1301 & 0.02 \\
\hline 8 & 1396 & 1356 & 1274 & 1302 & 1209 & 1424 & 954 & 1023 & 1427 & 1350 & 1391 & 1415 & 1126 & 1421 & 1274 & 1265 & 1205 & 1345 & 1306 & 1208 & 1276 & 0.11 \\
\hline 9 & 1318 & 1231 & 1295 & 1254 & 1235 & 1306 & 1109 & 1125 & 1221 & 1388 & 1253 & 1334 & 1224 & 1344 & 1196 & 1304 & 1004 & 1234 & 1348 & 1326 & 1249 & 0.08 \\
\hline 10 & 1191 & 1155 & 1061 & 990 & 1184 & 1134 & 1098 & $\begin{array}{lll}1 & 102\end{array}$ & 1124 & 1221 & 1063 & 1294 & 1251 & 1199 & 1104 & 1174 & 823 & 1017 & 1262 & 1306 & 1132 & 0.11 \\
\hline 11 & 931 & 972 & 922 & 938 & 927 & 852 & 930 & 890 & 993 & 976 & 910 & 1085 & 1126 & 962 & 1001 & 963 & 764 & 897 & 1013 & 1021 & & \\
\hline 12 & 541 & 564 & 563 & 693 & 500 & 490 & 573 & 502 & 628 & 654 & 634 & 669 & 706 & 688 & 681 & 683 & 534 & 736 & 635 & 685 & 613 & 0.13 \\
\hline
\end{tabular}


Table (5.3): Negative moments produced at the ends of middle-span beams of 12-story RC frame by 20 ground motions for Western Canada, moments ${ }^{*}$ in $\mathrm{kNm}$

\begin{tabular}{|c|c|c|c|c|c|c|c|c|c|c|c|c|c|c|c|c|c|c|c|c|}
\hline \multirow{2}{*}{ Story } & \multicolumn{20}{|c|}{ Ground motions } \\
\hline & 1 & 2 & 3 & 4 & 5 & 6 & 7 & 8 & 9 & 10 & 11 & 12 & 13 & 14 & 15 & 16 & 17 & 18 & 19 & 20 \\
\hline 1 & 1287 & 1287 & 1155 & 1227 & 1010 & 1287 & 1287 & 1140 & 1186 & 1231 & 1145 & 1072 & 1150 & 1287 & 1278 & 1282 & 1167 & 1287 & 1246 & 1287 \\
\hline 2 & 1287 & 1287 & 1210 & 1287 & 1125 & 1287 & 1287 & 1227 & 1287 & 1258 & 1180 & 1097 & 1240 & 1287 & 1278 & 1198 & 1287 & 1287 & 1261 & 1287 \\
\hline 3 & 1287 & 1287 & 1287 & 1287 & 1102 & 1287 & 1287 & 1152 & 1287 & 1199 & 1118 & 976 & 1166 & 1252 & 1278 & 1091 & 1287 & 1287 & 1186 & 1287 \\
\hline 4 & 1287 & 1287 & 1287 & 1287 & 1016 & 1287 & 1287 & 1036 & 1139 & 1040 & 1166 & 844 & 994 & 1120 & 1273 & 1095 & 1287 & 1287 & 1109 & 1249 \\
\hline 5 & 1283 & 1213 & 1200 & 1271 & 921 & 1287 & 1221 & 942 & 1052 & 1072 & 1103 & 870 & 898 & 1165 & 1098 & 1061 & 1209 & 1287 & 1009 & 1095 \\
\hline 6 & 1287 & 1279 & 1115 & 1287 & 1007 & 1287 & 1113 & 927 & 1218 & 1163 & 1137 & 1061 & 979 & 1287 & 1083 & 1095 & 1177 & 1287 & 1005 & 1141 \\
\hline 7 & 1035 & 1035 & 938 & 1035 & 984 & 1035 & 844 & 846 & 1035 & 1035 & 1035 & 1035 & 924 & 1035 & 976 & 1005 & 1028 & 1035 & 993 & 1006 \\
\hline 8 & 1035 & 1035 & 1028 & 1035 & 1025 & 1035 & 842 & 920 & 1035 & 1035 & 1035 & 1035 & 971 & 1035 & 1035 & 1035 & 973 & 1035 & 1035 & 1035 \\
\hline 9 & 1035 & 1035 & 670 & 940 & 1035 & 1035 & 874 & 940 & 985 & 1035 & 988 & 1035 & 1035 & 1035 & 1035 & 1035 & 829 & 964 & 1035 & 1035 \\
\hline 10 & 724 & 724 & 724 & 724 & 724 & 724 & 724 & 724 & 724 & 724 & 724 & 724 & 724 & 724 & 724 & 724 & 72 & 724 & 724 & 724 \\
\hline 11 & 724 & 724 & 724 & 724 & 724 & 724 & 724 & 721 & 724 & 724 & 715 & 724 & 724 & 724 & 724 & 724 & 657 & 724 & 724 & 724 \\
\hline 12 & 523 & 520 & 498 & 524 & 494 & 492 & 486 & 478 & 524 & 522 & 505 & 546 & 585 & 535 & 541 & 528 & 479 & 528 & 509 & 553 \\
\hline
\end{tabular}

* Maximum negative moment capacity is $1287 \mathrm{kNm}$ for 6 lower story beams, $1035 \mathrm{kNm}$ for beams of stories 7 to 9 and $724 \mathrm{kNm}$ for beams of stories 10 to 12 . 
Table (5.4): Positive moments at the ends of the middle-span beams in the 12-story RC frame under 20 ground motions for Western Canada, moments ${ }^{* *}$ in $\mathrm{kNm}$

\begin{tabular}{|c|c|c|c|c|c|c|c|c|c|c|c|c|c|c|c|c|c|c|c|c|}
\hline \multirow{2}{*}{ Story } & \multicolumn{20}{|c|}{ Ground motions } \\
\hline & 1 & 2 & 3 & 4 & 5 & 6 & 7 & 8 & 9 & 10 & 11 & 12 & 13 & 14 & 15 & 16 & 17 & 18 & 19 & 20 \\
\hline 1 & 800 & 800 & 565 & 638 & 420 & 800 & 725 & 550 & 596 & 642 & 555 & 482 & 560 & 732 & 784 & 692 & 578 & 800 & 656 & 772 \\
\hline 2 & 800 & 800 & 620 & 782 & 536 & 800 & 800 & 638 & 742 & 668 & 591 & 508 & 650 & 741 & 800 & 609 & 727 & 800 & 671 & 800 \\
\hline 3 & 800 & 800 & 710 & 800 & 514 & 800 & 800 & 564 & 714 & 611 & 530 & 388 & 578 & 663 & 800 & 502 & 756 & 800 & 598 & 782 \\
\hline 4 & 773 & 708 & 703 & 749 & 428 & 800 & 738 & 449 & 552 & 452 & 579 & 257 & 407 & 533 & 683 & 508 & 722 & 800 & 522 & 660 \\
\hline 5 & 693 & 626 & 613 & 682 & 335 & 711 & 633 & 356 & 466 & 486 & 517 & 284 & 312 & 579 & 512 & 475 & 623 & 800 & 423 & 509 \\
\hline 6 & 800 & 690 & 531 & 710 & 423 & 773 & 529 & 343 & 633 & 580 & 554 & 477 & 394 & 702 & 499 & 511 & 593 & 775 & 421 & 557 \\
\hline 7 & 529 & 529 & 351 & 492 & 397 & 529 & 257 & 258 & 529 & 481 & 497 & 492 & 337 & 529 & 388 & 418 & 439 & 529 & 406 & 418 \\
\hline 8 & 529 & 529 & 439 & 462 & 437 & 529 & 255 & 334 & 529 & 529 & 510 & 529 & 385 & 529 & 466 & 477 & 387 & 469 & 518 & 447 \\
\hline 9 & 529 & 472 & 372 & 354 & 474 & 529 & 288 & 354 & 398 & 529 & 401 & 481 & 527 & 492 & 468 & 471 & 244 & 379 & 529 & 529 \\
\hline 10 & 384 & 384 & 291 & 294 & 384 & 384 & 384 & 384 & 384 & 384 & 294 & 384 & 384 & 384 & 384 & 384 & 133 & 314 & 384 & 384 \\
\hline 11 & 230 & 214 & 153 & 162 & 179 & 154 & 142 & 136 & 207 & 247 & 130 & 309 & 361 & 207 & 219 & 213 & 76 & 143 & 225 & 271 \\
\hline 12 & 0 & 0 & 0 & 0 & 0 & 0 & 0 & 0 & 0 & 0 & 0 & 0 & 1 & 0 & 0 & 0 & 0 & 0 & 0 & 0 \\
\hline
\end{tabular}

** Maximum positive moment capacity is $800 \mathrm{kNm}$ for 6 lower story beams, $529 \mathrm{kNm}$ for beams of stories 7 to 9 and $384 \mathrm{kNm}$ for beams of stories 10 to 12 . 
Table (5.5): Shear forces of the middle-span beams in the 12-story RC frame under 20 ground motions for Western Canada, shear forces in $\mathrm{kN}$

\begin{tabular}{|c|c|c|c|c|c|c|c|c|c|c|c|c|c|c|c|c|c|c|c|c|c|c|}
\hline \multirow{2}{*}{ Story } & \multicolumn{20}{|c|}{ Ground motions } & \multirow{2}{*}{ Median } & \multirow{2}{*}{ Dispersion } \\
\hline & 1 & 2 & 3 & 4 & 5 & 6 & 7 & 8 & 9 & 10 & 11 & 12 & 13 & 14 & 15 & 16 & 17 & 18 & 19 & 20 & & \\
\hline 1 & 482 & 482 & 436 & 454 & 399 & 482 & 473 & 433 & 444 & 455 & 43 & 416 & 435 & 474 & 480 & 468 & 439 & 482 & 459 & 479 & 405 & 0.53 \\
\hline 2 & 482 & 482 & 450 & 480 & 429 & 482 & 482 & 454 & 475 & 462 & 443 & 422 & 457 & 475 & 511 & 477 & 473 & 482 & 463 & 482 & 468 & 0.05 \\
\hline 3 & 482 & 482 & 445 & 482 & 423 & 482 & 482 & 436 & 471 & 448 & 427 & 392 & 439 & 461 & 482 & 420 & 477 & 482 & 444 & 480 & 456 & 0.06 \\
\hline 4 & 479 & 471 & 470 & 476 & 402 & 482 & 474 & 407 & 433 & 408 & 439 & 359 & 396 & 428 & 466 & 422 & 472 & 482 & 425 & 460 & 441 & .08 \\
\hline 5 & 468 & 451 & 448 & 465 & 378 & 471 & 453 & 384 & 411 & 416 & 424 & 366 & 373 & 439 & 422 & 413 & 450 & 482 & 400 & 422 & 425 & 0.08 \\
\hline 6 & 482 & 467 & 427 & 471 & 400 & 479 & 426 & 380 & 452 & 439 & 432 & 413 & 393 & 470 & 419 & 422 & 443 & 479 & 399 & 433 & 435 & 0.07 \\
\hline 7 & 417 & 417 & 376 & 412 & 394 & 417 & 359 & 359 & 417 & 411 & 413 & 412 & 379 & 417 & 392 & 399 & 405 & 417 & 396 & 399 & 400 & 0.05 \\
\hline 8 & 417 & 417 & 405 & 408 & 404 & 417 & 358 & 378 & 417 & 417 & 414 & 417 & 391 & 417 & 409 & 410 & 391 & 409 & 415 & 406 & 406 & 0.04 \\
\hline 9 & 417 & 410 & 387 & 383 & 410 & 417 & 366 & 383 & 394 & 417 & 395 & 411 & 417 & 412 & 409 & 409 & 355 & 389 & 417 & 417 & 400 & 0.05 \\
\hline 10 & 360 & 360 & 348 & 349 & 360 & 360 & 360 & 360 & 360 & 360 & 348 & 360 & 360 & 360 & 360 & 360 & 328 & 351 & 360 & 360 & 356 & 0.02 \\
\hline 11 & 340 & 338 & 331 & 332 & 334 & 331 & 329 & 328 & 338 & 343 & 327 & 350 & 357 & 338 & 339 & 338 & 313 & 330 & 340 & 346 & 336 & 0.03 \\
\hline 12 & 277 & 276 & 270 & 277 & 269 & 269 & 267 & 265 & 277 & 276 & 264 & 282 & 292 & 279 & 281 & 278 & 265 & 278 & 273 & 284 & 275 & 0.03 \\
\hline
\end{tabular}


Table (5.6): Moments at the bottom of the interior columns in the 12-story RC frame under 20 ground motions for Western Canada, moments ${ }^{*}$ in $\mathrm{kNm}$

\begin{tabular}{|c|c|c|c|c|c|c|c|c|c|c|c|c|c|c|c|c|c|c|c|c|c|c|}
\hline \multirow{2}{*}{ Story } & \multicolumn{20}{|c|}{ Ground motions } & \multirow{2}{*}{ Median } & \multirow{2}{*}{ Dispersion } \\
\hline & 1 & 2 & 3 & 4 & 5 & 6 & 7 & 8 & 9 & 10 & 11 & 12 & 13 & 14 & 15 & 16 & 17 & 18 & 19 & 20 & & \\
\hline 1 & 1961 & 1962 & 1943 & 1964 & 1698 & 1965 & 1941 & 1950 & 1954 & 1950 & 1950 & 1946 & 1948 & 1948 & 1953 & 1957 & 1962 & 1976 & 1949 & 1949 & - & - \\
\hline 2 & 1200 & 1270 & 1110 & 1248 & 986 & 1351 & 1267 & 1094 & 1240 & 109 & 1011 & 957 & 1100 & 1188 & 1311 & 1023 & 1171 & 1516 & 1082 & 1267 & 1167 & 0.12 \\
\hline 3 & 1158 & 1218 & 1113 & 1165 & 870 & 1228 & 1256 & 960 & 1097 & 972 & 916 & 761 & 937 & 986 & 1127 & 880 & 1127 & 1323 & 964 & 1152 & 1050 & 0.15 \\
\hline 4 & 1100 & 1071 & 1080 & 1033 & 769 & 1162 & 1159 & 862 & 901 & 805 & 1018 & 664 & 731 & 900 & 998 & 890 & 1051 & 1264 & 878 & 968 & 953 & 0.17 \\
\hline 5 & 1005 & 925 & 942 & 983 & 627 & 1026 & 944 & 697 & 791 & 799 & 920 & 590 & 641 & 891 & 871 & 809 & 927 & 1120 & 755 & 742 & 838 & 0.18 \\
\hline 6 & 1156 & 968 & 904 & 1031 & 740 & 1048 & 855 & 681 & 961 & 693 & 844 & 782 & 719 & 1012 & 843 & 836 & 914 & 1082 & 749 & 874 & 875 & 0.15 \\
\hline 7 & 1321 & 1085 & 829 & 1021 & 883 & 1132 & 731 & 701 & 1120 & 978 & 1023 & 991 & 814 & 1144 & 885 & 919 & 945 & 1033 & 874 & 910 & 956 & 0.16 \\
\hline 8 & 967 & 883 & 878 & 834 & 797 & 969 & 636 & 714 & 933 & 927 & 921 & 970 & 758 & 980 & 883 & 889 & 764 & 848 & 955 & 873 & 864 & 0.12 \\
\hline 9 & 821 & 756 & 758 & 722 & 778 & 753 & 643 & 670 & 704 & 837 & 722 & 830 & 806 & 764 & 824 & 805 & 580 & 727 & 881 & 900 & 760 & 0.11 \\
\hline 10 & 791 & 790 & 682 & 599 & 789 & 719 & 722 & 695 & 750 & 795 & 659 & 895 & 934 & 802 & 728 & 738 & 487 & 631 & 891 & 897 & 742 & 0.16 \\
\hline 11 & 507 & 493 & 483 & 542 & 445 & 478 & 522 & 482 & 550 & 532 & 565 & 560 & 531 & 543 & 574 & 537 & 441 & 541 & 589 & 604 & 524 & 0.09 \\
\hline 12 & 266 & 289 & 293 & 371 & 248 & 243 & 284 & 269 & 310 & 333 & 337 & 384 & 316 & 344 & 362 & 358 & 291 & 391 & 323 & 352 & 315 & 0.14 \\
\hline
\end{tabular}

\begin{tabular}{|l|l|l|l|l|l|l|l|l|l|l|l|l|l|l|l|l|l|l|l|l|}
\hline$\theta_{\mathrm{P}}(\times 1000)$ & 5.48 & 17.1 & 1.27 & 1.52 & 0.10 & 9.05 & 3.08 & 0.58 & 0.68 & 4.19 & 1.07 & 0.10 & 0.84 & 5.25 & 8.15 & 3.45 & 1.78 & 15.9 & 2.79 & 3.97 \\
\hline
\end{tabular}

2.13

1.42

* Maximum moment capacity of the first story column at the gravity axial load of $5331 \mathrm{kN}$ is equal to $1933 \mathrm{kNm}$ 
Table (5.7): Median and dispersion values of the $\beta$ factor calculated from NL-TH analyses

\begin{tabular}{|c|c|c|c|c|c|c|}
\hline $\begin{array}{c}\text { Structural } \\
\text { System }\end{array}$ & \multirow{2}{*}{ Stories } & \multicolumn{2}{|c|}{ Vancouver } & \multicolumn{2}{c|}{ Montreal } & Recommended \\
\cline { 2 - 7 } & & Median & Dispersion & Median & Dispersion & Value \\
\hline \multirow{4}{*}{ RCFR } & 6 & 0.625 & 0.16 & 0.545 & 0.18 & 0.60 \\
\cline { 2 - 7 } & 12 & 0.465 & 0.26 & 0.435 & 0.25 & 0.45 \\
\cline { 2 - 7 } & 15 & 0.424 & 0.22 & 0.393 & 0.25 & 0.40 \\
\cline { 2 - 7 } & 20 & 0.384 & 0.25 & 0.334 & 0.27 & 0.35 \\
\hline \multirow{4}{*}{ SMRF } & 6 & 0.641 & 0.17 & 0.548 & 0.19 & 0.60 \\
\cline { 2 - 7 } & 12 & 0.469 & 0.22 & 0.410 & 0.64 & 0.45 \\
\cline { 2 - 7 } & 15 & 0.453 & 0.24 & 0.41 & 0.30 & 0.42 \\
\cline { 2 - 7 } & 20 & 0.433 & 0.19 & 0.381 & 0.33 & 0.40 \\
\hline CBF & 12 & 0.304 & 0.41 & & & \\
\hline
\end{tabular}




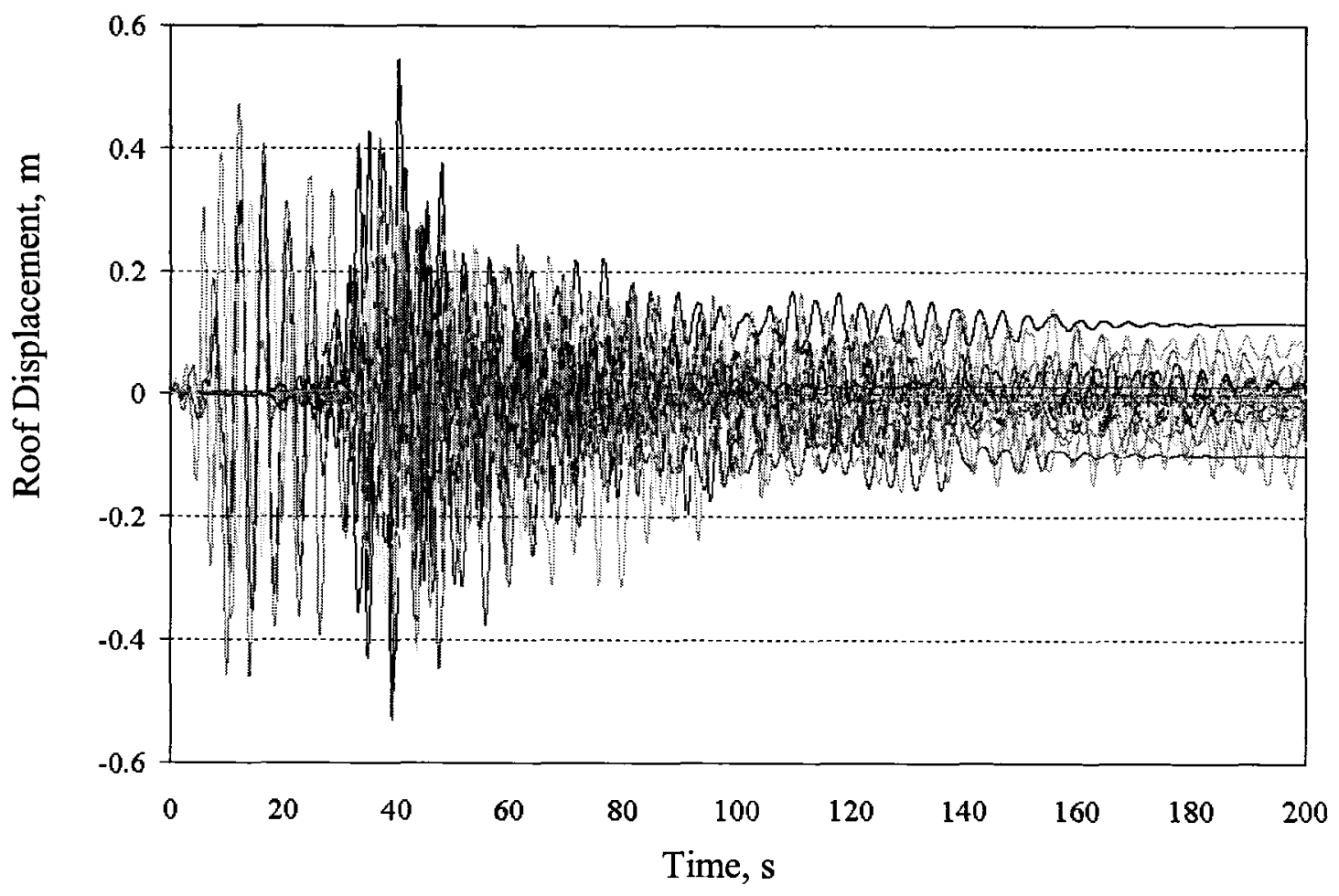

Figure (5.1): Roof displacements in the 12-story RC frame under 20 selected ground motions for western Canada 
(a)

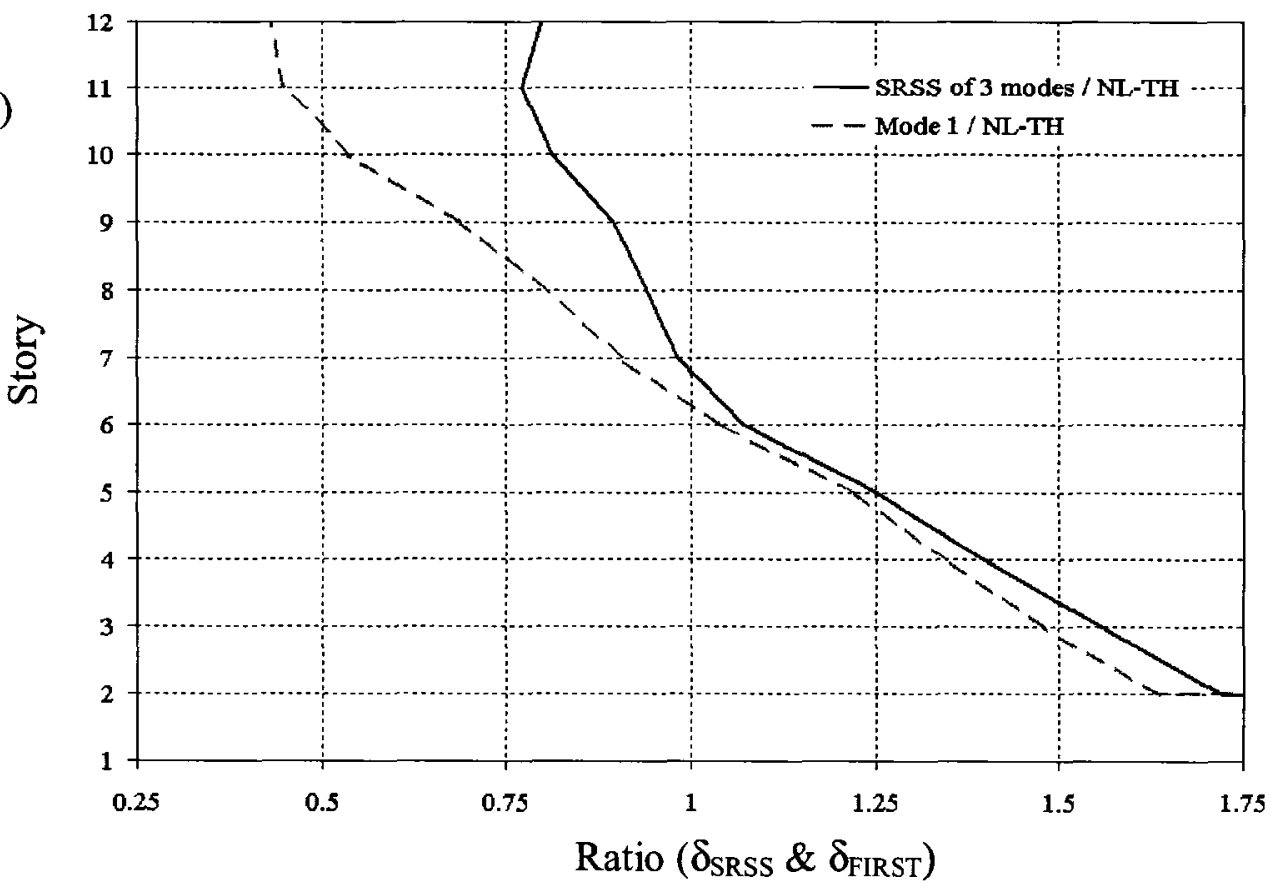

(b)

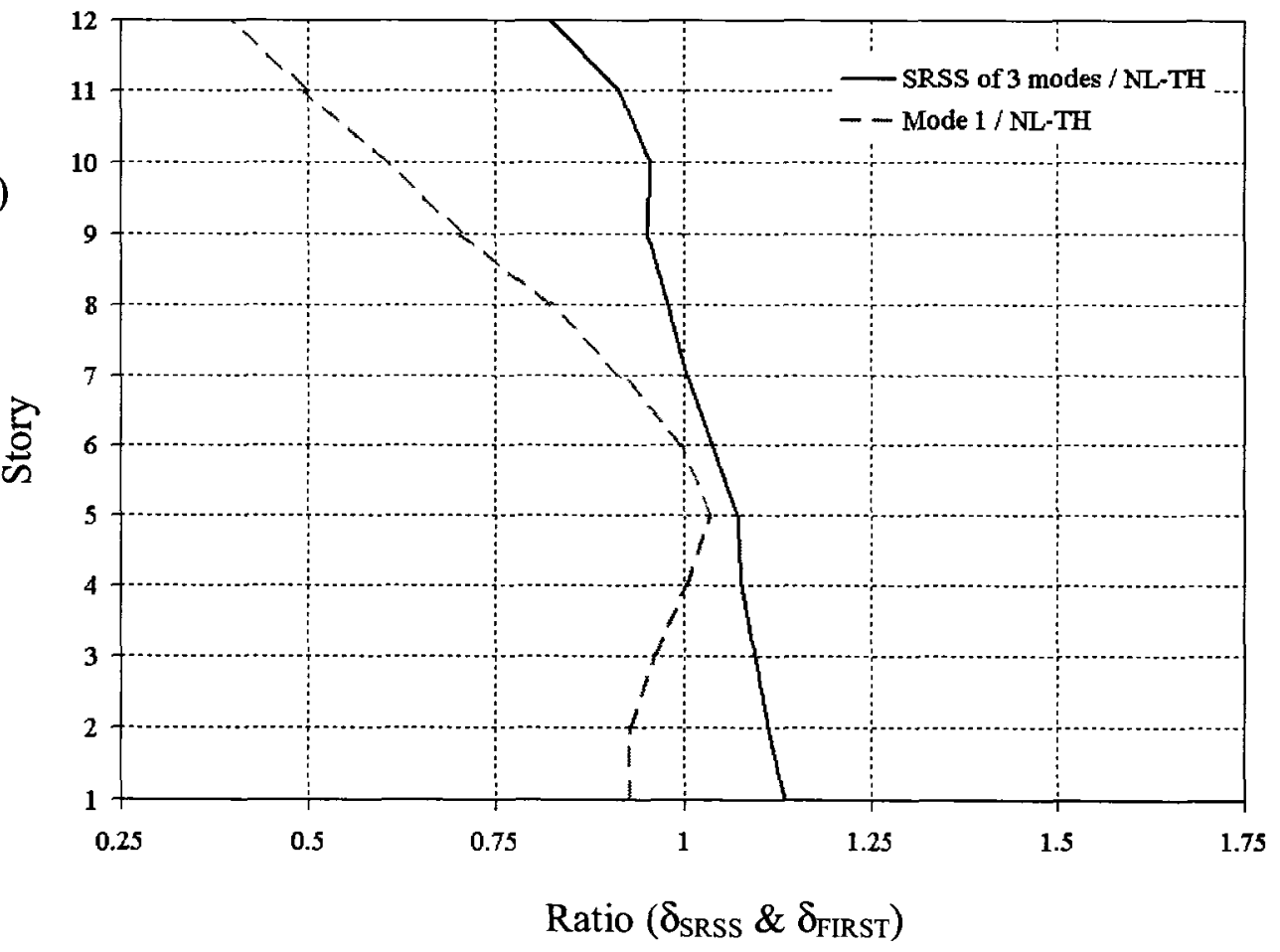

Figure (5.2): Comparison of the modal and first mode responses with the results of Nonlinear Time History analyses for 12 story RC frame in Vancouver;

(a) Inter-story drifts, (b) Story shears 
(a)

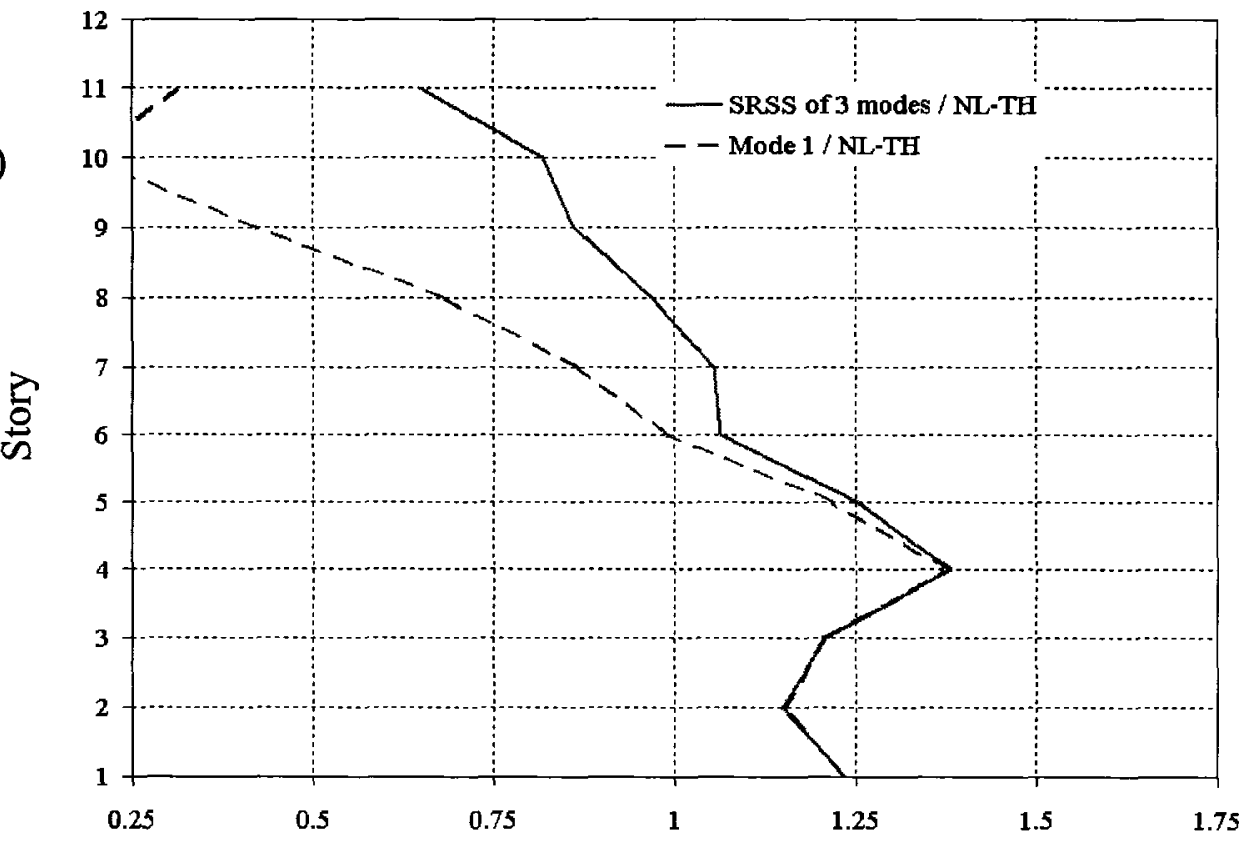

Ratio $\left(\delta_{\text {SRSS }} \& \delta_{\text {FIRST }}\right)$

(b)

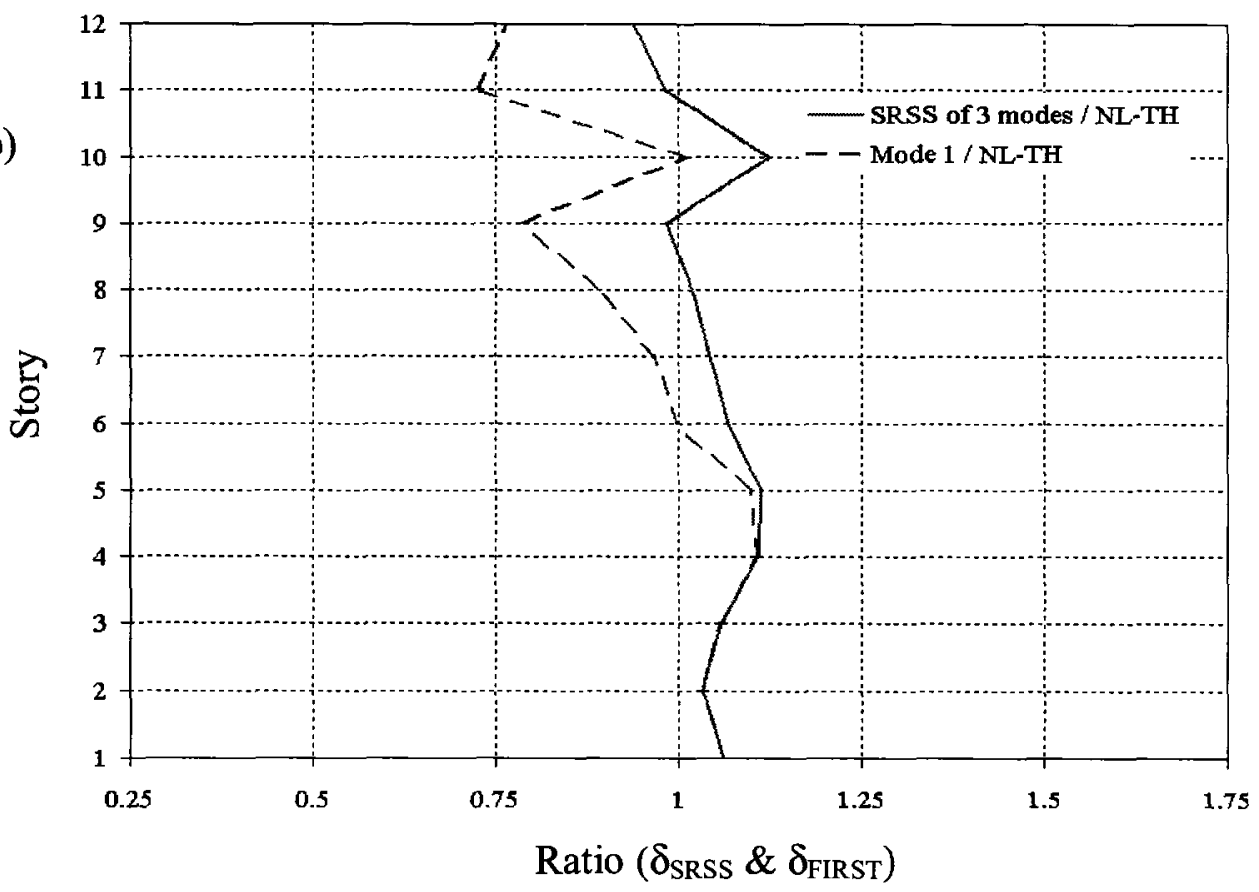

Figure (5.3): Comparison of the modal and first mode responses with the results of Nonlinear Time History analyses for 12 story RC frame in Vancouver;

(a) Positive moment at the ends of middle span beams (b) Negative moment at the ends of middle span beams 
(a)

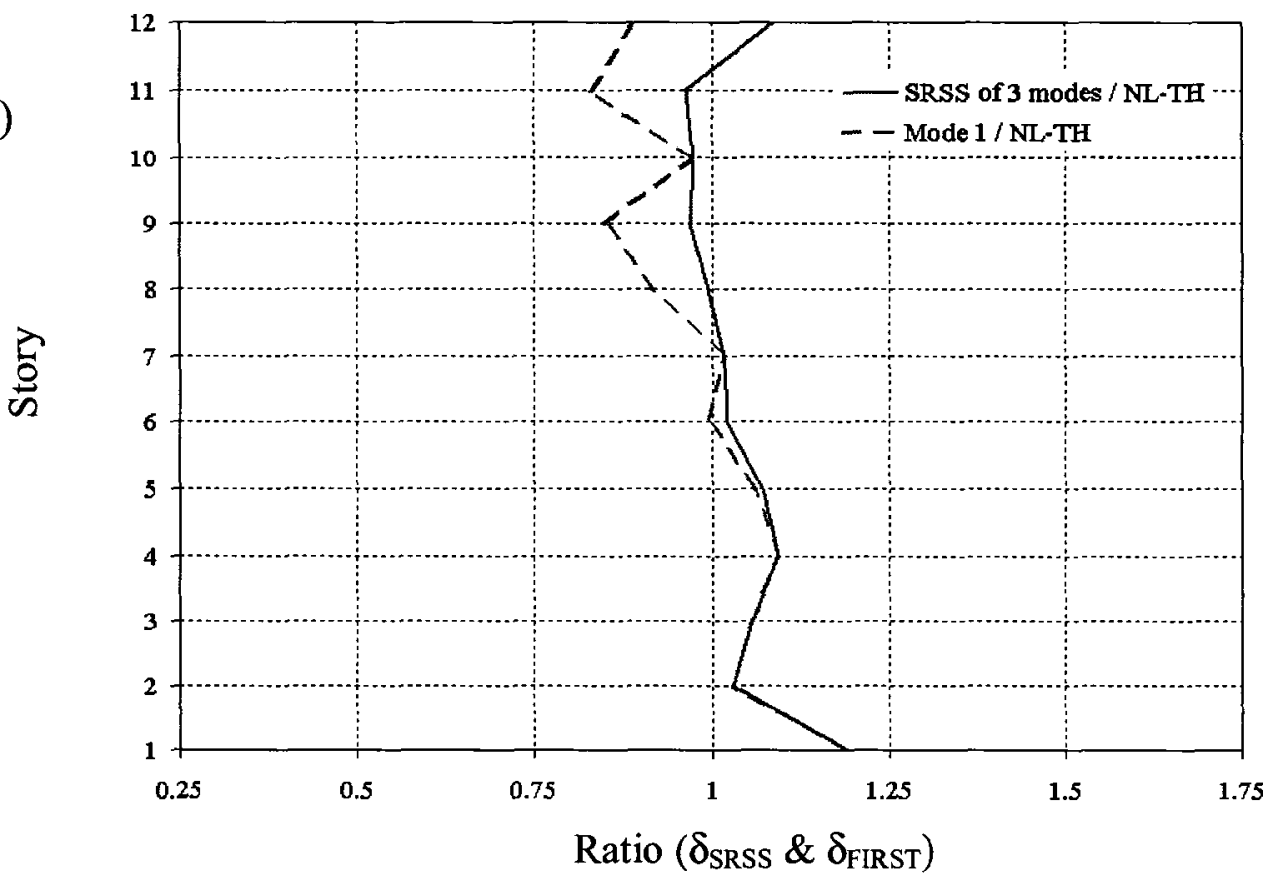

(b)

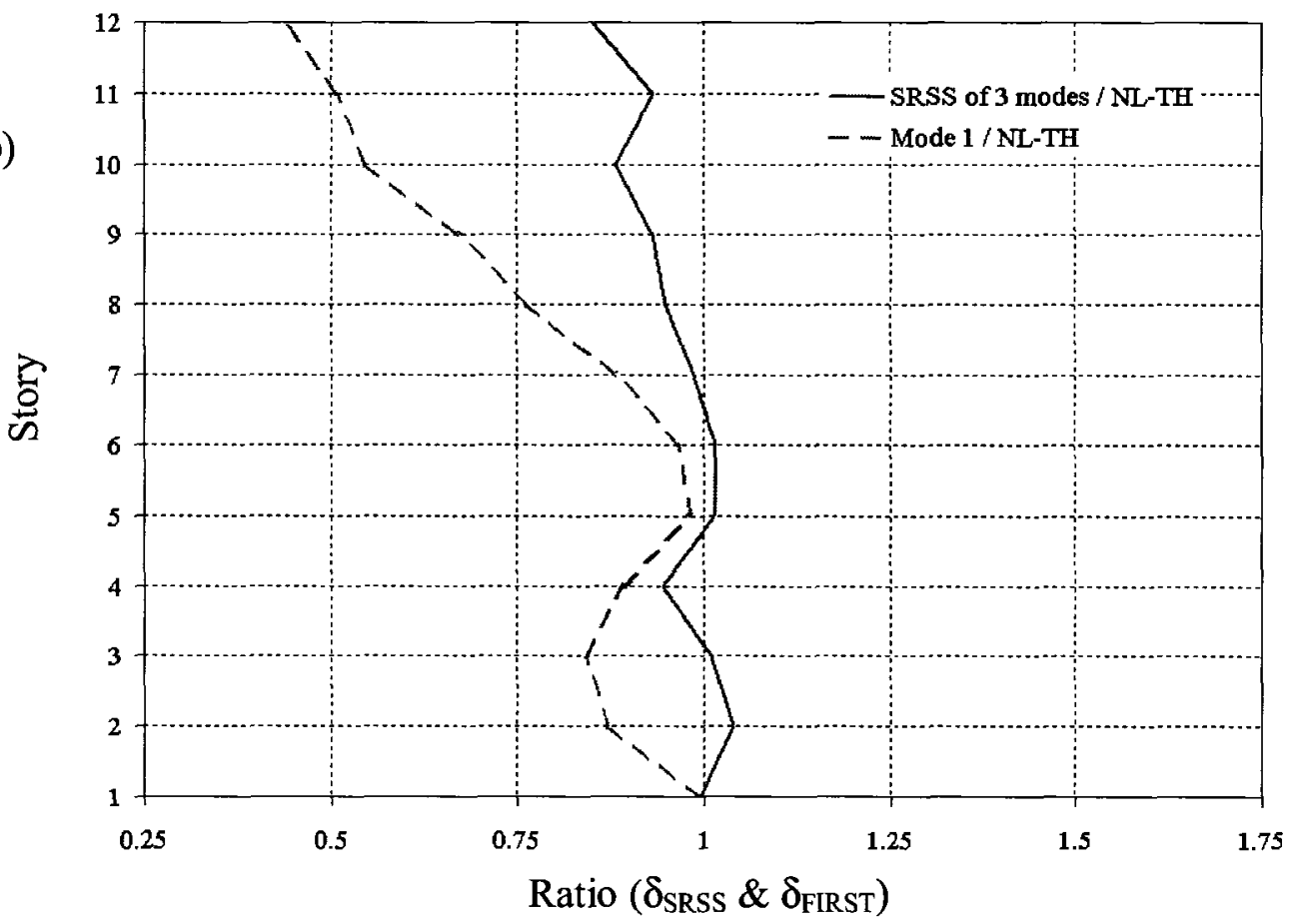

Figure (5.4): Comparison of the modal and first mode responses with the results of Nonlinear Time History analyses for 12 story RC frame in Vancouver;

(a) Shear force in middle span beams, (b) Moment in the interior columns at the base of each story 
(a)

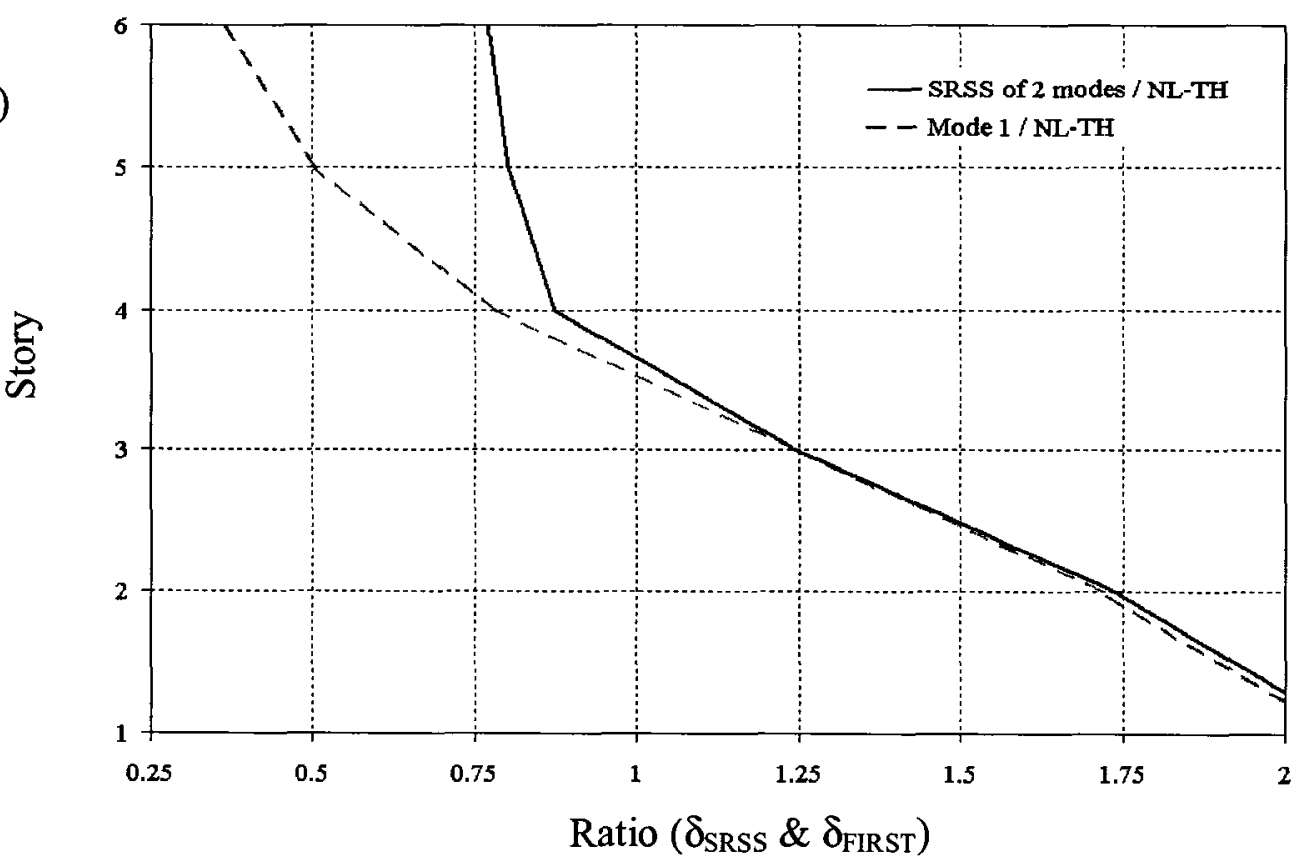

(b)

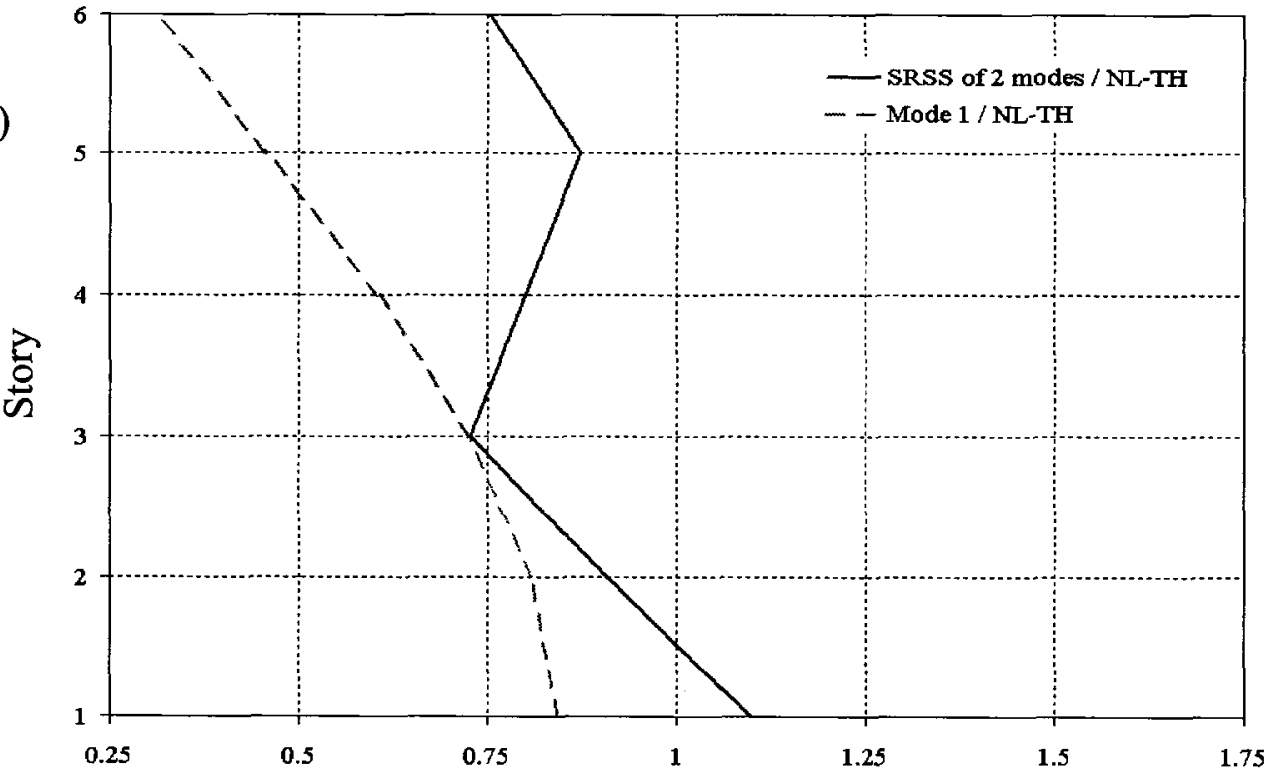

Ratio $\left(\delta_{\text {SRSS }} \& \delta_{\text {FIRST }}\right)$

Figure (5.5): Comparison of the modal and first mode responses with the results of Nonlinear Time History analyses for 6 story RC frame in Vancouver;

(a) Inter-story drifts, (b) Story shears 
(a)
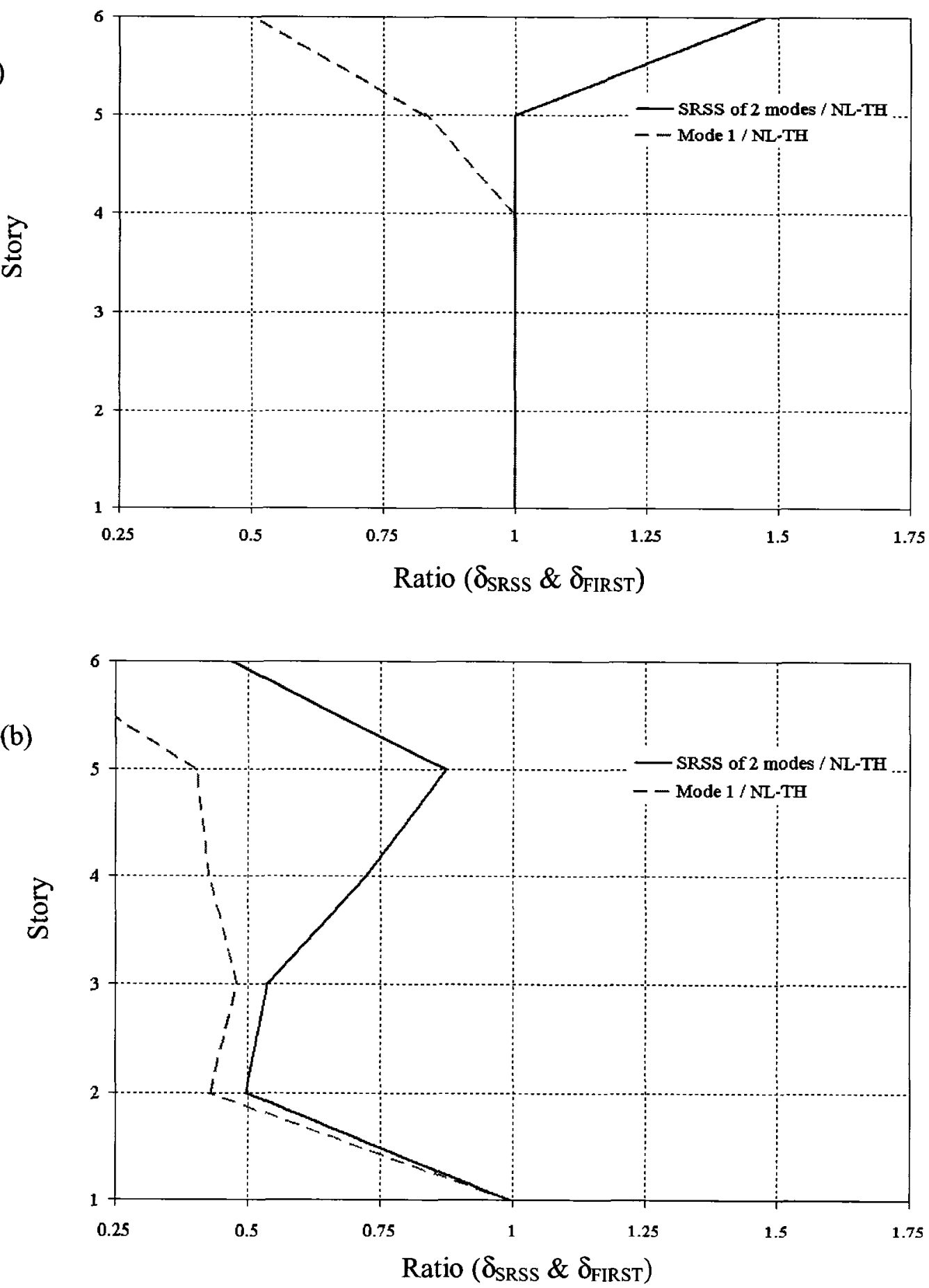

Figure (5.6): Comparison of the modal and first mode responses with the results of Nonlinear Time History analyses for 6 story RC frame in Vancouver;

(a) Negative moment at the ends of middle span beams (b) Moment in the interior columns at the base of each story 

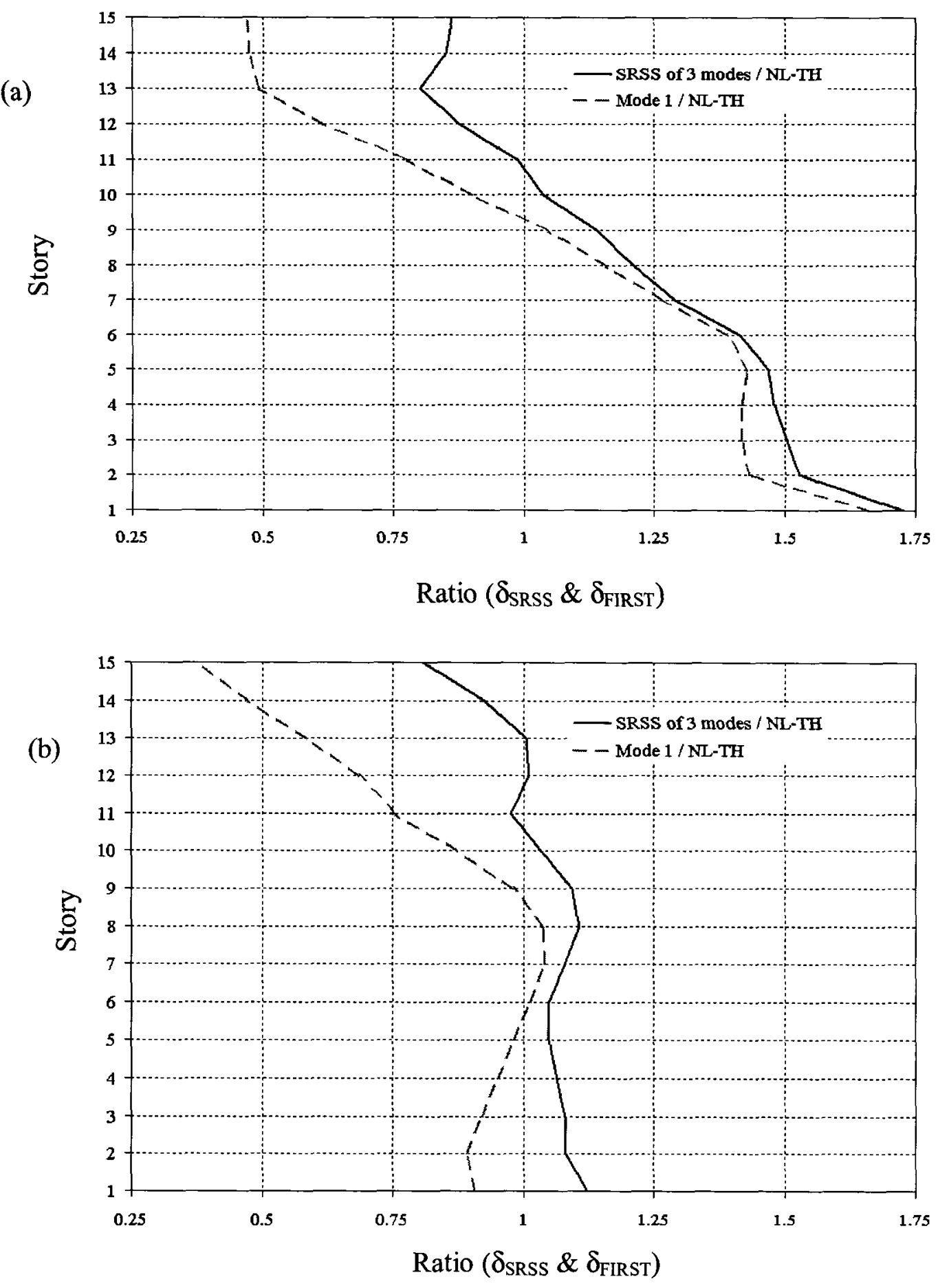

Figure (5.7): Comparison of the modal and first mode responses with the results of Nonlinear Time History analyses for 15 story RC frame in Vancouver; (a) Inter-story drifts, (b) Story shears 

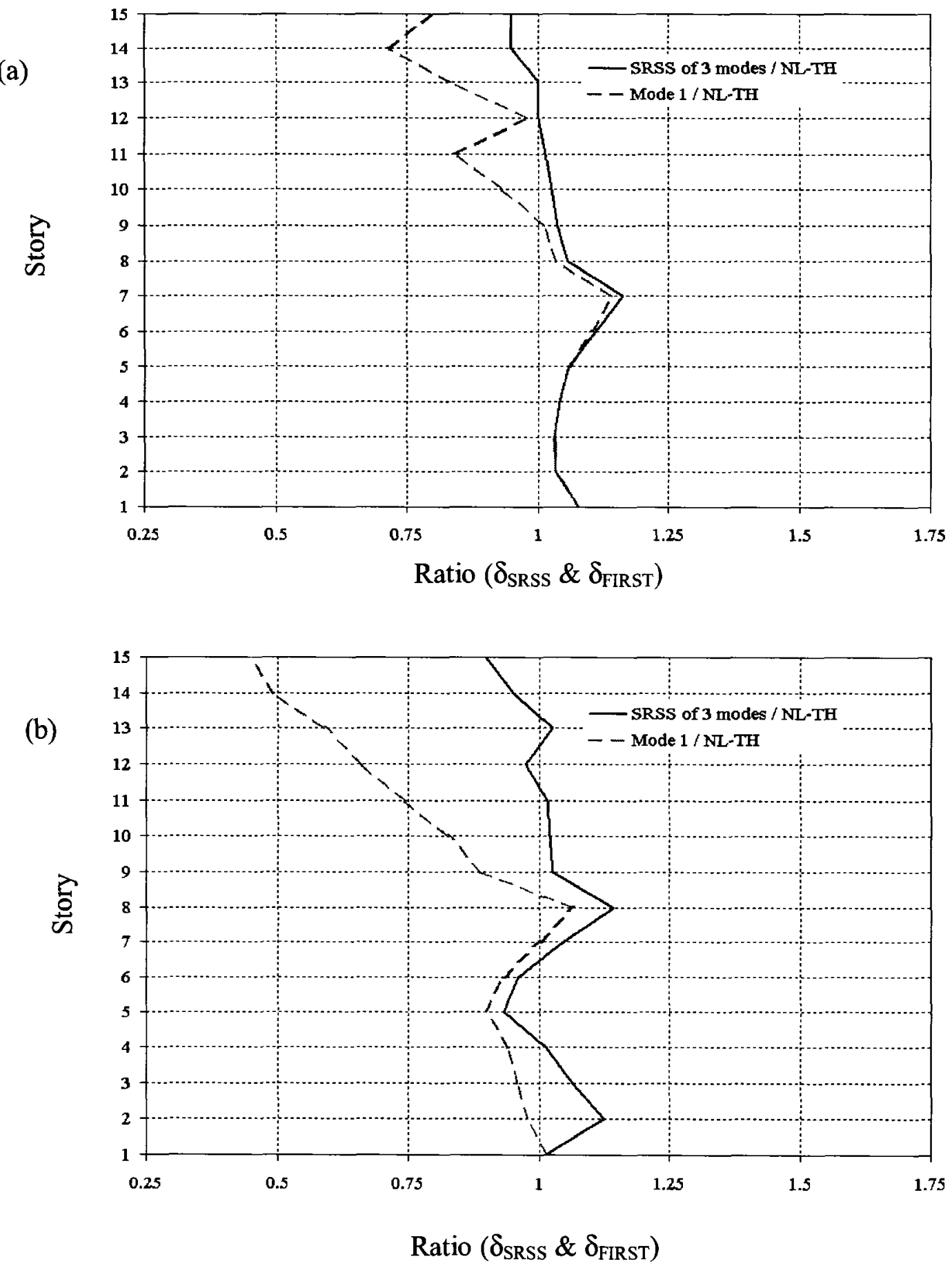

Figure (5.8): Comparison of the modal and first mode responses with the results of Nonlinear Time History analyses for 15 story RC frame in Vancouver;

(a) Negative moment at the ends middle span beams (b) Moment in the interior columns at the base of each story 

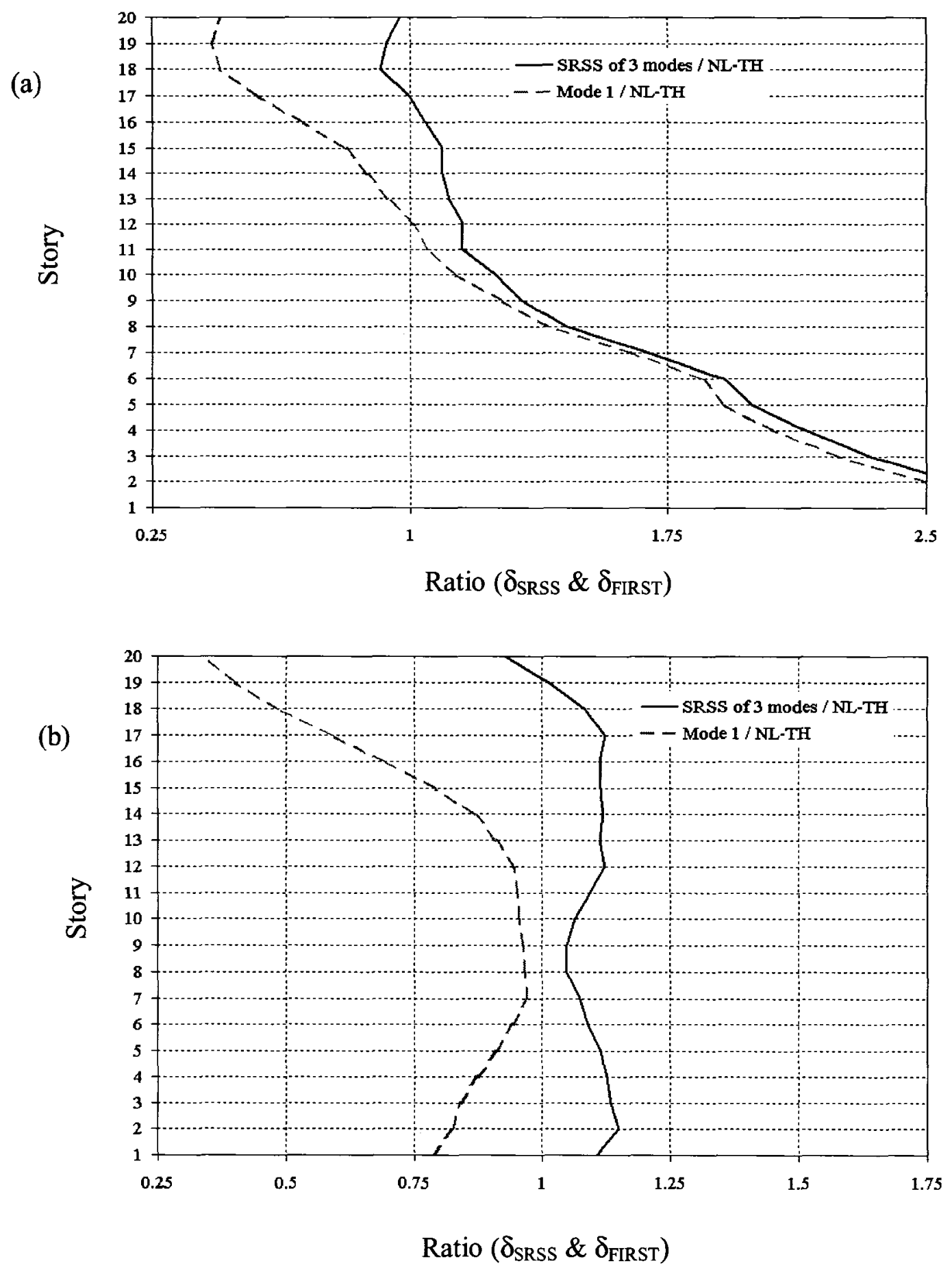

Figure (5.9): Compariosn of the modal and first mode responses with the results of Nonlinear Time History analyses for 20 story RC frame in Vancouver;

(a) Inter-story drifts, (b) Story shears 
(a)
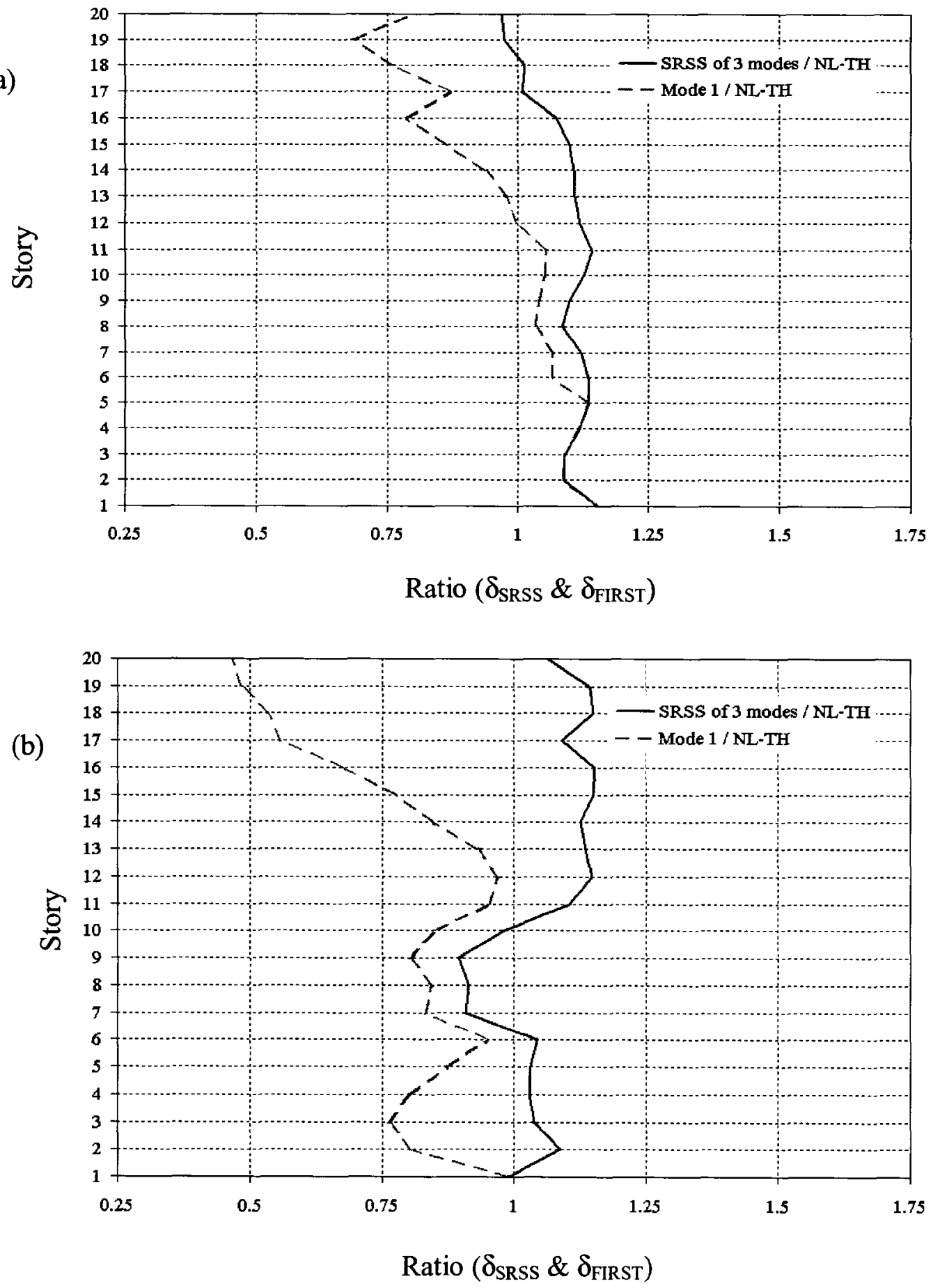

Figure (5.10): Comparison of the modal and first mode responses with the results of Nonlinear Time History analyses for 20 story RC frame in Vancouver;

(a) Negative moment at the ends of middle span beams (b) Moment in the interior columns at the base of each story 
(a)

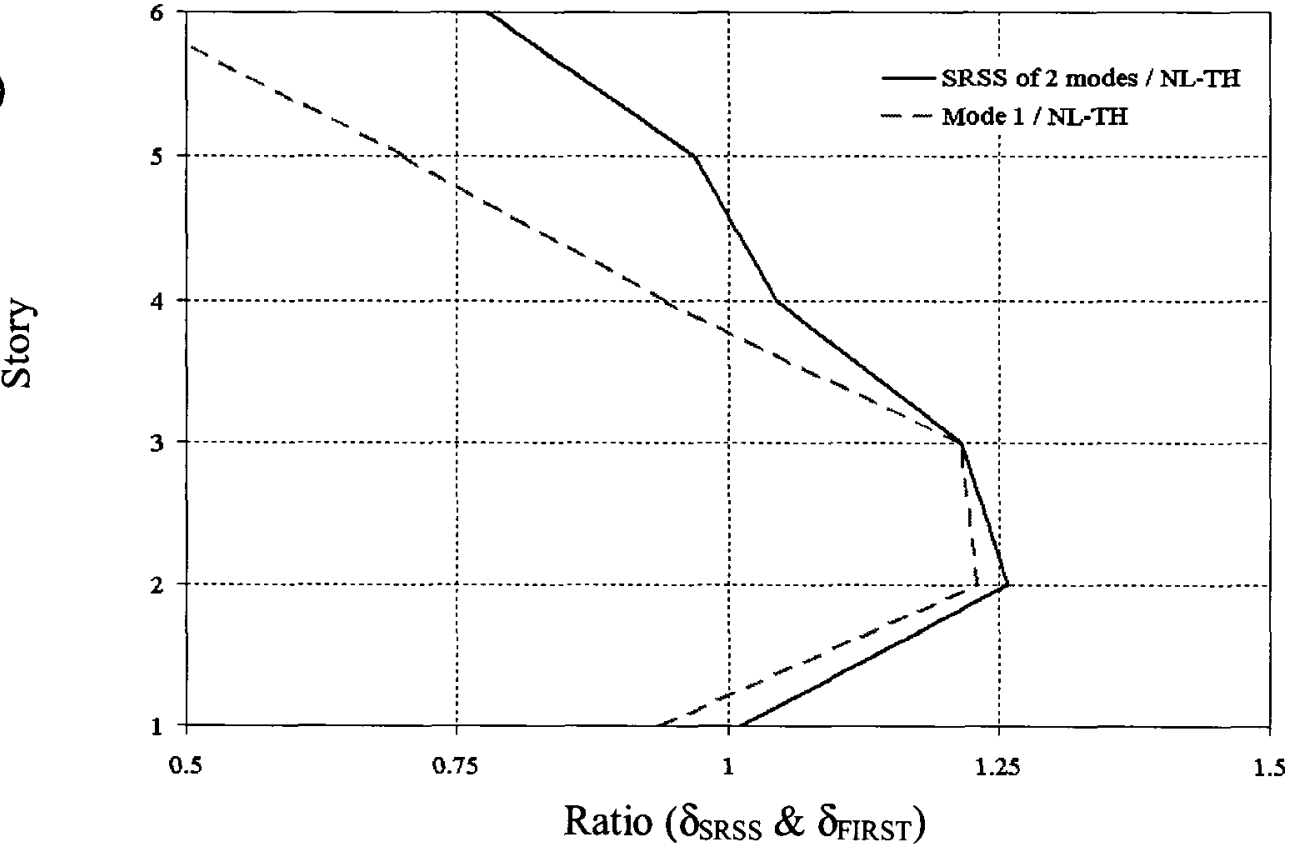

(b)

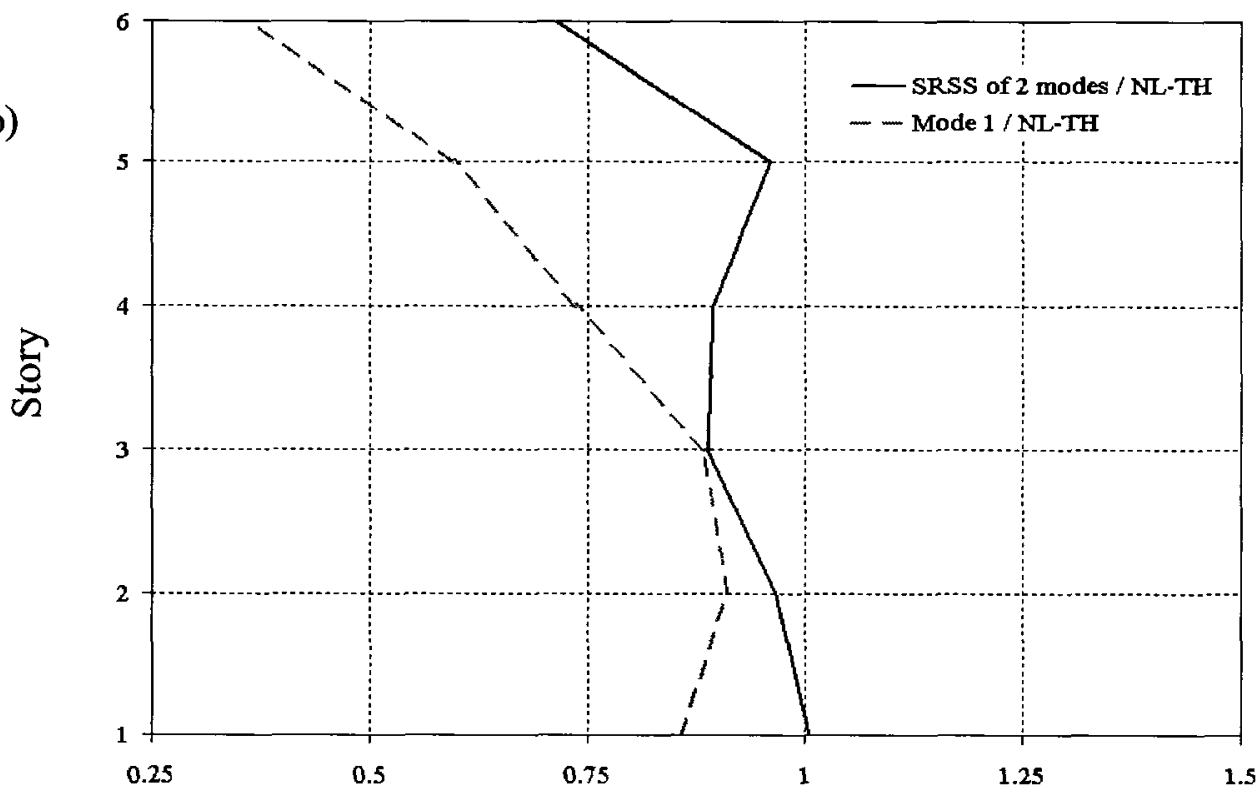

Ratio $\left(\delta_{\text {SRSS }} \& \delta_{\text {FIRST }}\right)$

Figure (5.11): Comparison of the modal and first mode responses with the results of Nonlinear Time History analyses for 6 story RC frame in Montreal;

(a) Inter-story drifts (b) Story shears 
(a)

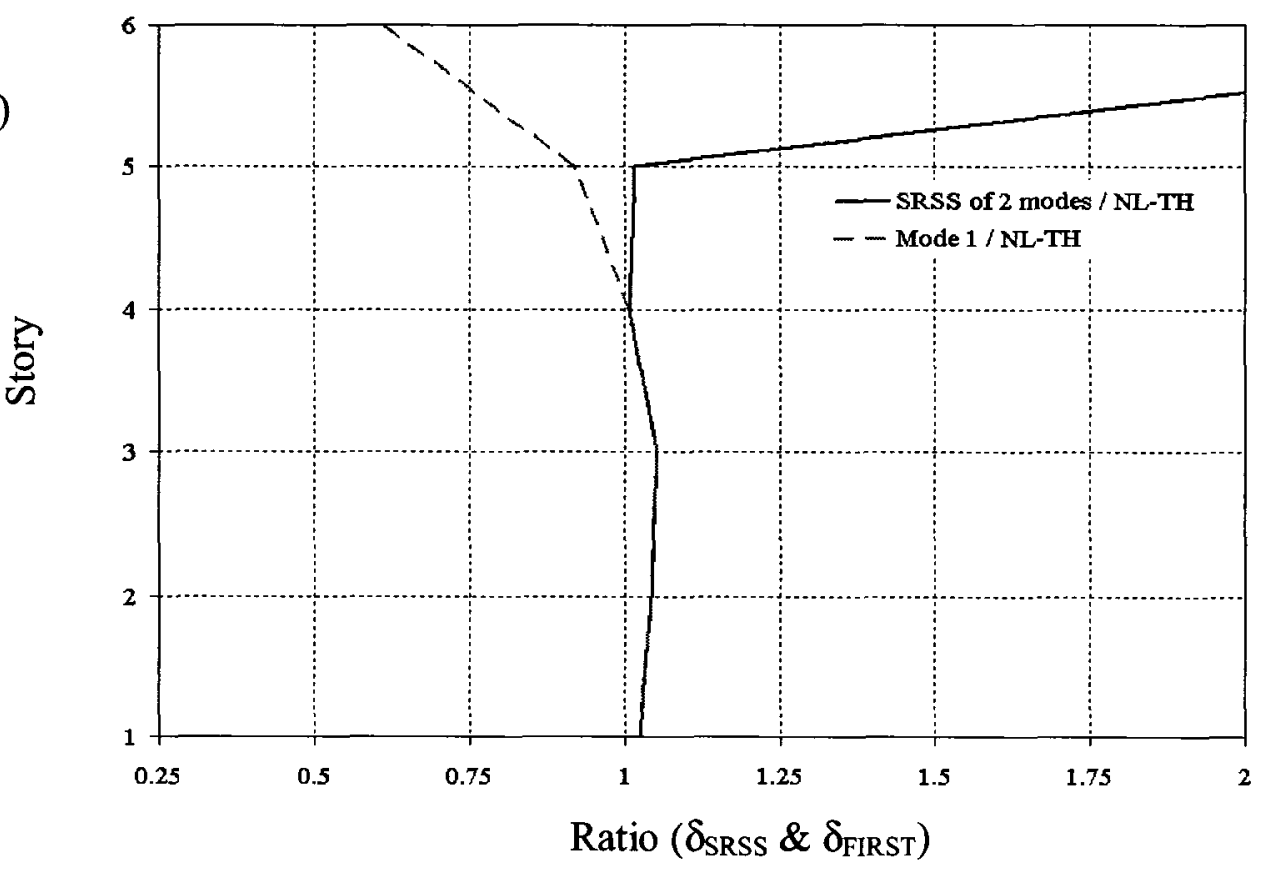

(b)

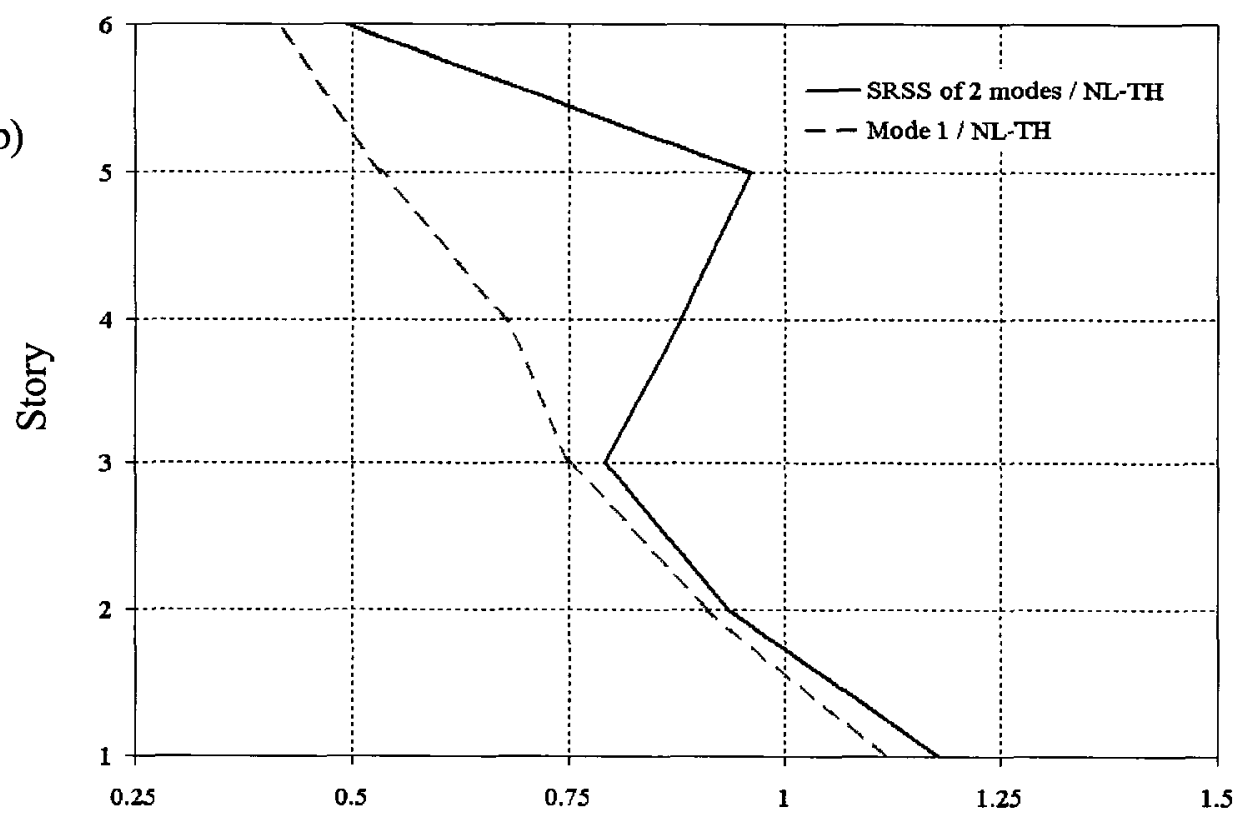

Ratio $\left(\delta_{\mathrm{SRSS}} \& \delta_{\mathrm{FIRST}}\right)$

Figure (5.12): Comparison of the modal and first mode responses with the results of Nonlinear Time History analyses for 6 story RC frame in Montreal

(a) Negative moment at the ends of middle span beams (b) Moment in the interior columns at the base of each story 
(a)
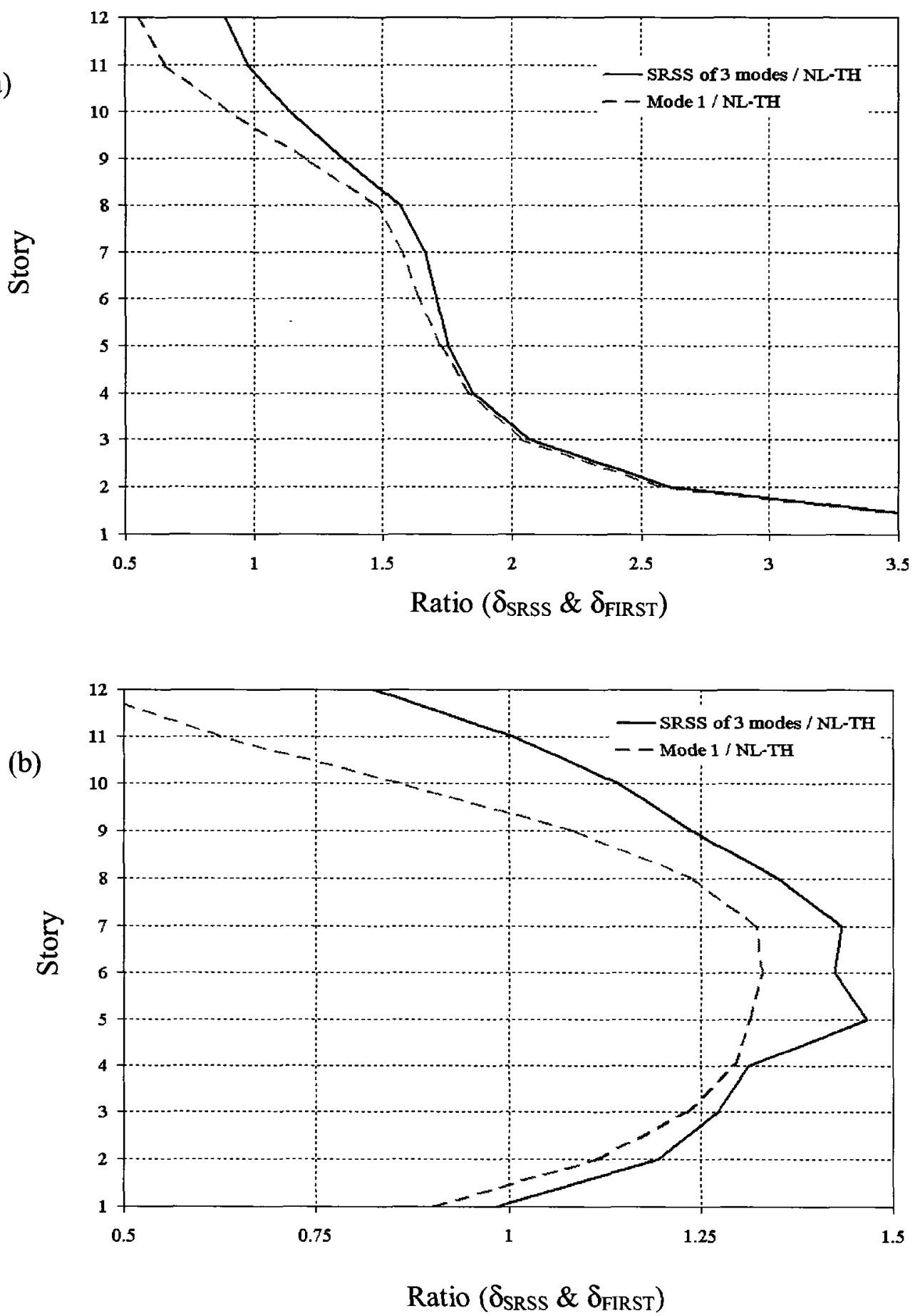

Figure (5.13): Comparison of the modal and first mode responses with the results of Nonlinear Time History analyses for 12 story RC frame in Montreal

(a) Inter-story drifts (b) Story shears 
(a)

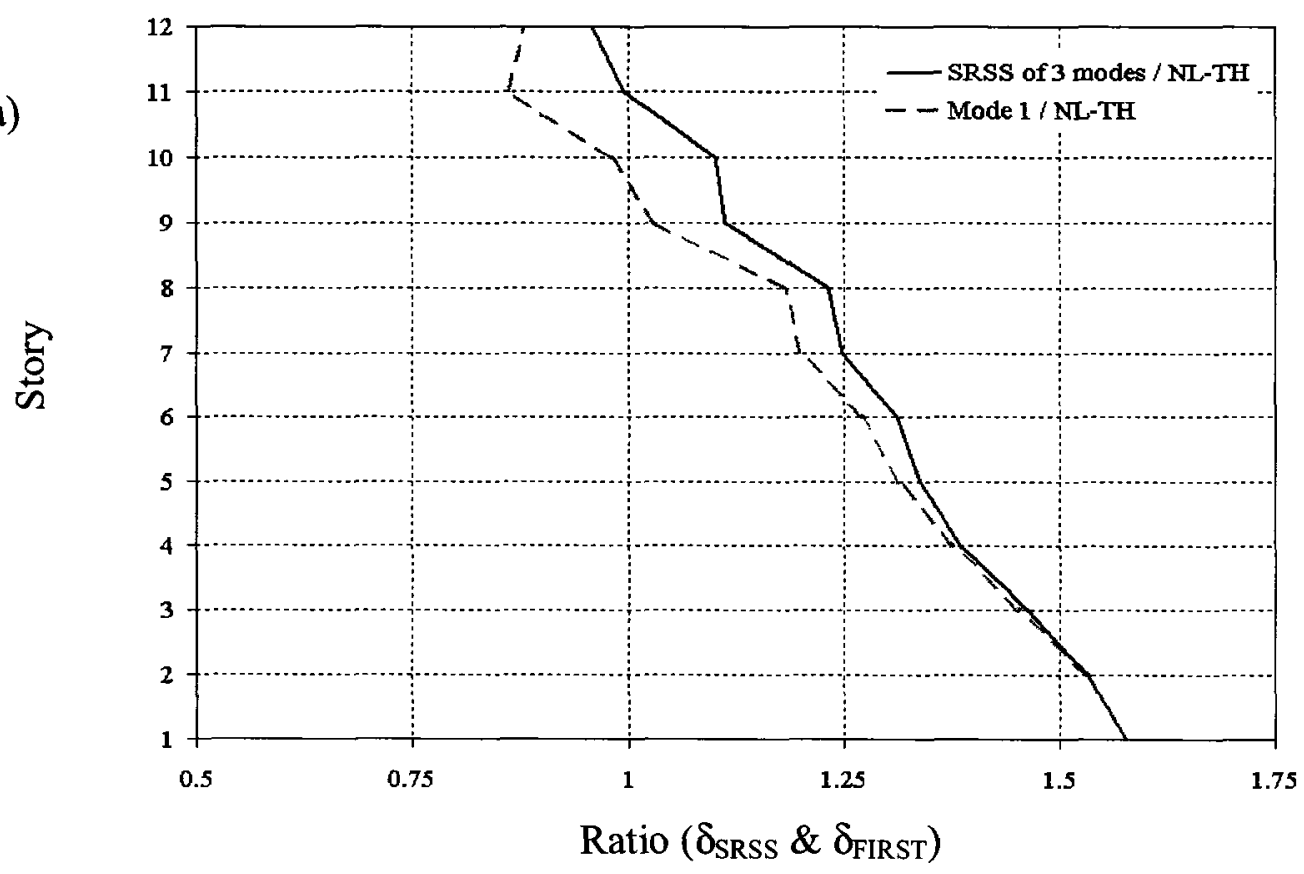

(b)

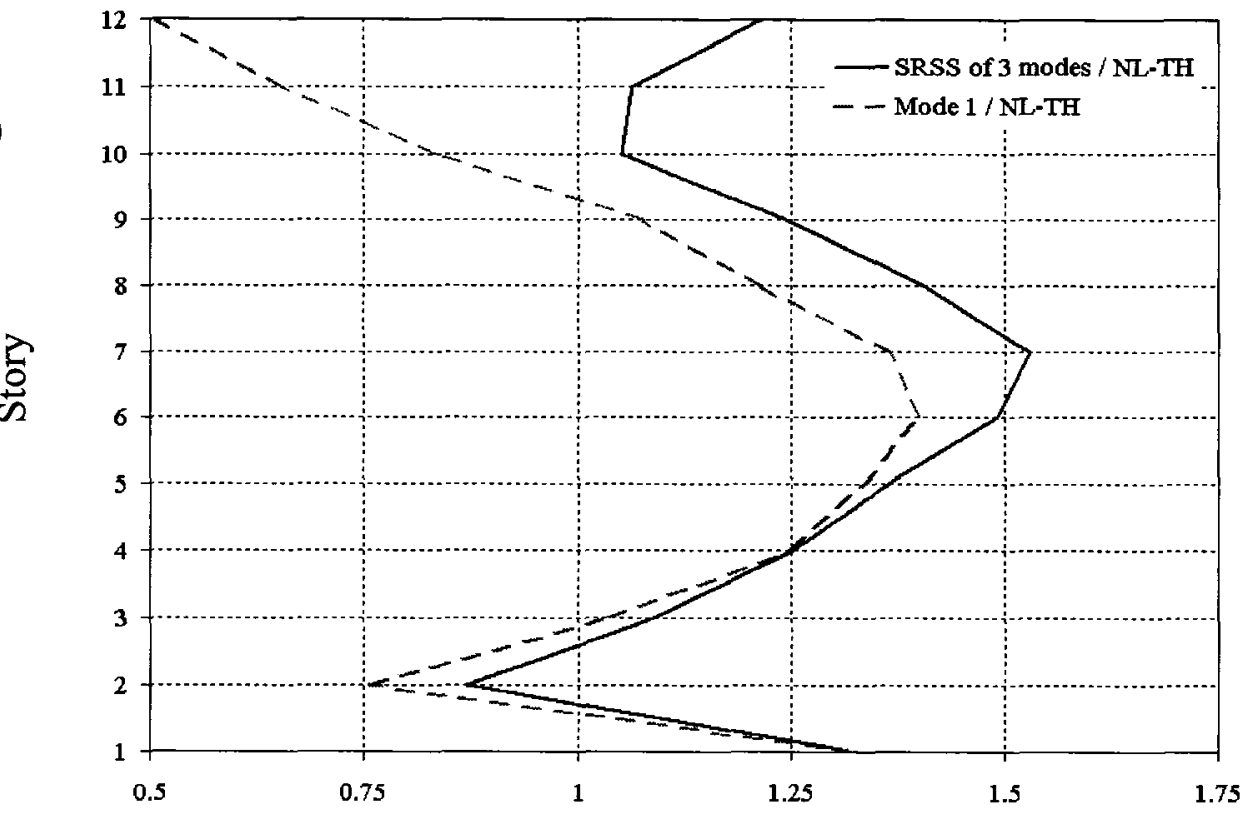

Ratio $\left(\delta_{\text {SRSS }} \& \delta_{\text {FIRST }}\right)$

Figure (5.14): comparison of the modal and first mode responses with the results of Nonlinear Time History analyses for 12 story $\mathrm{RC}$ frame in Montreal

(a) Negative moment at the ends of middle span beams (b) Moment in the interior columns at the base each story 
(a)

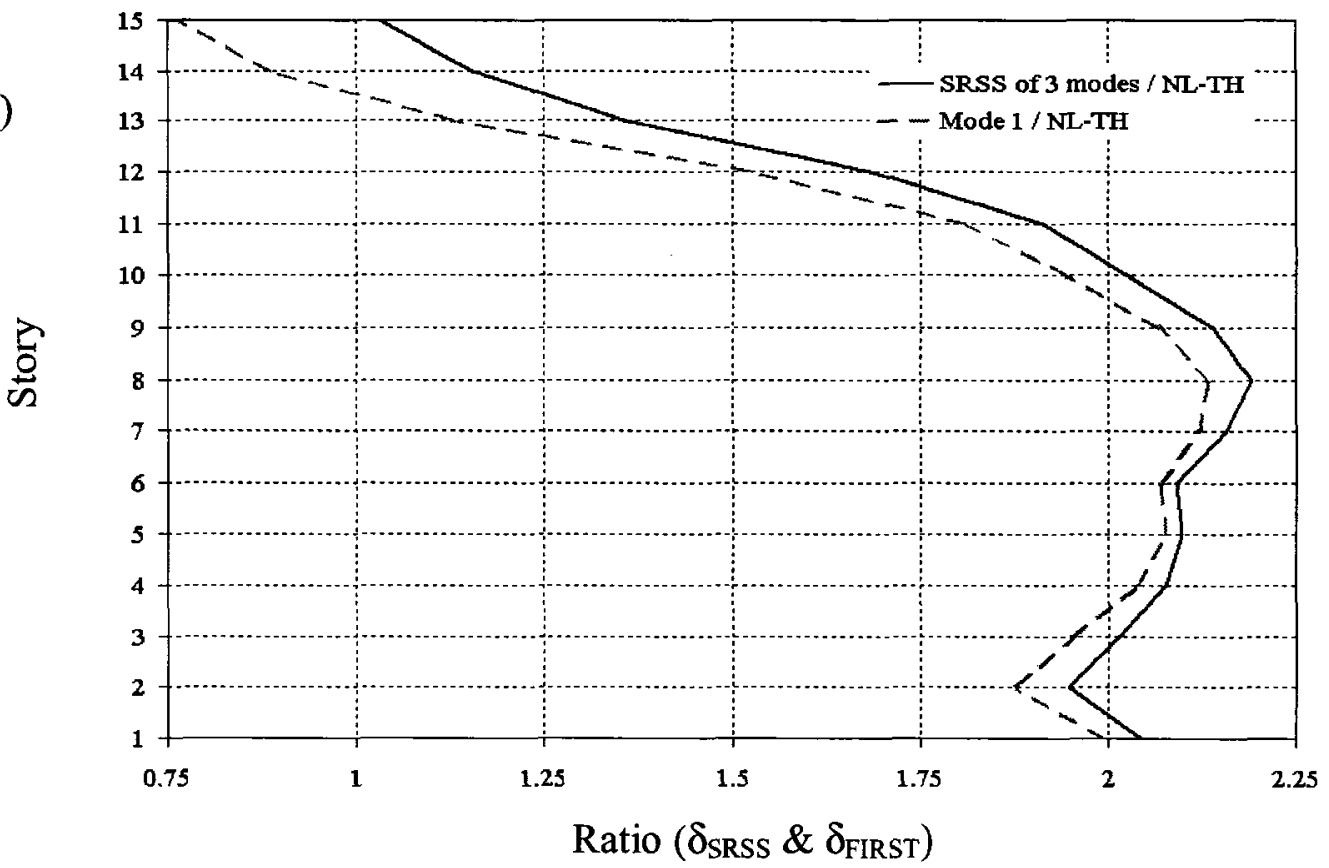

(b)

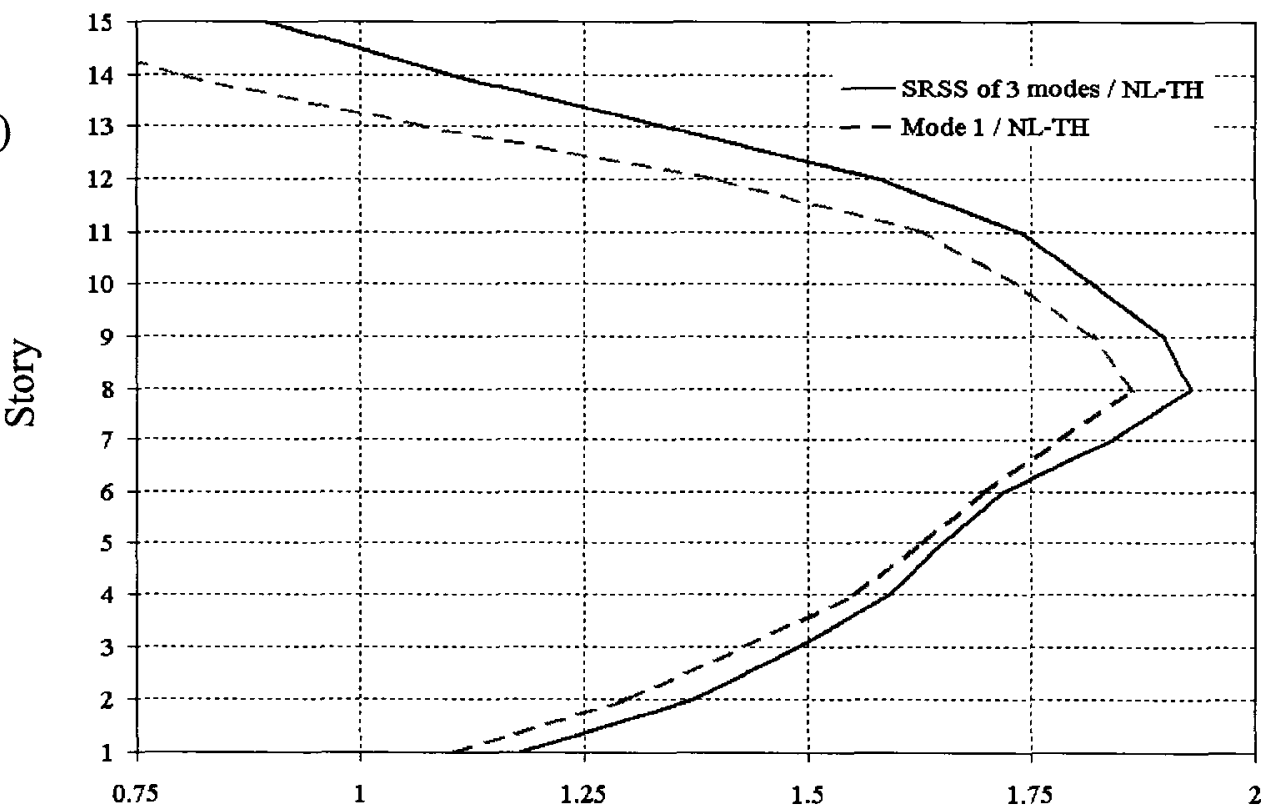

Ratio $\left(\delta_{\text {SRSS }} \& \delta_{\text {FIRST }}\right)$

Figure (5.15): Comparison of the modal and first mode response with the results of Nonlinear Time History analyses for 15 story RC frame in Montreal

(a) Inter-story drifts (b) Story shears 
(a)
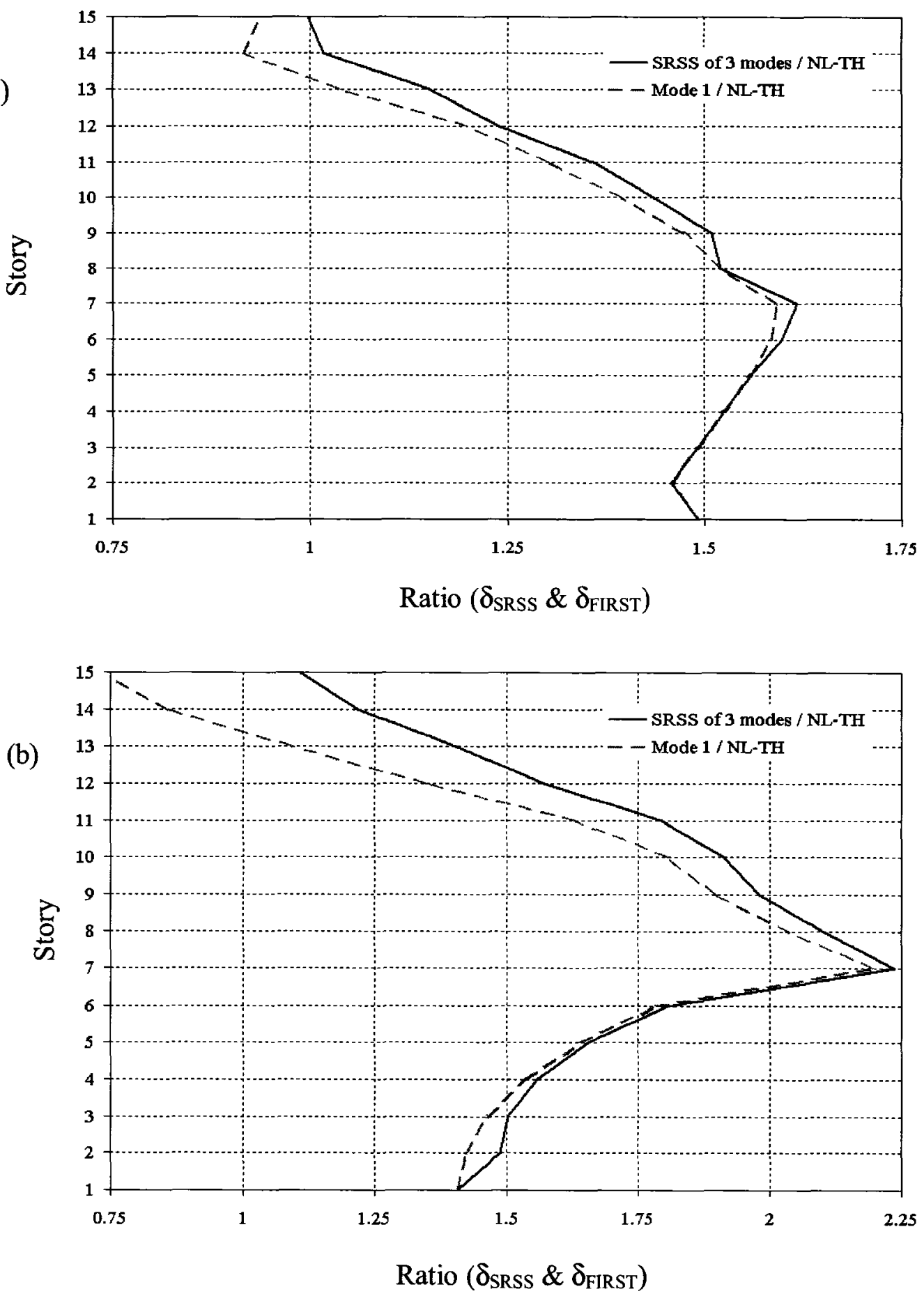

Figure (5.16): Comparison of the modal and first mode responses with the results of Nonlinear Time History analyses for 15 story RC frame in Montreal

(a) Negative moment at the ends of middle span beams (b) Moment in the interior columns at the base of each story 

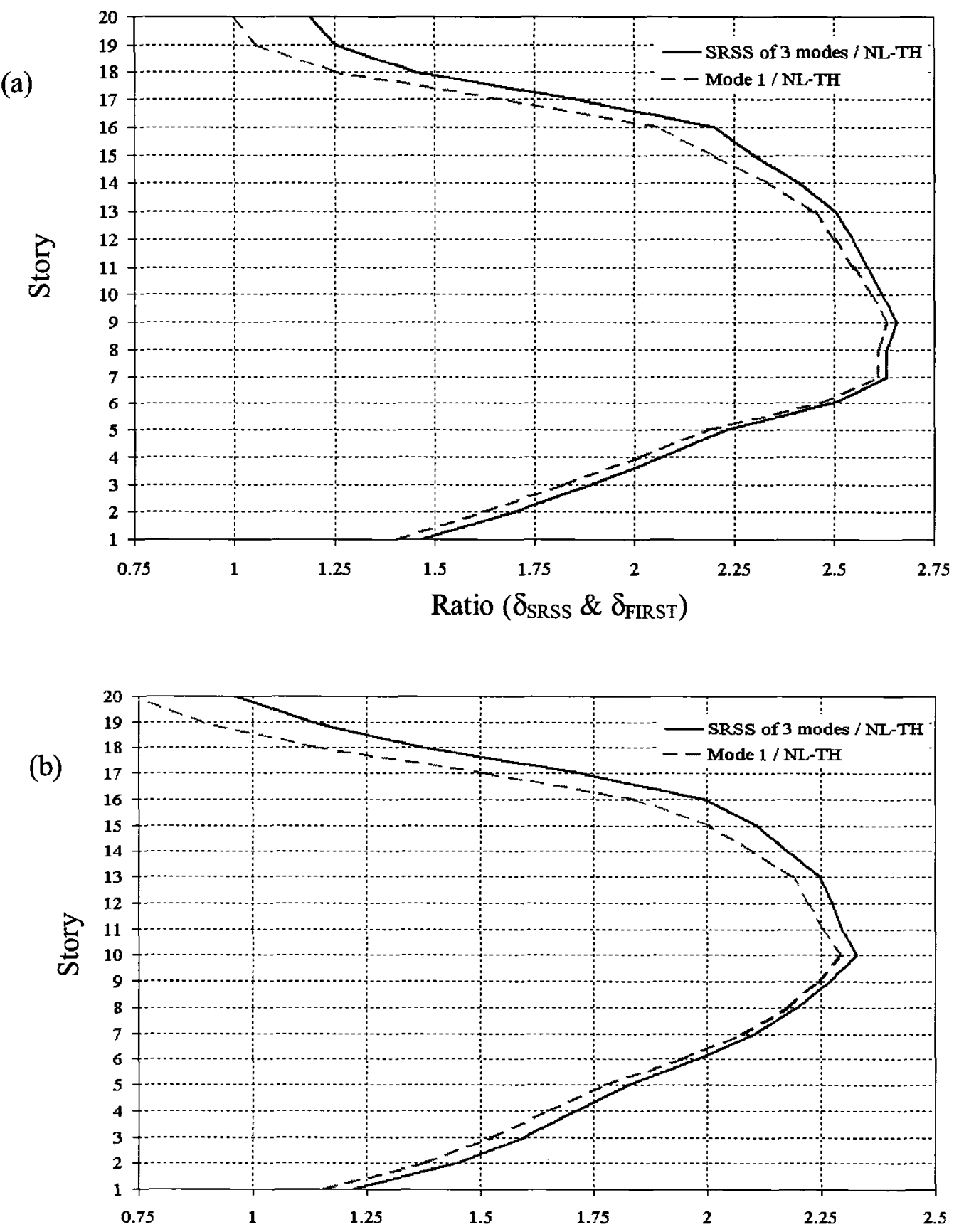

Ratio $\left(\delta_{\text {SRSS }} \& \delta_{\text {FIRST }}\right)$

Figure (5.17): Comparison of the modal and first mode responses with the results of Nonlinear Time History analyses for 20 story RC frame in Montreal (a) Inter-story drifts (b) Story shears 
(a)
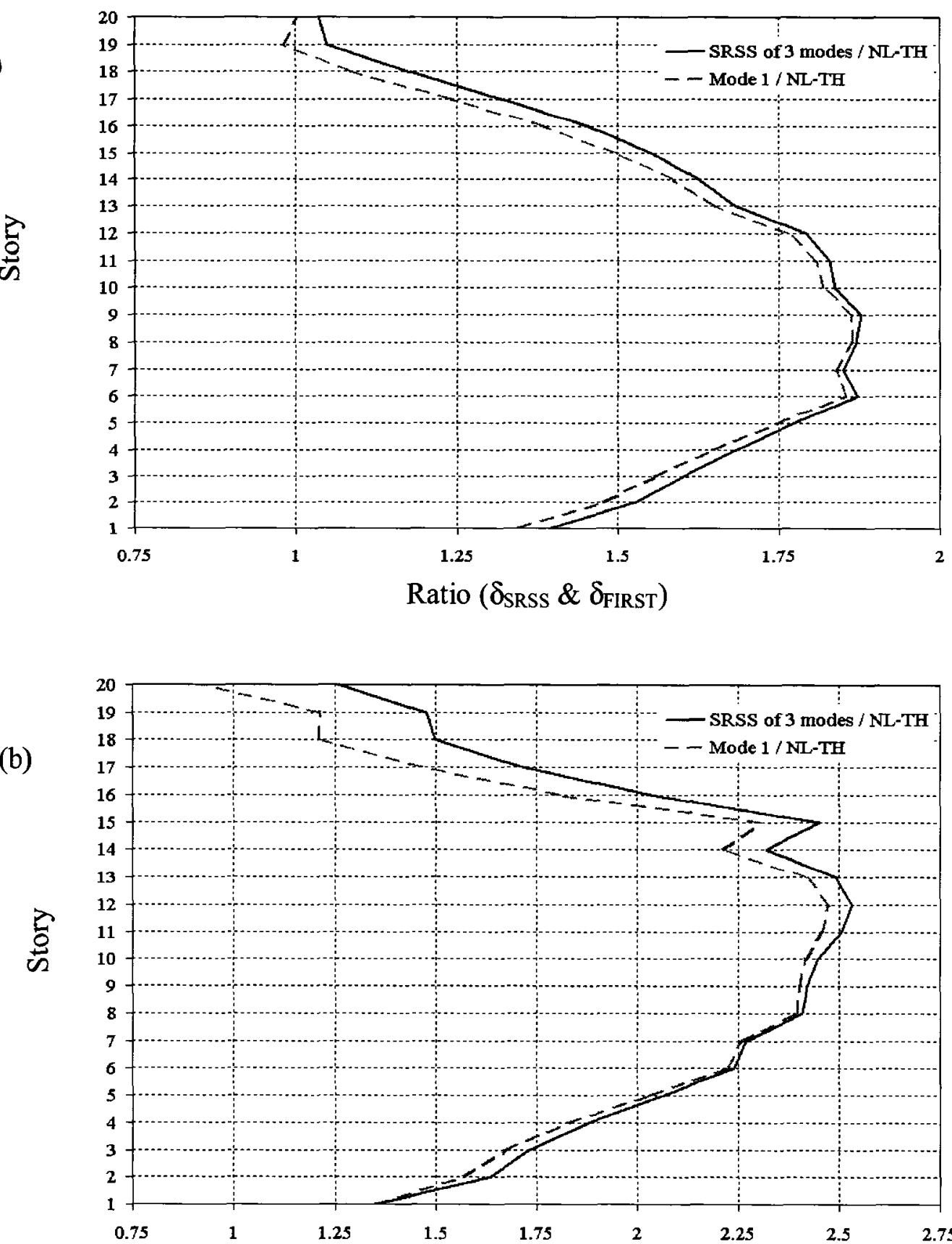

Ratio $\left(\delta_{\text {SRSS }} \& \delta_{\text {FIRST }}\right)$

Figure (5.18): Comparison of the modal and first mode responses with the results of Nonlinear Time History analyses for 20 story RC frame in Montreal

(a) Negative moment at the ends of middle span beams (b) Moment in the interior columns at the base of each story 
(a)
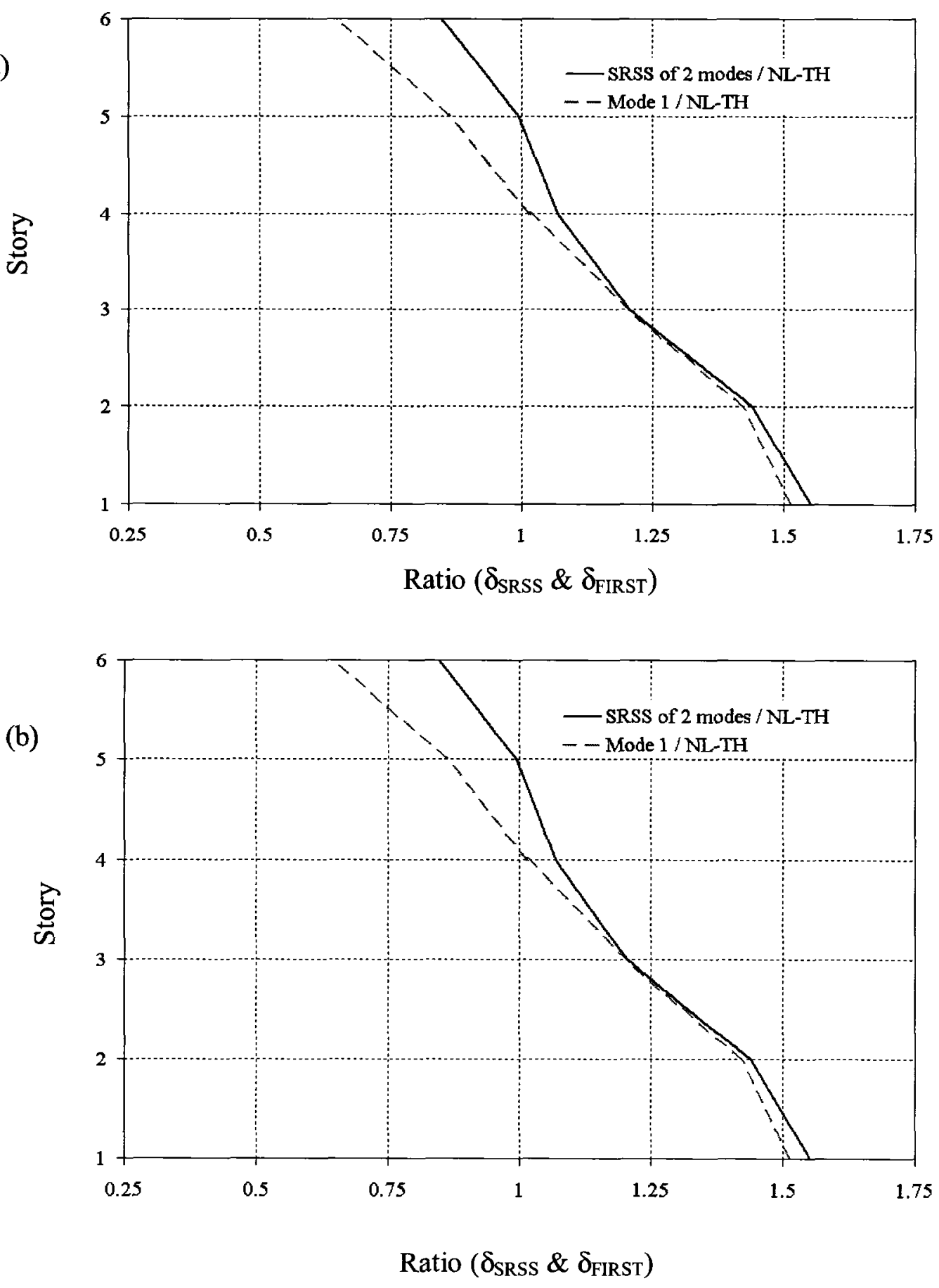

Figure (5.19): Comparison of the modal and first mode responses with the results of Nonlinear Time History analyses for 6 story steel moment-resisting frame in Vancouver (a) Inter-story drifts (b) Story shears 
(a)

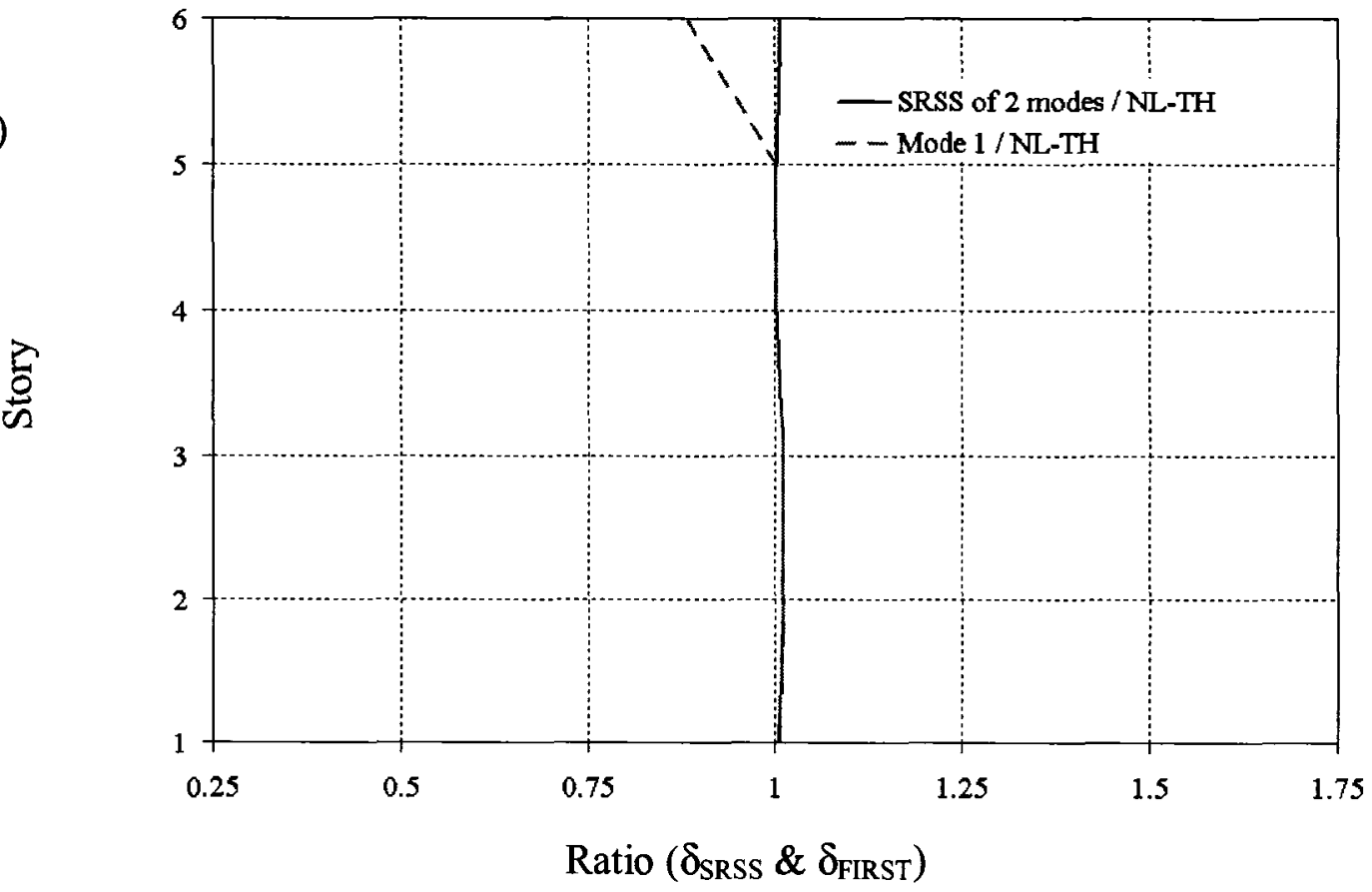

(b)

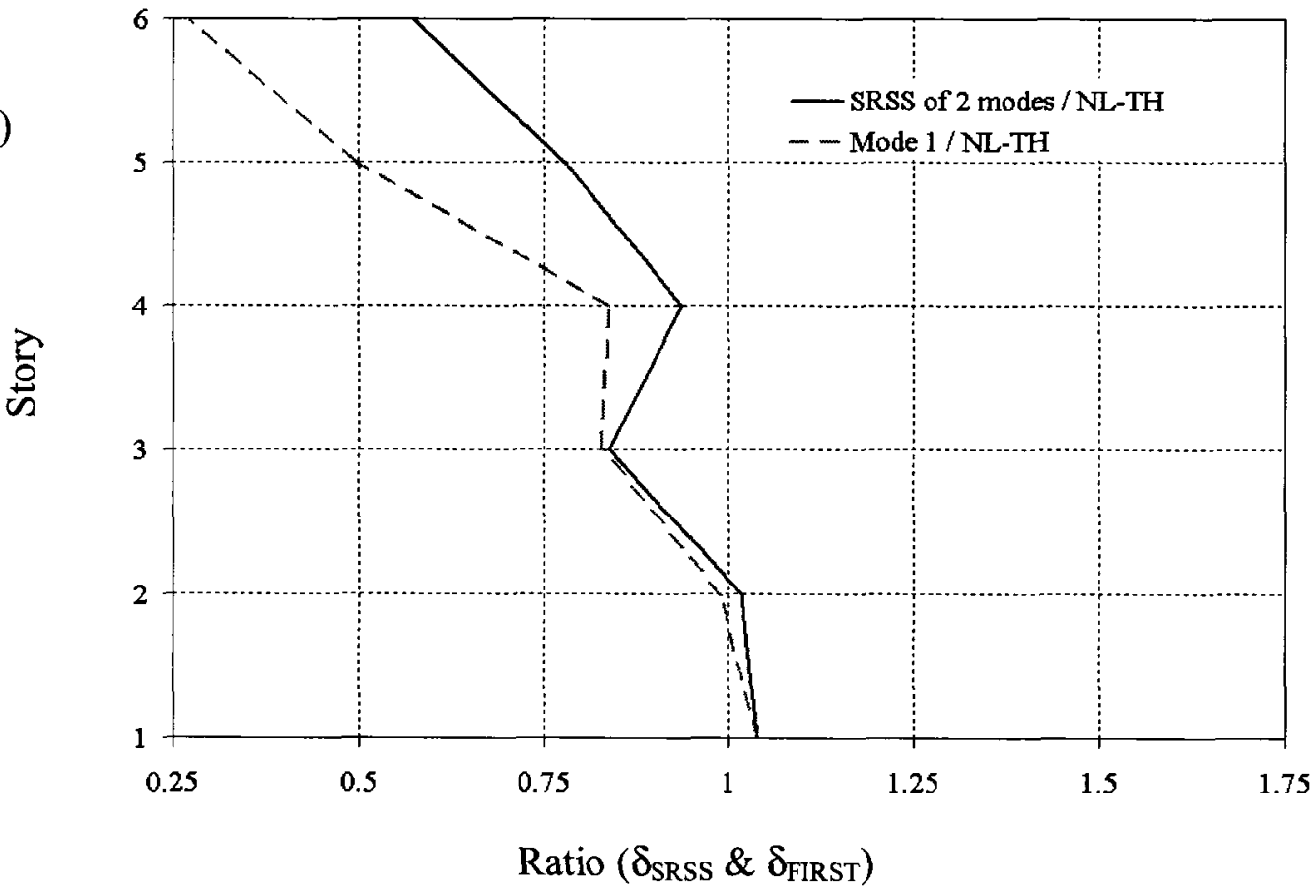

Figure (5.20): Comparison of the modal and first mode responses with the results of Nonlinear Time History analyses for 6 story steel moment-resisting frame in Vancouver (a) Negative moment at the ends of middle span beams (b) Moment in the interior columns at the base of each story 
(a)
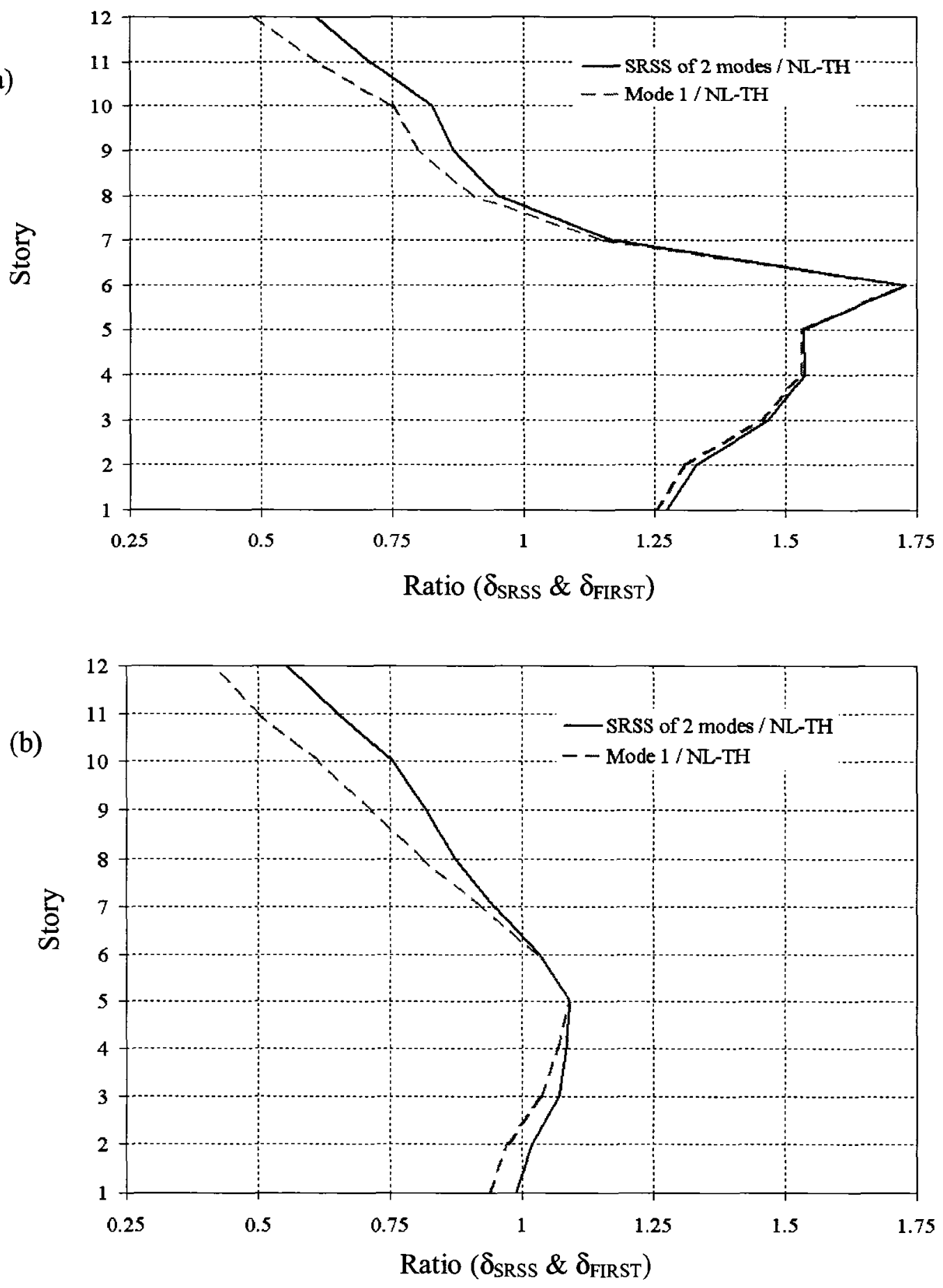

Figure (5.21): Comparison of the modal and first mode responses with the results of Nonlinear Time History analyses for 12 story steel moment-resisting frame in Vancouver (a) Inter-story drifts (b) Story shears 
(a)

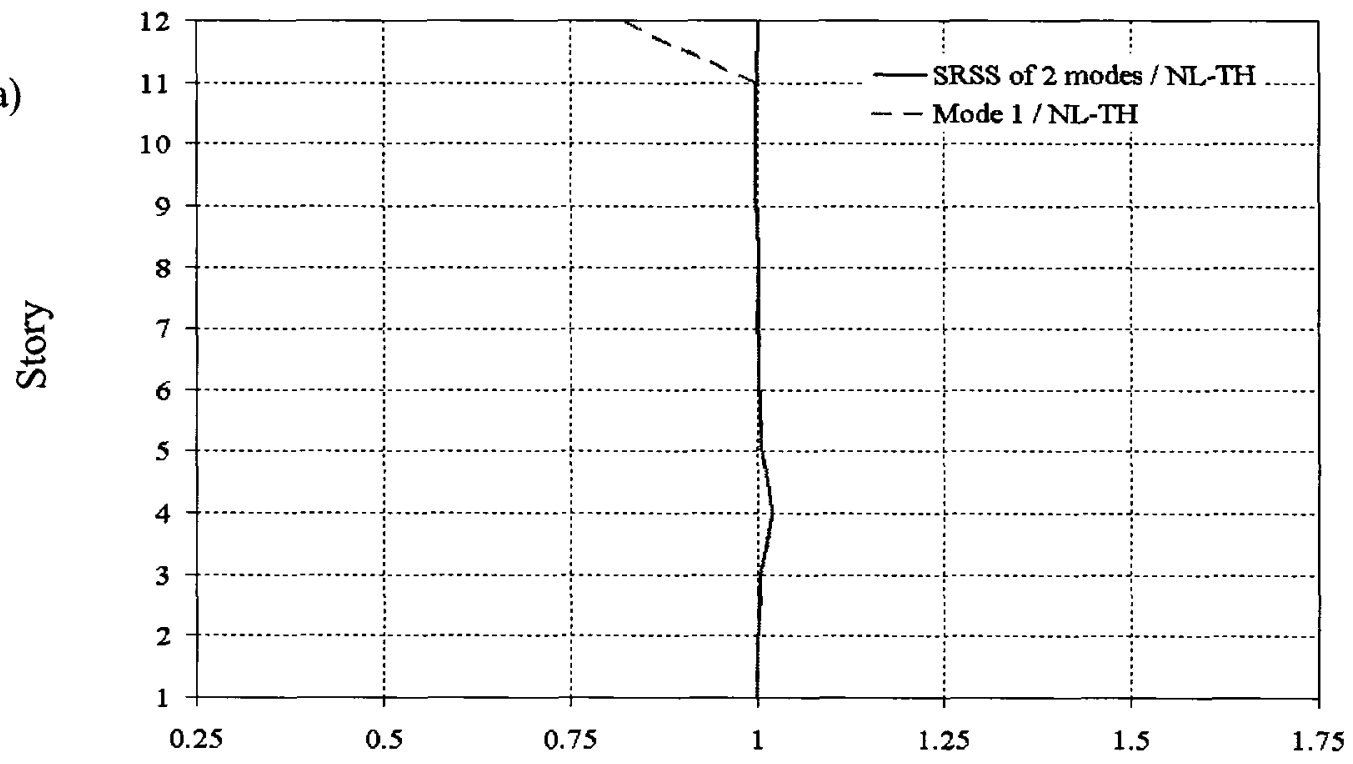

Ratio $\left(\delta_{\text {SRSS }} \& \delta_{\text {FIRST }}\right)$

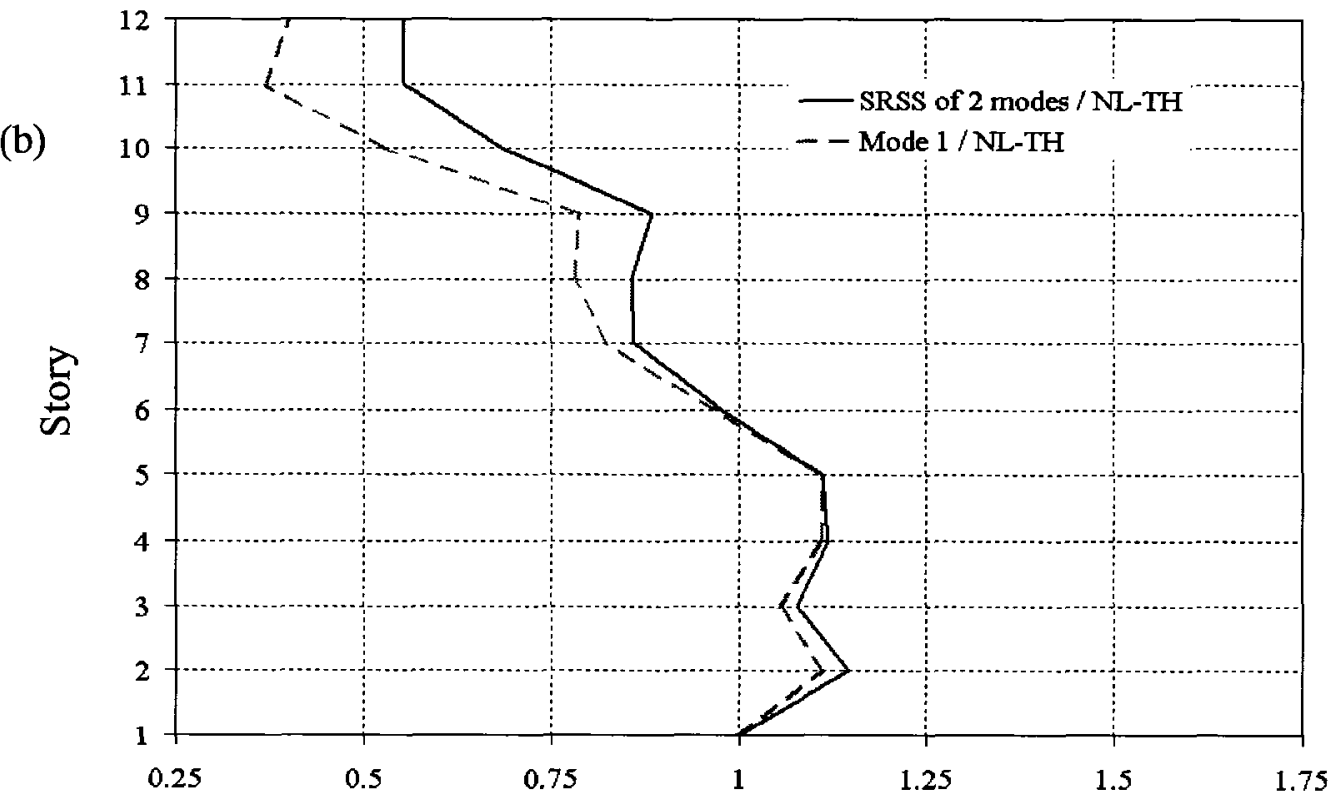

Ratio $\left(\delta_{\text {SRSS }} \& \delta_{\text {FIRST }}\right)$

Figure (5.22): Comparison of the modal and first mode responses with the results of Nonlinear Time History analyses for 12 story steel moment-resisting frame in Vancouver

(a) Negative moment at the ends of middle span beams (b) Moment in the interior columns at the base of each story 
(a)

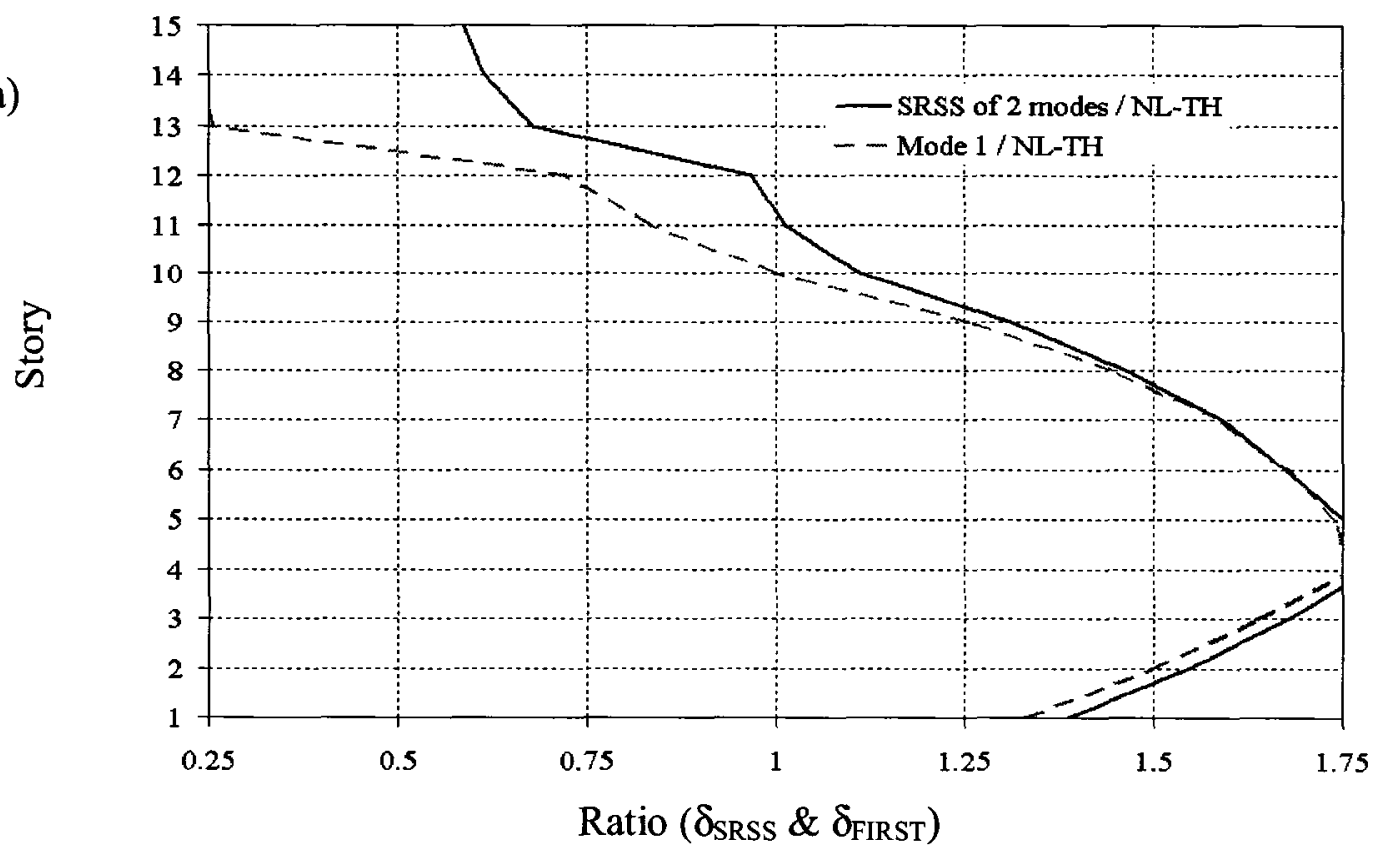

(b)

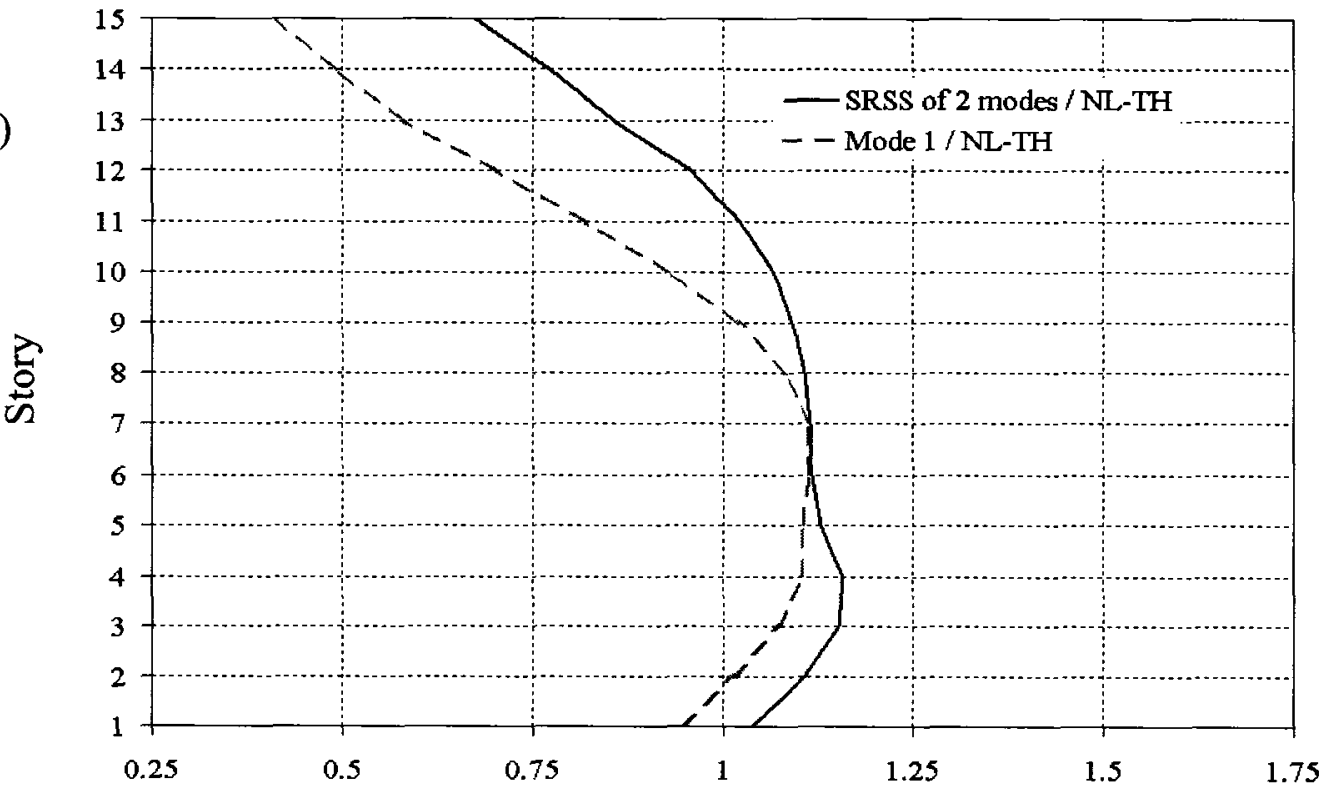

Ratio $\left(\delta_{\mathrm{SRSS}} \& \delta_{\mathrm{FIRST}}\right)$

Figure (5.23): Comparison of the modal and first mode responses with the results of Nonlinear Time History analyses for 15 story steel moment-resisting frame in Vancouver (a) Inter-story drifts (b) Story shears 
(a)

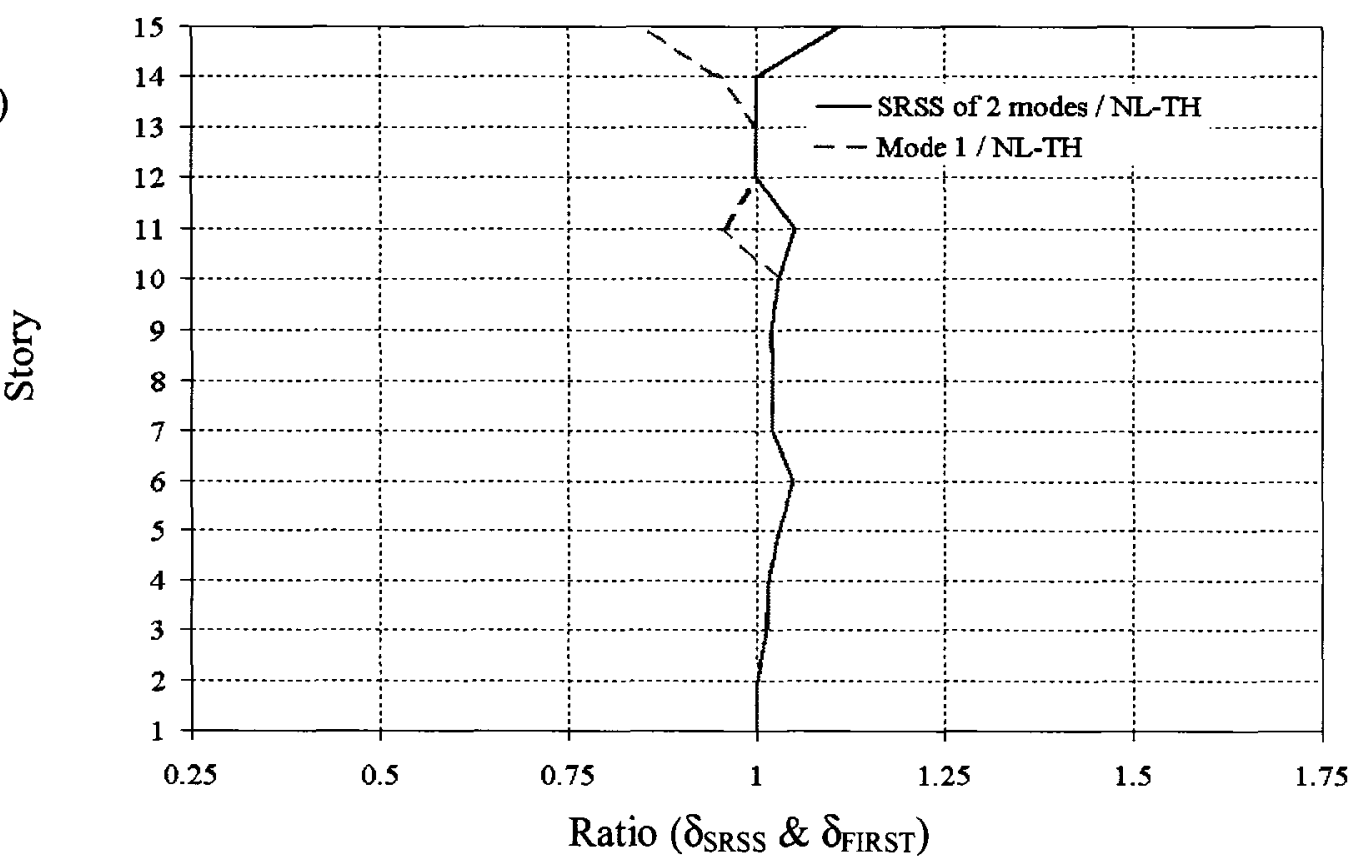

(b)

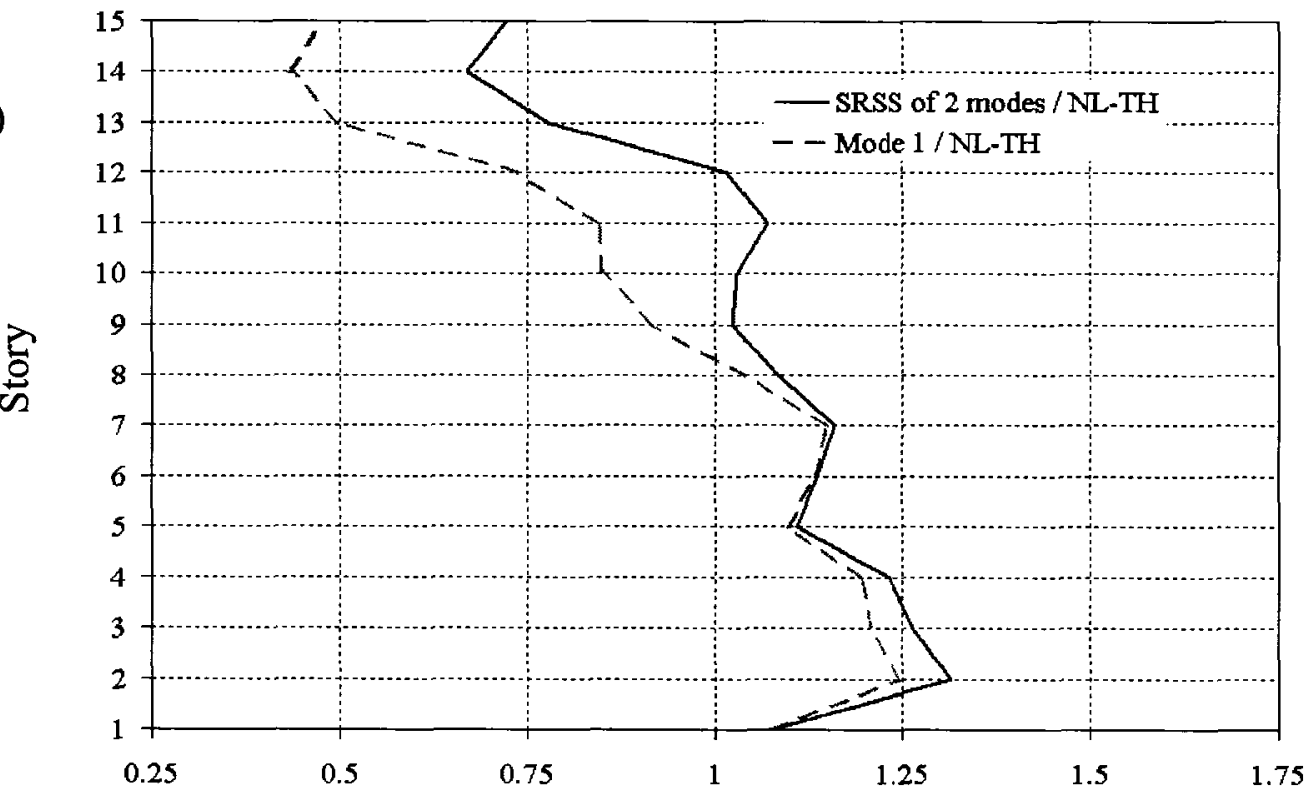

Ratio $\left(\delta_{\text {SRSS }} \& \delta_{\text {FIRST }}\right)$

Figure (5.24): Comparison of the modal and first mode responses with the results of Nonlinear Time History analyses for 15 story steel moment-resisting frame in Vancouver (a) Negative moment at the ends of middle span beams (b) Moment in the interior columns at the base of each story 
(a)
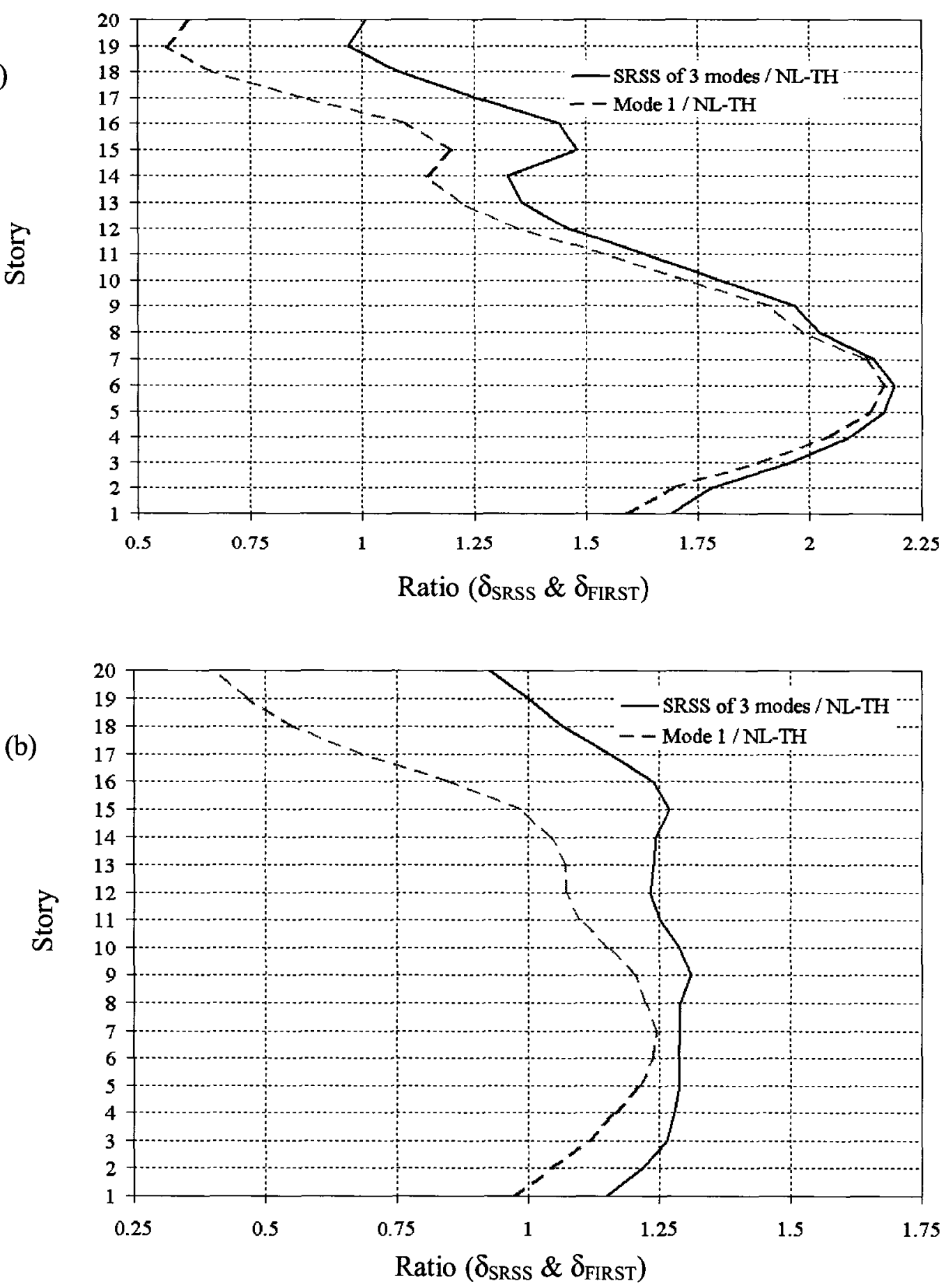

Figure (5.25): Comparison of the modal and first mode responses with the results of Nonlinear Time History analyses for 20 story steel moment-resisting frame in Vancouver (a) Inter-story drifts (b) Story shears 

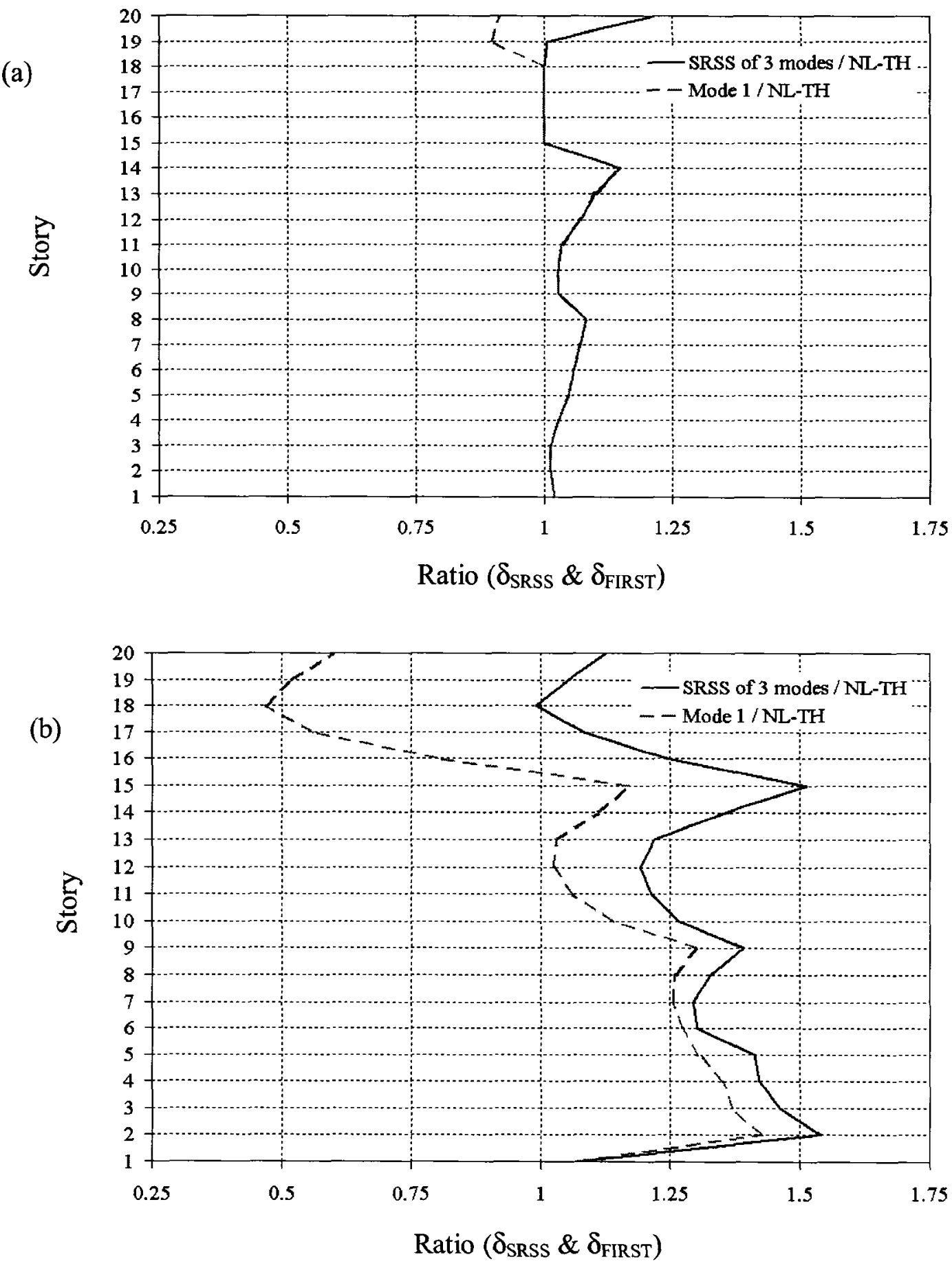

Figure (5.26): Comparison of the modal and first mode responses with the results of Nonlinear Time History analyses for 20 story steel moment-resisting frame in Vancouver (a) Negative moment at the ends of middle span beams (b) Moment in the interior columns at the base of each story 
(a)

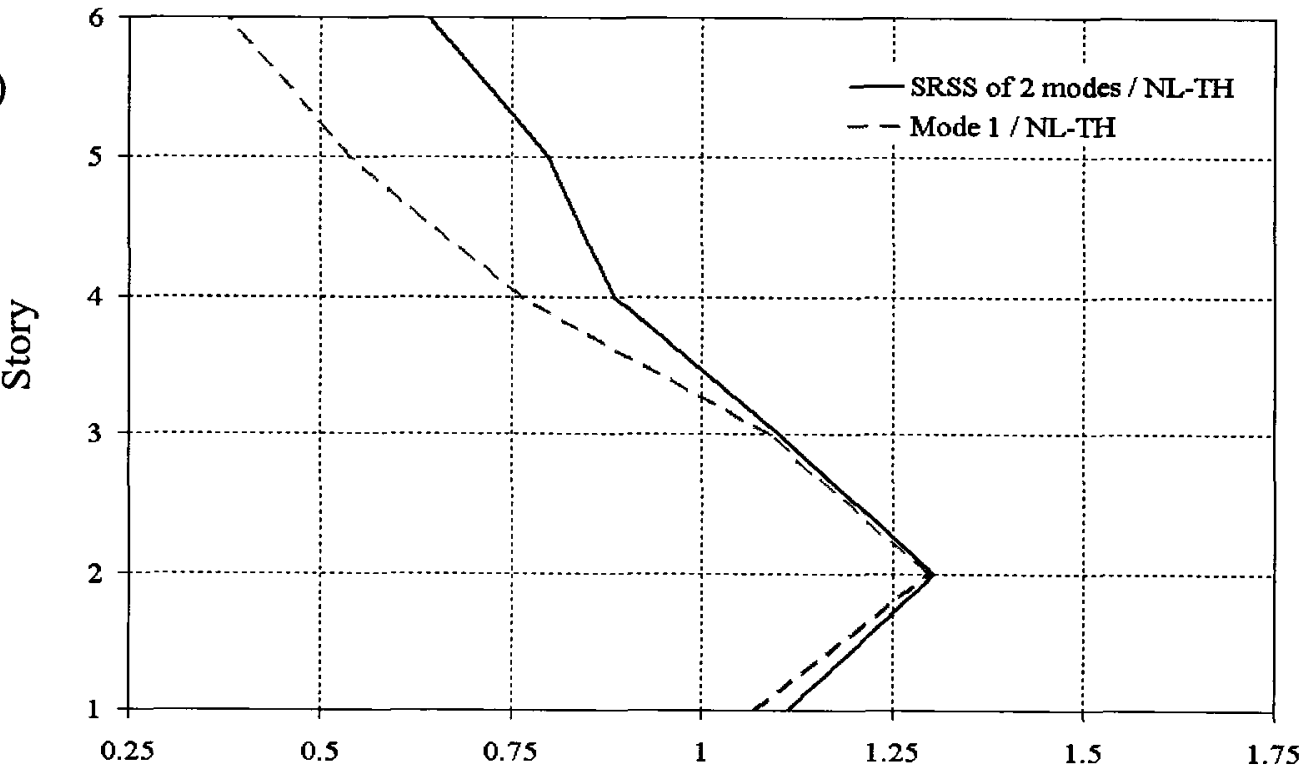

Ratio $\left(\delta_{\text {SRSS }} \& \delta_{\text {FIRST }}\right)$

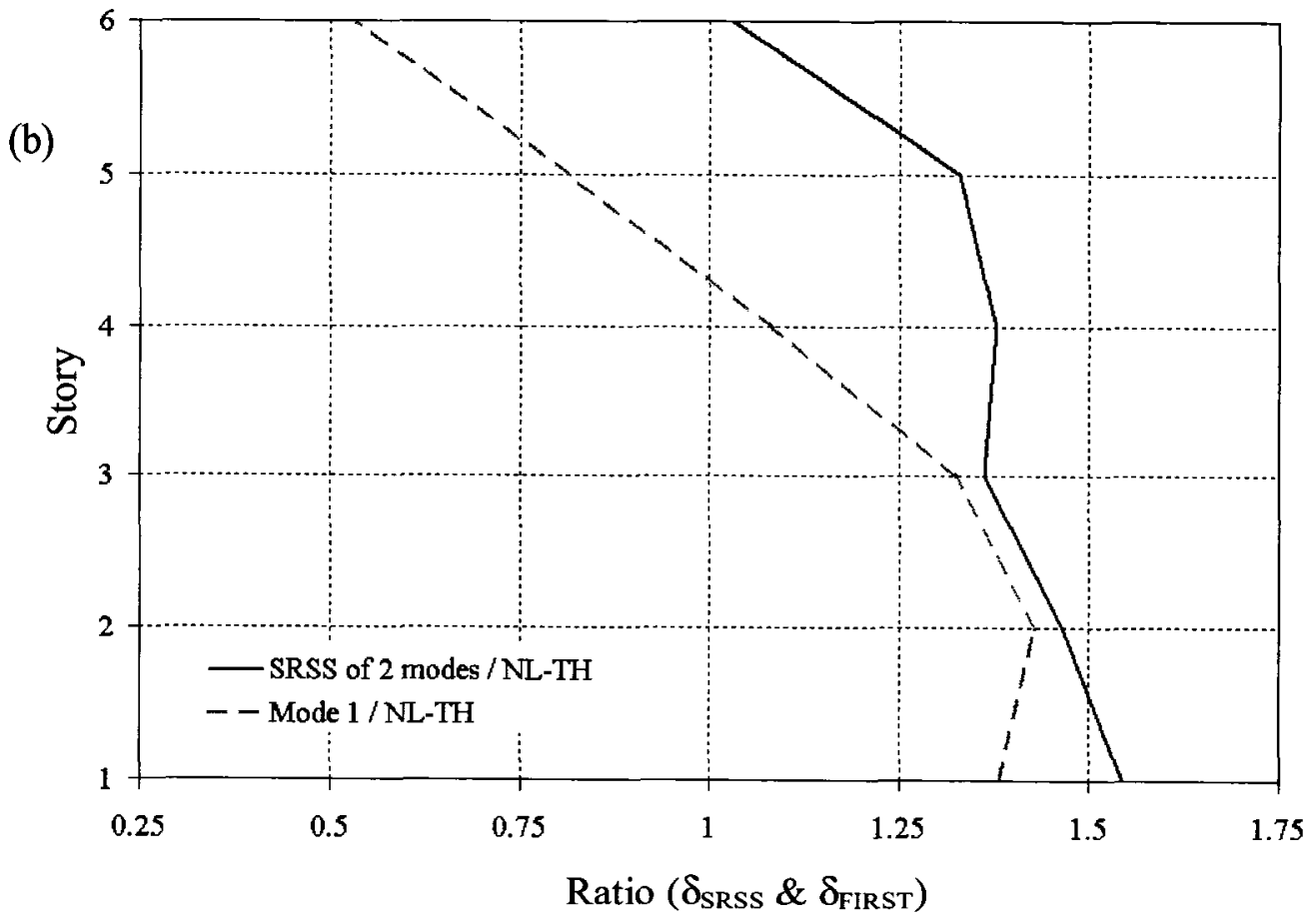

Figure (5.27): Comparison of the modal and first mode responses with the results of Nonlinear Time History analyses for 6 story steel moment-resisting frame in Montreal (b) Inter-story drifts (b) Story shears 
(a)
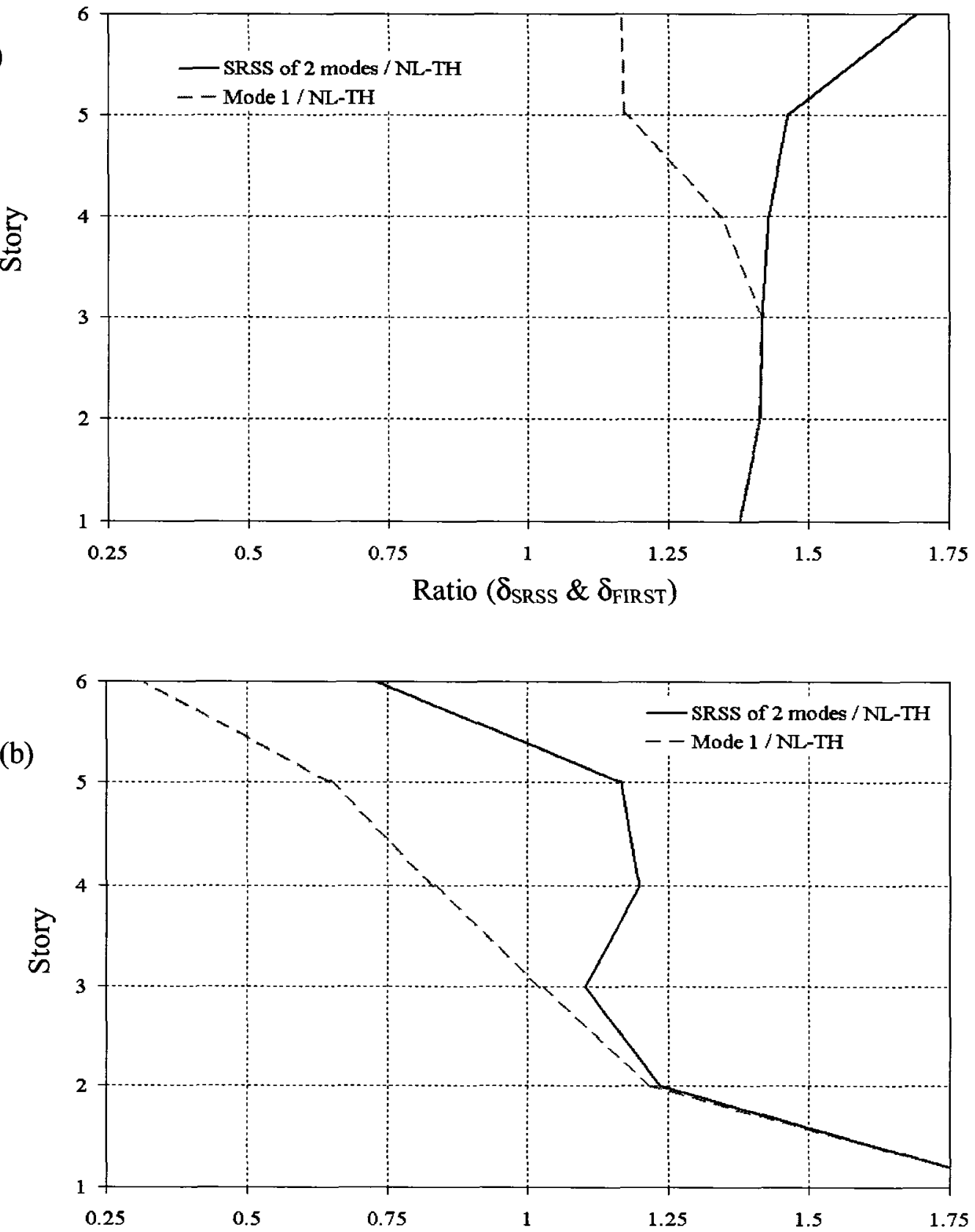

Ratio $\left(\delta_{\text {SRSS }} \& \delta_{\text {FIRST }}\right)$

Figure (5.28): Comparison of the modal and first mode responses with the results of Nonlinear Time History analyses for 6 story steel moment-resisting frame in Montreal (b) Negative moment at the ends of middle span beams (b) Moment in the interior columns at the base of each story 
(a)

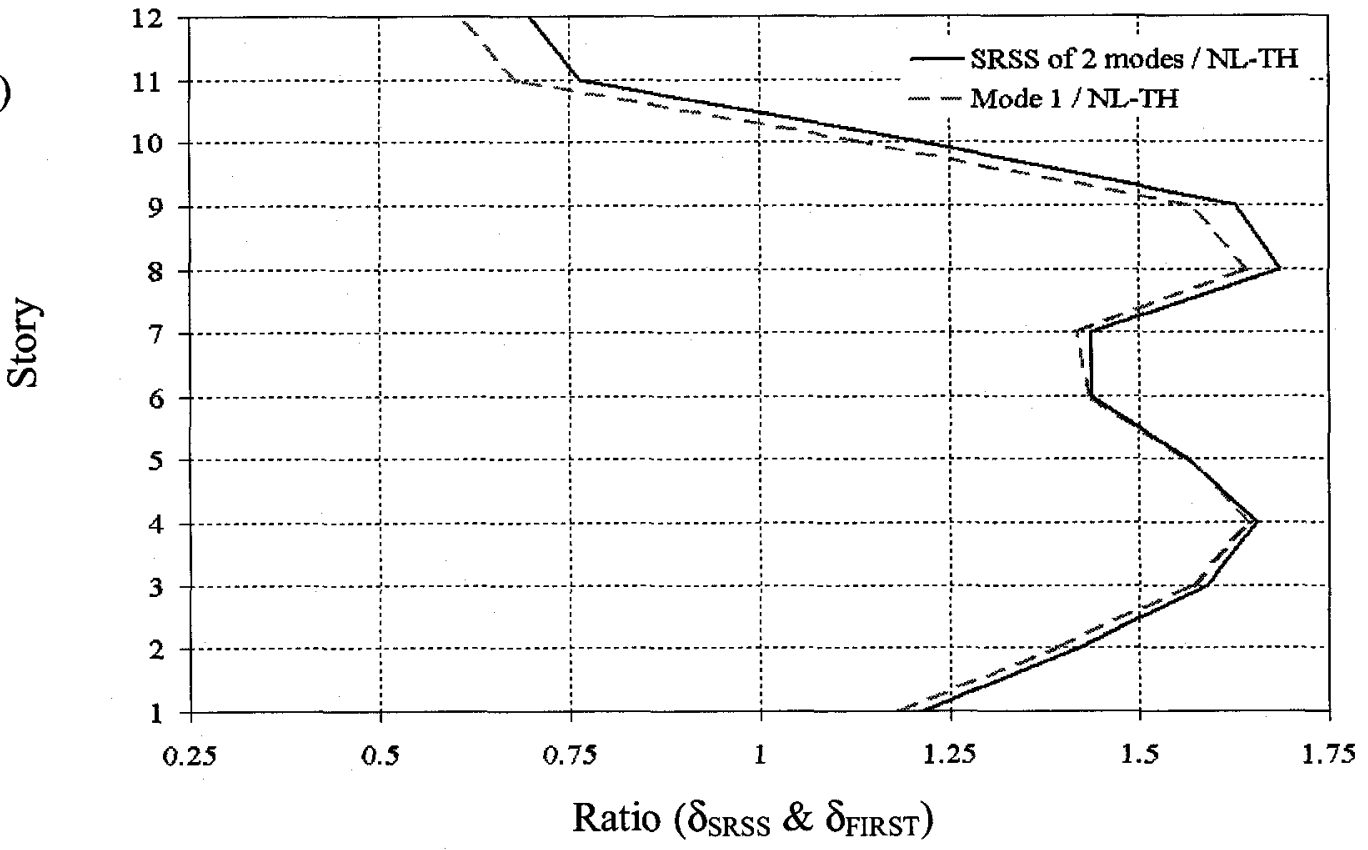

(b)

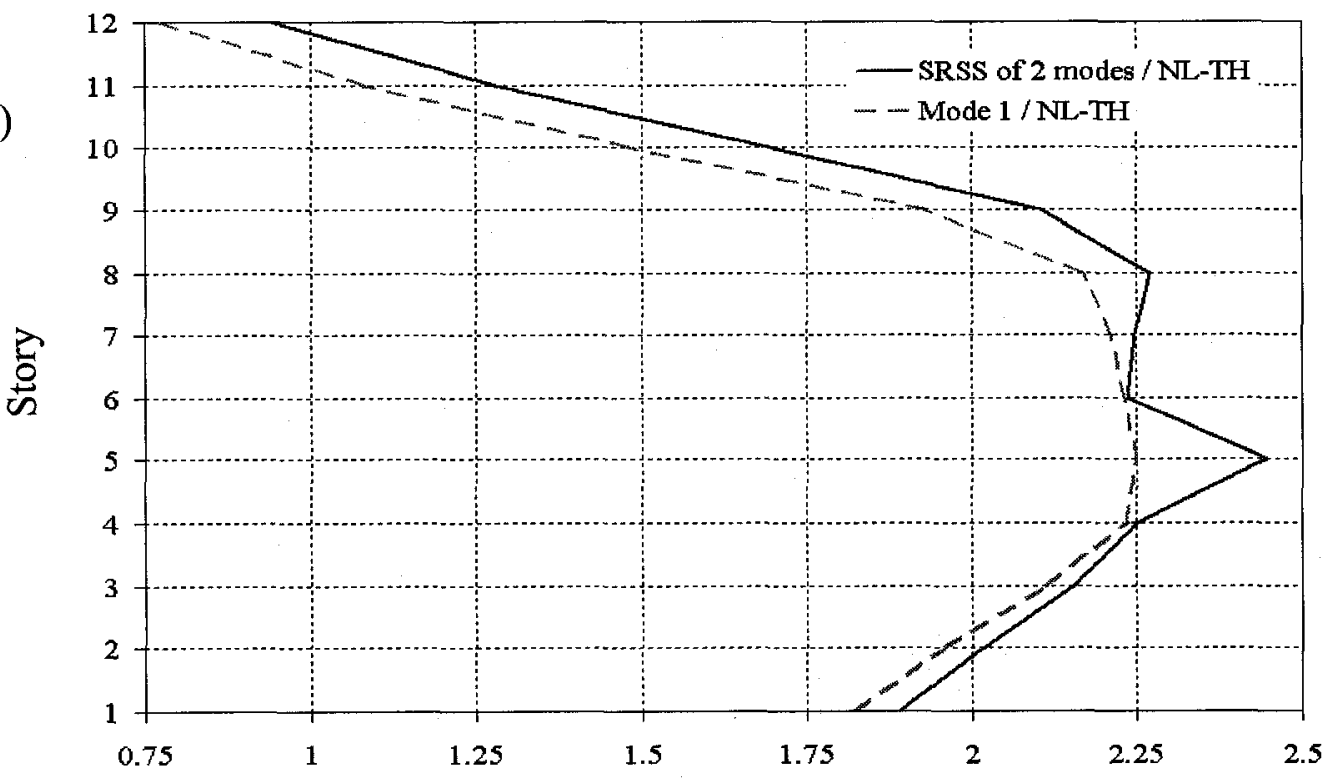

Ratio $\left(\delta_{\text {SRSS }} \& \delta_{\text {FIRST }}\right)$

Figure (5.29): Comparison of the modal and first mode responses with the results of Nonlinear Time History analyses for 12 story steel moment-resisting frame in Montreal (b) Inter-story drifts (b) Story shears 
(a)
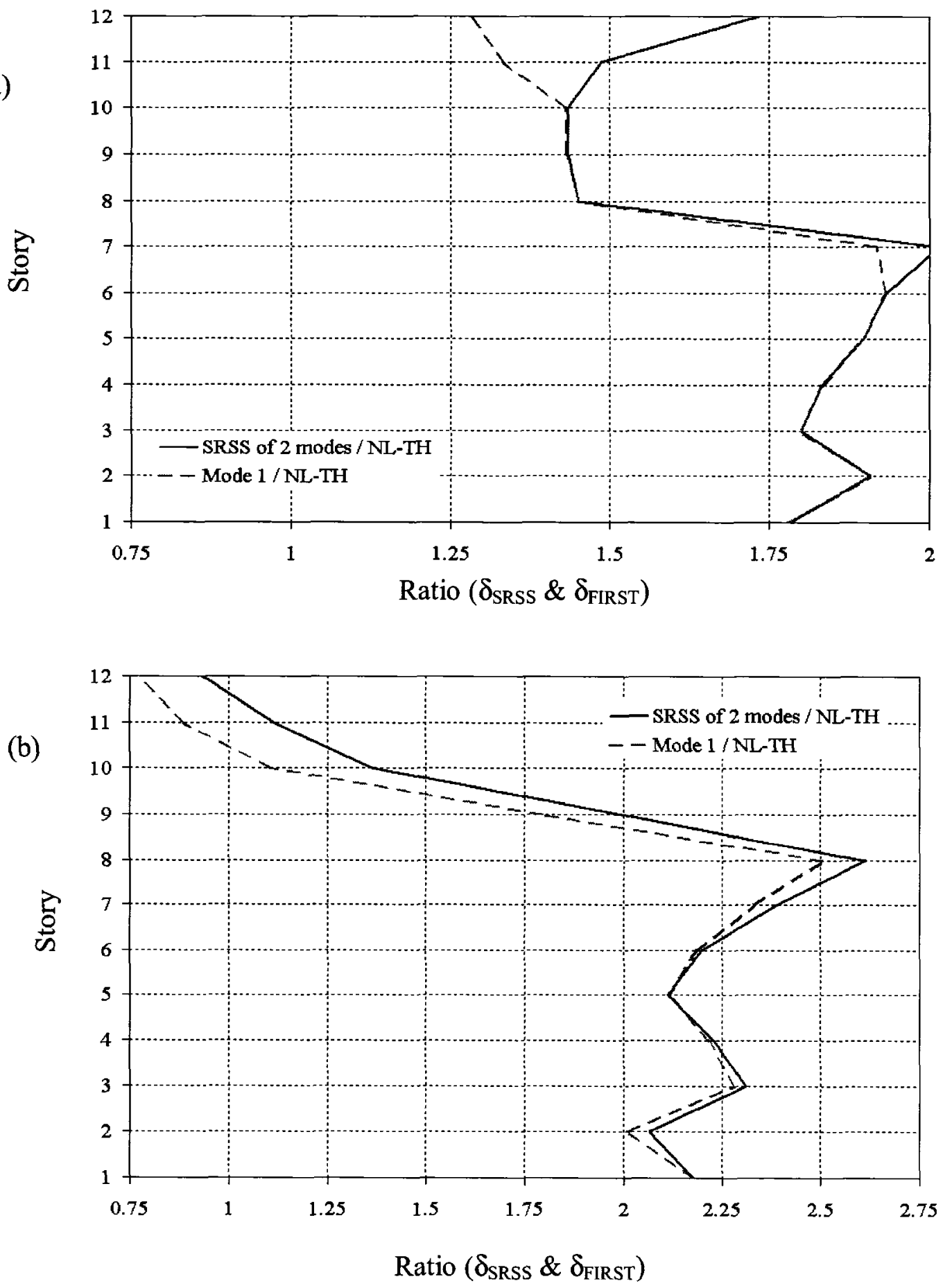

Figure (5.30): Comparison of the modal and first mode responses with the results of Nonlinear Time History analyses for 12 story steel moment-resisting frame in Montreal (a) Negative moment at the ends of middle span beams (b) Moment in the interior columns at the base of each story 
(a)
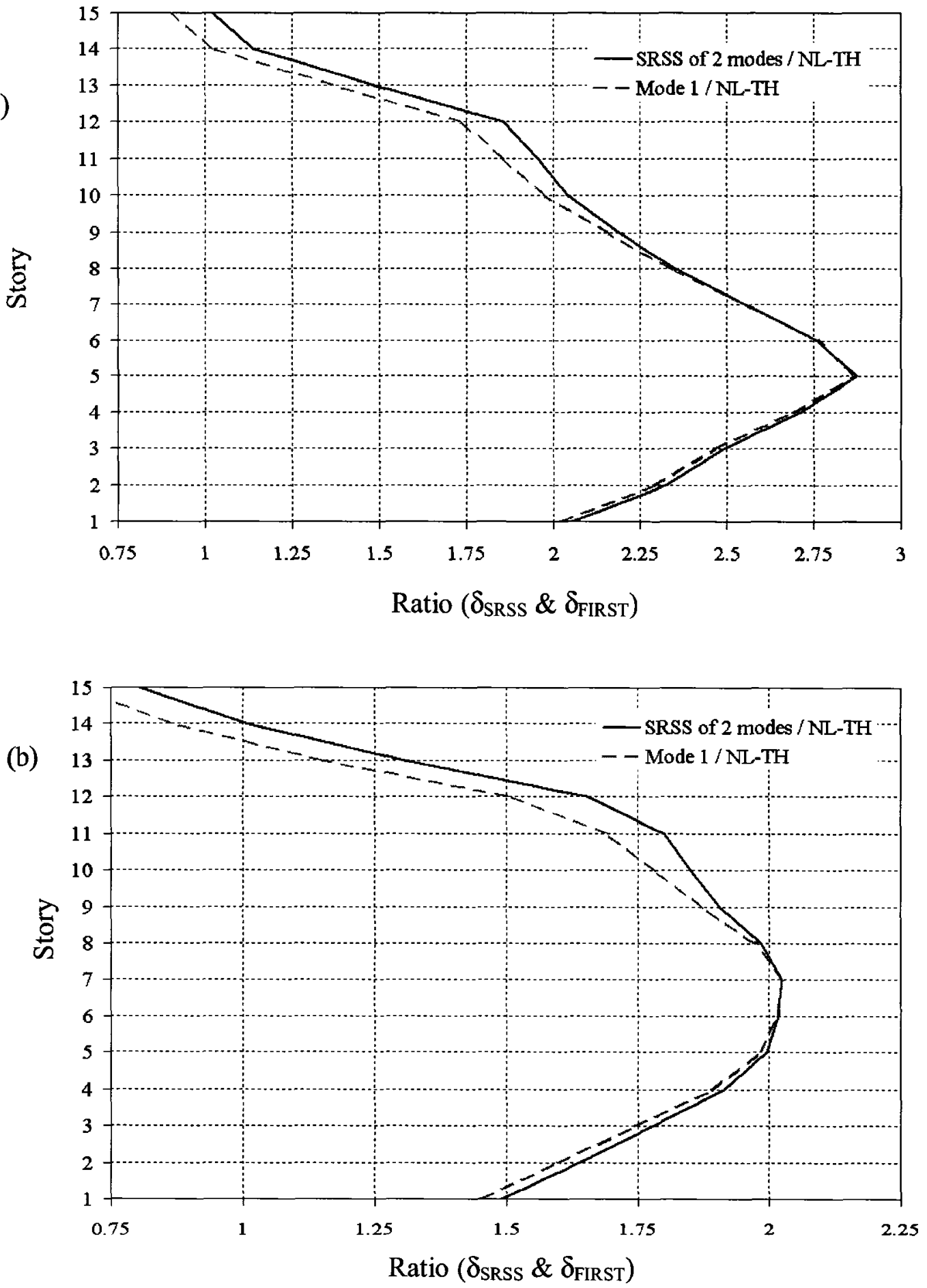

Figure (5.31): Comparison of the modal and first mode responses with the results of Nonlinear Time History analyses for 15 story steel moment-resisting frame in Montreal (b) Inter-story drifts (b) Story shears 

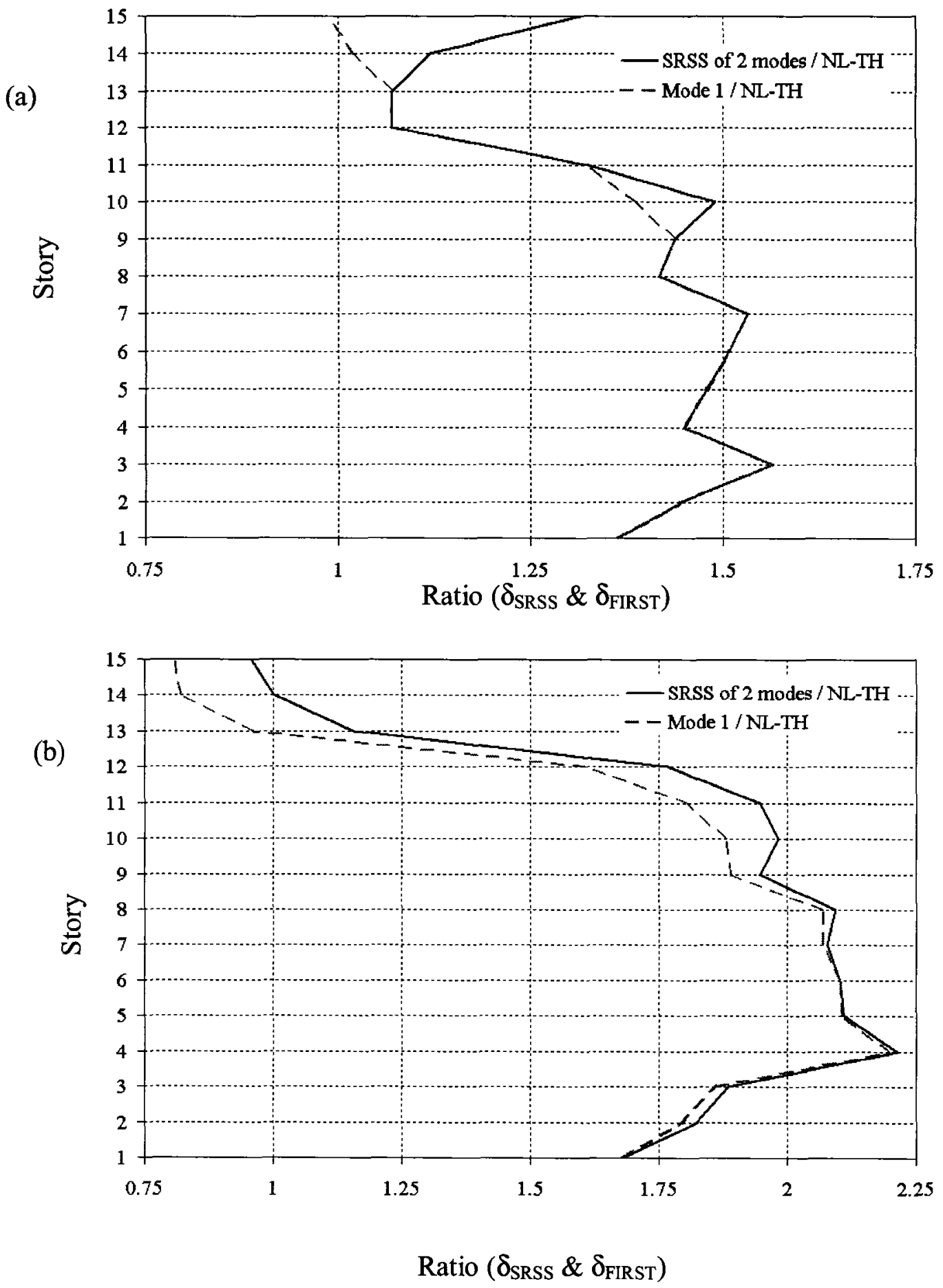

Figure (5.32): Comparison of the modal and first mode responses with the results of Nonlinear Time History analyses for 15 story steel moment-resisting frame in Montreal

(a) Negative moment at the ends of middle span beams (b) Moment in the interior columns at the base of each story 
(a)
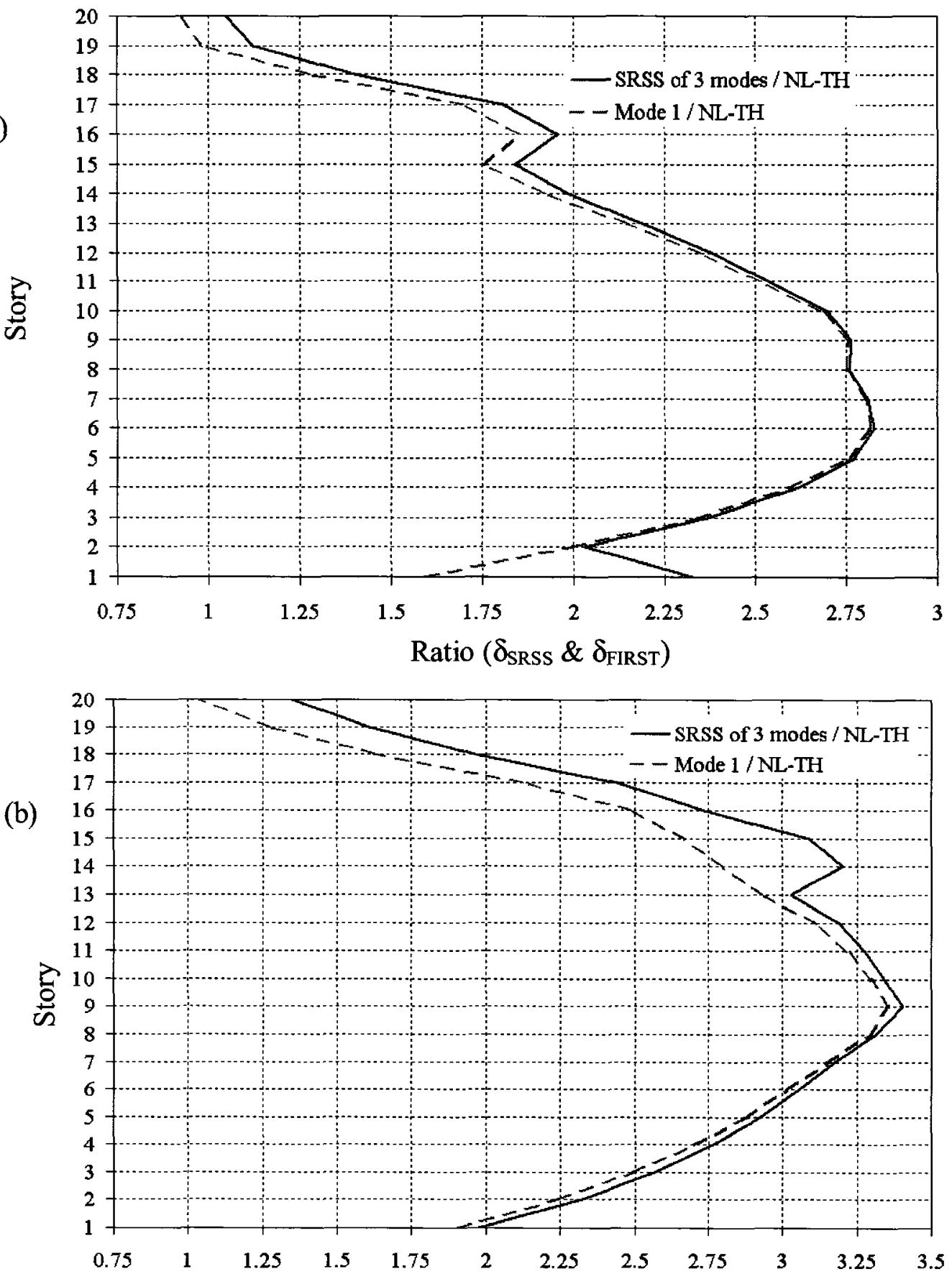

Ratio $\left(\delta_{\text {SRSS }} \& \delta_{\text {FIRST }}\right)$

Figure (5.33): Comparison of the modal and first mode responses with the results of Nonlinear Time History analyses for 20 story steel moment-resisting frame in Montreal (a) Inter-story drifts (b) Story shears 
(a)
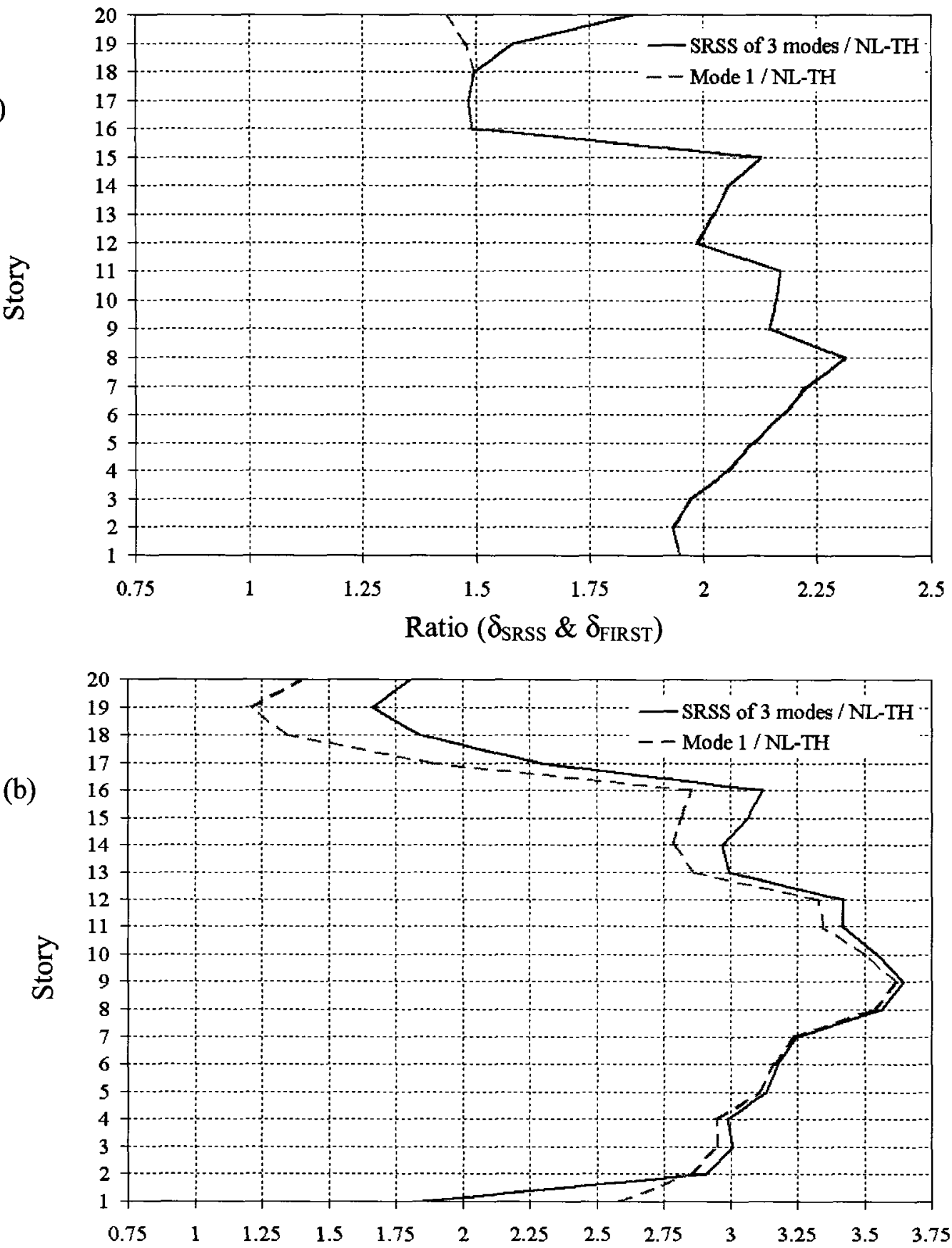

Ratio $\left(\delta_{\text {SRSS }} \& \delta_{\text {FIRST }}\right)$

Figure (5.34): Comparison of the modal and first mode responses with the results of Nonlinear Time History analyses for 20 story steel moment-resisting frame in Montreal (a) Negative moment at the ends of middle span beams (b) Moment in the interior columns at the base of each story 

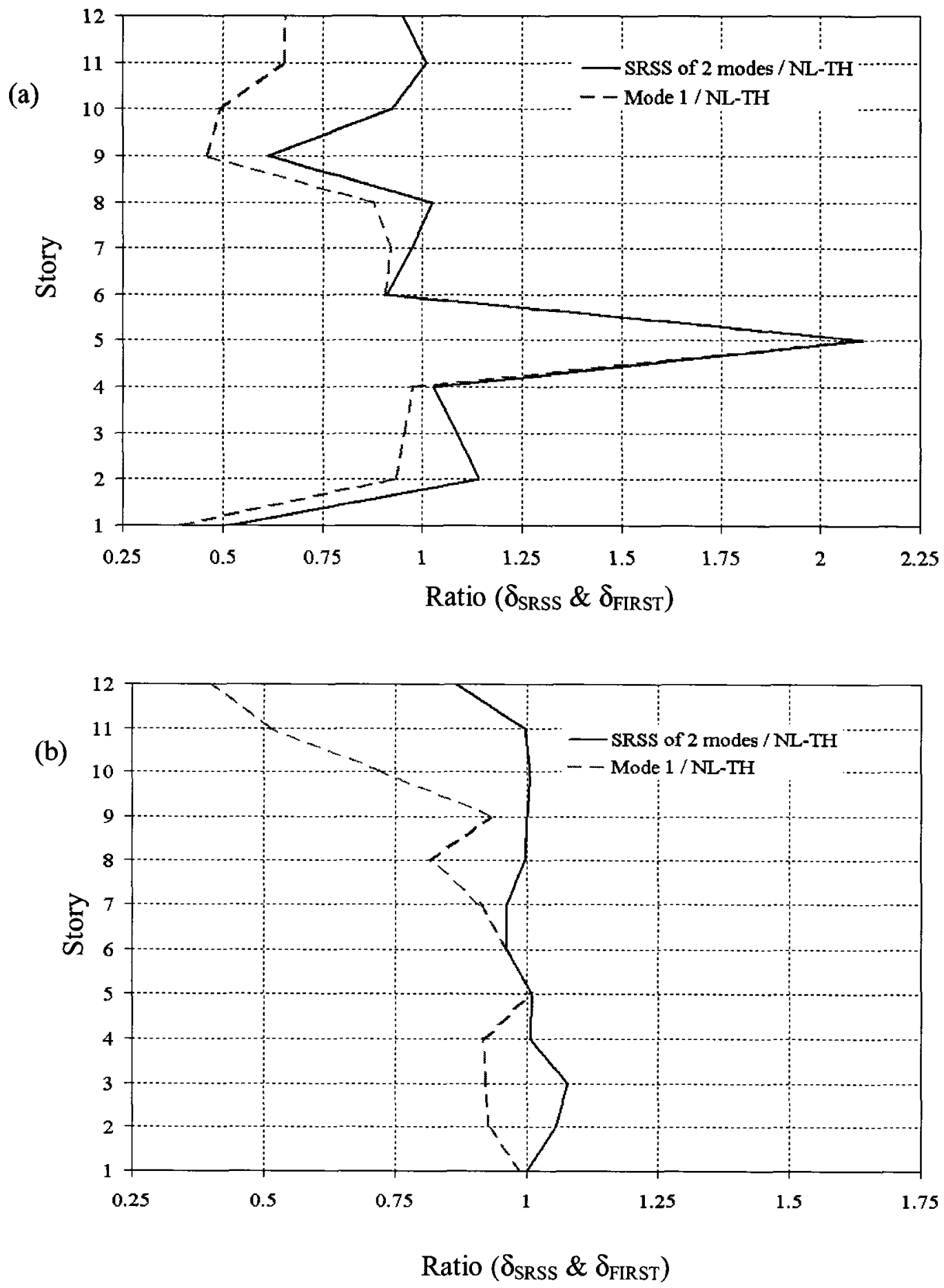

Figure (5.35): Comparison of the modal and first mode responses with the results of Nonlinear Time History analyses for 12 story concentric braced frame in Vancouver (a) Inter-story drifts (b) Tensile forces in braces 
(a)
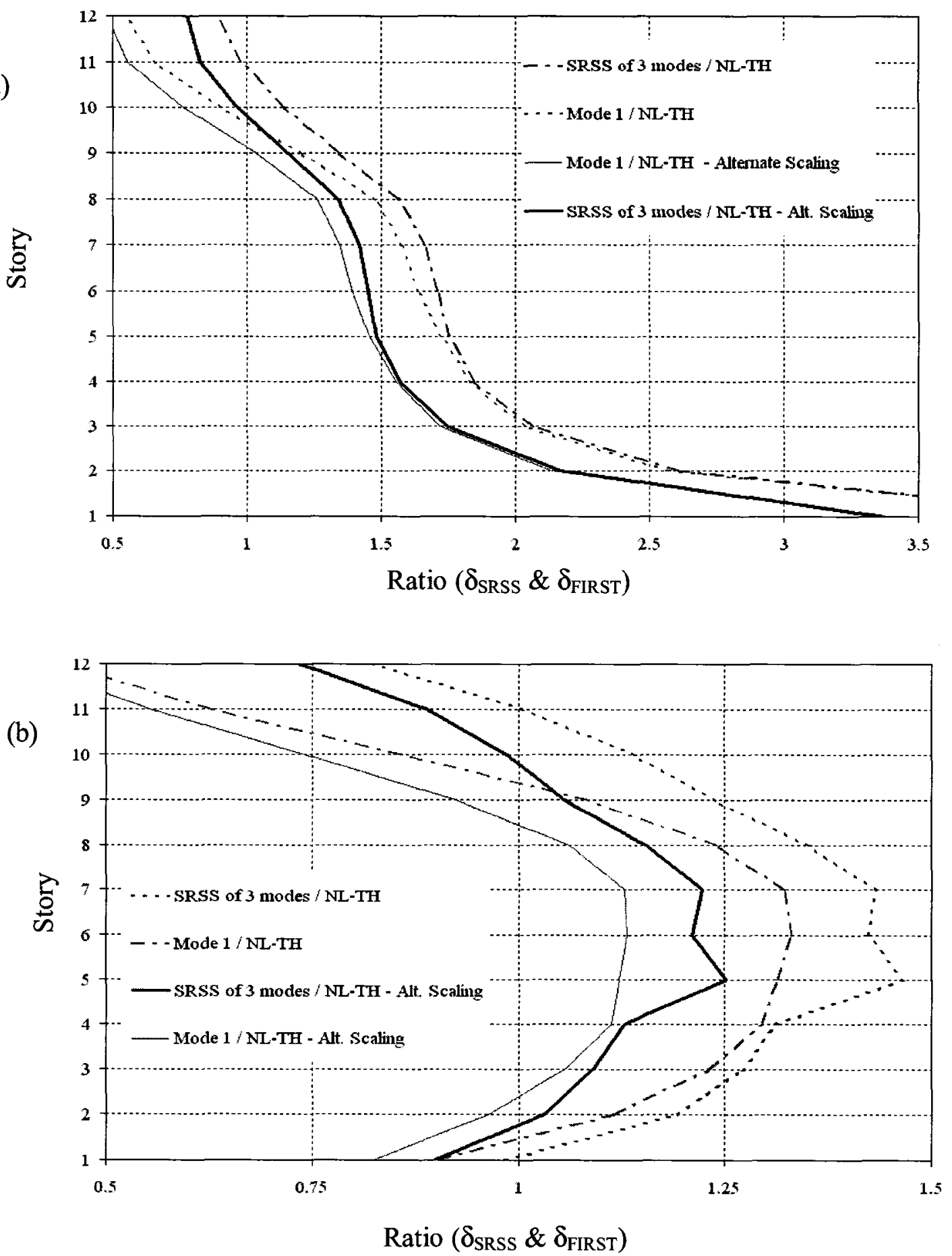

Figure (5.36): Comparison of the modal and first mode responses with the results of Nonlinear Time History analyses for 12 story RC frame in Montreal, Alternative scaling factor for ground motions (a) Inter-story drifts (b) Story shears 


\section{Chapter 6}

\section{Summary and Conclusions}

\subsection{Summary}

A practical method of displacement-based seismic design of buildings of regular configuration is presented. It represents an essential step in the performance-based design of such structures. The proposed method is based on the assumption that the structure deforms predominantly in its first mode, however effect of higher modes is incorporated through modal pushover analysis. Based on this assumption the structure is converted into an equivalent SDOF system.

For preliminary design the yield displacement of the structure is based on approximate empirical relationships. The acceptable ultimate displacement is based on the code prescribed drift limit, the element ductility capacity or the P- $\Delta$ instability limit, whichever gives a smaller value. The ratio of the two displacements provides the ductility capacity.

The seismic demand is represented by an inelastic spectrum corresponding to this ductility. This spectrum is obtained from the design UHS using reduction factors that depend on the ductility and the period. The intersection of the demand curve and the vertical through the ultimate displacement provides the required base shear strength. 
Subsequent iterations in design are based on obtaining better estimates of the yield and ultimate displacements from a pushover analysis for forces that are distributed according to the first mode.

After the process has converged a full modal pushover analysis using several modes to capture $90 \%$ mass participation, is carried out. The demand roof displacement is calculated for each mode, structure is pushed up to the calculated target roof displacement and the response parameters at each mode are obtained at target displacement and combined using SRSS method. Provided that demand local ductilities remains less than the corresponding ductility capacity, the inter-story drift at all levels are below the $2.5 \%$ limit and shears forces after modal combination do not exceed corresponding shear capacities, the design is considered satisfactory,

Once the near collapse (primary) performance objective is achieved, performance of the structure at the secondary level is evaluated. In this work the secondary performance objective is to ensure that the structure remains operational during a more frequent earthquake. Design spectra corresponding to $2 \%$ probability of being exceeded in 50 years and $50 \%$ chance of being exceeded in 50 years are used to define the seismic hazard for primary and secondary objectives, respectively. 
To validate the proposed displacement-based design method, behavior of the designed structure when subjected to appropriate ground motions is observed. Spectrum-compatible ground motions for eastern Canada are selected, filtered, baseline corrected and scaled to be used in the nonlinear time history analyses of the designed structures. The $5 \%$ damped UHS of NBCC 2005 is used as target spectrum. In order to develop ground motions with less bias, preference is given to the records that are local, compatible with the results of deaggregation, have smaller scaling factor, and have spectra that are similar in spectral intensity value and spectral shape when compared to the target spectrum. Ground motions of the other stable continental regions are also considered in the selection process.

The uncorrected ground motions are filtered using high pass Butterworth filter with frequency limit of $0.5 \mathrm{~Hz}$ and low pass filter with limit of $50 \mathrm{~Hz}$. Two baseline shifts are calculated and removed, one from the strong shaking part of the acceleration time history and one from the rest of the record. Zero velocity constraint at the end of record is applied to the correction process. Another set of ground motions selected in an independent research is used for the dynamic analyses of buildings designed for western Canada.

Steel and concrete moment resisting frames of 6,12, 15 and 20 stories and a 12-story concentrically braced frame located in both eastern and western regions of Canada are 
designed using the presented DBD and MPA procedure. First mode as well as higher mode values of the major response parameters are calculated for these buildings.

Using the selected spectrum compatible ground motions, nonlinear time history analyses of the designed buildings are carried out and results are compared to the estimated first mode and modal response parameters. In addition, the ratios between the maximum interstory drift and roof drift for various structural systems are calculated. The results of the analyses show that this ratio varies between 0.3 and 0.6 for 20 and 6 story buildings, respectively.

\subsection{Conclusions}

The following conclusions can be drawn from the study presented here:

1. The proposed DBSD presented in this work is both conceptually straightforward and simple to implement, which makes it suitable for design office use. The method represents an important step in the performance-based design. One advantage of the method is that it can be used to satisfy multiple objectives, and the designer has freedom to choose the value of the quantitative measure of performance level. It is recognized that further development will be required before the procedure is translated into practice. 
2. The preliminary design is based on the values of yield and ultimate displacements that depend only on the geometry and material properties of the structure. Assuming a triangular shape for the first mode provides a reasonable first design. Further iterations may be used to refine the design, however, the method converges quite rapidly.

3. In reinforced concrete moment resisting frames and shear wall structure, one of: the drift limit specified in the codes, the limited ductility capacity based on a concrete strain of 0.0035 for unconfined, or the instability limit governs the design, and the ductility capacities based on a fully confined concrete are rarely mobilized.

4. A similar situation exists for moment resisting or concentrically braced steel frames in which either the inter-story drift or the P- $\Delta$ instability limit governs the design and the code specified general or local ductility capacities are almost never reached.

5. Modal pushover analyses confirm that displacements and inter-story drift ratios are not affected by higher modes. However, the shear response especially in taller structures is highly influenced by higher modes. 
6. Results of the NL-TH analyses of the buildings designed for Western Canada show better agreement with the estimated values whereas in the buildings designed for Eastern Canada there is higher discrepancy between the estimated and exact values. In both regions higher mode effect, which is fully captured only through the NL$\mathrm{TH}$ analysis could cause this bias. The bias is, in fact, more significant in taller structures.

7. Validation process proves the effectiveness of the presented DBD method in the design of both steel and reinforced concrete moment-resisting frames located in west. This method successfully predicts the pattern of the plastic hinges and also guarantees sufficient ductility capacity in the designed structures. These structures remain stable under all ground motions with the median roof displacement close to the target displacement. The inter-story drifts exceed under the individual ground motions however the median values generally are within the maximum allowable drift of $2.5 \%$.

8. In general, the modal estimates of the critical response parameters are slightly above the median values obtained from NL-TH analyses, providing a reasonable over-strength factor. 
9. For Eastern Canada, the estimated structural response parameters differ quite significantly from the results of NL-TH analyses. However, the estimates of the critical design parameters including the maximum inter-story drift and base shear are still acceptable.

10. Larger tributary gravity forces in buildings designed for eastern Canada makes earthquake forces less critical in the design of certain members. In these members the earthquake-induced forces are smaller than gravity forces and ductility capacity of these members are not utilized during the earthquake excitation.

11. The selected records for Eastern Canada have been scaled based on their spectral values at $0.3,1,2$ and 4 seconds. The natural period of the structures designed for eastern Canada are well above 4 seconds where the selected records are not scaled properly, so that a high scatter in the results is observed. The Somerville scaling method of ground motions that is used in this study works well where ground motions are used for a structure with natural period of less than $5 \mathrm{~s}$ (as was the case for most of the buildings designed for Western Canada).

12. In order to make earthquake forces critical in the design of buildings in the east, the design spectrum for Montreal is kept constant for periods larger than $4.0 \mathrm{~s}$. Since this is not accounted for in the Somerville's scaling method, a significant 
bias between the estimated performance parameters and results of the NL-TH analyses is expected as is the case for buildings designed for Eastern Canada. This error could be minimized if the sampling points of the Somerville method are selected from the constant acceleration range as well. It is shown that an alternative scaling method that accounts for the natural period of the designed structures is more effective.

\subsection{Recommended future research}

The following issues need to be considered in any future research:

- Application of the presented method to other types of bracings including eccentrically braced frames.

- Application of the proposed displacement based design method to 3D structures and considering the effect of torsion in irregular buildings.

- Study of the spectral shape for periods larger than 4.0 seconds, particularly for Canadian locations.

- Search for more ground motions that are compatible with the design spectrum of eastern Canada and require smaller scaling factors.

- Use of alternative scaling methods for ground motions or different weight factors and periods in the Somerville's method to make it suitable for longer period structures. 


\section{Appendix A}

\section{Displacement based design of a concrete frame building}

\section{Description of the building}

The building located in Vancouver is 6 stories high and has three bays, each $8 \mathrm{~m}$ wide, in the $\mathrm{E}-\mathrm{W}$ direction. In the $\mathrm{E}-\mathrm{W}$ direction there are 6 bays, each $8 \mathrm{~m}$ wide. The first story is $4.75 \mathrm{~m}$ high, all other stories are $3.65 \mathrm{~m}$. The structural framing consists of $200 \mathrm{~mm}$ thick $\mathrm{RC}$ slab beams and columns. Lateral resistance in the $\mathrm{N}-\mathrm{S}$ direction is provided by 3 moment-resisting frames located in the $2^{\text {nd }}, 4^{\text {th }}$ and $6^{\text {th }}$ framing lines. The other frames take only gravity loads. The building is shown in plan and elevation in Figure (A.1). The following data is used in the design.

$\begin{array}{lll}\text { Dead load: } & \text { Partitions } & 0.5 \mathrm{kN} / \mathrm{m}^{2} \\ & \text { Electrical, mechanical, ceiling } & 0.5 \mathrm{kN} / \mathrm{m}^{2} \\ & \text { Roof insulation and water proofing } & 0.5 \mathrm{kN} / \mathrm{m}^{2}\end{array}$
Live load:
Snow load on roof
$2.2 \mathrm{kN} / \mathrm{m}^{2}$
Floor load
$2.4 \mathrm{kN} / \mathrm{m}^{2}$
Material properties: $f_{y}=400 \mathrm{MPa}$
$\mathrm{f}_{\mathrm{c}}{ }^{\prime}=30 \mathrm{MPa}$
$\varphi_{\mathrm{c}}=0.6$
$\varphi_{\mathrm{s}}=0.85$


We design the building for earthquake forces in N-S direction neglecting the accidental torsion effect.

For the calculation of self-weight we will assume that all beams are $400 \mathrm{~mm}$ by $600 \mathrm{~mm}$ deep; columns are $600 \mathrm{~mm}$ by $600 \mathrm{~mm}$ in stories 1 to 3 and $500 \mathrm{~mm}$ by $500 \mathrm{~mm}$ in stories 4 to 6.

\section{Load calculation}

Floor dead load:

Slab

$\frac{200 \times 24}{1000}=4.8 \mathrm{kN} / \mathrm{m}^{2}$

Partitions

$0.5 \mathrm{kN} / \mathrm{m}^{2}$

Ceiling, Mechanical, Electrical

$0.5 \mathrm{kN} / \mathrm{m}^{2}$

Total

$5.8 \mathrm{kN} / \mathrm{m}^{2}$

The roof dead load is also $5.8 \mathrm{kN} / \mathrm{m}^{2}$ since partition load is replaced by an equal amount of insulation and roofing load.

Load due to self-weight:

Self-weight of beams

Tributary area for each frame

Floor weight for floors 1 to 3

Floor weight for floors 4 to 6
$0.4 \times 0.4 \times 24=3.84 \mathrm{kN} / \mathrm{m}$

$24 \times 8=192 \mathrm{~m}^{2}$

$192 \times 5.8+3.84 \times(24-1.8)=1198.8 \mathrm{kN}$

$192 \times 5.8+3.84 \times(24-1.5)=1200.0 \mathrm{kN}$ 
Contribution from columns to roof weight $0.5 \times 0.5 \times 24 \times \frac{3.45}{2} \times 4=41.4 \mathrm{kN}$ Contribution from columns to the floors 4 and $50.5 \times 0.5 \times 24 \times 3.45 \times 4=82.8 \mathrm{kN}$ Contribution of columns to the weight of floor 3

$$
0.6 \times 0.6 \times 24 \times \frac{3.45}{2} \times 4+0.5 \times 0.5 \times 24 \times \frac{3.45}{2} \times 4=101.0 \mathrm{kN}
$$

Contribution of columns to floor 2 $0.6 \times 0.6 \times 24 \times 3.45 \times 4=119.2 \mathrm{kN}$

Contribution of columns to floor 1 $0.6 \times 0.6 \times 24 \times \frac{3.45+4.65}{2} \times 4=140.0 \mathrm{kN}$

Total dead loads:

Roof

Floors 4 and 5

Floor 3

Floor 2

Floor 1

Snow load on roof

$$
\begin{array}{r}
1200.0+41.4=1241.4 \mathrm{kN} \\
1200.0+82.8=1282.8 \mathrm{kN} \\
1198.8+101.0=1299.8 \mathrm{kN} \\
1198.8+119.2=1318.0 \mathrm{kN} \\
1198.8+140.0=1338.8 \mathrm{kN} \\
0.25 \times 2.2 \times 192=105.6 \mathrm{kN}
\end{array}
$$

Total dead load per frame

$$
1241.4+2 \times 1282.8+1299.8+1318.0+1338.8+105.6=7869.2 \mathrm{kN}
$$

Note that we have ignored the weight contributed by beams in EW direction, and cladding on the periphery of the building. We will assume that the partition load takes this into account.

Inertia mass tributary to each lateral load-resisting frame: $\quad \frac{2 \times 7869.2}{9.81}=1604.3$ tonnes 
This mass is distributed as follows:

Roof

Floors 4 and 5

Floor 3

Floor 2

Floor 1
$274.6 \mathrm{t}$ $261.5 \mathrm{t}$ $265.1 \mathrm{t}$ $268.7 \mathrm{t}$ $272.9 \mathrm{t}$

\section{Data for gravity load design}

Live load reduction factor for floor live load

$$
0.3+\sqrt{\frac{9.8}{192}}=0.526
$$

Reduced live load

$$
0.526 \times 2.4=1.262 \mathrm{kN} / \mathrm{m}^{2}
$$

Dead load on the beam $5.8 \times 8+3.84=50.24 \mathrm{kN} / \mathrm{m}$

Live load on beam $1.262 \times 8=10.1 \mathrm{kN} / \mathrm{m}$

Floor load based on 1.25D + 1.5L $77.95 \mathrm{kN} / \mathrm{m}$

Roof load based on $1.25 \mathrm{D}+1.5 \mathrm{~L}$ $1.25 \times 50.24+1.5 \times 2.2 \times 8=89.2 \mathrm{kN} / \mathrm{m}$

Floor load based on $\mathrm{D}+0.5 \mathrm{~L}$ $55.29 \mathrm{kN} / \mathrm{m}$

Roof load based on D +0.25 snow load $50.24+0.25 \times 2.2 \times 8=54.64 \mathrm{kN} / \mathrm{m}$

\section{Fixed end forces}

$$
\text { Based on 1.25D + 1.5L }
$$

Floor Moment $\frac{77.95 \times 8^{2}}{12}=415.7 \mathrm{kNm}$

Floor Shear $77.95 \times 4=311.8 \mathrm{kN}$

Roof moment $\frac{89.2 \times 8^{2}}{12}=475.7 \mathrm{k}-\mathrm{Nm}$

Roof shear

$89.2 \times 4=356.8 \mathrm{kN}$ 
Based on $\mathrm{D}+0.5 \mathrm{~L}$

Floor moment

Floor shear

Roof moment

Roof shear $\frac{55.29 \times 8^{2}}{12}=294.9 \mathrm{kNm}$

$55.29 \times 4=221.2 \mathrm{kN}$ $\frac{54.64 \times 8^{2}}{12}=291.4 \mathrm{kNm}$

$54.64 \times 4=218.6 \mathrm{kN}$

\section{$P-\Delta$ loads}

Each lateral load resisting frame resists $\mathrm{P}-\Delta$ effect arising from gravity loads on two bays. For the earthquake load combination, namely $\mathrm{D}+0.5 \mathrm{~L}$, the following calculations provide the floor loads. As a conservative approach, assuming that the live loads are reduced corresponding to the floor tributary area of $384 \mathrm{~m}^{2}$, we have:

Live load reduction factor

$$
0.3+\sqrt{\frac{9.8}{384}}=0.460
$$

Reduced live load $=0.46 \times 2.4 \times 384=424 \mathrm{kN}$

$\begin{array}{ll}\text { Poof }-\Delta \text { loads } & 2 \times 1241.4+211.2=2694.0 \mathrm{kN} \\ \text { Floors } 4 \text { and } 5 & 2 \times 1282.8+212.0=2777.6 \mathrm{kN} \\ \text { Floor 3 } & 2 \times 1299.8+212.0=2811.6 \mathrm{kN} \\ \text { Floor 2 } & 2 \times 1318.0+212.0=2848.0 \mathrm{kN} \\ \text { Floor 1 } & 2 \times 1338.8+212.0=2889.6 \mathrm{kN}\end{array}$


Excess over the gravity load applied through beam shears:

$\begin{array}{ll}\text { Roof } & 2694.0-54.64 \times 24=1382.6 \mathrm{kN} \\ \text { Floors 4 and 5 } & 2777.6-55.29 \times 24=1450.6 \mathrm{kN} \\ \text { Floor 3 } & 2811.6-55.29 \times 24=1484.6 \mathrm{kN} \\ \text { Floor 2 } & 2848.0-55.29 \times 24=1521.0 \mathrm{kN} \\ \text { Floor 1 } & 2889.6-55.29 \times 24=1562.6 \mathrm{kN}\end{array}$

\section{Displacement Estimates}

The DBD for near collapse level is presented here. According to Gupta and Krawinkler (2000) the ratio of maximum story drift to roof drift for low-rise steel structures is around 1.2. Adopting the same value for our R.C. building and assuming a beam depth of $600 \mathrm{~mm}$, yield displacement at roof level is estimated from the following:

$$
\Delta_{y}=\frac{0.5 \varepsilon_{y} \frac{l_{b}}{h_{b}} H}{1.2}=\frac{0.5 \times 0.002 \times \frac{800}{60} \times 2300}{1.2}=25.6 \mathrm{~cm}
$$

In order to meet the code requirements the maximum inter-story drift is taken as $2.5 \%$. The ultimate displacement at roof is thus given by:

$$
\Delta_{u}^{R o o f}=\frac{0.025 \times 2300}{1.2}=47.9 \mathrm{~cm}
$$

and the ductility requirement works out to

$$
\mu=\frac{\Delta_{u}}{\Delta_{y}}=1.87
$$




\section{Equivalent SDOF system}

We carry out a modal analysis using the member dimensions assumed for self load calculations, and the effective moment of inertia as $70 \%$ of the gross moment of inertia for both the beams and the columns. The following properties are obtained when $\mathrm{P}-\Delta$ effect is ignored:

$T_{1}=2.512 \mathrm{~s}$

$\phi_{1}^{\mathrm{T}}=\left[\begin{array}{llllll}0.193 & 0.398 & 0.592 & 0.783 & 0.921 & 1.0\end{array}\right]$

$\Gamma_{1}=1.292$

$M_{1}^{*}=1339.6 \mathrm{t}$

The displacements of the equivalent SDOF system become:

$\delta_{y}=25.6 / 1.292=19.81 \mathrm{~cm}$

$\delta_{u}=47.9 / 1.292=37.07 \mathrm{~cm}$

\section{Capacity and Demand Diagrams}

A portion of the elastic response spectrum for Vancouver is shown in Figure (A.2) in acceleration-displacement format. The inelastic spectrum or the demand diagram for a ductility of 1.87 , obtained by using the Krawinler Nassar $R_{\mathrm{y}}-\mu-T$ relationships, is also shown. The performance point is given by the intersection of the ultimate displacement and the demand diagram. The capacity curve is obtained by drawing a horizontal line 
from the performance point to the yield displacement and from the latter to the origin. The spectral acceleration at yield is found to be $A_{y}=0.0451 \mathrm{~g}$, and the corresponding design base shear works out to:

$V_{b}=A_{y} M^{*}=0.0451 \times 9.81 \times 1339.6=593 \mathrm{kN}$

\section{Calculation of design forces}

The calculated shear is distributed across the height in proportion to the product, $\mathbf{M} \boldsymbol{\phi}_{1}$. The resulting forces are given by:

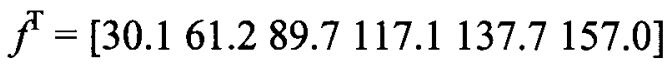

A static analysis is carried out for the combination $\mathrm{D}+0.5 \mathrm{~L}+\mathrm{E}$. In the analysis we take the effective inertias for beams as 0.7 times the gross inertia based on the dimensions 400 by 600 deep. For the columns, as well, the effective inertia is taken as 0.7 times the gross inertia. The results of the analysis are shown in Figures (A.3) to (A.5).

\section{Design of beams}

The governing design forces are produced by the combination $\mathrm{D}+0.5 \mathrm{~L}+\mathrm{E}$. We design all beams in floors 1 to 3 for a negative moment of $610 \mathrm{kNm}$ and a positive moment of half that value or $305 \mathrm{kNm}$. Note that in positive moment the beam acts as a $\mathrm{T}$ beam. The selected design is shown in Figure (A.6). The moment-curvature relationships are shown in Figures (A.7) and (A.8). The effective moment of inertia in the negative moment 
region is 0.598 times the gross moment of inertia of the rectangular section. In the positive moment region the effective moment of inertia is 0.485 times the moment of inertia of a 400 by 600 section.

For floors 4 to 6 the design negative moment is $512 \mathrm{kNm}$, and the positive design moment can be taken as half that value, namely $256 \mathrm{kNm}$. The selected section is shown in Figure (A.6) and the moment curvature relations are shown in Figures (A.9) and (A.10).

\section{Design of columns}

In designing the columns we will also check the capacity design principles, to the extent that the sum of column resistances at a joint must be larger than the sum of beam resistances. For the interior columns in the lowest story, the design axial force is $2474 \mathrm{kN}$ and the design moment is $537 \mathrm{kNm}$. Capacity design will require the moment to be at least $(630+370) / 2=500 \mathrm{kNm}$. The selected column is 600 by $600 \mathrm{~mm}$ with 12 No. 25 bars. The cover to the centers of the bars is $70 \mathrm{~mm}$. The moment curvature relationship is shown in Figure (A.11). The column fails by crushing of concrete at $770 \mathrm{kNm}$, when the concrete strain is 0.0035 .

It is interesting to note that the effective moment of inertia based on a straight line from the origin to the first steel yield is only 0.35 times the gross moment of inertia. However, 
if an idealized bilinear curve is fitted to the moment-curvature relation the effective moment of inertia is substantially higher, and close to about 0.6 times the gross moment of inertia.

For stories 4 to 6 the design axial force is $1124 \mathrm{kN}$ and the design moment is moment is $267 \mathrm{kNm}$. We use 500 by 500 column with 8 No. 25 bars. The moment curvature relationship for the section is shown in Figure (A.12). The column fails by crushing of concrete at a moment of $420 \mathrm{kNm}$. For facility in construction, we use the same sections for exterior columns as those for interior columns.

\section{Modal analysis}

A modal analysis on the revised design is carried out using column and beam moments of inertia equal to 0.6 times the gross moments of inertia. This value is selected based on the moment curvature relationships for the selected sections. The following properties are obtained for the first mode not taking P- $\Delta$ effect into account:

$$
\begin{aligned}
& T_{1}=2.67 \mathrm{~s} \\
& \phi_{1}^{\mathrm{T}}=\left[\begin{array}{llllll}
0.200 & 0.404 & 0.594 & 0.785 & 0.922 & 1.000
\end{array}\right] \\
& \Gamma_{1}=1.286 \\
& M_{1}^{*}=1355.1 \mathrm{t}
\end{aligned}
$$




\section{Push over analysis}

In the computer input for the designed structure, an interaction diagram is required for each column. For example, the computed values for first story columns are: a moment capacity of $510 \mathrm{kNm}$ at zero axial load, a maximum moment capacity of $770 \mathrm{kNm}$ at an axial load of $2475 \mathrm{kN}$, and an axial load capacity of $5740 \mathrm{kN}$, when the moment is negligible. Using these values and a load distribution given by $\mathbf{M} \phi_{1}$ a pushover analysis is carried out. The results are shown in Figure (A.13). It will be observed that the actual base shear capacity of the structure is $720 \mathrm{kN}$, although we designed it to take $593 \mathrm{kN}$. This is because with practical arrangements of reinforcement and availability of only discrete sizes of bars, the beam and section capacities work out to be larger than those required. In addition similar column and beam reinforcement layouts are used over several floors and stories, so as not to require the construction of many different layouts. Also, we have conservatively taken the exterior columns to be of the same size as the interior columns. Assuming that a 5\% drop in the strength because of excursion in the negative slope region is acceptable the ultimate displacement works out to $32 \mathrm{~cm}$. The roof displacement limit to keep the inter-story drift within $2.5 \%$, obtained from the curves shown in Figure (A.14), is $31 \mathrm{~cm}$, which thus becomes the governing value of roof displacement. The yield displacement obtained from the idealized curve is $12.4 \mathrm{~cm}$. 
It may be noted that the limit on inter-story limit and the P- $\Delta$ effect both place a severe restriction on the acceptable ultimate displacement. The yield and ultimate displacements for the equivalent SDOF system are worked out as follows:

$\delta_{y}=12.4 / 1.292=9.60 \mathrm{~cm}$

$\delta_{u}=31.0 / 1.292=24.00 \mathrm{~cm}$

$\mu=\frac{24.00}{9.60}=2.50$

The demand and capacity curves are shown in Figure (A.15). The yield level spectral acceleration is $0.050 \mathrm{~g}$. Hence the design base shear is calculated as follows:

$V_{b}=0.05 \times 9.81 \times 1355.1=664.7 \mathrm{kN}$

The pushover diagram of the existing design in Figure (A.13) shows a strength of $720 \mathrm{kN}$. Thus the design is satisfactory. The demand roof displacement in the first mode is equal to $30.9 \mathrm{~cm}$. It is calculated using the procedure presented in Section 3.2.8.

\section{Multi-Mode Pushover Analysis}

The mass participation in the first mode is $84.5 \%$ of the total mass. A dynamic analysis of the designed structure gives the vibration period and mode shape for mode 2, $\mathrm{T}_{2}=0.87 \mathrm{~s}$

$\phi_{2}{ }^{\mathrm{T}}=\{0.612,0.977,0.939,0.378,-0.407,-1.000\}$

$\Gamma_{2}=0.418$ 
$\mathrm{M}_{2}{ }^{*}=165.7$ tonnes $\quad(10.3 \%$ of total mass $)$

First two modes are sufficient to capture $90 \%$ mass participation. Similarly, the demand roof displacement in second mode is calculated as $3.3 \mathrm{~cm}$.

Following the procedure presented in Section 3.2.9, the demand values of inter-story drifts, story shears, beam moments and shear forces and column moments are obtained at the demand roof displacements of modes 1 and 2 . The modal values are combined using the square root of the sum of squares, and compared to the corresponding limiting values or capacities.

\section{Operational level performance}

The performance of the designed structure at operational level is evaluated next. The demand base shear in a frequent earthquake can be calculated for this structure as follows. For the first mode period of $2.67 \mathrm{~s}$, the demand acceleration obtained using Equation (2.35) is equal to,

$\mathrm{S}_{\mathrm{a}}(2.67)=2 \times 0.034 \mathrm{~g} / 2.67=0.0255 \mathrm{~g}$

$\mathrm{V}=\mathrm{S}_{\mathrm{a}} \mathrm{M}=0.0255 \times 9.81 \times 1604.3=401 \mathrm{kN}$

Referring to the pushover curve of Figure (A.13), the corresponding roof displacement for the calculated base shear is equal to $7 \mathrm{~cm}$. At this roof displacement the maximum inter-story drift reaches $0.4 \%$ as shown in Figure (A.14), which is less than the $0.5 \%$ limit. Thus, the design is satisfactory. 
Table (A.1): Inter-story drifts (\%)

\begin{tabular}{|c|c|c|c|}
\hline Story & Mode 1 & Mode 2 & SRSS \\
\hline 1 & 2.48 & 0.38 & 2.51 \\
\hline 2 & 2.03 & 0.29 & 2.05 \\
\hline 3 & 1.38 & 0.03 & 1.38 \\
\hline 4 & 0.98 & 0.48 & 1.09 \\
\hline 5 & 0.55 & 0.68 & 0.87 \\
\hline 6 & 0.27 & 0.51 & 0.58 \\
\hline
\end{tabular}

Table (A.2): Story Shears $(\mathrm{kN})$

\begin{tabular}{|c|c|c|c|}
\hline Story & Mode 1 & Mode 2 & SRSS \\
\hline 1 & 726 & 607 & 946 \\
\hline 2 & 687 & 351 & 771 \\
\hline 3 & 609 & 51 & 611 \\
\hline 4 & 498 & 432 & 659 \\
\hline 5 & 356 & 583 & 683 \\
\hline 6 & 189 & 420 & 461 \\
\hline
\end{tabular}


Table (A.3): Moments and plastic hinge rotations - middle span beam, Negative Moment (moments in $\mathrm{kN}-\mathrm{m}$ and rotations in radians)

\begin{tabular}{|c|c|c|c|c|}
\hline Story & Mode 1 & Mode 2 & $\mu_{\text {Demand }}$ & $\mu_{\text {Capacity }}$ \\
\hline 1 & $\begin{array}{c}630 \\
\theta=21.13 \mathrm{E}-3\end{array}$ & 69 & 11.0 & 12 \\
\hline 2 & $\begin{array}{c}630 \\
\theta=14.12 \mathrm{E}-3\end{array}$ & 216 & 7.8 & 12 \\
\hline 3 & $\begin{array}{c}630 \\
\theta=7.61 \mathrm{E}-3\end{array}$ & 405 & 4.7 & 12 \\
\hline 4 & $\begin{array}{c}557 \\
\theta=2.03 \mathrm{E}-3\end{array}$ & 550 & 2.2 & 9 \\
\hline 5 & 461 & $\begin{array}{c}557 \\
\theta=4.07 \mathrm{E}-4\end{array}$ & 1.7 & 9 \\
\hline 6 & 130 & 198 & 1 & 9 \\
\hline
\end{tabular}

Table (A.4): Moments and plastic hinge rotations - the interior column (moments in $\mathrm{kN}-\mathrm{m}$ and rotations in radians)

\begin{tabular}{|c|c|c|c|c|}
\hline Story & Mode 1 & Mode 2 & SRSS & $\mu_{\text {Capacity }} / \mu_{\text {Demand }}$ \\
\hline 1 & 760 & 528 & 760 & 0.97 \\
\hline 2 & 248 & 143 & 286 & $>1$ \\
\hline 3 & 272 & 137 & 305 & $>1$ \\
\hline 4 & 213 & 290 & 360 & $>1$ \\
\hline 5 & 183 & 354 & 399 & $>1$ \\
\hline 6 & 31 & 157 & 160 & $>1$ \\
\hline
\end{tabular}


(a)
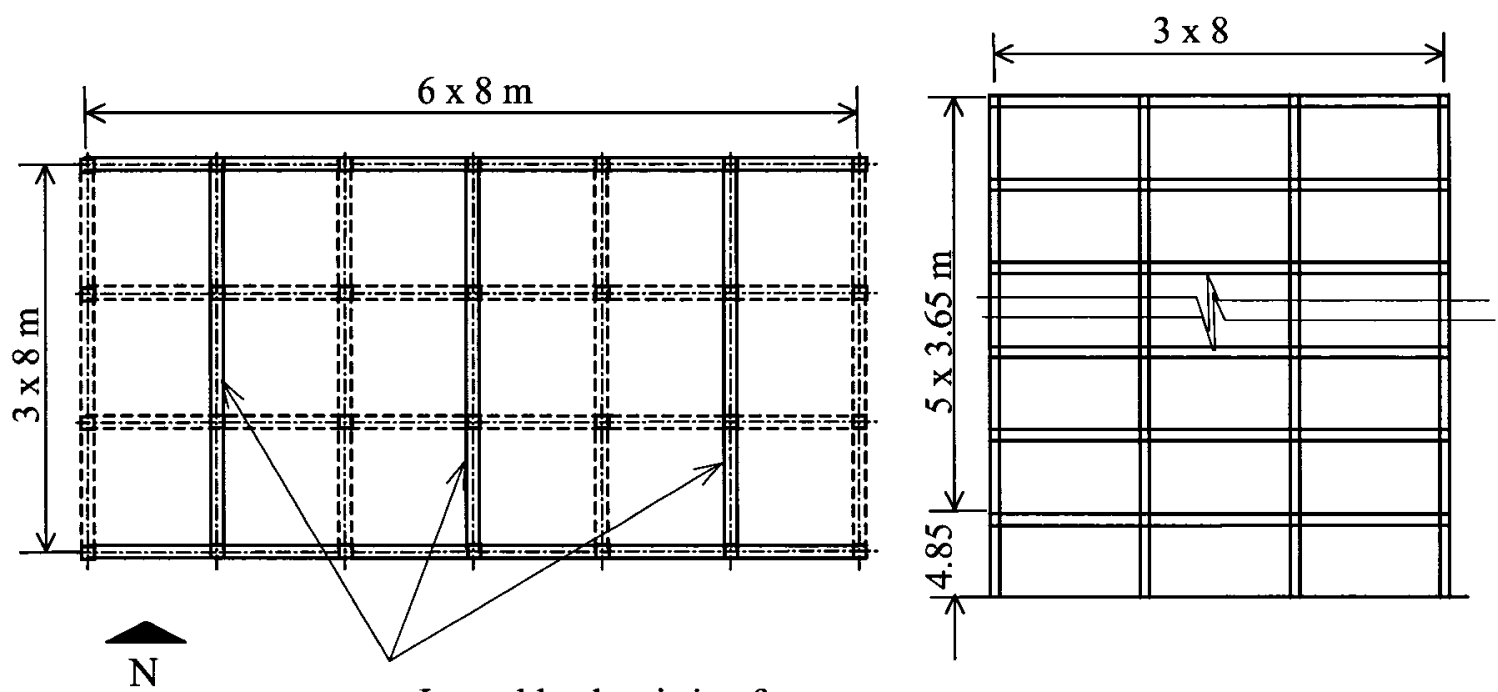

Lateral load resisting frames

Figure (A.1): Plan and elevation of the 6-story building

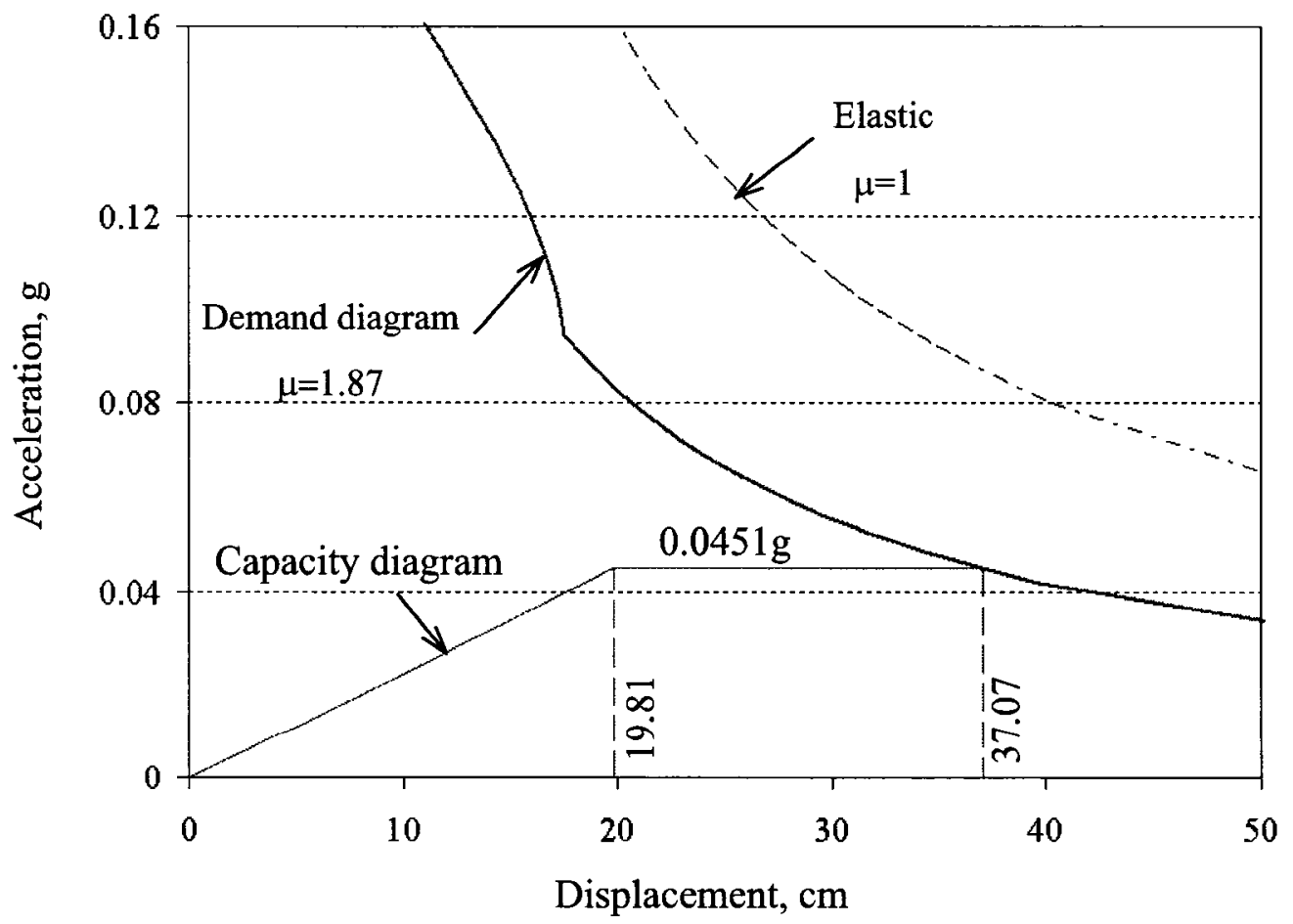

Figure (A.2): Demand and capacity curve for preliminary design 


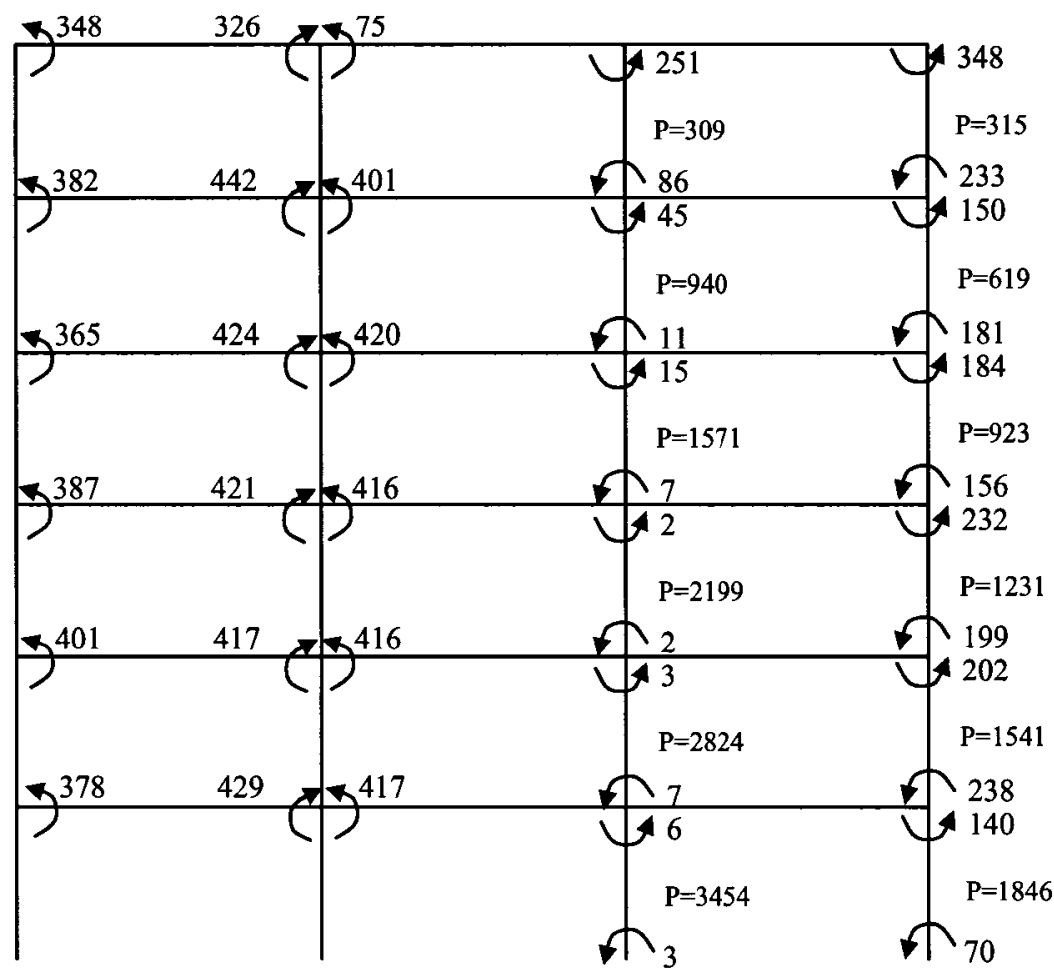

Figure (A.3): Beam and Column forces under gravity loads for load combination of $1.25 \mathrm{D}+1.5 \mathrm{~L}$ (moments in $\mathrm{kNm}$ and forces in $\mathrm{kN}$, values are symmetrical)

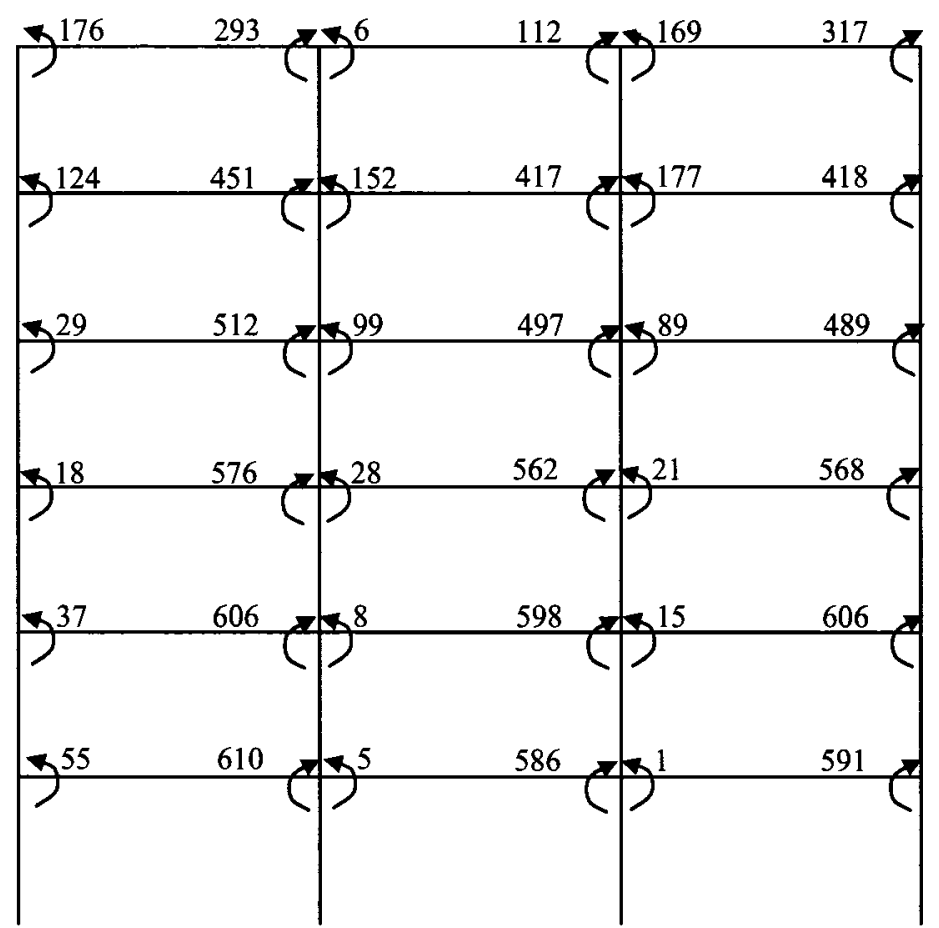

Figure (A.4): Beam moments for load combination of $D+0.5 \mathrm{~L}+\mathrm{E}$ 


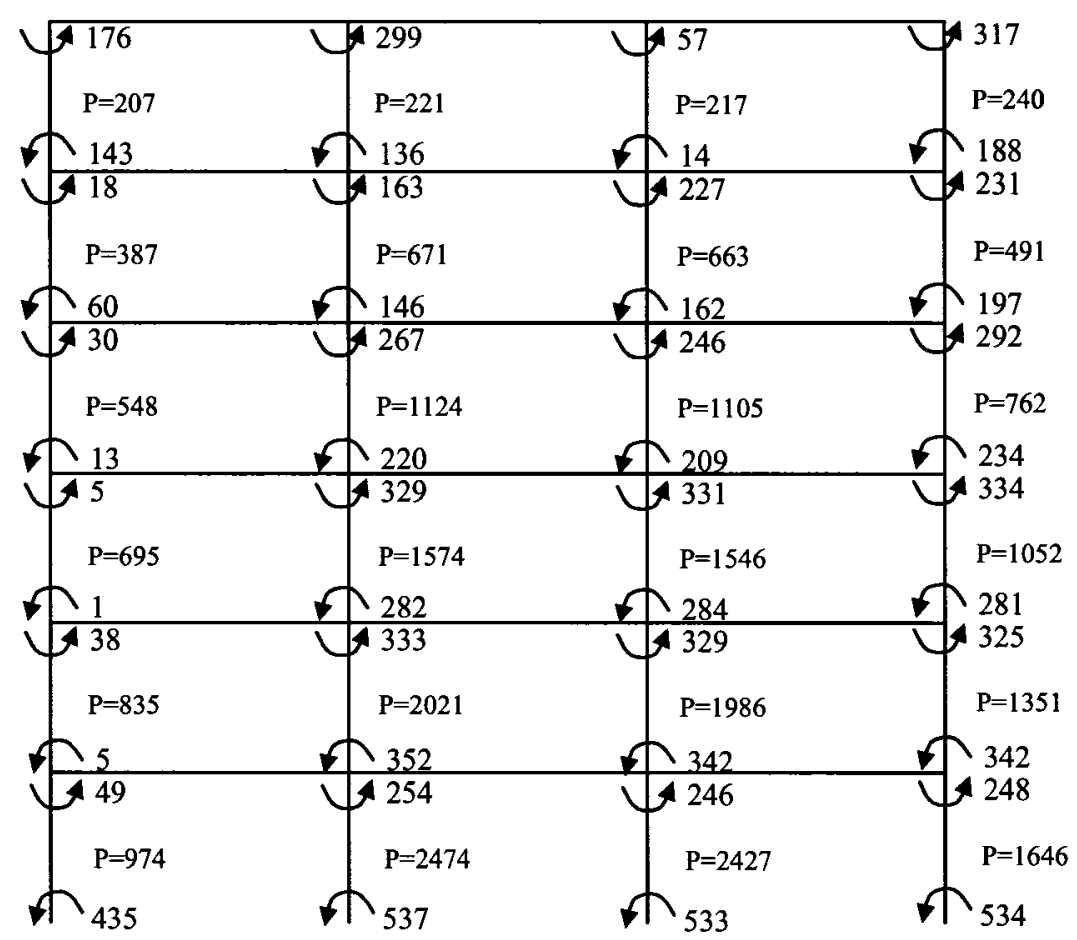

Figure (A.5): Column forces for load combination of D+0.5L+E

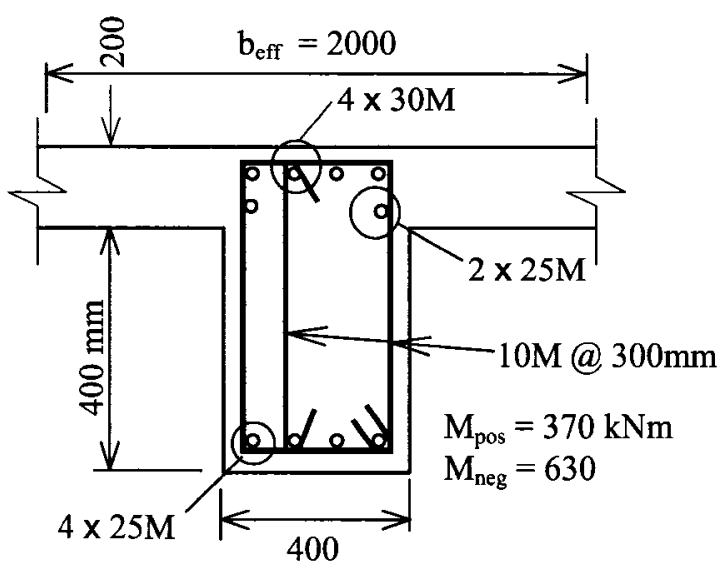

Beams of stories 1 to 3

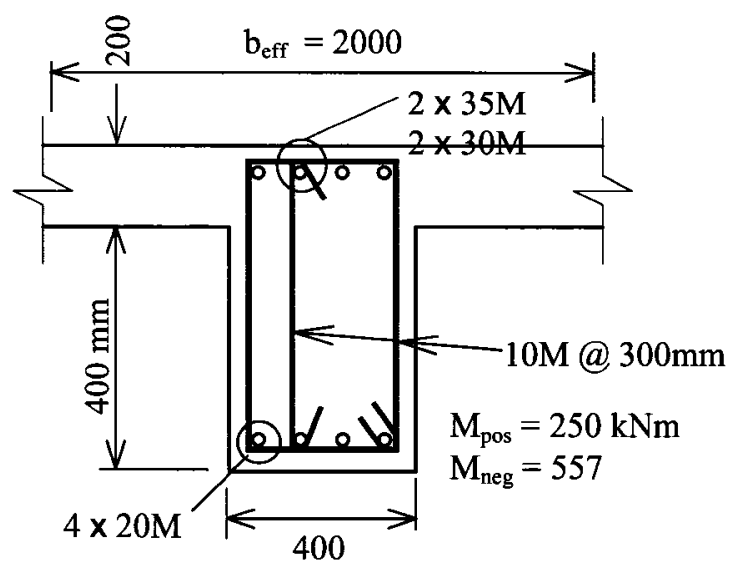

Beams of stories 4 to 6

Figure (A.6): Preliminary beam sizes 


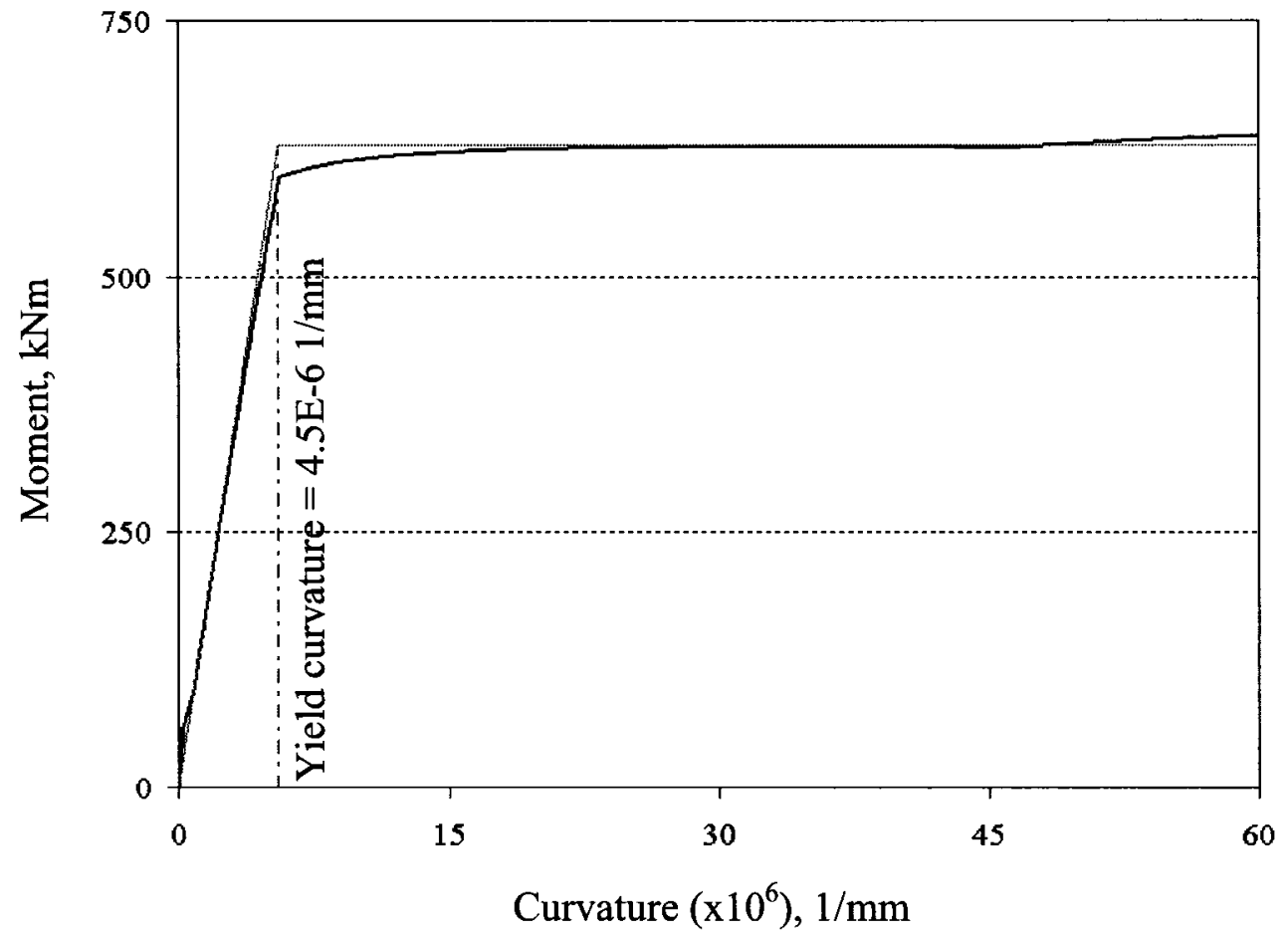

Figure (A.7): Moment-curvature relation for negative moment on the beam, floors 1 to 3

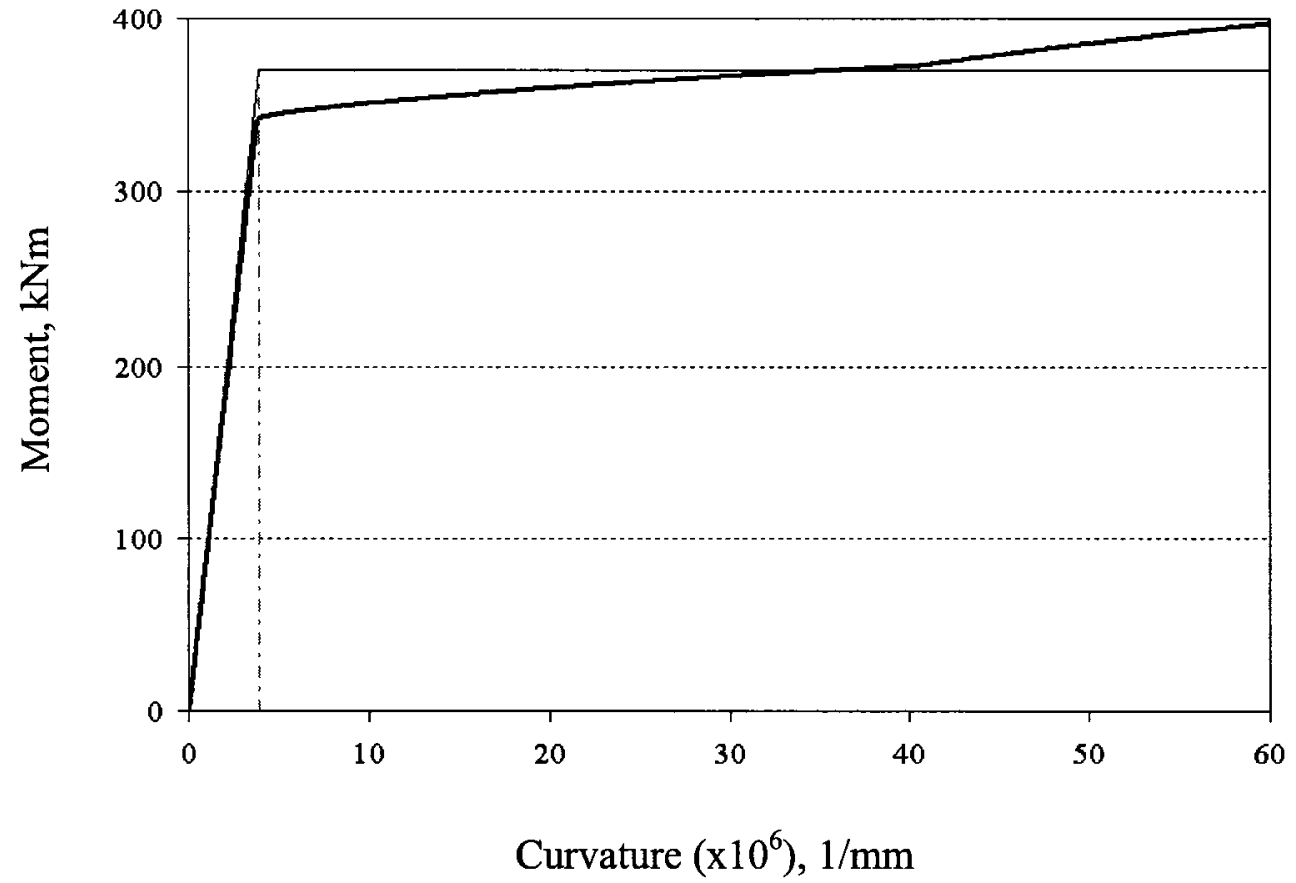

Figure (A.8): Moment-curvature relation for positive moment on the beam, floors 1 to 3 


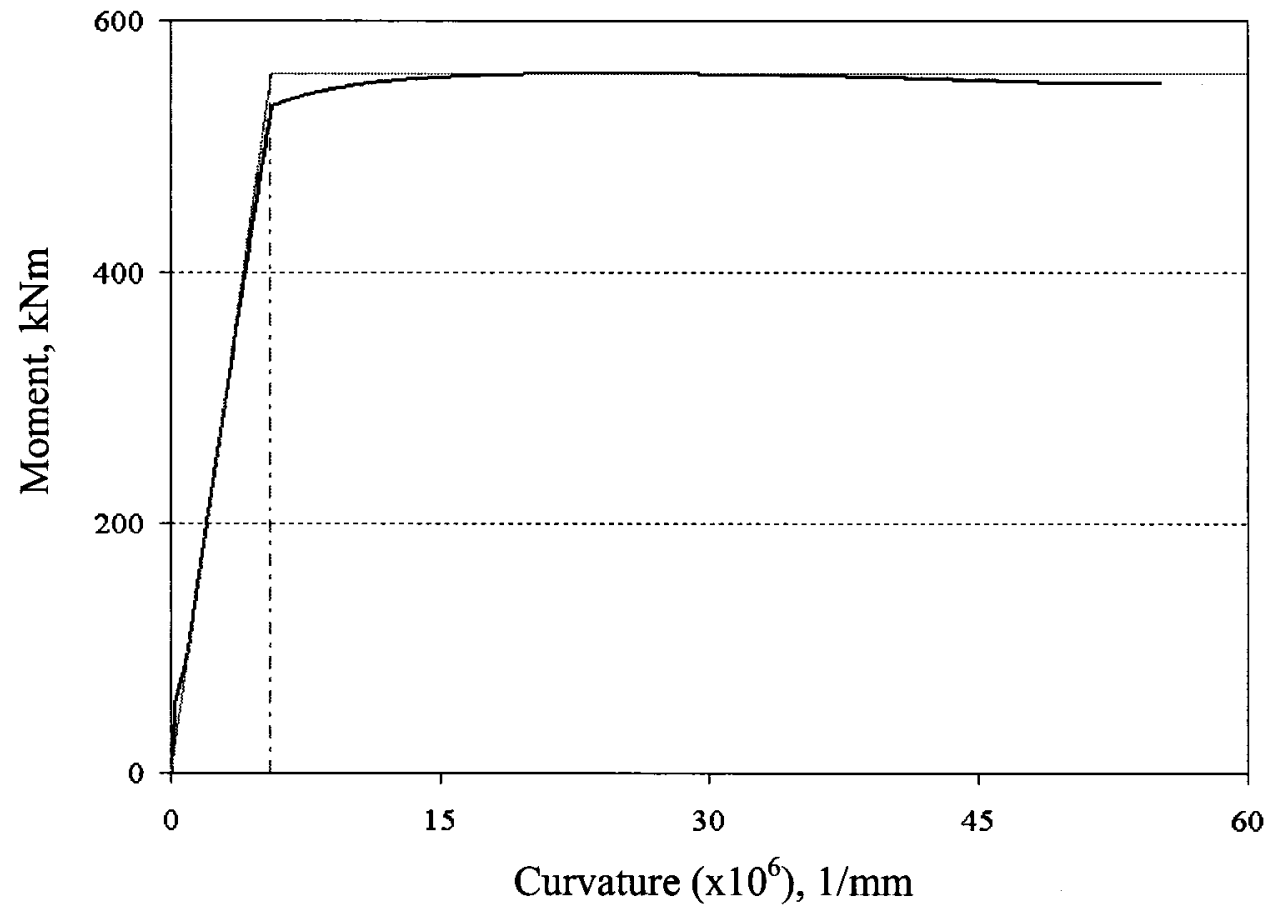

Figure (A.9): Moment-curvature relation for negative moment on the beam, floors 4 to 6

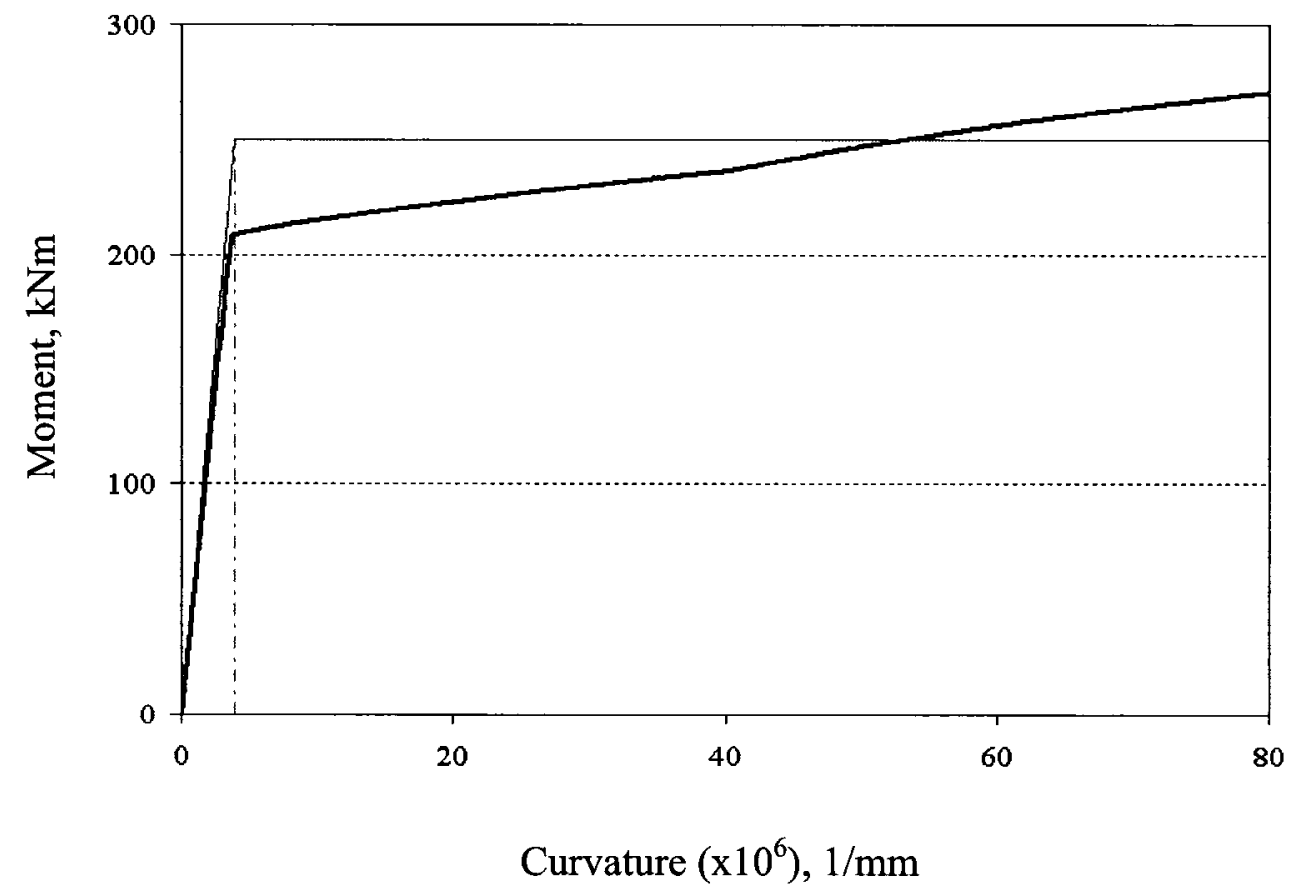

Figure (A.10): Moment-curvature relation for positive moment on the beam, floors 4 to 6 


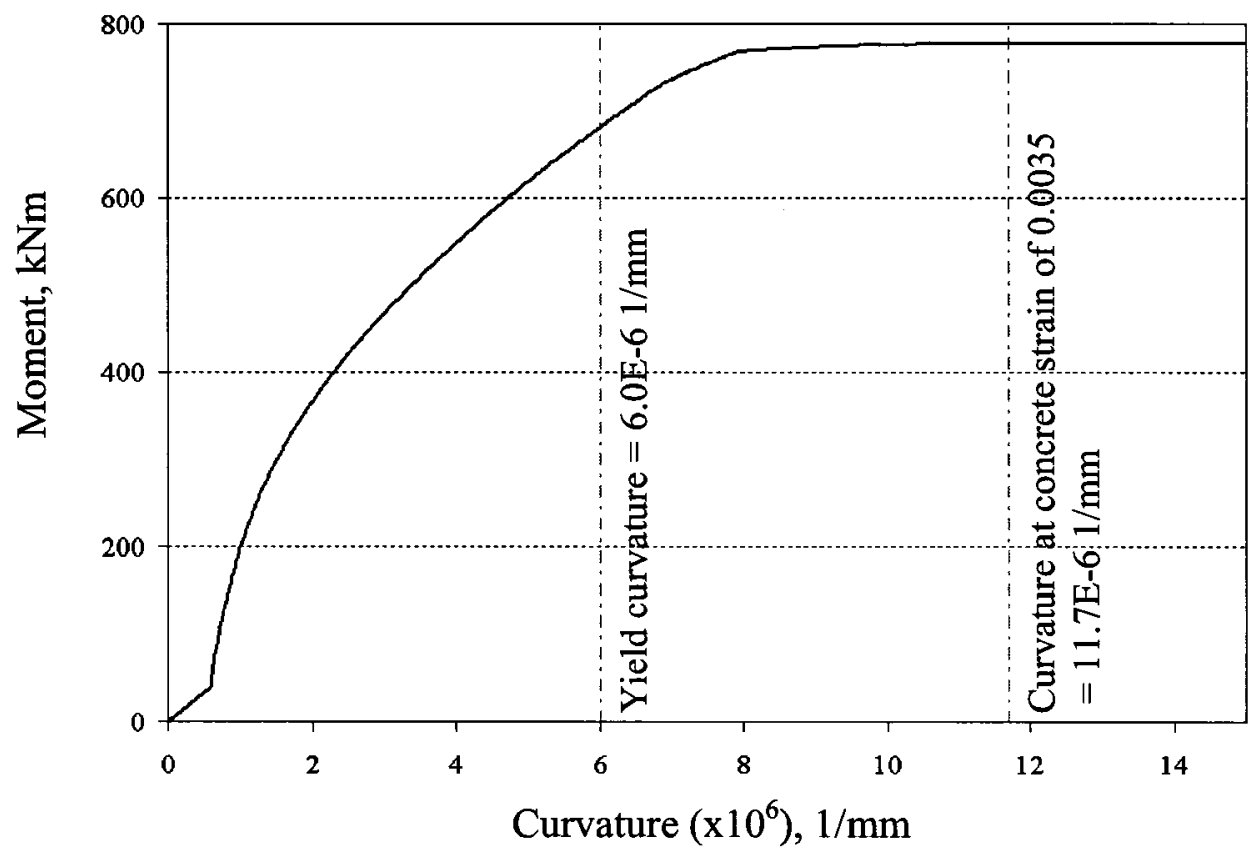

Figure (A.11): Moment curvature relationship for $600 \times 600$ column in stories 1 to 3

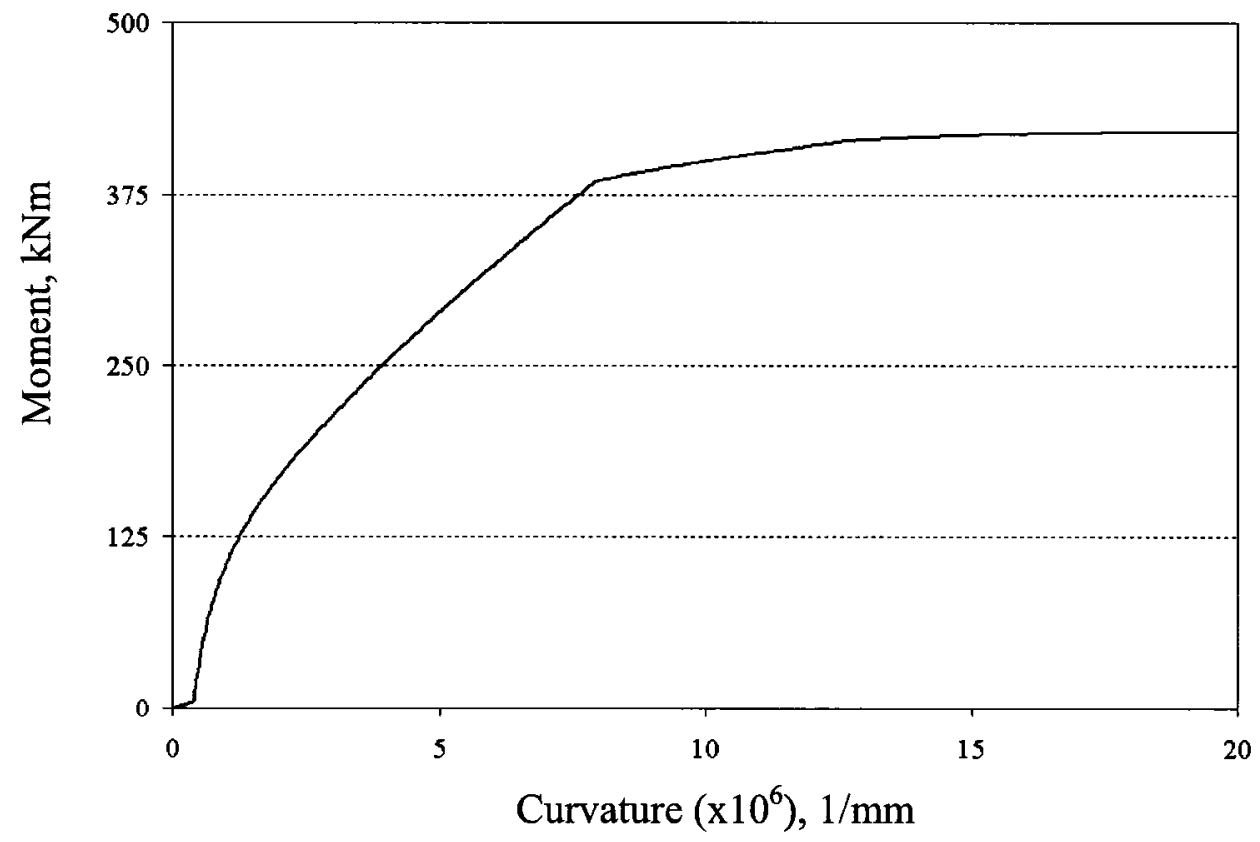

Figure (A.12): Moment curvature relation for the $500 \times 500$ column in stories 4 to 6 


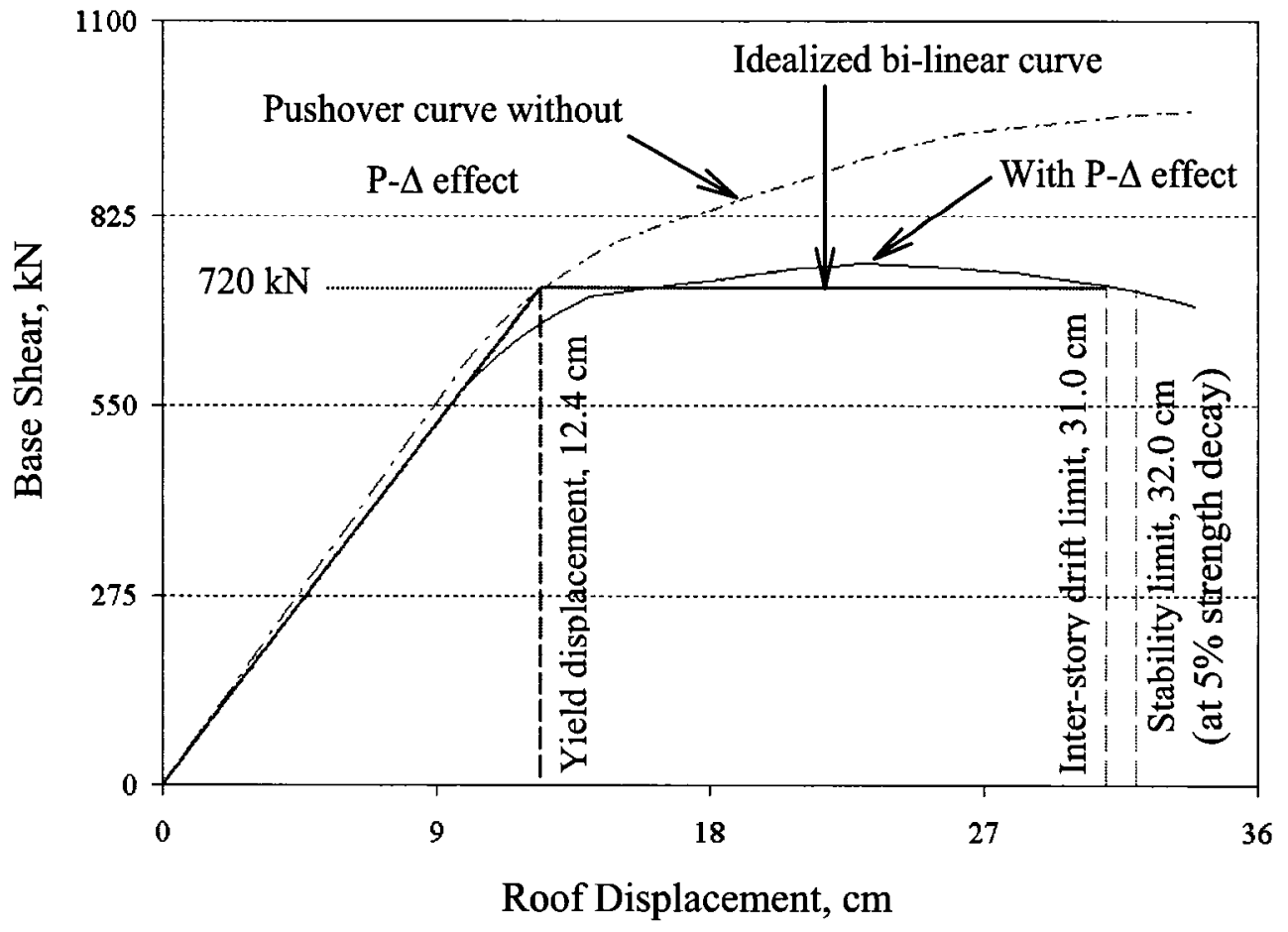

Figure (A.13): Base shear versus roof displacement relations obtained from a push over analysis.

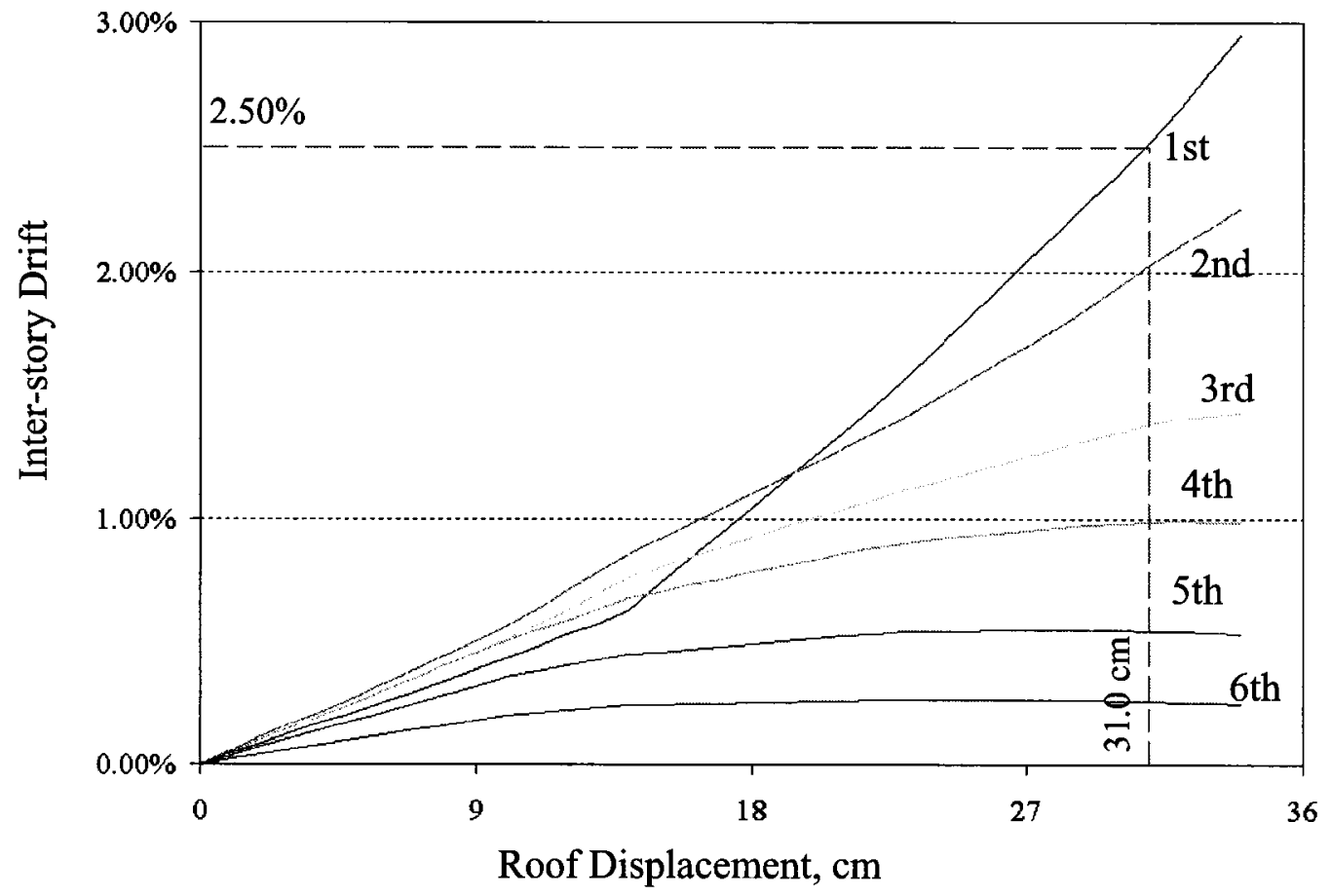

Figure (A.14): Inter-story drifts versus roof displacement 


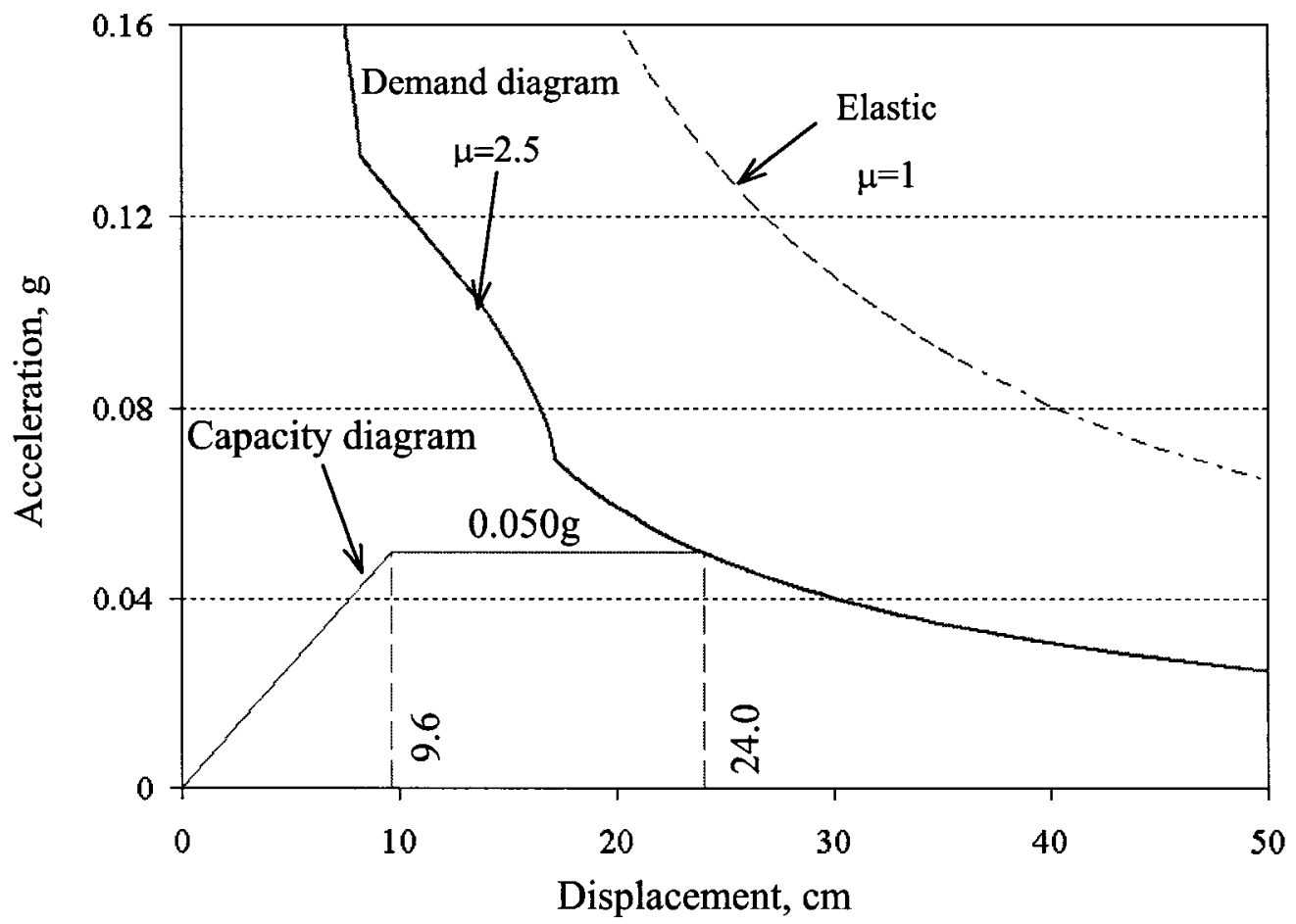

Figure (A.15): Demand and capacity curve for DBD design 


\section{References}

Abrahamson, N. 1993. Non-stationary spectral matching program RSPMATCH. $P G \& E$ Internal report.

Adebar, P., Mutrie, J., DeVall, R. 2005. Ductility of concrete walls: the Canadian seismic design provisions 1984 to 2004. Canadian Journal of Civil Engineering. 32:1124-1137.

Adams, J., Halchuk, S. 2003. Fourth generation seismic hazard maps of Canada. Geological Survey of Canada, Open file report 4459.

Akkar, S., Gulkan, P. 2000. Comparative performance evaluation of displacement based design procedures for near field earthquakes. Proceedings of the $12^{\text {th }}$ world conference on earthquake engineering, Auckland, New Zealand, paper 0444.

Aschheim, M. 2002. Seismic design based on the yield displacement. Earthquake Spectra. Vol. 18, No, 4, pp. 581-600.

Aschheim, M., Black, E. 2000. Yield point spectra for seismic design and rehabilitation. Earthquake Spectra. Vol. 16, No. 2, pp. 317-335.

Bertero, R. D., Bertero, V. V. 2002. Performance-based seismic engineering: The need for a reliable conceptual comprehensive approach. Earthquake Engineering and Structural Dynamics, Vol. 31, No. 3, pp. 627-652.

Boore, D. 2001. Effect of baseline correction on displacements and response spectra for several recordings of the 1999 Chi-chi Taiwan earthquake. Bulletin of the Seismological Society of America. Vol. 91, No. 5 pp. 1199-1211. 
Canadian Commission on Fire and Building Codes. 2005. The National Building Code of Canada, National Research Council of Canada, Ottawa, Canada.

Chintanapakdee, C., Chopra, A. 2003. Evaluation of modal pushover analysis using generic frames. Earthquake Engineering and Structural Dynamics, Vol. 32, No. 3, pp. 417-442.

Chintanapakdee, C., Chopra, A. 2004. Evaluation of modal pushover analysis using vertically irregular frames. Proceedings of the $13^{\text {th }}$ world conference on earthquake engineering, Vancouver, B.C., Canada, paper 2139.

Chopra, A. 2004. Estimating seismic demands for performance-based engineering of buildings. Proceedings of the $13^{\text {th }}$ world conference on earthquake engineering, Vancouver, B.C., Canada, paper 5007.

Chopra, A., Chintanapakdee C. 2001. Drift Spectrum vs. Modal Analysis of Structural Response to Near-Fault Ground Motions. Earthquake Spectra, Vol. 17, No. 2, p 221234.

Chopra A., Goel R. 1999. Capacity-Demand-Diagram Methods Based on Inelastic Design Spectrum. Earthquake Spectra, Vol. 15, No. 4, pp. 637-656.

Chopra, A., Goel, R. 2000. Evaluation of a NSP to estimate seismic deformation: SDF systems. Journal of Structural Engineering, ASCE, Vol. 126, No. 4, pp. 482-490.

Chopra, A., Goel, R. 2001. Direct Displacement-Based Design: Use of Inelastic vs. Elastic Design Spectra. Earthquake Spectra, Vol. 17, No. 1, pp. 47-64. 
Chopra, A., Goel, R. 2002. A modal pushover analysis procedure for estimating seismic demands for buildings. Earthquake Engineering and Structural Dynamics, Vol. 31, pp. $561-582$.

Chopra, A. Goel, R. 2004. A modal pushover analysis procedure to estimate seismic demands for unsymmetric-plan buildings. Earthquake Engineering and Structural Dynamics, Vol. 33, pp. 903-927.

Chopra, A., Goel, R. 2006. Evaluation of the modal pushover analysis procedure for unsymmetric-plan buildings. Proceedings of the $8^{\text {th }}$ US national conference on earthquake engineering, san Francisco, Ca, USA, paper 188.

Fajfar, P. 1999. Capacity spectrum method based on inelastic demand spectra. Earthquake Engineering and Structural Dynamics, Vol. 28, No. 9, pp. 979-993.

Fajfar, P. 2000. Nonlinear analysis method for performance-based seismic design. Earthquake Spectra, Vol. 16, No. 3, pp. 573-592.

Fajfar, P., Gaspersic, P. 1996. The N2 method for seismic damage analysis of RC buildings. Earthquake Engineering and Structural Dynamics, Vol. 25, pp. 31-46.

FEMA. 2002. Pre-standard and Commentary for the seismic rehabilitation of buildings. FEMA 356, Federal Emergency Management Agency, Washington, D.C.

FEMA. 2005. Improvement of Nonlinear Static Seismic analyses Procedures. FEMA 440, Federal Emergency Management Agency, Washington, D.C.

Geological Survey of Canada. 2006. Email communications with Halchuk, S. 
Goel, R., Chopra, A. 2004. Evaluation of modal and FEMA pushover analyses: SAC buildings. Earthquake Spectra, Vol. 20, No. 1, pp. 225-254.

Goel, R., Chopra, A. 2005. Extension of modal pushover analysis to compute member forces. Earthquake Spectra, Vol. 21, No. 1, pp. 125-139.

Goel, R., Chopra, A. 2006. Additional developments in modal pushover analysis. Proceedings of the $8^{\text {th }}$ US national conference on earthquake engineering, San Francisco, Ca, USA, paper 185.

Gupta, A., Krawinkler, H. 1999. Seismic demands for performance evaluation of steel moment resisting frame structures. SAC report no. $132, \mathrm{CD}$.

Gupta, A., Krawinkler, H. 2000. Estimation of seismic drift demands for frame structures. Earthquake Engineering and Structural Dynamics, Vol. 29, pp. 1287-1305.

Gupta, A., Krawinkler, H. 2002. Relating the seismic drift demands of SMRFs to element deformation demands. Engineering Journal, Vol. 39, No. 2, pp. 100-108.

Halchuk, S., Adams, J. 2004. Deaggregation of seismic hazard for selected Canadian cities. Proceedings of the $13^{\text {th }}$ world conference on earthquake engineering, Vancouver, B.C., Canada, paper 2470 .

Iwan, W., Moser, M., Peng, C. 1985. Some observations on strong-motion earthquake measurement using a digital accelerograph. Bulletin of the Seismological Society of America. Vol. 75, No. 5, pp. 1225-1246. 
Johnston, A. 1990. The stable continental region earthquake database. Earthquakes of Stable Continental Regions, Electric Power Research Institute, Palo Alto, CA, Chapter 3.

Kilar, V., Fajfar, P. 1997. Simple pushover analysis of asymmetric buildings. Earthquake Engineering and Structural Dynamics, Vol. 26, No. 2, pp. 233-249.

Kowlasky, M.J. 2001. RC structural walls designed according to UBC and displacementbased method. Journal of Structural Engineering, Vol. 127, pp. 506-516.

Krawinkler, H., Nassar, AA. 1992. Seismic deign based on ductility and cumulative damage demands and capacities. In Nonlinear Seismic Analysis and Design of Reinforced Concrete Buildings. Elsevier Applied Science, New York.

Krawinkler, H., Seneviratna, G. 1998. Pros and cons of a pushover analysis of seismic performance evaluation. Engineering Structures, Vol. 20, No. 4-6, pp. 452-464.

Lestuzzi, P., Schwab, P., Koller, M., Lacave, C. 2004. How to choose earthquake recordings for non-linear seismic analysis of structures. Proceedings of the $13^{\text {th }}$ world conference on earthquake engineering, Vancouver, B.C., Canada, paper 1241.

Mattock, A.H. 1967. Discussion of "Rotational capacity of reinforced concrete beams", by W.G. Corley. Journal of Structural Division, ASCE, Vol. 93, pp. 519-522.

Medhekar, M.S., Kennedy, D. 2000. Displacement-based seismic design of buildings theory. Engineering Structures, Vol. 22, No. 3, pp. 201-209.

Medhekar, M.S., Kennedy, D. 2000. Displacement-based seismic design of buildings application. Engineering Structures, Vol. 22, No. 3, pp. 210-221. 
Munshi, J. Ghosh, S.K. 2000. Displacement-based seismic design for coupled wall systems. Earthquake Spectra, Vol. 16, No. 3, pp. 621-642.

Naumoski N. 1998. Program SYNTH- theoretical background, McMaster Earthquake Engineering Software Library, Department of Civil Engineering and Engineering Mechanics, McMaster University, Hamilton, Ontario.

Naeim, F., Lew, M. 1995. On the use of design-spectrum compatible time histories. Earthquake Spectra, Vol. 11, No. 1, pp. 111-127.

Panagiotakos, T.B., Fardis, M.N. 2001. A displacement-based seismic design procedure for RC buildings and comparison with EC8. Earthquake Engineering and Structural Dynamics, Vol. 30, No. 10, pp. 1439-1462.

Paulay, T. 1998. Torsional mechanisms in ductile building systems. Earthquake Engineering and Structural Dynamics, Vol. 27, No. 10, pp. 1101-1121.

Paulay, T. 2001(a). Seismic response of structural walls: recent developments. Canadian Journal of Civil Engineering, Vol. 28, pp. 922-937.

Paulay, T. 2001(b). A re-definition of the stiffness of reinforced concrete elements and its implication in seismic design. Structural Engineering International, Vol. 11, No. 1, pp. $36-41$.

Paulay, T. 2001(c). Some design principles relevant to torsional phenomena in ductile buildings. Journal of earthquake Engineering, Vol. 5, No. 3, pp. 273-308.

Paulay, T. 2002(a). A displacement-focused seismic design of mixed building systems. Earthquake Spectra, Vol. 18, No. 4, pp. 689-718. 
Paulay, T. 2002(b). An estimation of displacement limits for ductile systems. Earthquake Engineering and Structural Dynamics, Vol. 31, pp. 583-599.

Pina, F. 2006. Displacement-based seismic design of shear wall buildings. Master's Thesis, Carleton University, Ottawa, Canada.

Prakash, V., Powell, G., Campbell, S. 1993. DRAIN-2DX: Static and Dynamic Analysis of Inelastic Plane Structures. Department of Civil Engineering, Universityof California, Berkeley, US.

Priestley, M.J. 1998. Brief comments on elastic flexibility of reinforced concrete frames. Bulletin of the New Zealand National Society for Earthquake Engineering, Vol. 31, No. 4, pp. 246-259.

Priestley, M.J. 2002. Direct displacement-based design of precast/prestressed concrete buildings. PCI Journal, Vol. 47, No. 6, pp. 66-79.

Priestley, M.J., Calvi, G. 1997. Concepts and procedures for direct displacement based design and assessment. Proceedings international conference on seismic design methodologies for the next generation of codes, Bled, Slovenia, pp. 171-182.

Priestley, M.J., Kowalski, M.J. 1998. Aspects of drift and ductility capacity of rectangular cantilever structural walls. Bulletin of the New Zealand National Society for Earthquake Engineering, Vol. 31, No. 2, pp. 73-85.

Rubinstein, M., Moller, O., Giuliano, A. 2001. Inelastic displacement-based design approach of R/C building structures in seismic regions. Structural Engineering and Mechanics, Vol. 12, No. 6, pp. 573-594. 
Schulte, S., Mooney, W. 2005. An updated earthquake catalog for stable continental regions, intraplate earthquakes (495-2002). United States geological survey (USGS) website. http://earthquake.usgs.gov/research/data/scr_catalog.php

Seismology committee, Structural Engineers Association of California (SEAOC) 1999. Recommended lateral force requirements and commentary. Appendix I parts A and B, USA.

Shome, N., Cornell, C., Bazzurro, P., Carballo, J. 1998. Earthquake records and nonlinear responses. Earthquake Spectra, Vol. 14, No. 3, pp. 469-500.

Somerville, P., Smith, N., Punyamurthula, S., Sun J. 1997. Development of ground motion time histories for phase 2 of FEMA/SAC steel project. SAC Joint Venture, Report No. SAC/BD-97/04, California.

Tjhin, T. 2004. Yield displacement estimates for displacement-based seismic design of ductile reinforced concrete structural wall buildings. Proceedings of the $13^{\text {th }}$ world conference on earthquake engineering, Vancouver, B.C., Canada, paper 1035.

Whittaker, A., Constantinou, M., Tsopelas, P. 1998. Displacement estimates for performance-based seismic design. Journal of Structural Engineering, Vol. 124, No. 8, pp. $905-912$. 


\section{Ground Motion Resources}

COSMOS (Consortium of Organizations for Strong-Motion Observation Systems) data center. http://www.cosmos-eq.org

ESD (the European Strong-Motion Database).

http://www.isesd.cv.ic.ac.uk/esd

Lamont-Doherty Cooperative Seismographic Network (LCSN), Columbia University. http://www.ldeo.columbia.edu/LCSN/

McMaster University Earthquake Engineering Research Group, Report 93-1. 1993. Floppy Disks.

Natural Resources Canada, Earth Sciences Sector, Earthquakes Canada. http://earthquakescanada.nrcan.gc.ca/index_e.php

NGDC (National Geophysical Data Center). http://www.ngdc.noaa.gov/seg/hazard/earthqk.shtml

PEER (Pacific Earthquake Engineering Research Center) Strong Motion Database. http://peer.berkeley.edu/smcat/index.html

SMCAT Earthquake Strong-Motion Data Catalog for Personal Computers. 1992. Floppy Disks.

US Geological Survey Digitized Strong-Motion Accelerograms for North \& Central America. http://nsmp.wr.usgs.gov/data_sets/ncae.html 